\title{
Exercise training in the treatment of obesity
}

Citation for published version (APA):

van Aggel-Leijssen, D. P. (2000). Exercise training in the treatment of obesity: metabolic and cardiovascular effects. [Doctoral Thesis, Maastricht University]. UM. https://doi.org/10.26481/dis.20001130da

Document status and date:

Published: 01/01/2000

DOI:

10.26481/dis.20001130da

Document Version:

Publisher's PDF, also known as Version of record

\section{Please check the document version of this publication:}

- A submitted manuscript is the version of the article upon submission and before peer-review. There can be important differences between the submitted version and the official published version of record.

People interested in the research are advised to contact the author for the final version of the publication, or visit the DOI to the publisher's website.

- The final author version and the galley proof are versions of the publication after peer review.

- The final published version features the final layout of the paper including the volume, issue and page numbers.

Link to publication

\footnotetext{
General rights rights.

- You may freely distribute the URL identifying the publication in the public portal. please follow below link for the End User Agreement:

www.umlib.nl/taverne-license

Take down policy

If you believe that this document breaches copyright please contact us at:

repository@maastrichtuniversity.nl

providing details and we will investigate your claim.
}

Copyright and moral rights for the publications made accessible in the public portal are retained by the authors and/or other copyright owners and it is a condition of accessing publications that users recognise and abide by the legal requirements associated with these

- Users may download and print one copy of any publication from the public portal for the purpose of private study or research.

- You may not further distribute the material or use it for any profit-making activity or commercial gain

If the publication is distributed under the terms of Article $25 \mathrm{fa}$ of the Dutch Copyright Act, indicated by the "Taverne" license above, 


\section{Exercise training in the treatment of obesity metabolic and cardiovascular effects}




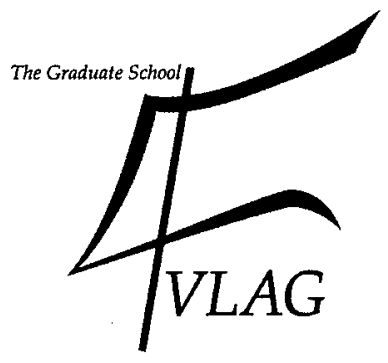

The study presented in this thesis was performed at the Nutrition and Toxicology Research Institute Maastricht (NUTRIM) which participates in the Graduate School VLAG (Food, Technology, IUffin the Royal Netherlands Academy of Arts and Sciences.

(C) Dorien P.C. van Aggel-Leijssen, Maastricht 2000

Thesis Maastricht University, Maastricht, The Netherlands

ISBN: 90-9013994-x

Cover design: Karin Leijssen

Lay-out: Karin Leijssen

Printed by Hub. Tonnaer B.V., Kelpen-Oler 


\section{Exercise training in the treatment of obesity \\ - metabolic and cardiovascular effects -}

\section{Proefschrift}

ter verkrijging van de graad van doctor aan de Universiteit Maastricht,

op gezag van de Rector Magnificus, Prof. Dr. A.C. Nieuwenhuijzen

Kruseman, volgens het besluit van het College van Decanen, in het openbaar te verdedigen op donderdag 30 november 2000 om 14.00 uur

door:

Dorien Petra Catharina van Aggel-Leijssen

geboren te Weert op 30 november 1971 


\section{Promotor:}

Prof. Dr. Ir. W.H.M. Saris

\section{Co-promotor:}

Dr. M.A. van Baak

\section{Beoordelingscommissie:}

Prof. Dr. H. Kuipers (voorzitter)

Prof. Dr. T.W.A. de Bruin

Dr. M.D. Jensen (Mayo Clinic, Rochester, VS)

Prof. Dr. P.W. de Leeuw

Prof. Dr. K.R. Westerterp (Katholieke Universiteit Leuven)

The studies described in this thesis were supported by a grant from the Netherlands Heart Foundation.

Financial support by the Netherlands Heart Foundation and the Dutch Diabetes Research Foundation for the publication of this thesis is gratefully acknowledged.

In addition, the author thanks Medtronic (Bakken Research Center), Cemex, Bosman Medische \& Orthopedische Hulpmiddelen and the Nederlandse Associatie voor de Studie van Obesitas (NASO) for printing of this thesis. 
Aan mijn ouders 

Chapter 2 Effects of exercise training at different intensiries on fat metabolism in obese men

Chapter 3 Effects of exercise training on B-adrenergic stimulation of fat metabolism in obese men

Chapter 4 Effects of low intensity exercise training on fat metabolism in obese women

Chapter 5 Short term effects of weight loss with or without low intensity exercise training on fat metabolism in obese men

Chapter 6 Long term effects of low intensity exercise training on fat metabolism in weight-reduced obese men

Chapter 7 Effects of low intensity exercise training on weight maintenance and cardiovascular risk factors in obese men

Chapter 8 General discussion

Acknowledgements

Summary

Samenvatting

Abbreviarions

Nawoord

About the author 

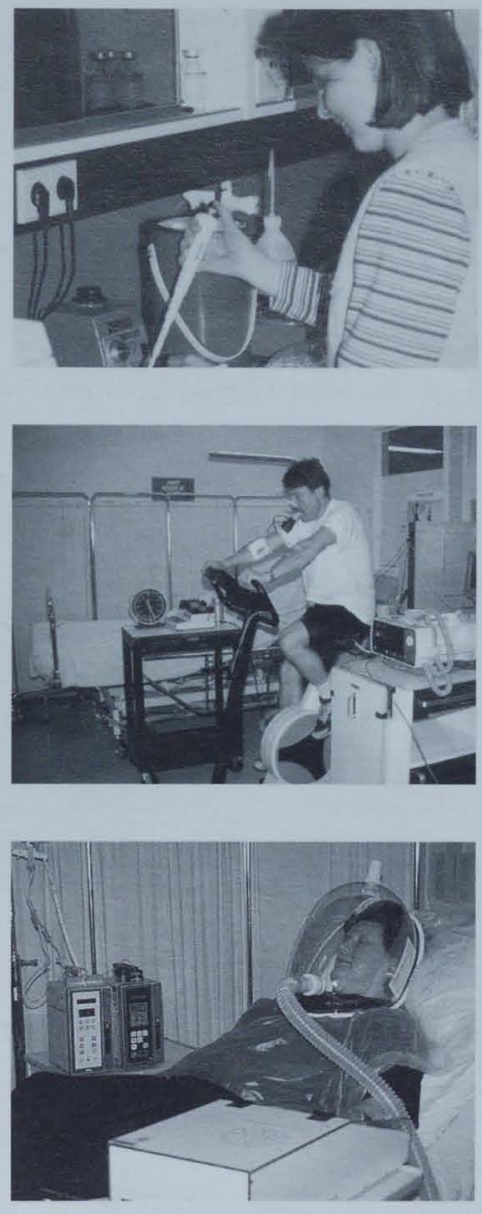

Analysis of plasma samples

Measurement of substrate oxidation during exercise

Measurement of substrate oxidation at rest 


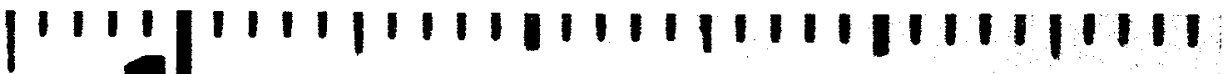 General introduction}

\section{Prevalence of obesity and related bealtb consequences}

The prevalence of obesity is increasing worldwide at an alarming rate in both developed and developing countries. In the United States the prevalence of obesity, defined as a body mass index $(B M I) \geqslant 30 \mathrm{~kg} \cdot \mathrm{m}^{-2}$, was $20 \%$ in men and $25 \%$ in women aged 20-74 years in 1991 (34). In Europe, the most recent data from individual national studies suggest that the prevalence of obesity is in the range of $10-20 \%$ in men and $10-25 \%$ in women (86). In the Netherlands, $8 \%$ of the adult men and women were obese in 1995, which is one of the lowest rates in Europe (67). Over the years 1987-1995, the prevalence of obesity in The Netherlands has increased from $6 \%$ to $8 \%$ in men and remained at $8 \%$ in women (68). This is relatively stable in contrast to the dramatic increase in England (an increase from 1980 to 1991 from $7 \%$ to $15 \%$ in men and from 8 to $15 \%$ in women) (74). Figure 1.1 illustrates the prevalence of obesity in the USA, Germany, UK and The Netherlands (66).
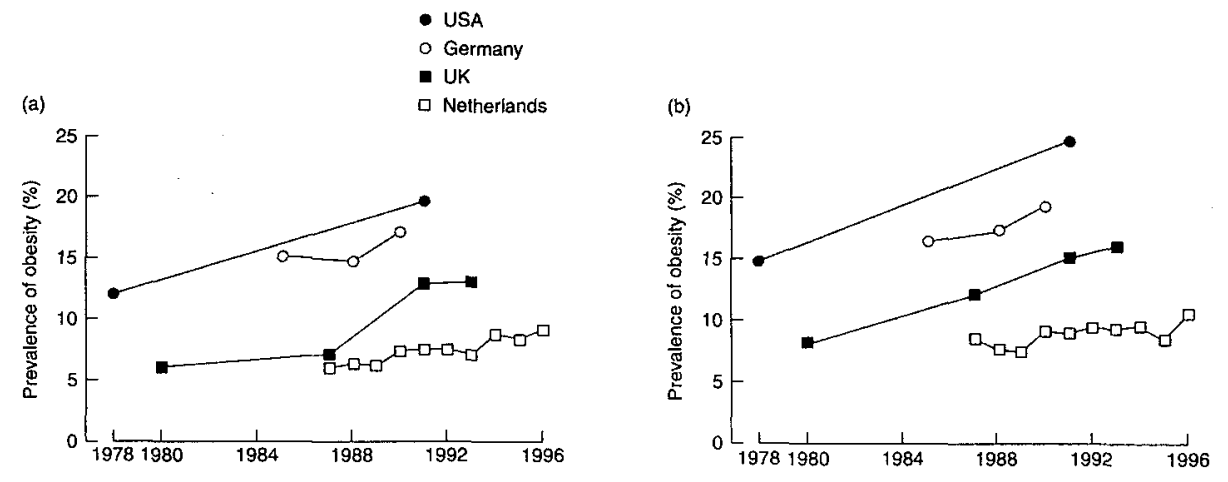

Fig. 1.1 Secular trends in the prevalence of obesity in men [a] and women [b] in various countries. 
Obesity or weight gain can be caused by excessive food intake relative to energy needs. In the USA, the prevalence of overweight rose from 1988 to 1991, although fat and energy intake decreased. This indicates that a reduced daily physical activity, rather than an increased energy intake, has played an important role in the increase of obesity (23). This has also been suggested by other studies performed in England (50) and Sweden (56). An increase in body weight is directly associated with an increase in mortality from all causes (39). The risk for cardiovascular disease is 3.3 fold increased in subjects with a BMI above $29 \mathrm{~kg} \cdot \mathrm{m}^{-2}$ compared to those with a BMI of less than $21 \mathrm{~kg} \cdot \mathrm{m}^{-2}$ (38). With a BMI between 25 and $29 \mathrm{~kg} \cdot \mathrm{m}^{-2}$, the relative risk is increased to 1.8 . Of the deaths due to coronary heart disease in subjects with a BMI between 25 and $30 \mathrm{~kg} \cdot \mathrm{m}^{-2}, 20-28 \%$ might have been prevented if their BMI was below $25 \mathrm{~kg} \cdot \mathrm{m}^{-2}(65)$. Obese subjects have an increased risk for cardiovascular disease due to their increased risk to develop a reduced large artery compliance (21), insulin resistance (35), hypertension and hyperlipidemia (3). Besides body fat mass, body fat distribution plays an important role in the risk for cardiovascular disease. Obese with mainly abdominal body fat are at higher risk for cardiovascular disease than obese with mainly gluteal body fat $(13,32)$. In addition to cardiovascular diseases, obesity is also strongly associated with the development of non-insulin-dependent diabetes mellitus (NIDDM) (3). At a BMI of $\geqslant 35 \mathrm{~kg} \cdot \mathrm{m}^{-2}$ the relative risk for NIDDM is 40 -fold increased compared to a BMI of $<23 \mathrm{~kg} \cdot \mathrm{m}^{-2}(7)$. Furthermore, the risk for certain forms of cancer is linked to obesity. Obese males have an increased risk for colon, rectum and prostate cancer, while obese women are at risk for cancers of the reproductive system and gallbladder. Breast cancer seems to be related to the amount of visceral fat (3). Obesity can also cause sleep-disordered breathing (SDB) with features of obstructive sleep apnea and hypoventilation. Morbidly obese men seem to have SDB more frequently and more severely than morbidly obese women (80). The incidence of gallbladder disease increases gradually with BMI up to $30 \mathrm{~kg} \cdot \mathrm{m}^{-2}$ and exponential with BMI $>30 \mathrm{~kg} \cdot \mathrm{m}^{-2}$ (73). Furthermore, osteoarthritis is significantly increased in obesity. Osteoarthritis develops in the knees and ankles and may be directly related to trauma associated with the degree of excess body weight.

However, since osteoarthritis can also develop in non-weight-bearing joints in obese subjects, the obesity syndrome might be associated with an altered cartilage and bone metabolism (3). 


\section{Metabolic disorders associated witb obesity}

Obesity is associated with an impaired ability to use fat as a fuel, which may contribute to the development and maintenance of large fat stores (62). In Pima Indians, a population with a high prevalence of obesity, a high 24 h respiratory exchange ratio (RER) is associated with a high rate of body weight gain (90). This reduced ability to oxidize fat is suggested to be due to a reduced post-absorptive FFA utilization by the muscle (8). It seems that the impaired ability to oxidize fatty acids is not a result of the obese state per se, since it is also found in formerly obese women (53). Several explanations have been put forward for this reduced fat utilization in obesity, such as a low activity of the enzymes of the beta-oxidation (91), low skeletal muscle lipoprotein lipase activity (16) and an impaired mobilization of fat stores (2). Fat distribution does not seem to affect fat oxidation $(4,63)$.

In addition to this defect in basal fat oxidation, obese subjects appear to have a blunted $\beta$-adrenergic mediated lipolysis and consequently lower levels of fat oxidation $(2,60)$. In vitro lipolysis studies suggest that the blunted $\beta$-adrenergic mediated fat oxidation is caused by an increased $\alpha$ adrenergic and a decreased $\beta$-adrenergic lipolytic response (41). This was found in both femoral and abdominal adipose cells (42). The decreased $B-$ adrenergic response was associated with a decreased expression of $\beta_{2}$-adrenoceptors in obese women (55). In vivo $\beta$-adrenergic stimulation increased the contribution of fat oxidation to total energy expenditure in lean subjects but failed to increase this in obese subjects $(2,9,60,84)$. Pima Indians are found to have a low $\beta$-adrenergic sensitivity in vivo which is correlated with a low $24 \mathrm{~h}$ fat oxidation (75). Furthermore, they have an impaired $B$-adrenergic mediated lipolysis in situ, which is positively correlated with a low basal fat oxidation (72).

\section{Effects of weight loss}

The increased risk for mortality and morbidity associated with obesity can be lowered by even modest weight loss (10\% or less) (22). In obese subjects with medical complications due to obesity, modest weight loss improves glycemic control, hypertension and serum lipid levels $(22,26,82,87)$. Since on a population basis, a progressive increase in the risk for mortality exists with increasing BMI (3), individuals with the highest BMI will 
benefit most from modest weight loss (22).

In addition to weight loss, it is even more important to maintain body weight loss, since weight cycling may be associated with a greater risk for mortality compared with equally obese individuals who maintain their body weight $(14,37)$. The ability to sustain the weight-loss-induced improvements in co-morbidities of obesity appears to be directly related to the persistence and magnitude of weight loss maintenance (26). There are also indications that long-term maintenance of a lower body weight improves cardiovascular risk factors more than initial weight loss. Wing et al (87) reported that the effects of weight maintenance on HDL-cholesterol, HDL-to-total cholesterol ratio and waist-to-hip ratio were greater than the short term effect of a $13 \%$ weight reduction. However, in that study only $30 \%$ of the subjects succeeded to achieve and maintain weight loss of that magnitude. Therefore, because of its health benefits, achievement and maintenance of a modest amount of weight loss should be recommended, rather than achieving a large amount of weight loss that is unlikely to be maintained.

Achievement of body weight loss by energy restriction is often only successful on short term. On long term there is a high risk for regain of body weight $(20,25,71,81)$. The poor long-term outcome of energy restriction may in part be due to metabolic adaptations to weight loss. Body weight loss has been shown to decrease fat oxidation (45) and resting metabolic rate after stabilization of body weight $(18,36,52,64)$. This may predispose to weight regain $(1,54)$.

\section{Effects of excrcise training}

Exercise training is thought to play an essential role in the treatment of obesity $(59,79)$. However, hardly any data are available on effects of exercise training on metabolism of obese subjects. In lean subjects, endurance exercise training is known to increase fat oxidation during sub-maximal exercise at a fixed work load $(24,27,40,47,69)$.

Cross-sectional studies also report a higher fat oxidation during exercise after an overnight fast $(28,31,33,70,78)$ or with glucose ingestion (29, $83)$ in trained compared to sedentary men. Some studies also found an enhanced resting fat oxidation after endurance exercise training $(5,47,48$, 58), but not all (19). Furthermore, in vitro studies have shown that endurance trained lean individuals have an increased sensitivity of abdominal 
adipocytes to the lipolytic action of catecholamines compared to sedentary individuals $(10-12,43,57,77)$. Thus, in lean subjects exercise training (at moderate to high intensity) increases fat mobilization and oxidation. Since obese subjects have an impaired ability to mobilize and oxidize fatty acids, exercise training might not have the same effects on fat oxidation in obese as in lean subjects. Furthermore, in obese subjects low intensity exercise training ( $\$ 40 \% \mathrm{VO}_{2} \max$ ) is to be preferred above moderate ( 40 $70 \% \mathrm{VO}_{2} \mathrm{max}$ ) and high intensity ( $\geqslant 70 \% \mathrm{VO}_{2} \max$ ) exercise training due to better adherence and decreased risk for musculoskeletal injuries (49). Low intensity exercises are brisk walking and easily cycling.

Exercise training is suggested to play an important role in long-term weight management $(44,51)$. Several studies have shown that addition of exercise training during and after energy restriction limits the regain of body weight compared to energy restriction alone $(15,25,81)$, but others did not find this reduction in body weight regain $(17,85)$. Addition of exercise training may limit regain of body weight after weight loss by increasing total energy expenditure (61). Considering the above described effects of exercise training and energy restriction on fat metabolism, addition of exercise training to energy restriction may also prevent the weightloss induced decline in fat oxidation. Nicklas et al (45) described this at rest after a low intensity exercise training. Prevention of a decrease in fat oxidation could contribute to a better long-term weight maintenance of body weight loss (79). No long-term study has investigated the effect of low intensity exercise training on fat metabolism yet.

\section{Effects of long term maintenance of weight loss and exercise training on cardiovascular risk factors}

Long-term weight loss combined with moderate to high intensity exercise training is known to be associated with improvements in several cardiovascular risk factors in obese individuals. It has been shown that blood pressure decreases in obese subjects following a weight loss program combined with long-term exercise training $(26,46)$. Furthermore, at a long-term perspective, serum total cholesterol and LDL-cholesterol concentrations have been reported to decrease by body weight loss and exercise training $(26,30)$, while serum HDL-cholesterol concentrations increased $(30,88)$. The effect of weight loss combined with exercise training on compliance of large arteries has, as far as we know, not been studied yet. 
However, positive effects of short-term weight loss in obese $(76,89)$ and short-term exercise training in lean subjects (6) have been reported. Finally, long-term weight loss combined with exercise training is known to improve insulin sensitivity measured with an oral glucose tolerance test $(30,85)$. However, the above mentioned studies used moderate to high intensity exercise training. The effects of weight loss combined with low intensity exercise training on cardiovascular risk factors are unknown.

In conclusion, although a permanent modest weight loss can induce considerable cardiovascular health effects in obese subjects, maintaining a lower body weight on long term is difficult. Further studies on the contribution of exercise training, especially with respect to exercise training intensity, to weight maintenance and cardiovascular risk reduction are clearly needed.

\section{Outline of the thesis}

The studies described in the present thesis were intended to obtain more information on the long-term influence of exercise training on metabolic processes involved in weight reduction and weight maintenance and on cardiovascular risk factors.

The first step in this project was to investigate the effect of high and low intensity exercise training on fat metabolism (chapter 2) and $\beta$-adrenergicmediated fat oxidation (chapter 3 ) in obese men. Low intensity exercise training showed positive effects on fat metabolism in obese men. In obese women, differences in fat distribution are associated with different metabolic and cardiovascular complications. Therefore, the effect of low intensity exercise rraining on fat metabolism in upper body and lower body obese women was studied (chapter 4). In order to study the effects of exercise training independent of changes in body weight, body weight was kept constant during the studies described in chapter 2, 3 and 4 . Fat metabolism was measured using stable isotope tracers. Subsequently, in chapters 5, 6 and 7, effects of addition of low intensity exercise training during and after weight reduction were studied. Chapter 5 describes short-term effects of energy restriction in combination with low intensity exercise training. Chapter 6 describes the long-term effect of continuation of low intensity exercise training during the follow-up period. In both the short- and longterm study changes in body weight, fat metabolism and sympatheticallymediated fat metabolism were measured. Since modest changes in body 
weight may induce substantial changes in cardiovascular risk factors, effects of initial weight loss and long-term weight maintenance with and without exercise training were studied on cardiovascular risk factors such as blood pressure, serum lipid profile, large artery compliance and plasma insulin and glucose concentrations (chapter 7).

\section{References}

I. Astrup, A., B. Buemann, C. Gluud, P. Bennett, T. Tjur, and N. Christensen. Prognostic markers for diet-induced weight loss in obese women. Int J Obes. I9: 275-8, I995.

2. Blaak, E. E., M. A. Van Baak, G. J. Kemerink, M. T. Pakbiers, G. A. Heidendal, and W. H. Saris. Beta-adrenergic stimulation of energy expenditure and forearm skeletal muscle metabolism in lean and obese men. Am J Physiol. 267: E306-r5, I994.

3. Bray, G. A. Obesity and surgery for a chronic disease. Obes Res. 4: 30I-3, I996.

4. Buemann, B., A. Astrup, F. Quaade, and J. Madsen. 24-Hour energy expenditure and substrate oxidation rates are unaffected by body fat distribution in obese women. Metabolism. 43: I09-II3, 1994.

5. Calles-Escandón, J., M. I. Goran, M. O'Connell, K. S. Nair, and E. Danforth, Jr. Exercise increases fat oxidation at rest unrelated to changes in energy balance or lipolysis. Am J Physiol. 270: EI009-14, 1996.

6. Cameron, J. D., and A. M. Dart. Exercise training increases total systemic arterial compliance in humans. Am J Physiol. 266: $\mathrm{H6}^{6} 3-\mathrm{H}_{7} \mathrm{Or}$, I994.

7. Chan, J. M., E. B. Rimm, G. A. Colditz, M. J. Stampfer, and W. C. Willett. Obesity, fat distribution, and weight-gain as risk-factors for clinical diabetes in men. Diabetes Care. 17: 96I-969, r994.

8. Colberg, S. R., J. A. Simoneau, F. L. Thaete, and D. E. Kelley. Skeletal muscle utilization of free fatty acids in women with visceral obesity. $J$ Clin Invest. 95: $1846-53$, 1995.

9. Connacher, A. A., W. M. Bennet, R. T. Jung, D. M. Bier, C. C. Smith, C. M. Scrimgeour, and M. J. Rennie. Effect of adrenaline infusion on fatty acid and glucose turnover in lean and obese human subjects in the post-absorptive and fed states. Clin Sci Colch. 8I: 635-44, I99I.

10. Crampes, F, M. Beauville, D. Rivière, and M. Garrigues. Effect of physical training in humans on the response of isolated fat cells to 
epinephrine. J Appl Physiol. 6r: 25-9, 1986.

II. Crampes, F, D. Rivière, M. Beauville, M. Marceron, and M. Garrigues. Lipolytic response of adipocytes to epinephrine in sedentary and exercisetrained subjects: sex-related differences. Eur J Appl Physiol. 59: 249-55, Ig89.

I2. Després, J. P., C. Bouchard, R. Savard, A. Tremblay, M. Marcotte, and $G$. Theriault. Level of physical fitness and adipocyte lipolysis in humans. $J$ Appl Physiol. 56: II57-6I, I984.

13. Després, J. P., S. Moorjani, P. J. Lupien, A. Tremblay, A. Nadeau, and C. Bouchard. Regional distribution of body fat, plasma lipoproteins, and cardiovascular disease. Arteriosclerosis. 10: 497-5II, I9go.

14. Ernsberger, P., and R. J. Koletsky. Biomedical rationale for a wellness approach to obesity; an alternative to a focus on weight loss. I Soc Issues. 55: $221-260$, I999.

I5. Ewbank, P. P., L. L. Darga, and C. P. Lucas. Physical activity as a predictor of weight maintenance in previously obese subjects. Obes Res. 3: 257-263, 2995 .

I6. Ferraro, R. T., R. H. Eckel, D. E. Larson, A. M. Fontvieille, R. Rising, $D$. R. Jensen, and E. Ravussin. Relationship between skeletal muscle lipoprotein lipase activity and 24-hour macronutrient oxidation. J Clin Invest. 92: 44I-5, I993.

17. Fogelholm, M., K. Kukkonen-Harjula, and P. Oja. Eating control and physical activity as determinants of short-term weight maintenance after a very-low-calorie diet among obese women. Int J Obes. 23: 203-210, I999.

18. Franssila Kallunki, A., A. Rissanen, A. Ekstrand, A. Ollus, and L. Groop. Weight loss by very-low-calorie diets: effects on substrate oxidation, energy expenditure, and insulin sensitivity in obese subjects. Am J Clin Nutr. 56 : 247S-248S, 1992.

I9. Friedlander, A. L., G. A. Casazza, M. A. Horning, T. F. Buddinger, and G. A. Brooks. Effects of exercise intensity and training on lipid metabolism in young women. Am J Physiol. 275: E853-63, 1998.

20. Froidevaux, F, Y. Schutz, L. Christin, and E. Jéquier. Energy expenditure in obese women before and during weight loss, after refeeding, and in the weight-relapse period. Am J Clin Nutr. 57: 35-42, 1993.

2I. Giannattasio, C., M. Failla, A. A. Mangoni, L. Scandola, N. Fraschini, and $G$. Mancia. Evaluation of arterial compliance in humans. Clin Exp Hypertens. 18: 347-362, 1996.

22. Goldstein, D. J. Beneficial health effects of modest weight loss. Int J Obes. I6: 397-415, 1992 . 
23. Heini, A. F, and R. L. Weinsier. Divergent trends in obesity and fat intake patterns: The American paradox. Am J Med. 102: 259-264, 1997.

24. Henriksson, $J$. Training induced adaptation of skeletal muscle and metabolism during submaximal exercise. J Physiol Lond. 270: 66I-75, 1977.

25. Hensrud, D. D., R. L. Weinsier, B. E. Darnell, and G. R. Hunter. A prospective study of weight maintenance in obese subjects reduced to normal body weight without weight-loss training. Am J Clin Nutr. 60: 688-94, I994.

26. Hensrud, D. D., R. L. Weinsier, B. E. Darnell, and G. R. Hunter. Relationship of co-morbidities of obesity to weight loss and four-year weight maintenancelrebound. Obes Res. 3: 217S-222S, 1995.

27. Hurley, B. F., P. M. Nemeth, W. H. d. Martin, J. M. Hagberg, G. P. Dalsky, and $J$. $O$. Holloszy. Muscle triglyceride utilization during exercise: effect of training. J Appl Physiol. 60: 562-7, 1986.

28. Jansson, E., and L. Kaijser. Substrate utilization and enzymes in skeletal muscle of extremely endurance-trained men. J Appl Physiol. 62: 999-10o5, Ig87.

29. Jeukendrup, A. E., M. Mensink, W. H. Saris, and A. J. Wagenmakers. Exogenous glucose oxidation during exercise in endurance-trained and untrained subjects. J Appl Physiol. 82: 835-40, 1997.

30. Katzel, L. I., R. Bleecker, E. M. Rogus, and A. P. Goldberg. Sequential effects of aerobic exercise training and weight loss on risk factors for coronary disease in healthy, obese middle-aged and older men.

Metabolism. 46: I44I-I447, 1997.

31. Kiens, B., B. Essen Gustausson, N. J. Christensen, and B. Saltin. Skeletal muscle substrate utilization during submaximal exercise in man: effect of endurance training. J Physiol Lond. 469: 459-78, 1993.

32. Kissebah, A. H., N. Vydelingum, R. Murray, D. J. Evans, A. J. Hartz, R. K. Kalkhoff, and P. W. Adams. Relation of body fat distribution to metabolic complications of obesity. I Clin Endocrinol Metab. 54: 254-60, Ig82.

33. Klein, S., E. F. Coyle, and R. R. Wolfe. Fat metabolism during lowintensity exercise in endurance-trained and untrained men. Am J Physiol. 267: E934-40, 1994.

34. Kuczmarski, R. J., K. M. Flegal, S. M. Campbell, and C. L. Johnson. Increasing prevalence of overweight among US adults. The National Health and Nutrition Examination Surveys, Ig6o to Ig9I. JAMA. 272: 205-II, I994. 
35. Landin, K., P. Lonnroth, M. Krotkiewski, G. Holm, and U. Smith. Increased insulin resistance and fat cell lipolysis in obese but not lean women with a high waist/hip ratio. Eur J Clin Invest. 20: 530-5, r9go.

36. Leibel, R. L., M. Rosenbaum, and J. Hirsch. Changes in energy expenditure resulting from altered body weight. $N$ Engl $J$ Med. 332: 62I-8, 1995.

37. Lissner, L., P. M. Odell, R. B. D'Agostino, J. Stokes, B. E. Kreger, A. J. Belanger, and K. D. Brownell. Variability of body weight and health out comes in the Framingham population. N Eng J Med. 324: I839-1844, I99I.

38. Manson, J. E., G. A. Colditz, M. J. Stampfer, W. C. Willett, B. Rosner, R. R. Monson, F. E. Speizer, and C. H. Hennekens. A prospective study of obesity and risk of coronary heart disease in women. $N$ Engl J Med. 322: 882-889, 1990.

39. Manson, J. E., W. C. Willett, M. J. Stampfer, G. A. Colditz, D. J. Hunter, S. E. Hankinson, C. H. Hennekens, and F. E. Speizer. Body weight and mortality among women. $N$ Engl J Med. 333: 677-85, 1995.

40. Martin III, W. H., G. P. Dalsky, B. F. Hurley, D. E. Matthews, D. M. Bier, J. M. Hagberg, M. A. Rogers, D. S. King, and J. O. Holloszy. Effect of endurance training on plasma free fatty acid turnover and oxidation during exercise. Am J Physiol. 265: E708-14, 1993.

4I. Mauriège, P., J. P. Després, D. Prud'homme, M. C. Pouliot, M. Marcotte, A. Tremblay, and C. Bouchard. Regional variation in adipose tissue lipolysis in lean and obese men. J Lipid Res. 32: 1625-33, 1991.

42. Mauriège, P., D. Prud'homme, S. Lemieux, A. Tremblay, and J. P. Després. Regional differences in adipose tissue lipolysis from lean and obese women: existence of postreceptor alterations. Am J Physiol. 260: E34IE350, rogs.

43. Mauriège, P., D. Prud'homme, M. Marcotte, M. Yoshioka, A. Tremblay, and J. P. Després. Regional differences in adipose tissue metabolism between sedentary and endurance-trained women. Am J Physiol. 273: E497-506, 1997.

44. Miller, W. C., D. M. Koceja, and E. J. Hamilton. A meta-analysis of the past 25 years of weight loss research using diet, exercise or diet plus exercise intervention. Int J Obes. 21: 94I-7, 1997.

45. Nicklas, B. J., E. M. Rogus, and A. P. Goldberg. Exercise blunts declines in lipolysis and fat oxidation after dietary-induced weight loss in obese older women. Am J Physiol. 273: EI49-55, 1997.

46. Pasman, W. J., W. H. Saris, E. Muls, G. Vansant, and M. S. Westerterp Plantenga. Effect of exercise training on long-term weight maintenance in weight-reduced men. Metabolism. 48: 15-2I, I999. 
47. Phillips, S. M., H. J. Green, M. A. Tarnopolsky, G. F. Heigenhauser, R. E. Hill, and S. M. Grant. Effects of training duration on substrate turn over and oxidation during exercise. J Appl Physiol. 8I: 2182-9I, I9g6.

48. Poehlman, E. T., A. W. Gardner, P. J. Arciero, M. I. Goran, and J. Calles Escandon. Effects of endurance training on total fat oxidation in elderly persons. I Appl Physiol. 76: 228I-7, r994.

49. Pollock, M. L., H. Miller, R. Janeway, A. C. Linnerud, Robertson, B., and $R$. Valentino. Effects of walking on body composition and cardiovascular function of middle-aged men. J Appl Physiol. 30: 126-130, I97I.

5o. Prentice, A. M., and S. A. Jebb. Obesity in Britain: gluttony or sloth? Br Med J. 3II: 437-439, r995.

5I. Pronk, N. P., and R. R. Wing. Physical activity and long-term maintenance of weight loss. Obes Res. 2: 587-599, 1994.

52. Racette, S. B., D. A. Schoeller, R. F. Kushner, K. M. Neil, and K. Herling Iaffaldano. Effects of aerobic exercise and dietary carbohydrate on energy expenditure and body composition during weight reduction in obese women. Am J Clin Nutr. 6I: 486-94, I995.

53. Ranneries, C., J. Bulow, B. Buemann, N. J. Christensen, J. Madsen, and A. Astrup. Fat metabolism in formerly obese women. Am J Physiol. 274: Ex55-61, rg98.

54. Ravussin, E., and B. A. Swinburn. Metabolic predictors of obesity: crosssectional versus longitudinal data. Int J Obes. I7: $S_{4 I-2,}$ rg93.

55. Reynisdottir, S., H. Wahrenberg, K. Carlstrom, S. Rossner, and P. Arner. Catecholamine resistance in fat cells of women with upper-body obesity due to decreased expression of beta 2-adrenoceptors. Diabetologia. 37: 428-35, 1994 .

56. Rissanen, A. M., M. Heliovaara, P. Knekt, A. Reunanen, and A. Aromaa. Determinants of weight gain and overweight in adult Finns. Eur J Clin Nutr. 45: 419-430, I99I.

57. Rivière, D., F. Crampes, M. Beauville, and M. Garrigues. Lipolytic response of fat cells to catecholamines in sedentary and exercise-trained women. J Appl Physiol. 66: 330-5, 1989.

58. Romijn, J. A., S. Klein, E. F. Coyle, L. S. Sidossis, and R. R. Wolfe. Strenuous endurance training increases lipolysis and triglyceride-fatty acid cycling at rest. J Appl Physiol. 75: 108-13, r993.

59. Saris, W. H. M. Fit, fat and fat free: The metabolic aspects of weight control. Int J Obes. 22: SIS-S2I, Igg8.

6o. Schiffelers, S. L. H., W. H. M. Saris, and M. A. Van Baak. 
$\beta_{2}$-adrenoceptor mediated lipolysis and lipid oxidation are reduced in obese men. Int J Obes. 22: S75, I998.

6I. Schoeller, D. A., K. Shay, and R. F. Fushner. How much physical activity is needed to minimize weight gain in previously obese women? Am J Clin Nutr. 66: 551-556, 1997.

62. Schutz, Y., J. P. Flatt, and E. Jéquier. Failure of dietary fat intake to promote fat oxidation: a factor favoring the development of obesity. Am J Clin Nutr. 50: 307-314, 1989 .

63. Schutz, $Y$, and A. Tremblay. Does lipid oxidation differ in gynoid and android obese women? Int J Obes. 16: 67-69, 1992.

64. Schutz, Y., A. Tremblay, R. L. Weinsier, and K. M. Nelson. Role of fat oxidation in the long-term stabilization of body weight in obese women. Am J Clin Nutr. 55: 670-4, 1992.

65. Seidell, J. C. Dietary fat and obesity: an epidemiologic perspective. Am J Clin Nutr. 67: 546S-550S, 1998.

66. Seidell, J. C. Obesity: a growing problem. Acta Paediatr Suppl. 428: 46so, xog9.

67. Seidell, J. C. Time trends in obesity: An epidemiological perspective. Horm Metab Res. 29: 155-158, 1997.

68. Seidell, J. C., and K. M. Flegal. Assessing obesity: classification and epidemiology. Br Med Bull. 53: 238-252, 1997.

69. Sial, S., A. R. Coggan, R. C. Hickner, and S. Klein. Training-induced alterations in fat and carbohydrate metabolism during exercise in elderly subjects. Am J Physiol. 274: E785-90, 1998.

70. Sidossis, L. S., R. R. Wolfe, and A. R. Coggan. Regulation of fatty acid oxidation in untrained vs. trained men during exercise. Am I Physiol. 274: E5I0-5, 1998.

7I. Sikand, G., A. Kondo, J. P. Foreyt, P. H. Jones, and A. M. Gotto, Jr. Two-year follow-up of patients treated with a very-low-calorie diet and exercise training. J Am Diet Assoc. 88: 487-8, 1988.

72. Snitker, S., J. Hellmér, M. Boschmann, M. B. Monroe, and E. Ravussin. Whole body fat oxidation is related to in situ adipose tissue lipolytic response to isoproterenol in males. Am J Physiol. 275: E400-04, 1998.

73. Stampfer, M. J., K. M. Maclure, G. A. Colditz, J. E. Manson, and W. C. Willett. Risk of symptomatic gallstones in women with severe obesity. Am, J Clin Nutr. 55: 652-658, r992.

74. Task Forces, Nutrition and physical activity. Obesity; reversing the increasing problem of obesity in England. London: Department of Health, Iggs.

75. Tataranni, P. A., L. Christin, S. Snitker, G. Paolisso, and E. Ravussin. 
Pima Indian males have lower beta-adrenergic sensitivity than Caucasian males. J Clin Endocrinol Metab. 83: 1260-3, 1998.

76. Toto-Moukouo, J. J., A. Achimastos, R. G. Asmar, C. J. Hugues, and M. $E$. Safar. Pulse wave velocity in patients with obesity and hypertension. Am Heart J. II2: 136-I40, 1986.

77. Tremblay, A., S. Conveney, J. P. Després, A. Nadeau, and D.

Prud'homme. Increased resting metabolic rate and lipid oxidation in exercise-trained individuals: evidence for a role of $\beta$-adrenergic stimulation. Can J Physiol Pharmacol. 70: 1342-1347, 1992.

78. Turcotte, L. P. E. A. Richter, and B. Kiens. Increased plasma FFA uptake and oxidation during prolonged exercise in trained vs. untrained humans. Am J Physiol. 262: E79I-9, rggz.

79. Van Baak, M. A. Exercise training and substrate oxidation in obesity. Int J Obes. 23: $S_{I I}-S_{I 7}$, I9g9.

80. Van Boxem, T. J. M., and G. H. De Groot. Prevalence and severity of sleep disordered breathing in a group of morbidly obese patients.

Netherlands J Med. 54: 202-206, I999.

8I. Van Dale, D., W. H. Saris, and F. ten Hoor. Weight maintenance and resting metabolic rate I $8-40$ months after a dietlexercise treatment. Int $J$ Obes. 14: 347-59, I990.

82. Van Gaal, L. F, M. A. Wauters, and I. H. De Leeuw. The beneficial effects of modest weight loss on cardiovascular risk factors. Int J Obes. 2I: $S_{5}-S g, 1997$.

83. Van Loon, L. J. C., A. E. Jeukendrup, W. H. M. Saris, and A. J. M. Wagenmakers. Effect of training status on fuel selection during submaximal exercise with glucose ingestion. I Appl Physiol. 87: 1413-14I8, 1999.

84. Webber, J., J. Taylor, H. Greathead, J. Dawson, P. J. Buttery, and I. A. Macdonald. A comparison of the thermogenic, metabolic and haemodynamic responses to infused adrenaline in lean and obese subjects. Int $J$ Obes. I8: $717-24,1994$.

85. Weinstock, R. S., H. Dai, and T. A. Wadden. Diet and exercise in the treatment of obesity. Arch Intern Med. I58: 2477-2483, I998.

86. WHO. Obesity; preventing and managing the global epidemic. Geneva: WHO, 1998 .

87. Wing, R. R., R. W. Jeffery, L. R. Burton, C. Thorson, L. H. Kuller, and $A$. R. Folsom. Change in waist-hip ratio with weight loss and its association with change in cardiovascular risk factors. Am J Clin Nutr. 55: 1086-1092, 1992.

88. Wood, P. D., M. L. Stefanick, P. D. Williams, and W. L. Haskell. 
The effects on plasma lipoproteins of a prudent weight-reducing diet with or without exercise, in overweight men and women. $N$ Engl J Med. 325: 46I-466, I9gI.

89. Yamashita, T., T. Sasahara, S. E. Pomeroy, G. Collier, and P. J. Nestel. Arterial compliance, blood pressure, plasma leptin, and plasma lipids in women are improved with weight reduction equally with a meat-based diet and a plant-based diet. Metabolism. 47: 1308-1314, 1998.

9o. Zurlo, F, S. Lillioja, A. Esposito Del Puente, B. L. Nyomba, I. Raz, M. F. Saad, B. A. Swinburn, W. C. Knowler, C. Bogardus, and E. Ravussin. Low ratio of fat to carbohydrate oxidation as predictor of weight gain: study of 24-h RQ. Am J Physiol. 259: E650-7, 1990.

9I. Zurlo, F, P. M. Nemeth, R. M. Choksi, S. Sesodia, and E. Ravussin. Whole-body energy metabolism and skeletal muscle biochemical characteristics. Metabolism. 43: 48I-6, I994. 


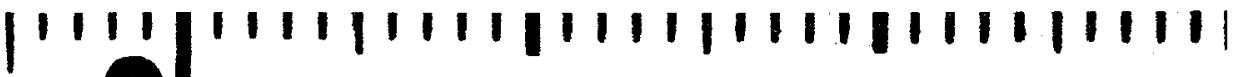 Effects of exercise training at different intensities on fat metabolism in obese men
}

\author{
Dorien P.C. van Aggel-Leijssen, Wim H.M. Saris, Anton J.M. \\ Wagenmakers, Joan M.G. Senden and Marleen A. van Baak.,
}

Submitted International Journal of Obesity

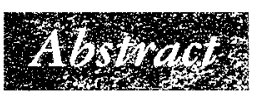

Objective: To investigate the effect of exercise training at different intensities on fat oxidation in obese subjects. Metbods: Twenty-four bealtby male obese subjects were randomly divided in either a low (40\%VO2max) or a bigh intensity exercise training program (70\%VO2max) ( $3 x$ per week for I 2 weeks) or a non-exercising control group. Before and after the intervention measurements of fat metabolism at rest and during exercise were performed using indirect calorimetry, $\left\{U^{-3} \mathrm{C}\right\}$ palmitate and (I,2- ${ }^{13}$ C)acetate. Furthermore body composition and maximal aerobic capacity were measured.

Results: Total fat oxidation did not change at rest in any group. During exercise fat oxidation increased $40 \%$ in the low intensity exercise training group $(P<0.05)$ due to an increased non-plasma fatty acid ( $F A)$ oxidation $(P<0.05)$. High intensity exercise training did not affect total fat oxidation during exercise; a decrease in plasma FFA oxidation $\left(P<0.0_{5}\right)$ was compensated by a non-significant increase in non-plasma FA oxidation.

Conclusion: Low intensity exercise training in obese subjects increased fat oxidation during exercise but failed to affect fat oxidation at rest. No effect of bigh intensity exercise training on fat oxidation could be shown. 


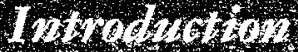

Obesity is associated with an impaired ability to use fat as a fuel. This may contribute to the development and maintenance of large fat stores. Upper body obesity is associated with an impaired post-absorptive FFA utilization in skeletal muscle in women (5). Isoprenaline-induced fat oxidation and skeletal muscle FFA uptake are impaired in obese men and no improvement was found after weight loss (1-3). Lean, formerly obese women have lower fasting fat oxidation rates compared to lean never-obese women (31). Moreover, in Pima Indians, a population with a high prevalence of obesity, weight gain is association with a low $24 \mathrm{~h}$ ratio of fat to carbohydrate oxidation (47). Several explanations have been put forward for this reduced fat utilization in obesity, such as a low activity of the enzymes of the betaoxidation (48), low skeletal muscle lipoprotein lipase activity (6) and impaired mobilization of fat stores (1). Interventions that will increase the capacity of the skeletal muscle to utilize fat may therefore make an important contribution to weight management in obese individuals and individuals at risk for obesity.

Endurance exercise training is known to increase fat oxidation during submaximal exercise at a fixed work load in lean subjects $(13,16,22,29,37)$. Cross-sectional studies also report a higher fat oxidation during exercise after an overnight fast $(17,19,20,39,44)$ or with glucose $(18,45)$ in trained compared to sedentary men. Some studies also found an enhanced resting fat oxidation after endurance training $(4,30,33)$. Thus, endurance exercise training appears to have the capacity to increase fat oxidation in lean subjects.

However, all studies reporting an effect of exercise training on fat metabolism involved moderate to high intensity exercise training ( $>60 \% \mathrm{VO}_{2} \max$ ). No studies with lower training intensities have been performed. In the obese population low intensity exercise training may be preferable to high intensity exercise training, because of a lower risk of musculoskeletal injuries and better adherence. Since fat mobilization and utilization appear to be impaired in obesity, it is not clear whether endurance exercise training, at high or low intensity, will improve fat oxidation in obese individuals. The aim of the present study was therefore to compare the effects of low $(40 \% \mathrm{VO}, \max )$ and high $\left(70 \% \mathrm{VO}_{2}\right.$ max) intensity endurance training on fat metabolism in obese men. The energy expenditure per training session was kept the same with low and high intensity training, which meant that training sessions were twice as long in the low intensity program than in 
the high intensity program. Since fat oxidation (in $\mathrm{g} / \mathrm{min}$ ) is approximately the same during exercise at 40 and $70 \% \mathrm{VO}_{2} \max (15)$, total fat oxidation during the LI exercise sessions was twice that during the $\mathrm{HI}$ exercise sessions. The study was advertized as a training study, not as a weight loss or weight management study, in an attempt to prevent weight and body composition changes that might interfere with the effects of training on fat metabolism.

\section{Metbods}

\section{Subjects}

Twenty-four obese male subjects participated in this study. Physical characteristics are indicated in Table 2.1. All subjects were in good health as assessed by medical history and physical examination. They did not take medication known to influence the variables measured and had a stable body weight ( $<3 \mathrm{~kg}$ change) during two months prior to selection. The subjects did not spend more than $2 \mathrm{~h}$ per week in sports activities and had no physically demanding job. Subjects were matched in groups of three for age, BMI, fat percentage and maximal oxygen uptake per $\mathrm{kg}$ fat free mass $\left(\mathrm{VO}_{2} \mathrm{max} / \mathrm{FFM}\right)$. Members of each group were subsequently randomly divided over three groups, the low intensity (LI) or high intensity (HI) exercise training group or the control group (C). Subjects were requested to maintain their dietary habits during the study. The study protocol was approved by the Ethics Committee of Maastricht University. Written informed consent was obtained from all subjects.

Table 2.1 Subject characteristics before and after the intervention period in the low intensity [LI] [ $\mathrm{n}=81$, high intensity [HI] $[n=8]$ and control [C] [n=8] group.

\begin{tabular}{|c|c|c|c|c|c|c|}
\hline & $\mathbf{L I}$ & & H & & i & \\
\hline & lefore & after & before & after & before & after \\
\hline Agre (y) & $43.4 \pm 6.3$ & & $40.0 \pm 6.3$ & & $43.3 \pm 5.4$ & \\
\hline Boxly weight (kg) & $102.7 \pm 10.8$ & $103.1 \pm 11.4$ & $105.5 \pm 6.6$ & $105.1 \pm 6.2$ & $96.5 \pm 10.3$ & $95.9 \pm 9.6$ \\
\hline $\operatorname{BMI}(\mathrm{kg} \cdot \mathrm{m}-2)$ & $31.6 \pm 3.1$ & $31.7 \pm 3.1$ & $32.2 \pm 1.6$ & $32.1 \pm 1.3$ & $31.5 \pm 2.4$ & $31.4 \pm 2.5$ \\
\hline Bocly far $(\%)$ & $31.9 \pm 2.4$ & $31.5 \pm 2.2$ & $31.3 \pm 4.3$ & $31.8 \pm 4.4$ & $31.6 \pm 5.1$ & $31.7 \pm 5.0$ \\
\hline FFM $(\mathrm{kg})$ & $70.0 \pm 9.6$ & $70.7 \pm 8.7$ & $72.8 \pm 5.4$ & $71.8 \pm 6.7$ & $66.2 \pm 10.3$ & $65.7 \pm 9.5$ \\
\hline $\mathrm{VO}_{2} \mathrm{n}$ ax $(\mathrm{ml} \cdot \mathrm{min}-1)$ & $3191 \pm 532$ & $3556 \pm 542 *$ & $3312 \pm 448$ & $3820 \pm 453^{*}$ & $2944 \pm 443$ & $3019 \pm 557$ \\
\hline $\mathrm{VO}_{2} \mathrm{max} / \mathrm{FFM}\left(\mathrm{ml} \cdot \mathrm{kg}^{\mathrm{kg}-1} \cdot \mathrm{min}-1\right)$ & $45.3 \pm 5.6$ & $50.4 \pm 5.7 *$ & $45.6 \pm 3.2$ & $53.3 \pm 3.7^{*}$ & $44.6 \pm 3.3$ & $45.8 \pm 3.3$ \\
\hline Rescing heart rate (beats.min-1) & $66.3 \pm 10.1$ & $63.4 \pm 6.3$ & $59.9 \pm 8.7$ & $58.1 \pm 8.2$ & $68.0 \pm 12.2$ & $65.8 \pm 11.5$ \\
\hline
\end{tabular}




\section{$\underline{\text { Experimental design }}$}

Two of the three groups participated in an exercise training intervention of 12 weeks. The third group served as a non-training control group (C). Measurements of body composition, maximal aerobic capacity and fat merabolism were made before the start of the exercise training program and repeated within two weeks after 12 weeks exercise training. The exercise training program was continued until all measurements were performed.

\section{$\underline{\text { Exercise training }}$}

The exercise training program consisted of cycling on an ergometer (Bodyguard Cardiocycle, Sandnes, Norway or Lode, Groningen, The Netherlands) at either low intensity ( $\mathrm{LI} ; 40 \%$ of pre-determined $\mathrm{VO}_{2} \max$ ) or high intensity ( $\mathrm{HI} ; 70 \%$ of pre-determined $\mathrm{VO}_{2} \max$ ). Eight subjects participated in the LI and eight subjects in the HI training program. Subjects trained during 12 weeks, three times per week. Energy expenditure of each subject in each training session was $5 \mathrm{kcal} . \mathrm{kg}$ fat free mass ${ }^{-1}$ $(\sim 350 \mathrm{kcal})$. Training duration for subjects in the LI and HI training program was $57.1 \pm 8.0$ and $32.8 \pm 2.5$ min respectively. Heart rate was monitored continuously during the training sessions (Polar Electro, Oy, Finland). After 4 and 8 weeks of exercise training, a maximal aerobic exercise test was performed and the training workload and duration was adjusted if necessary. All training sessions took place at the laboratory under supervision of a professional instructor.

\section{Measurements}

1. Body composition

Subjects were weighed on a digital balance accurate to $0.1 \mathrm{~kg}$ (Sauter D-7470, Ebingen, Germany). Height was measured to the nearest $0.1 \mathrm{~cm}$ using a wall-mounted stadiometer (Seca, model 220, Hamburg, Germany). Body density was measured by hydrostatic weighing, with correction for residual lung volume measured by helium dilution with a spirometer (Volugraph 2000, Mijnhardt, The Netherlands) at the moment of under water weighing. Body 
composition was calculated according to the formula of Siri (40).

2. Maximal aerobic capacity

Maximal $\mathrm{O}_{2}$ uptake ( $\mathrm{VO}_{2}$ max) for each subject was determined by an incremental exercise test on an electromagnetically braked cycle ergometer (Excalibur, Lode, Groningen, The Netherlands). After a warming up period of 5 minutes at $100 \mathrm{~W}$, workload was increased every 4 minutes by $40 \mathrm{~W}$ until exhaustion. During the experiment ventilatory and gas exchange responses were measured continuously, using indirect calorimetry (Oxycon B, Mijnhardt, The Netherlands). Heart rate was recorded continuously by an electrocardiogram. The highest oxygen uptake achieved over $30 \mathrm{~s}$ was taken as $\mathrm{VO}_{2} \max$.

3. Measurements of fat oxidation and Ra FFA during rest and exercise

Fat metabolism was studied by means of indirect calorimetry and stable isotope tracer methodology. In order to study fat metabolism, all subjects participated in two tracer tests before and after the training intervention, in which palmitate and acetate was infused respectively. The acetate infusion test was performed to obtain a correction factor for the loss of ${ }^{13} \mathrm{C}$ label in the tricarboxylic acid cycle. The tracer tests were separated by a week to prevent carry over of the label. The sequence of the tracer tests was random. Subjects filled in a food and exercise questionnaire 3 days before the first tracer test. They were instructed to adjust to the same food and exercise habits 3 days before the second tracer test and the tracer tests after the training intervention in order to exclude bias by these factors.

\section{3a. $\left[\mathrm{U}-{ }^{1:} \mathrm{C}\right]$-palmitate infusion}

This experiment was performed at least $36 \mathrm{~h}$ after the last exercise bout. Subjects were asked to refrain from consumption of naturally ${ }^{1:} \mathrm{C}$-enriched food products for one week before the experiment. After an overnight fast, subjects came to the laboratory by car or bus. Subjects remained in semi-supine position throughout the first $2.5 \mathrm{~h}$ of the experiment. Catheters were inserted in an arm vein for infusion of the palmitate tracer and retrogradely into a contralateral dorsal hand vein for blood sampling. The cannulated hand was placed in a hot box, 
in which warm air of $60^{\circ} \mathrm{C}$ circulated, in order to obtain arterialized venous blood. A baseline arterialized blood sample was taken after 30 min. Baseline expired breath was sampled in a $15 \mathrm{ml}$ vacutainer tube (Becton Dickinson, Meyland Cedex, France) in order to determine the background enrichment.

Immediately after taking baseline samples, subjects were given an intravenous dose of $1.0 \mu \mathrm{mol} / \mathrm{kg} \mathrm{NaH}{ }^{13} \mathrm{CO}_{3}$ to prime the bicarbonate pool. Then a constant infusion $0.0053 \mu \mathrm{mol} . \mathrm{kg}^{-1} \cdot \mathrm{min}^{-1}\left[\mathrm{U}-{ }^{15} \mathrm{C}\right]$-palmitate was started $(\mathrm{t}=0)$, using IVAC pumps (IVAC Medical, Amersfoort, The Netherlands). These infusions were continued for $120 \mathrm{~min}$, with the subjects in semi-supine position. Subsequently, subjects started to exercise in sitting position for $1 \mathrm{~h}$ at $50 \%$ of pretraining $\mathrm{VO}_{2} \max$ on a cycle ergometer (Excalibur, Lode, Groningen, The Netherlands). The infusion rate during exercise was doubled to minimize changes in isotopic enrichment.

$\mathrm{VCO}_{2}$ and $\mathrm{VO}_{2}$ were measured using an open circuit ventilated hood system (Oxycon $B$, Mijnhardt, The Netherlands). At rest and during exercise, $\mathrm{VCO}_{2}$ and $\mathrm{VO}_{2}$ were measured during 5 min immediately before taking a breath sample for measurement of ${ }^{1:} \mathrm{CO}_{2}$ enrichment. The accuracy of the ventilated hood system for measuring $\mathrm{VCO}_{2}$ and $\mathrm{VO}_{2}$ was tested regularly to be within $5 \%$. Breath samples were taken at $\mathrm{t}=100,110$ and $120 \mathrm{~min}$ at rest and at $\mathrm{t}=40,50$ and $60 \mathrm{~min}$ during exercise.

The exact infusion rate of $\left[U-{ }^{13} \mathrm{C}\right]$-palmitate was determined for each experiment by measuring the concentrations of the infusates (see sample analyses). Blood samples were taken at $t=90,100,110$ and $120 \mathrm{~min}$ of rest and at $t=30,40,50$ and $60 \mathrm{~min}$ during exercise. Blood samples were put into an EDTA or heparin and $300 \mu \mathrm{l}$ glutathion $(45 \mu \mathrm{g} / \mathrm{l}$ saline) containing chilled $10 \mathrm{ml}$ tube and immediately centrifuged at for $10 \mathrm{~min}$ at $800 \mathrm{~g}$ at $4^{\circ} \mathrm{C}$. Plasma was stored at $-80^{\circ} \mathrm{C}$ until analyses. The EDTA containing blood was used for analyses of glucose, FFA, insulin, triglyceride and palmitate concentrations as well as the plasma enrichment of palmitate. The heparin and glutathion containing blood was used for analysis of catecholamines. During rest $(t=0,90$ and 120) and exercise ( $t=30$ and 60) blood was sampled for the measurement of oxygen saturation (Hemoxymeter OSM2, Copenhagen, Denmark) in order to check the arterialization. Before infusion, the palmitate tracer $\left(60 \mathrm{mg}\right.$ of potassium salt of $\left[\mathrm{U}^{-1 \mathrm{C}} \mathrm{C}\right]$-palmitate, enrichment $98.9 \%$, Cambridge Isotope Laboratories, Andover, MA) was bound to albumin 
by dissolving it in heated $\left(60^{\circ} \mathrm{C}\right)$ sterile water and passing it through a $0.2 \mu \mathrm{m}$ filter into a $5 \%$ warm $\left(60^{\circ} \mathrm{C}\right)$ human serum albumin solution to make a $0.670 \mathrm{mM}$ solution.

\section{3b. $\left[1,2-^{1:} \mathrm{C}\right]$-acetate infusion}

Palmitate oxidation rates were corrected for loss of tracer in products of the tricarboxylic acid cycle using the acetate correction factor previously described by Sidossis et al. (38) and Schrauwen et al. (35). The protocol for the acetate infusion experiment was the same as for the palmitate infusion experiment, except that no blood was sampled. The acetate tracer (sodium salt of $\left\{1,2-^{\prime i} \mathrm{C}\right\}$-acetate, enrichment $99 \%$, Cambridge Isotope Laboratories) was dissolved in $0.9 \%$ saline. The acetate infusion rate was $0.0496 \mu \mathrm{mol} . \mathrm{kg}^{-1} . \mathrm{min}^{-1}$ at rest and was doubled during exercise. Before starting the acerate infusion, an intravenous dose of $1.0 \mu \mathrm{mol} / \mathrm{kg}$ $\mathrm{NaH}^{13} \mathrm{CO}_{3}$ was given to prime the bicarbonate pool.

\section{$\underline{\text { Sample analysis }}$}

Plasma total FFA, glycerol, triglyceride concentrations were measured on a COBAS FARA centrifugal spectrophotometer. For analysis of plasma total FFA concentrations a NEFA C kit (Wako Chemicals, Neuss, Germany) was used. Plasma glycerol and triglyceride concentrations were analysed using a Glycerol kit (Boehringer, Mannheim, Germany). Plasma insulin concentrations were measured with a double-antibody radioimmunoassay (Insulin RIA 100; Pharmacia, Uppsala, Sweden). Plasma catecholamine concentrations were analyzed by HPLC with electrochemical detection (41).

The chemical and isotopic purity (99\%) of the palmitate and acetate tracers were checked by ' $\mathrm{H}$ and ${ }^{15} \mathrm{C}$ NMR and GC/MS. Breath samples were anayzed for ${ }^{13} \mathrm{C} /{ }^{2} \mathrm{C}$ ratio using a gas chromatography-isotope ratio mass spectrometer (GC-IRMS, Finnigan MAT 252, Bremen, Germany). For determination of the plasma palmitate concentration, FFA were extracted from plasma, isolated by thin-layer chromatography and derivatized to methyl esters. Palmitate concentration was determined on an analytical GC with flame ionisation detection using heptadecanoic acid as internal standard. The isotope tracer/tracee ratio of palmitate was determined using GC combustion IRMS, with correction for the extra methyl group in the derivative. 
The concentration of the acetate infusate was determined on a COBAS FARA with an enzymatic method kit no 148261 (Boehringer, Mannheim, Germany).

The concentration of the palmitate infusate was determined as described above for plasma samples.

\section{Calculations}

Total fat oxidation was calculated by the following equation (7): total fat oxidation $(\mathrm{g} / \mathrm{min})=1.67 * \mathrm{VO}_{2}-1.67 * \mathrm{VCO}_{2}$ with $\mathrm{VCO}_{2}$ and $\mathrm{VO}_{2}$ in liters per minute.

Total fatty acid (FA) oxidation was determined by converting the rate of total fat oxidation to its molar equivalent, with the assumption that the average molecular weight of triglyceride is $860 \mathrm{~g} / \mathrm{mol}$, and multiplying the molar rate of triglyceride oxidation by three, because each molecule contains three moles of fatty acids.

${ }^{15} \mathrm{C}$ enrichment of breath $\mathrm{CO}_{2}$ and plasma palmitate is expressed as tracer/tracee ratio (TTR).

TTR was defined as: $\left({ }^{13} \mathrm{C} /{ }^{12} \mathrm{C}\right)$ sa $-\left({ }^{15} \mathrm{C} /{ }^{12} \mathrm{C}\right)$ bk in which sa $=$ sample and $\mathrm{bk}=$ background

Fractional recovery of infused acetate ${ }^{\text {is }} \mathrm{C}$ label in breath $\mathrm{CO}_{2}$ was calculated as:

Acetate recovery $(\mathrm{ar})=\left(\mathrm{TTR} \mathrm{CO}_{2} * \mathrm{VCO}_{2}\right) / \mathrm{F}$

where $\mathrm{F}$ is infusion rate ( $\mathrm{mmol} / \mathrm{min})$.

The rate of $\left[\mathrm{U}^{-1:} \mathrm{C}\right]$-palmitate oxidation was calculated as:

Plasma palmitate oxidation $(\mu \mathrm{mol} / \mathrm{min})=$

$\left(\mathrm{TTR} \mathrm{CO}_{2} * \mathrm{VCO}_{2}\right) /(\mathrm{T} T R$ plasma $*$ ar) $* 1000$

The average $\mathrm{VCO}_{2}$ over the last three time points at rest and during exercise was used.

The total plasma FA oxidation was then calculated by dividing palmitate oxidation by the fractional contribution of palmitate to the total FFA concentration. The average fraction palmitate/FFA was used in this equation and total plasma FA oxidation per time point was calculated over the rest and exercise period. 
Non-plasma derived FA oxidation ( $\mu \mathrm{mol} / \mathrm{min}$ ) which refers to intramuscular triglycerides and plasma triacylglycerol, was calculated at rest and during exercise as the average total FA oxidation minus the average plasma FFA oxidation.

Rate of appearance ( $\mathrm{Ra}$ ) of palmitate in plasma, which under steady state conditions is equal to the rate of disappearance ( $\mathrm{Rd}$ ) minus tracer infusion rate, was calculated as:

$\mathrm{Ra}(\mu \mathrm{mol} / \mathrm{min})=(($ TTRinfusate $/$ TTRplasma $)-1) * \mathrm{~F}$

Percentage of plasma FFA cleared from the circulation that was oxidized was calculated as:

$\% \mathrm{Ra}$ oxidized = plasma FFA oxidation $/ \mathrm{Ra} F F A$

\section{$\underline{\text { Statistics }}$}

Data are expressed as means \pm SD. Differences in basal values among groups were tested by the Kruskal Wallis test. Post-hoc testing was done by the Mann-Whitney test. Where appropriate, $\mathrm{P}$ values of the post hoc comparisons were corrected according to Bonferroni inequalities. Changes within groups were analyzed using the Wilcoxon signed rank test. A P value $<0.05$ was regarded as statistically significant.

\section{Resultx}

\section{Subject characteristics}

The exercise training intervention did not lead to significant changes in body weight and body composition (Table 2.1). Both low (LI) and high (HI) intensity exercise training significantly increased $\mathrm{VO}_{2}$ max and $\mathrm{VO}_{2}$ max/FFM $(\mathrm{P}<0.05)$, while the $\mathrm{C}$ group showed no change. The absolute work load during the exercise test ( $50 \%$ of pretraining $\mathrm{VO}_{2} \max$ ) in the LI, $\mathrm{HI}$ and $\mathrm{C}$ group was respectively $102 \pm 33,104 \pm 23$ and $92 \pm 24 \mathrm{~W}$. Work loads were not significantly different among groups. Attendance at the exercise training sessions was $89.4 \pm 7.7 \%$ for the LI group and 92.6 $\pm 5.5 \%$ for the HI group. 
Table 2.2 Energy expenditure and substrate oxidation results from indirect calorimetry at rest and during exercise before and after the intervention period in the low intensity [LI], high intensity [HI] and control [C]group.

\begin{tabular}{|c|c|c|c|c|c|c|}
\hline & \multicolumn{2}{|l|}{ uI } & \multicolumn{2}{|l|}{ HI } & \multicolumn{2}{|l|}{ c } \\
\hline & before & after & before & after & before & after \\
\hline \multicolumn{7}{|l|}{ rest } \\
\hline $\mathrm{EE}\left(\mathrm{kJ} \cdot \mathrm{min}^{-1}\right)$ & $6.52 \pm 0.86$ & $6.42 \pm 0.90$ & $6.53 \pm 0.70$ & $6.01 \pm 0.45 *$ & $6.28 \pm 0.60$ & $5.90 \pm 0.61$ \\
\hline RER & $0.81 \pm 0.03$ & $0.80 \pm 0.04$ & $0.79 \pm 0.04$ & $0.82 \pm 0.03$ & $0.79 \pm 0.03$ & $0.80 \pm 0.05$ \\
\hline $\begin{array}{l}\text { total FA oxidation } \\
\left(\mu \text { mol.minn }^{-1}\right) \\
\text { exercise }\end{array}$ & $374 \pm 93$ & $366 \pm 77$ & $406 \pm 105$ & $322 \pm 64$ & $386 \pm 77$ & $339 \pm 91$ \\
\hline $\mathrm{EE}\left(\mathrm{kJ} \cdot \mathrm{min}^{-1}\right)$ & $36.03 \pm 6.26$ & $34.25 \pm 9.52$ & $35.12 \pm 5.21$ & $34.42 \pm 6.23$ & $33.84 \pm 5.92$ & $34.36 \pm 7.05$ \\
\hline RER & $0.89 \pm 0.03$ & $0.83 \pm 0.03 *$ & $0.84 \pm 0.05$ & $0.83 \pm 0.03$ & $0.89 \pm 0.05$ & $0.86 \pm 0.03$ \\
\hline $\begin{array}{l}\text { tocal FA oxidation } \\
\left(\mu \mathrm{mol} \mathrm{min}^{-1}\right)\end{array}$ & $1138 \pm 394$ & $1597 \pm 408^{*}$ & $1546 \pm 431$ & $1591 \pm 120$ & $1109 \pm 503$ & $1408 \pm 421$ \\
\hline
\end{tabular}

\section{Fat oxidation at rest}

Data from indirect calorimetry showed that relative fat oxidation during the last $20 \mathrm{~min}$ of the resting period, expressed as respiratory exchange ratio (RER), was not different after the intervention from before (Table 2.2). Total FA oxidation (Table 2.2) and percentage fat oxidized of total energy expenditure (Figure 1A) did not change in any of the groups due to the intervention either. Energy expenditure at rest was slightly lower after the intervention in all groups, but was only significantly lower in the HI group $(\mathrm{P}<0.05)$.
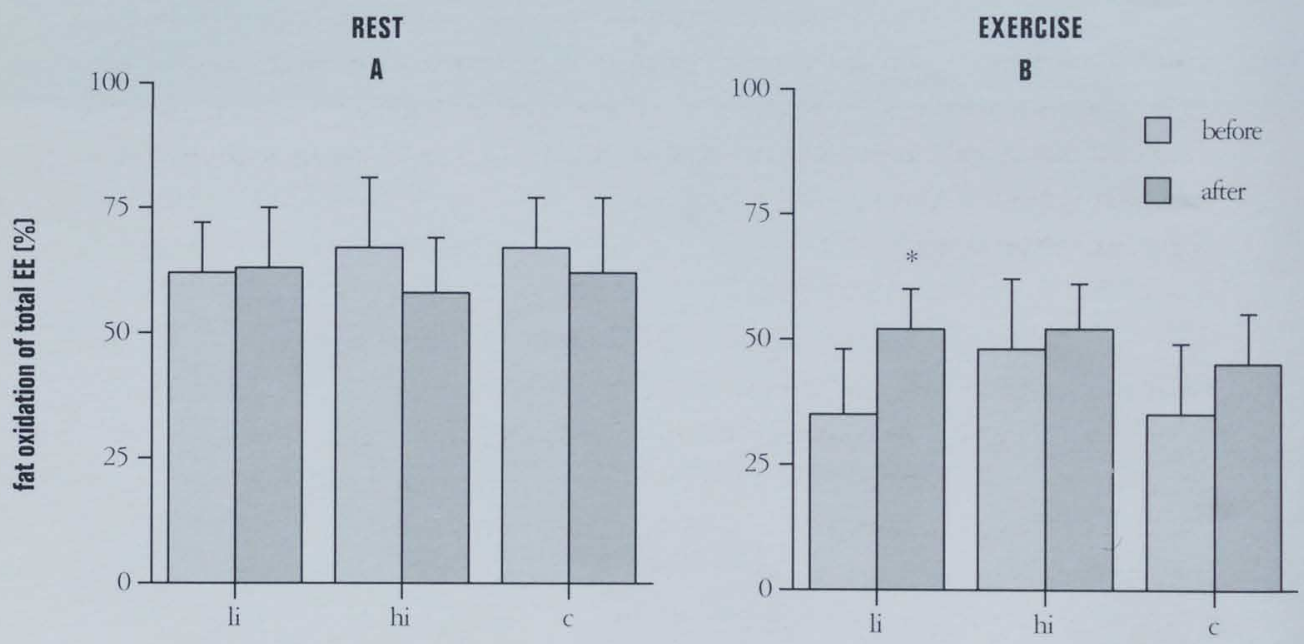
EXERCISE

C
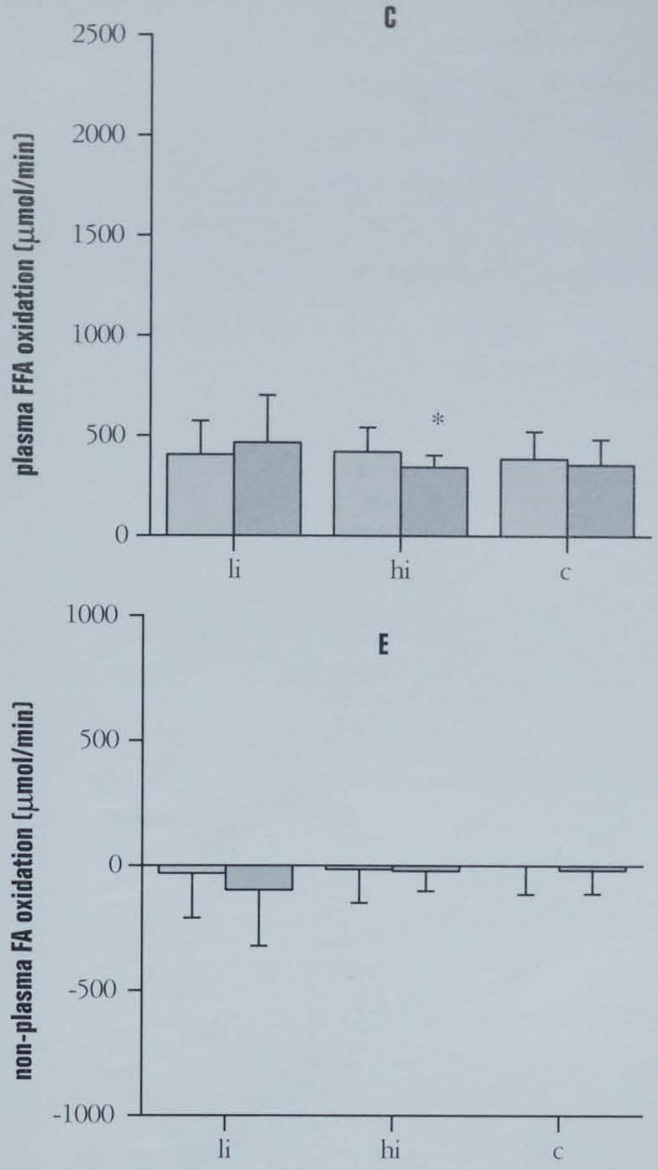

D
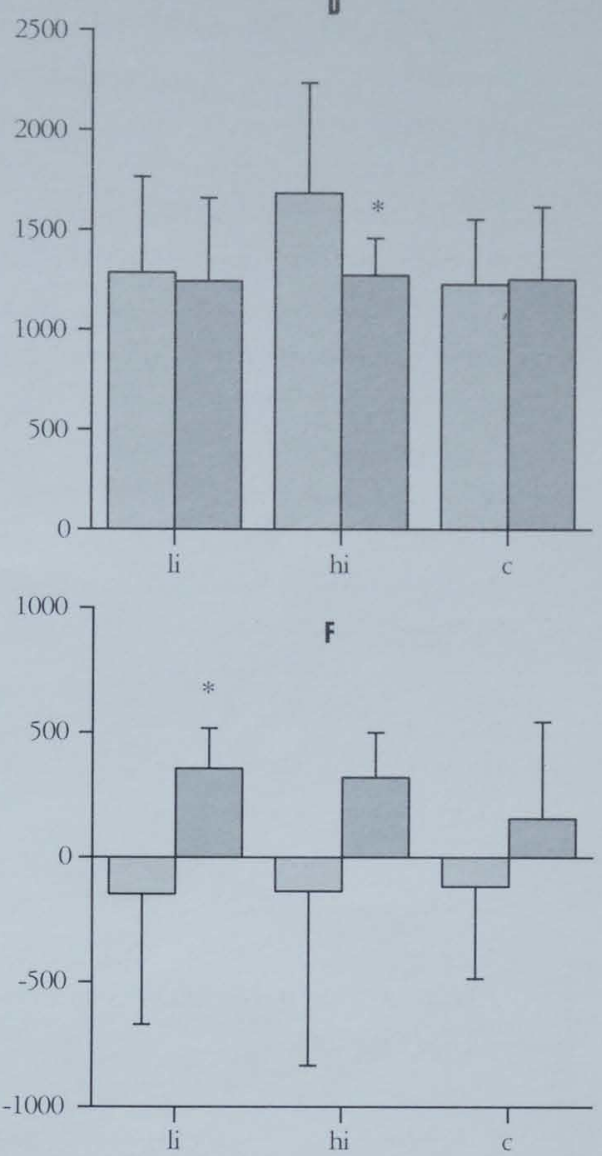

Figure 2.1 Fat oxidation as a percentage of total energy expenditure [\%], plasma FFA oxidation [umol/min] and nonplasma FA oxidation [intramuscular and VLDL-TG] [ $\mu \mathrm{mol} / \mathrm{min}$ ] over the last $20 \mathrm{~min}$ during rest and exercise in the low intensity [LI], high intensity [HI] and control group [C] at rest [respectively $\mathrm{A}, \mathrm{C}$ and $\mathrm{E}]$ and during exercise [respectively B, D and $\mathrm{F}$ ] before [1] and after [2] the intervention.

* significantly different from before $\mathrm{P}<0.05$

Plasma palmitate enrichment was at plateau (change -2.5\%) during the last 20 minutes of the resting period. Therefore, tracer calculations of plasma palmitate oxidation were made using the values of plasma palmitate enrichment measured over the $100-120$ min period. These tracer calculations were corrected by acetate recovery factors which were measured and calculated over the same time points. 
The fractional recovery of acetate increased gradually at rest from $22.3 \pm$ $2.5 \%$ at $100 \mathrm{~min}$ to $25.4 \pm 2.9 \%$ at $120 \mathrm{~min}$ after the start of the tracer infusion. Exercise training did not influence the acetate recovery factor significantly. Plasma FFA oxidation at rest was significantly decreased in the $\mathrm{HI}$ training group after training $(\mathrm{P}<0.05)$ (Figure $2.1 \mathrm{C}$ ), whereas in the $\mathrm{LI}$ and $\mathrm{C}$ group there was no change.

Non-plasma derived FA oxidation (plasma triglyceride and intramuscular triglycerides; calculated as total FA oxidation-plasma FFA oxidation) at rest was not significantly different from zero before as well as after exercise training (Figure 2.1E).

Rate of appearance of FFA at rest was significantly higher after training in the LI group $(\mathrm{P}<0.05)$ (Figure 2.2A). FFA oxidation as a percentage of the rate of appearance of FFA did not change due to the intervention (Figure 2.2A; numbers between brackets).

REST

A

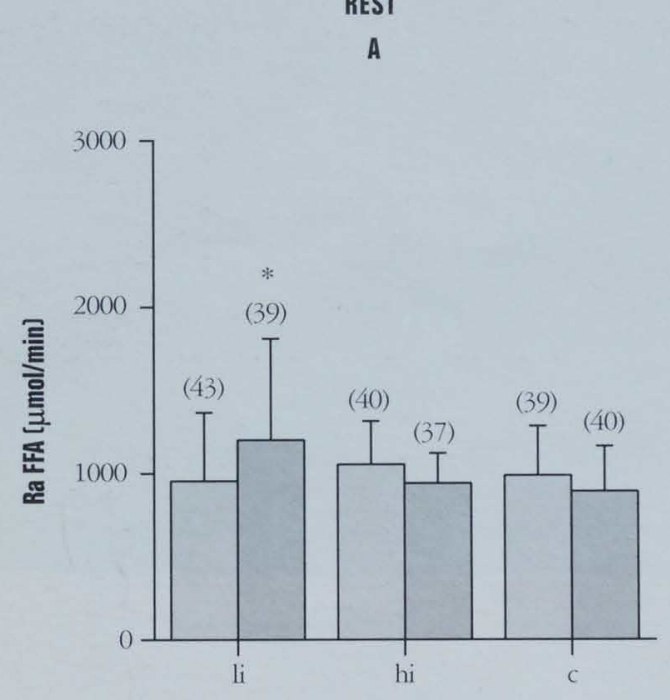

EXERCISE

B

$\square$ before

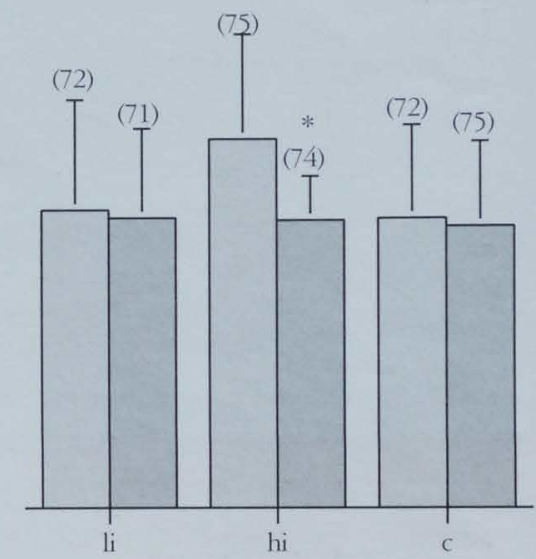

Figure 2.2 Rate of appearance of FFA [Ra FFA] [ $\mu \mathrm{mol} / \mathrm{min}]$ in the LI, HI and C group at rest [A] and during exercise [B] before [1] and after [2] the intervention. Numbers between brackets: \% Ra FFA oxidized.

* significantly different from before $[\mathrm{P}<0.05]$

Plasma concentrations of FFA (Figure 2.3A) and glycerol (Figure 2.3B) were not significantly different after the intervention from before. Plasma triglyceride concentrations were significantly reduced in the HI group after the intervention $(\mathrm{P}<0.05)$ (Figure $2.3 \mathrm{C})$. The average plasma FFA, glycerol and 
triglyceride concentrations, calculated over the last $20 \mathrm{~min}$ of rest and exercise, before the intervention were not significantly different between the groups. Plasma insulin, epinephrine and norepinephrine concentrations were not changed after the intervention (Table 2.3).
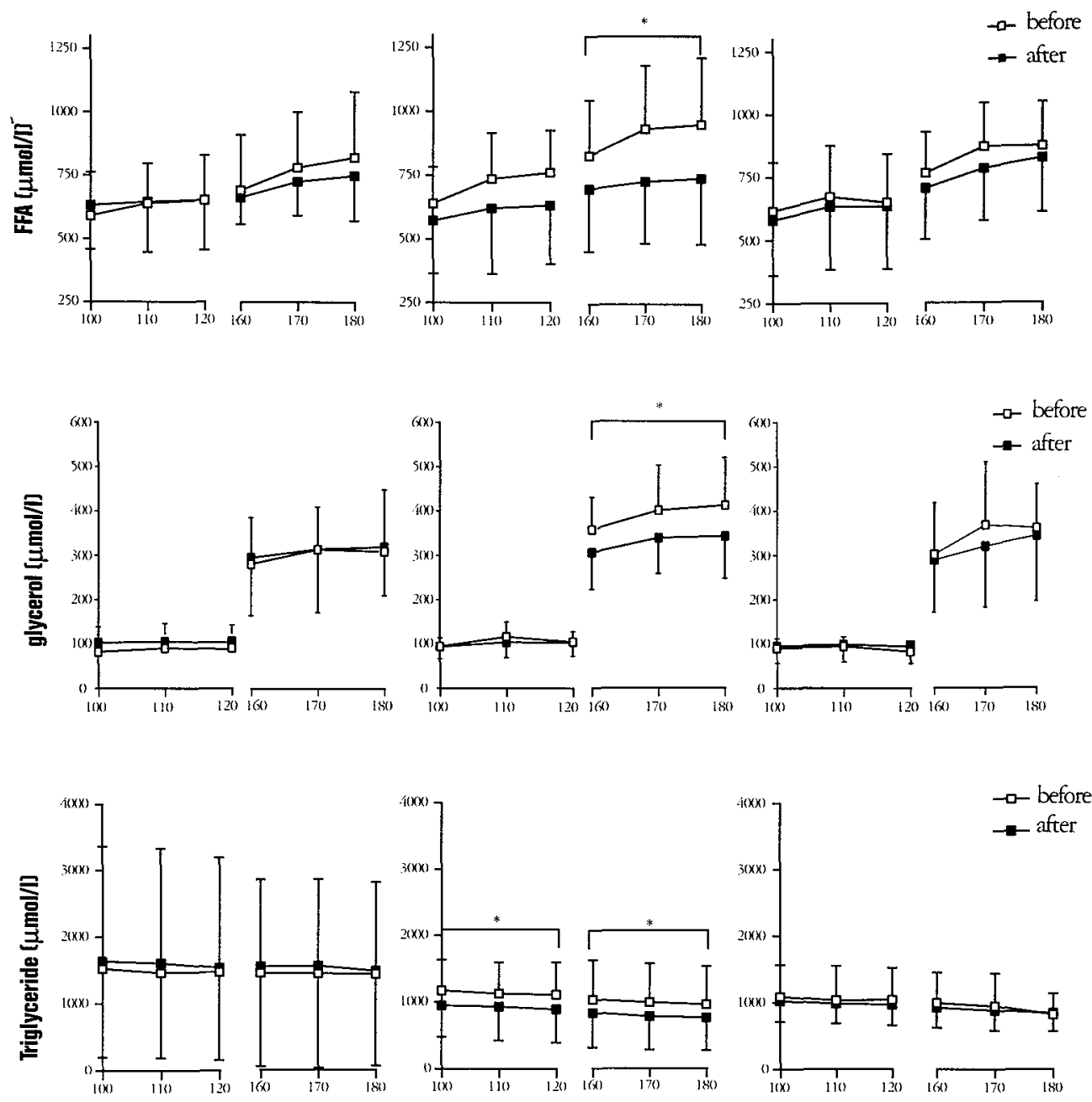

time [min]

Figure 2.3 Plasma FFA [A] [ $\mu \mathrm{mol} / / \mathrm{l}$, glycerol [B] [ $\mu \mathrm{mol} / /$ ] and triglyceride [TG] [C] [ $\mu \mathrm{mol} / / \mathrm{l}]$ concentrations during rest [100-120] and exercise [160-180] before and after the intervention in the $\mathrm{L}, \mathrm{HI}$ and $\mathrm{C}$ group.

* significantly different from before $[P<0.05]$ 


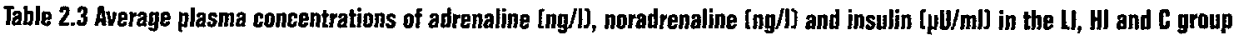
before [1] and after [2] the intervention.

$\begin{array}{lllllll}\text { group } & \begin{array}{l}\text { epinephrine } \\ \text { rest }\end{array} & \text { exercise } & \begin{array}{l}\text { norepinephrine } \\ \text { rest }\end{array} & \text { exercise } & \begin{array}{l}\text { insulin } \\ \text { rest }\end{array} & \text { exercise } \\ \text { LI } 1 & & & & & & \\ \text { LI } 2 & 50 \pm 20 & 200 \pm 112 & 590 \pm 297 & 1747 \pm 463 & 9.2 \pm 2.3 & 7.4 \pm 1.6 \\ \text { HI } 1 & 66 \pm 14 & 110 \pm 35^{*} & 600 \pm 307 & 1616 \pm 542 & 8.6 \pm 3.1 & 7.2 \pm 1.6 \\ \text { HI } 2 & 60 \pm 26 & 181 \pm 89 & 432 \pm 101 & 1605 \pm 658 & 8.2 \pm 1.6 & 6.8 \pm 1.8 \\ \text { C1 } & 55 \pm 13 & 112 \pm 38^{*} & 475 \pm 182 & 1338 \pm 457^{*} & 7.7 \pm 1.5 & 6.9 \pm 1.5 \\ \text { C2 } & 68 \pm 27 & 230 \pm 180 & 602 \pm 118 & 1813 \pm 383 & 9.0 \pm 2.1 & 6.6 \pm 1.6 \\ & 61 \pm 24 & 139 \pm 52^{*} & 557 \pm 223 & 1542 \pm 444^{*} & 7.9 \pm 1.2 & 6.2 \pm 0.8\end{array}$

* significantly different from before $\mathrm{P}<0.05$

\section{Fat oxidation during exercise}

During the last 20 min of exercise RER was significantly decreased in the LI group after exercise training, whereas in the HI and C group RER did not change. In addition, total fat oxidation over the last 20 min was significantly increased in the LI group after training in comparison with before $(\mathrm{P}<0.05)$ (Table 2.2). Fat oxidation as percentage of total energy expenditure was also increased in the LI group after the exercise intervention (Figure 2.1B). Pre-intervention fat oxidation rates were not significantly different among the groups.

Plasma palmitate enrichment was at semi plateau (change $-3.6 \%$ ) during the last 20 minutes of the exercise period. The acetate correction factor increased gradually during exercise from $69.0 \pm 8.2 \%$ after $40 \mathrm{~min}$ to $72.2 \pm 8.3 \%$ after 60 minutes of exercise at $50 \% \mathrm{VO}_{2} \mathrm{max}$ before the intervention. The intervention did not change the acetate recovery factor. Plasma FFA oxidation during exercise was significantly decreased in the $\mathrm{HI}$ group $(\mathrm{P}<0.05)$ after training whereas there were no changes in the $\mathrm{LI}$ and C group (Figure 2.1D). Plasma FFA oxidation before the intervention was not significantly different among the groups. Non plasma FA oxidation was significantly increased in the LI group $(\mathrm{P}<0.05)$ but not in the $\mathrm{HI}$ and $C$ group (Figure $1 F$ ). Non plasma FA oxidation before the intervention was not significantly different from zero.

The rate of appearance of FFA was significantly decreased in the HI group after training $(\mathrm{P}<0.05)$ but did not change in the LI and $\mathrm{C}$ group. The percentage FFA oxidized from the rate of appearance of FFA was not changed after the intervention (Figure 2B; numbers between brackets). Plasma FFA, glycerol and triglyceride concentrations after exercise training were 
significantly reduced from before in the HI group $(P<0.05)$ (Figure $2.3 A$, $\mathrm{B}$ respectively $\mathrm{C}$ ). However, concentrations before the intervention were not significantly different among the groups. Inter-individual differences in triglyceride concentrations were high in the LI group (Figure $2.3 \mathrm{C}$ ). However, excluding a subject with TG concentrations over $4000 \mu \mathrm{mol} / 1$ did not change the statistical outcome. After exercise training plasma epinephrine concentrations were significantly decreased in all groups during exercise $(\mathrm{P}<0.05)$ (Table 2.3). Plasma norepinephrine was significantly decreased during exercise in the $\mathrm{HI}$ and $\mathrm{C}$ group $(\mathrm{P}<0.05)$ (Table 2.3). The LI group showed a similar tendency. Plasma insulin concentrations were not different after the intervention for all groups (Table 2.3).

\section{Discussion}

The major new finding of the present study is that exercise training in obese men is effective in increasing total fat oxidation during moderate intensity exercise when exercise training is executed at low intensity $\left(40 \% \mathrm{VO}_{2} \mathrm{max}\right)$. Exercise training at high intensity $\left(70 \% \mathrm{VO}_{2} \mathrm{max}\right)$ does not significantly increase total fat oxidation during moderate intensity exercise. Unlike LI training, HI training induces a fall in Ra FFA and plasma FFA oxidation during exercise, which is compensated by an increase in nonplasma FA oxidation so that total fat oxidation is maintained but not increased. In contrast to the findings during exercise, no changes in fat metabolism due to exercise training were found under resting conditions. The low intensity training program increased total fat oxidation by $40 \%$ $(\mathrm{P}<0.05)$ during exercise. No significant changes were seen in the high intensity training group and control group in which total fat oxidation increased by $3 \%$ respectively $27 \%$. The increase in fat oxidation during moderate intensity exercise in the low intensity training group is in agreement with data from comparable studies performed in lean subjects after a high intensity ( $>60 \% \mathrm{VO}_{2} \max$ ) exercise training program $(22,29)$. The percentage of total energy expenditure coming from fat oxidation during exercise increased from 35 to $52 \%(\mathrm{P}<0.05)$ in the low intensity training group. This is similar to data reported in lean men after a high intensity exercise training (16).

The significant increase in total fat oxidation in the LI group during exercise $(\mathrm{P}<0.05)$ can not be explained by an increased plasma FFA oxidation but rather by an increase in non-plasma FA oxidation $(\mathrm{P}<0.05)$. In the $\mathrm{HI}$ 
group total fat oxidation during exercise failed to increase. Although in this group non-plasma FA oxidation increased slightly but not significantly, this was just enough to compensate for the significant decrease of the plasma FFA oxidation ( $\mathrm{P}<0.05)$. The decrease in plasma FFA oxidation in the HI group by exercise is paralleled by a significant decrease of the Ra of FFA in plasma. Together with the decrease of plasma FFA and glycerol concentration seen after exercise training $(P<0.05)$, this seems to point to a reduced rate of adipose tissue lipolysis in the $\mathrm{HI}$ group (14). The increase in non-plasma FA oxidation after exercise training can either implicate an increase in IMTG oxidation and/or an increase in VLDL-TG oxidation. However, the data in the present study are not able to distinguish between the two. No consistent data on training effects on VLDL-TG or IMTG oxidation are available in the literature. Some studies reported an increased IMTG oxidation by exercise training $(17,29)$ while others showed no change $(19,28)$. The IMTG content does not appear to be correlated with obesity in humans $(10,28)$, but does correlate with obesity in rats (42). The IMTG content is increased in trained compared to untrained human muscle $(19,23,28)$. Data on the contribution of VLDL-TG to fat oxidation during exercise in the literature are not consistent $(12,19,25)$. An exercise-induced TG clearance from the circulation is suggested, since lipoprotein lipase enzyme activity is increased in skeletal muscle by exercise $(27,36)$. This is in agreement with the decreased plasma TG concentrations after exercise training in the HI group but this decrease is not seen in the LI group. The cleared plasma TG may be used as fuel in the muscle. In spite of significant changes in the plasma FFA oxidation, the percentage FFA oxidized from the FFA released in plasma did not change due to exercise training and was about $40 \%$ at rest and $73 \%$ during exercise. This indicates that the Ra of FFA is not rate limiting in plasma fat oxidation. In lean untrained men çomparable data were reported at rest (30\%) and during exercise at $40 \% \mathrm{VO}_{2} \max (75 \%)(46)$. At $60 \% \mathrm{Wmax}$ and $63 \% \mathrm{VO}_{2} \max$ the percentage plasma FFA oxidation were found to be $76 \%$ (44) and 52\% (22) respectively, with no difference after exercise training. Friedlander et al. (8) however, showed a significantly increásed percentage FFA oxidized from FFA released in plasma after exercise training (from $51 \%$ to $61 \%$ at $65 \%$ prètraining $\mathrm{VO}_{2} \max$ ). However, in all these studies fat oxidation was underestimated, since no corrections were made for the loss of ${ }^{13} \mathrm{C}$ or ${ }^{14} \mathrm{C}$ label by using the acetate recovery factor. Although considerable effects of exercise training on fat oxidation in obese are found during exercise, at rest these effects are less obvious. Neither 
after low nor after high intensity exercise training effects were found on fat oxidation. However, other parameters measured suggest that fat metabolism is more positively influenced by LI training (significantly increased Ra FFA) than by HI training (significantly decreased plasma FFA oxidation). In lean subjects the effects of exercise training on fat metabolism at rest are not consistent. Some studies reported an increased fat oxidation at rest after exercise training $(4,29,30)$, while others found no change $(8,9,37)$. Cross sectional studies comparing trained and untrained lean subjects at rest : showed higher fat oxidation rates in trained compared to untrained subjects $(20,32,43)$. Obese subjects are known to have a diminished capacity $w$ mobilize and oxidize fatty acids during $\beta$-adrenergic stimulation ( ) and have a reduced postabsorptive FFA utilization by the muscle (5). However, the present study showed that fat oxidation during exercise can be improved by exercise training. Since the extra FA oxidized in the trained state are mainly coming from non-plasma FA pools (IMTG and VLDL-TG) rather than from plasma FFA (lipolysis from adipose tissue), the question can be raised whether training will help to reduce adipose mass in the obese. However, the depleted non-plasma FA pools after exercise could be restored by FFA from adipose tissue which could implicate the importance of trafficking of substrates between tissues. The IMTG pool is suggested to be restored by FFA from plasma TG or adipose tissue by activating muscle lipoprotein lipase after exercise and diminishing the lipoprotein lipase activity in adipose tissue $(21,24,26)$. A study in rats reported that plasma FFA is an important source for synthesis of IMTG (11). However, whether exercise training induced changes in fat utilization during exercise contribute to the positive/favorable effects of exercise training on body mass in the obese remains to be studied.

\section{Methodological considerations}

The test conditions in the present study did not allow the subjects to exercise $36 \mathrm{~h}$ before the test. This implicates that only the effect of exercise training on fat oxidation was measured and not the effect of an exercise bout. However, the effect of an exercise bout on fat oxidation last for about the time in between exercise sessions, when subjects perform exercise training 3 times a week. This effect, existing in a non-laboratory setting, is not included in the measurements.

In the present study the acetate recovery factor was used to correct for label 
loss in the tricarboxylic acid cycle (TCA) (38) during the palmitate infusion test. The acetate recovery factor has a high intra-individual reproducibility, but varies between subjects (34). The acetate recovery factor is correlated with basal metabolic rate, percentage body fat and RER (35). Therefore measurements of acerare recovery were performed individually both before and after exercise training. At rest the acetate recovery has a large impact on plasma FFA oxidation rates since only about $25 \%$ of ${ }^{13} \mathrm{C}$ label was recovered in expired breath. During exercise label recovery was about $72 \%$. When the acetate recovery factor would have been ignored, plasma palmitate oxidation would have been underestimated by about $75 \%$ at rest and about $28 \%$ during exercise. During exercise before the intervention and at rest, calculated non plasma FFA oxidation rates were not significantly different from zero, although in some subjects values were below zero. These negative values may indicate that values for plasma palmitate oxidation rates were overcorrected by using the acetate correction factor. This over correction may indicate that more ${ }^{13} \mathrm{C}$ acetate is trapped in the TCA cycle than ${ }^{13} \mathrm{C}$ palmitate. However, it can be assumed that this over correction is similar before and after the intervention and does not influence the comparisons.

In conclusion, although obesity is accompanied with an impaired fat metabolism, LX exercise training is effective in increasing fat oxidation during exercise, but not at rest. No effect of HI exercise training on total fat oxidation dould be shown.

\section{References}

I. Blaak, E. E., M. A. Van Baak, G. J. Kemerink, M. T. Pakbiers, G. A. Heidendal, and W. H. Saris. Beta-adrenergic stimulation of energy expenditure and forearm skeletal muscle metabolism in lean and obese men. Am J Physiol. 267: E306-I5, 1994.

2. Blaak, E. E., M. A. Van Baak, G. J. Kemerink, M. T. Pakbiers, G. A.Heidendal, and W. H. Saris. Beta-Adrenergic stimulation of skeletal muscle metabolism in relation to weight reduction in obese men. Am J Physiol.267: E3I6-22, I994.

3. Blaak, E. E., M. A. van Baak, A. D. Kester, and W. H. Saris. Betaadrenergically mediated thermogenic and heart rate responses: effect of obesity and weight loss. Metabolism 44: 520-4, ro95.

4. Calles-Escandón, J., M. I. Goran, M. O'Connell, K. S. Nair, 
and E. Danforth, Jr. Exercise increases fat oxidation at rest unrelated to changes in energy balance or lipolysis. Am J Physiol. 270: Eroog-I4, I996.

5. Colberg, S. R., J. A. Simoneau, F. L. Thaete, and D. E. Kelley. Skeletal muscle utilization of free fatty acids in women with visceral obesity. $J$ Clin Invest. 95: 1846-53, I995.

6. Ferraro, R. T., R. H. Eckel, D. E. Larson, A. M. Fontvieille, R. Rising, $D$. R. Jensen, and E. Ravussin. Relationship between skeletal muscle lipoprotein lipase activity and 24-hour macronutrient oxidation. J Clin Invest. 92: 44I-5, I993.

7. Frayn, $K . N$. Calculation of substrate oxidation rates in vivo from gaseous exchange. J Appl Physiol. 55: 628-34, 1983.

8. Friedlander, A. L., G. A. Casazza, M. A. Horning, T. F. Buddinger, and $G$. A. Brooks. Effects of exercise intensity and training on lipid metabolism in young women. Am J Physiol. 275: E853-63, I998.

9. Friedlander, A. L., G. A. Casazza, M. A. Horning, A. Usaj, and G. A. Brooks. Endurance training increases fatty acis turnover, but not fat oxidation, in young men. J Appl Physiol. 86: 2097-2105, I999.

10. Goodpaster, B. H., and D. E. Kelley. Role of muscle in triglyceride metabolism. Curr Opin Lipidol. 9: 231-6, I998.

II. Guo, Z., and M. D. Jensen. Intramuscular fatty acid metabolism evaluated with stable isotopic tracers. I Appl Physiol. 84: 1674-9, 1998.

I2. Havel, R. J., B. Pernow, and N. L. Jones. Uptake and release of free fatty acids and other metabolites in the legs of exercising men. $J$ Appl Physiol. 23: 90-9, 1967.

13. Henriksson, J. Training induced adaptation of skeletal muscle and metabolism during submaximal exercise. J Physiol Lond. 270: 66I-75, x977.

14. Hetenyi, G., Jr., G. Perez, and M. Vranic. Turnover and precursor-product relationships of nonlipid metabolites. Physiol Rev. 63: 606-67, 1983.

I5. Howley, E. T., G. E. Duncan, and P. Del Corral. Optimim intensity of exercise for fat oxidation (Abstract). Med Sci Sports Exerc. 29: Sigg, 1997.

I6. Hurley, B. F., P. M. Nemeth, W. H. d. Martin, J. M. Hagberg, G. P. Dalsky, and J. O. Holloszy. Muscle triglyceride utilization during exercise: effect of training. I Appl Physiol. 60: 562-7, 1986 .

i7. Jansson, E., and L. Kaijser. Substrate utilization and enzymes in skeletal muscle of extremely endurance-trained men. I Appl Physiol. 62: 999-1005, 2987 . 
I8. Jeukendrup, A. E., M. Mensink, W. H. Saris, and A. J. Wagenmakers. Exogenous glucose oxidation during exercise in endurance-trained and untrained subjects. J Appl Physiol. 82: 835-40, 1997.

I9.) Kiens, B., B. Essen Gustavsson, N. J. Christensen, and B. Saltin. Skeletal muscle substrate utilization during submaximal exercise in man: effect of endurance training. I Physiol Lond. 469: 459-78, I993.

20. Klein, S., E. F. Coyle, and R. R. Wolfe. Fat metabolism during low-intensity exercise in endurance-trained and untrained men. Am J Physiol. 267: E934-40, 1994.

21. Ladu, M. J., H. Kapsas, and W. K. Palmer. Regulation of lipoprotein lipase in muscle and adipose tissue during exercise. J Appl Physiol. 7I: 404-9, I99I.

22. Martin III, W. H., G. P. Dalsky, B. F. Hurley, D. E. Matthews, D. M. Bier, J. M. Hagberg, M. A. Rogers, D. S. King, and J. O. Holloszy. Effect of endurance training on plasma free fatty acid turnover and oxidation during exercise. Am J Physiol. 265: E708-I4, I993.

23. Morgan, T. E., F. A. Short, and L. A. Cobb. Effect of long-term exercise on skeletal muscle lipid composition. Am J Physiol. 216: 82-6, I969.

24. Nikkilä, E. A. Role of lipoprotein lipase in metabolic adaptation to exercise and training. In: Lipoprotein Lipase, edited by J. Borensztajn.

Chicago: Evener Publishers, Inc, 1987, p. I87-199.

25. Nikkilä, E. A., and A. Konttinen. Effect of physical activity on postprandial levels of fats in serum. Lancet I: IISI-IIS4, I962.

26. Oscai, L. B., D. A. Essig, and W. K. Palmer. Lipase regulation of muscle triglyceride hydrolysis. J Appl Physiol. 69: I57I-7, I990.

27. Oscai, L. B., J. A. Patterson, D. L. Bogard, R. J. Beck, and B. L. Rothermel. Normalization of serum triglycerides and lipoprotein electrophoretic patterns by exercise. Am J Cardiol. 30: 775-80, 1972.

28. Phillips, D. I., S. Caddy, V. Ilic, B. A. Fielding, K. N. Frayn, A. C. Borthwick, and R. Taylor. Intramuscular triglyceride and muscle insulin sensitivity: evidence for a relationship in nondiabetic subjects.

Metabolism 45: 947-50, I996.

29. Phillips, S. M., H. J. Green, M. A. Tarnopolsky, G. F. Heigenhauser, R.

E. Hill, and S. M. Grant. Effects of training duration on substrate turn over and oxidation during exercise. J Appl Physiol. 8I: 2182-9I, I996.

30. Poeblman, E. T., A. W. Gardner, P. J. Arciero, M. I. Goran, and J. Calles Escandon. Effects of endurance training on total fat oxidation in elderly persons. J Appl Physiol. 76: 2281-7, x994.

3I. Ranneries, C., J. Bulow, B. Buemann, N. J. Christensen, J. Madsen, and 
A. Astrup. Fat metabolism in formerly obese women. Am J Physiol. 274: EIS5-6r, 1998.

32. Romijn, J. A., E. F. Coyle, L. S. Sidossis, A. Gastaldelli, J. F. Horowitz, $E$. Endert, and R. R. Wolfe. Regulation of endogenous fat and carboby drate metabolism in relation to exercise intensity and duration. Am J Physiol. 265: E380-91, 1993.

33. Romijn, J. A., S. Klein, E. F. Coyle, L. S. Sidossis, and R. R. Wolfe. Strenuous endurance training increases lipolysis and triglyceride-fatty acid cycling at rest. I Appl Physiol. 75: 108-23, 1993.

34. Schrauwen, P., D. P. Van Aggel-Leijssen, W. D. Van Marken Lichtenbelt, M. A. Van Baak, A. P. Gijsen, and A. J. Wagenmakers. Validation of the $[I, 2-13 C]$ acetate recovery factor for correction of $\left[U{ }^{13} C\right]$ palmitate oxidation rates in humans. J Physiol Lond. 513: 215-23, x998.

35. Schrauwen, P., Blaak, E. E., Van Aggel-Leijssen, D.P.C., Borghouts, L.B., Wagenmakers, A.J. M. Determinants of the acetate recovery factor: impli cations for estimation of ${ }^{13} \mathrm{C}$ substrate oxidation. Clin Sci. 98: 587-592, 2000.

36, Seip, R. L., T. J. Angelopoulos, and C. F. Semenkovich. Exercise induces human lipoprotein lipase gene expression in skeletal muscle but not adipo se tissue. Am J Physiol. 268: E229-36, 1995.

37. Sial, S., A. R. Coggan, R. C. Hickner, and S. Klein. Training-induced alterations in fat and carbohydrate metabolism during exercise in elderly subjects. Am J Physiol. 274: E785-90, 1998.

38. Sidossis, L. S., A. R. Coggan, A. Gastaldelli, and R. R. Wolfe. A new cor rection factor for use in tracer estimations of plasma fatty acid oxidation. Am J Physiol. 269: E649-56, xg95.

39. Sidossis, L. S., R. R. Wolfe, and A. R. Coggan. Regulation of fatty acid oxidation in untrained vs, trained men during exercise. Am J Physiol. 274: ESI0-5, 1998.

40. Siri, W. E. The gross composition of the body. Adv Biol Med Physiol. 4: $239-280,1956$.

4I. Smedes, F, J. C. Kraak, and H. Poppe. Simple and fast solvent extraction system for selective and quantitative isolation of adrenaline, noradrenaline and dopamine from plasma and urine. J Chromatogr. 23I: 25-39, I982.

42. Storlien, L. H., A. B. Jenkins, D. J. Chisholm, W. S. Pascoe, S. Khouri, and $E$. W. Kraegen. Influence of dietary fat composition on development of insulin resistance in rats. Relationship to muscle triglyceride and omega-3 fatty acids in muscle phospholipid. Diabetes 40:280-9, rggr.

43. Tremblay, A., S. Conveney, J. P. Desprès, A. Nadeau, and D. Prud'homme. Increased resting metabolic rate and lipid oxidation in 
exercise-trained individuals: evidence for a role of beta-adrenergic stimulation. Can J Physiol Pharmacol. 70: 1342-1347, 1992.

44. Turcotte, L. P., E. A. Richter, and B. Kiens. Increased plasma FFA uptake and oxidation during prolonged exercise in trained vs. untrained humans. Am J Physiol. 262: E79I-9, I992.

45. Van Loon, L. J. C., A. E. Jeukendrup, W. H. M. Saris, and A. J. M. Wagenmakers. Effect of training status on fuel selection during submaximal exercise with glucose ingestion. J Appl Physiol. 87: I413-I4I8, I999.

46. Wolfe, R. R., S. Klein, F. Carraro, and J. M. Weber. Role of triglyceridefatty acid cycle in controlling fat metabolism in humans during and after exercise. Am J Physiol. 258: E382-9, 1990.

47. Zurlo, F, S. Lillioja, A. Esposito Del Puente, B. L. Nyomba, I. Raz, M. F. Saad, B. A. Swinburn, W. C. Knowler, C. Bogardus, and E. Ravussin. Low ratio of fat to carbohydrate oxidation as predictor of weight gain: study of 24-h RQ. Am J Physiol. 259: E650-7, I99o.

48. Zurlo, F, P. M. Nemeth, R. M. Choksi, S. Sesodia, and E. Ravussin. Whole-body energy metabolism and skeletal muscle biochemical characteristics. Metabolism 43: 48I-6, I994. 


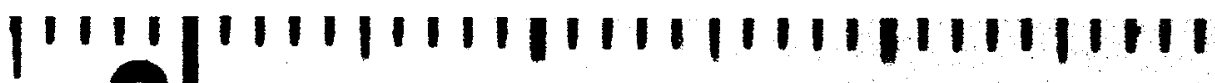 3 Effects of exercise training on B-adrenergic C stimulation of fat metabolism in obese men}

Dorien P.C. van Aggel-Leijssen, Wim H.M. Saris, Moniek, Homan and Marleen A.van Baak

Accepted International Journal of Obesity

\section{Abstract}

Objective: To investigate the in vivo effect of exercise training at high and low intensity on $\beta$-adrenergic stimulated fat metabolism in obese men at rest.

Methods: Twenty three obese, bealthy subjects were randomly divided in either a low intensity exercise training program (40\%VO2max) ( $n=7)$, a bigh intensity exercise training program $\left(70 \% \mathrm{VO}_{2} \max \right)(n=8)$ or a non-exercising control group $(n=8)$. The exercise training program lasted for 12 weeks with a training frequency of 3 times per week. Before and after the intervention body composition and maximal aerobic capacity were measured as well as fat metabolism at rest and during $\beta$-adrenergic stimulation by isoprenaline. For comparison, six lean subjects served as a control group. They participated in a low intensity exercise training program and underwent the same measurements as the obese subjects.

Results: Relative fat oxidation decreased significantly during infusion of an increasing dose of isoprenaline in the obese low intensity and high intensity exercise training group as well as in the lean group $(P<0.01)$. Exercise training failed to influence the effect of $\beta$-adrenergic stimulation on relative fat oxidation in obese men at both intensities and in lean men. In addition, $\beta$-adrenergic-mediated lipolysis did not seem to be different after $L I$ exercise training in 
lean and obese men. Lipolysis might be increased after $\mathrm{HI}$ exercise training in obese men.

Conclusion: Low and bigh intensity exercise training in obese men failed to affect $\beta$-adrenergic mediated relative fat oxidation in vivo. Beta-adrenergic mediated lipolysis might be increased in obese men after $H I$ exercise training only. The effect of low intensity exercise training on $\beta$ adrenergic mediated fat metabolism was similar in lean and obese men.

\section{Introduction}

Obese subjects appear to have an impaired catecholamine-induced lipolysis $(2,22)$. In vitro lipolysis studies suggest that this may be due to an increased $\alpha 2$-adrenergic and a decreased $\beta$-adrenergic lipolytic response in obese compared to lean men (16). The decreased $\beta$-adrenergic response was associated with a decreased expression of 32 -adrenoceptors in obese women (19). In vivo $\beta$-adrenergic stimulation increased relative fat oxidation (fat oxidation relative to total energy expenditure) in lean subjects but failed to increase relative fat oxidation in obese subjects $(2,5,22,31)$. Obese subjects seem to have an impaired utilization of FFA in the muscle (4).

Furthermore, a positive correlation has been reported between $24 \mathrm{~h}$ fat oxidation and B-adrenergic sensitivity in Pima Indian males (28) and between an impaired $\beta$-adrenergic mediated lipolysis in situ and a low basal fat oxidation rate (25). Together these data suggest that $\beta$-adrenergic stimulation of lipolysis and fat oxidation is impaired in the obese. Endurance exercise training is known to increase the rate of fat oxidation during exercise and maybe also at rest $(3,11,13,18,21,30)$. In a previous study we found that low intensity exercise training increased fat oxidation during exercise in obese subjects (14). Several cross-sectional in vitro studies have shown that the sensitivity of abdominal adipocytes to the lipolytic action of catecholamines is increased in lean endurance-trained compared to sedentary individuals $(6,7,10,17,20,29)$. This effect seems to be related to the increased response of the $\beta$-adrenergic pathway $(6,7,17)$ and possibly also to a decreased response of the $\alpha 2$-adrenergic pathway to a fixed stimulus $(7,17)$. On the other hand, a cross-sectional study using in situ microdialysis showed no difference in lipolytic sensitivity to adrenaline between trained and untrained lean men (26). 
Since $ß$-adrenergic stimulated lipolysis and fat oxidation are impaired in obese subjects, the effect of exercise training on $B$-adrenergic stimulated fat metabolism in obese is not necessarily similar to the effects in lean subjects. To our knowledge, only one study investigated the effect of moderate intensity exercise training on isoprenaline-induced lipolysis in obese subjects in vitro (8) and in situ by the microdialysis technique (27). These investigators reported an increased $B$-adrenergic stimulated lipolysis after exercise training. However, no data are available on the effect of exercise training on in vivo $ß$-adrenergic stimulated fat metabolism in obese subjects. Therefore, the present study was undertaken to investigate the effect of exercise training at different intensities on in vivo $B$-adrenergic stimulated lipolysis and fat oxidation in obese male subjects.

\section{Metbods}

\section{$\underline{\text { Subjects }}$}

Twenty three obese male subjects participated in the present study. Physical characteristics of the subjects are indicated in Table 3.1. All subjects were in good health as assessed by medical history and physical examination. They did not take medication known to influence the variables measured and had a stable body weight ( $<3 \mathrm{~kg}$ change) during two months prior to selection. They did not spend more than 2 hours per week in sports activities and had no physically demanding job. Subjects were matched in groups of three for age, BMI, fat percentage and maximal oxygen uptake per $\mathrm{kg}$ fat free mass $\left(\mathrm{VO}_{2} \mathrm{max} / \mathrm{kg}\right.$ FFM). Subsequently members of each group were randomly divided over three groups, the low intensity (LI) or high intensity (HI) exercise training group and the control group (C). Subjects were requested to maintain their dietary habits during the study. The study protocol was approved by the Ethics Committee of Maastricht University. Written informed consent was obtained from all subjects.

\section{Experimental design}

Two of the three obese groups participated in the exercise training program for 12 weeks. The third group served as a non-training control group (C). Measurements of body composition, maximal aerobic capacity and isoprena- 
line-induced thermogenesis and substrate oxidation were made before the start of the exercise training program and within one week after 12 weeks of exercise training (36-86 $\mathrm{h}$ after the last exercise bout). The exercise training program was continued until all measurements were performed.

Table 3.1 Subject characteristics [mean \pm 50 ] in obese $[n=23]$ and lean $[n=6]$ subjects before [1] and after [2] the exercise training period in the low intensity training group [LI], high intensity training group [HI] and the control group [C].

obese LI [1] obese LI [2] obese HI [1] obese HI [2] obese [ [1] obese C [2] lean LI [1] Jean LI [2]

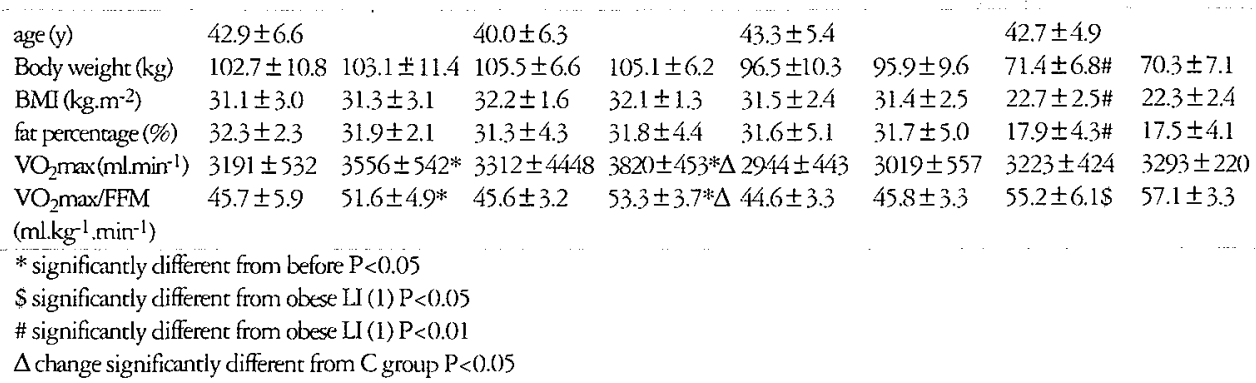

\section{Exercise training}

The exercise training program consisted of cycling on an ergometer (Bodyguard Cardiocycle, Sandnes, Norway or Lode, Groningen, The Netherlands) at either low intensity (LI; $40 \% \mathrm{VO}_{2} \max$ ) or high intensity $\left(\mathrm{HI} ; 70 \% \mathrm{VO}_{2} \max \right)$.

Seven obese subjects participated in the $L I$ and eight obese subjects in the $\mathrm{HI}$ training program. Subjects trained during 12 weeks, three times per week. Energy expenditure of each subject in each training session was fixed at 5 kcal.kg FFM ${ }^{-1}$. Training duration for obese subjects in the LI and $\mathrm{HI}$ training program during the first month was $57.1 \pm 8.0$ and $32.8 \pm 2.5$ min per session respectively. Heart rate was monitored continuously during the training sessions (Polar Electro, Oy, Finland). After 4 and 8 weeks of exercise training, a maximal aerobic exercise test was performed and the training workload and duration were adjusted if necessary. All training sessions took place at the laboratory under supervision of a professional trainer. 


\section{$\underline{\text { Lean control group }}$}

Considering no data were available in the literature on the effect of exercise training on in vivo $ß$-adrenergic mediated fat metabolism in lean subjects, besides the obese group also a lean group was included in the study. In this group 6 men participated. They were all lean (fat $\% \leqslant 24$ ) and matched for age with the obese group. They did not spend more than 2 hours a week in sports activities and had no physically demanding job. All subjects participated in the LI exercise training program and trained on average for $47.5 \pm 6.0$ min per session (energy expenditure 5 kcal. $\mathrm{kg} \mathrm{FFM}^{-1}$ ) with the same frequency as the obese group. The training and measurement protocol were the same as described for the obese group.

\section{$\underline{\text { Measurements }}$}

1. Body composition

Body density was measured by hydrostatic weighing, with a correction for residual lung volume estimated by helium dilution with a spirometer (Volugraph 2000, Mijnhardt, The Netherlands) at the moment of under water weighing. Body composition was calculated according to the formula of Siri (23).

\section{Maximal aerobic capacity}

Maximal $\mathrm{O}_{2}$ uptake ( $\mathrm{VO}_{2} \mathrm{max}$ ) for each subject was determined by an incremental exercise test on an electromagnetically braked cycle ergometer (Excalibur, Lode, Groningen, The Netherlands). After a warming up period of 5 minutes at $100 \mathrm{~W}$, workload was increased every 4 minutes by $40 \mathrm{~W}$ until exhaustion. During the experiment ventilatory and gas exchange responses were measured continuously, using indirect calorimetry (Oxycon $\beta$, Mijnhardt, The Netherlands). Heart rate was recorded continuously by an electrocardiogram. The highest oxygen uptake achieved over $30 \mathrm{~s}$ was taken as $\mathrm{VO}_{2} \max$.

\section{Isoprenaline infusion test}

An isoprenaline (ISO) infusion test was performed before and after the exercise training program to determine the effect of exercise training on $B$ adrenergically mediated thermogenic, metabolic and heart rate (HR) 
responses. The protocol of this test has been described previously (2). The experiments were mostly performed $38 \mathrm{~h}$ (at least $36 \mathrm{~h}$ and at maximum $86 \mathrm{~h}$ ) after the last exercise bout in a room with a temperature between 23 and $25{ }^{\circ} \mathrm{C}$. After an overnight fast, subjects came to the laboratory by car or bus. Catheters were inserted in a right and left fore-arm vein for infusion of the nonselective $\beta$-adrenoceptor agonist ISO and for blood sampling. The subjects remained in semi-supine position throughout the experiment. After a 30-min baseline measurement period, ISO was infused by a Harvard syringe pump in increasing doses of 6,12 and $24 \mathrm{ng} . \mathrm{kg}$ fat-free $\mathrm{mass}^{-1} \cdot \mathrm{min}^{-1}$, each dose for $30 \mathrm{~min}$. The dose is related to ISO sulphate, $69 \%$ of which corresponds to ISO free base. During the experiment blood pressure was recorded every $5 \mathrm{~min}$ and $\mathrm{HR}$ was recorded continuously by an electrocardiogram. When HR had risen 30 beats/min or more, infusion was stopped.

At the end of the baseline period and of each infusion period a blood sample was taken. During the whole experiment expired $\mathrm{CO}_{2}$, inspired $\mathrm{O}_{2}$ and respiratory exchange ratio (RER) were determined by an open circuit ventilated hood system (Oxycon B, Mijnhardt, The Netherlands). The accuracy of the ventilated hood system for gas exchanges was tested regularly to be within 5\%. Energy expenditure was calculated according to the formula of Weir (32). RER values reached a steady state after 20 min infusion. RER, $\mathrm{EE}$ and $\mathrm{HR}$ were averaged over the last $10 \mathrm{~min}$ of each infusion period.

\section{Biochemical analysis}

After blood sampling, blood was put into an EDTA containing chilled 10 $\mathrm{ml}$ tube (for analysis of FFA, glucose, insulin and glycerol) or a heparin containing $10 \mathrm{ml}$ tube with $300 \mu \mathrm{l}$ glutathione $(45 \mu \mathrm{g} / \mathrm{l}$ saline) (for analysis of (SO). Blood was immediately centrifuged for $10 \mathrm{~min}$ at $3000 \mathrm{rpm}$ at $4{ }^{\circ} \mathrm{C}$ and plasma was stored at $-80^{\circ} \mathrm{C}$.

Analysis of plasma concentrations FFA (NEFA C kit; Wako Chemicals, Neuss, Germany), glycerol (Glycerol kit; Boehringer, Mannheim, Germany) and lactate (12) were performed on a COBAS FARA centrifugal spectrophotometer. Plasma glucose concentrations (GLUC HK kit; Hoffmann-La Roche, Basel, Switzerland) were measured on a COBAS BIO centrifugal spectrophotometer. Plasma insulin concentrations were measured with a double-antibody radioimmunoassay (Insulin RIA 100; Pharmacia, Uppsala, Sweden). Plasma isoprenaline concentrations were analysed by HPLC with electrochemical detection (24). 


\section{Statistics}

Values were expressed as means \pm standard deviations. A Friedman test was performed to detect changes due to the dose ISO infused. All values were corrected for baseline values and the mean effect over all time points was calculated for each subject. Exercise training effects on the calculated mean values within a group were analyzed by a Wilcoxon signed rank test. A Kruskal-Wallis test was performed to test differences in initial values and changes due to the intervention among the three obese groups. Post hoc testing was done by the Mann-Whitney test. Where appropriate, $\mathrm{P}$ values of the post hoc comparisons were corrected according to Bonferroni inequalities. A Mann-Whitney test was used to compare the initial values between lean and obese and lean and the obese LI group and to test changes due to the intervention between lean and the obese LI group. A P-value smaller than 0.05 was regarded as statistically significant.

\section{Results}

\section{Subject characteristics}

After the intervention body composition was not changed in any group (Table 3.1). $\mathrm{VO}_{2} \max$ and $\mathrm{VO}_{2} \max / F F M$ were significantly improved in the obese $\mathrm{LI}$ and $\mathrm{HI}$ exercise groups $(\mathrm{P}<0.05)$, but not in the lean LI and obese $\mathrm{C}$ group. The change in $\mathrm{VO}_{2} \max$ and $\mathrm{VO}_{2} \max / \mathrm{FFM}$ were not significantly different between the $\mathrm{LI}$ and the $\mathrm{HI}$ exercise group, but significantly different between the $\mathrm{HI}$ and $\mathrm{C}$ group $(\mathrm{P}<0.01$ and $\mathrm{P}<0.05$ respectively). Attendance at the exercise training sessions was $88.7 \pm 8.7 \%$ for the LI group and $92.6 \pm 5.5 \%$ for the HI group.

\section{Effect of exercise training} on B-adrenergic stimulation of fat metabolism in obese

Before the intervention, infusion of an increasing dose of ISO decreased respiratory exchange ratio $(R E R)$ significantly $(P<0.01)$ in the obese $L I$ and $\mathrm{HI}$ group, but not in the $\mathrm{C}$ group (Figure 3.1). However, average ISOinduced effect on RER before the intervention was not significantly different among the three obese groups. None of the interventions affected the ISO-induced decrease in RER significantly. 
chapter 3
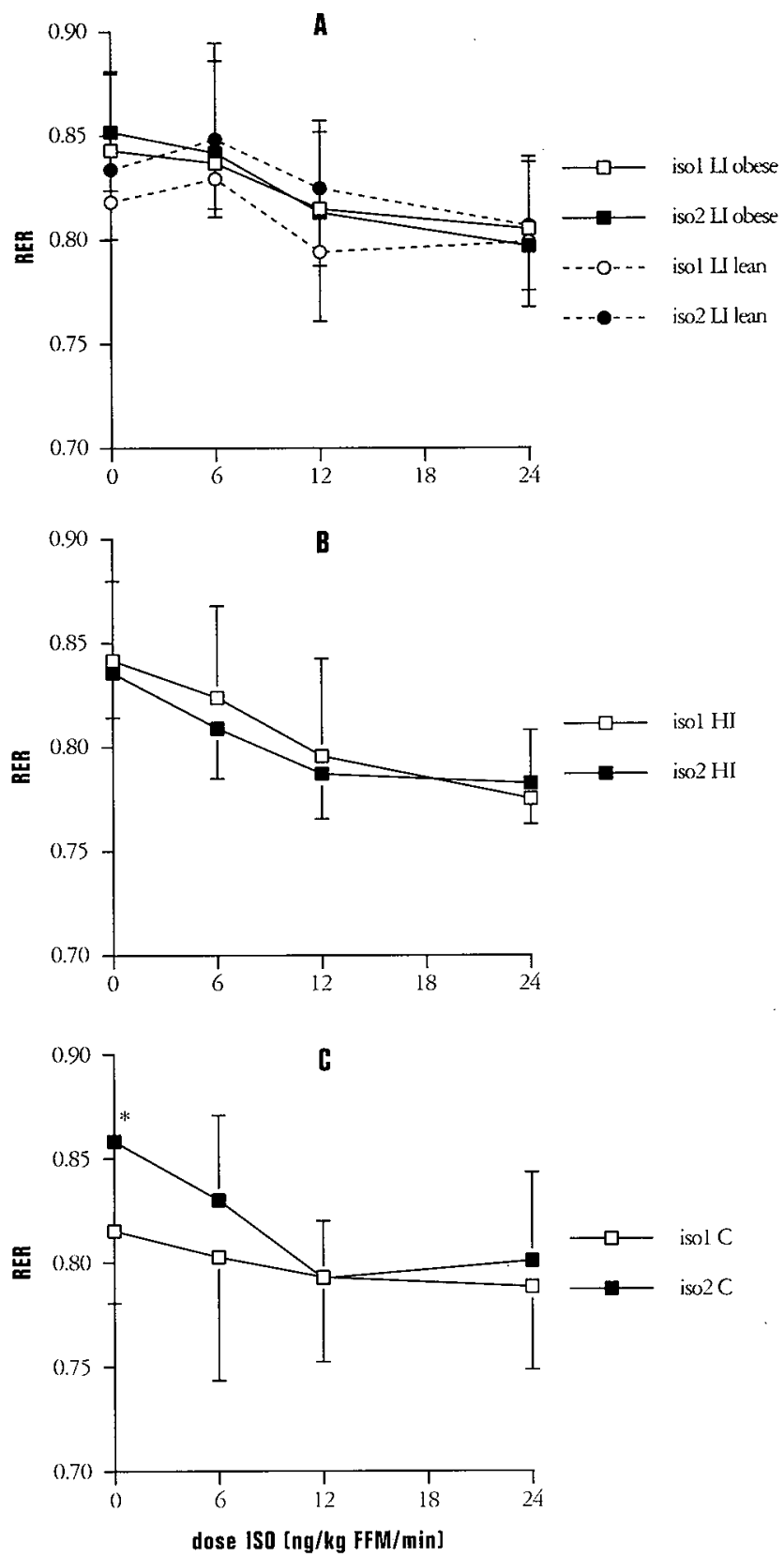

Figure 3.1 RER during increasing dose of isoprenaline [ISO] infusion before [1] and after [2] exercise training in the low intensity [LI] lean and ohese group (A] and the obese high intensity [HI] [B] and control [C] group [C].

* significant different from before $\mathbf{P}<0.05$ 
Basal energy expenditure and heart rate were not significantly different among the obese groups before the intervention (Table 3.2). Infusion of ISO significantly increased energy expenditure $(\mathrm{P}<0.01)$ (Figure 3.2) and heart rate $(\mathrm{P}<0.001)$ (Figure 3.3). The effect of ISO on energy expenditure and heart rate was not influenced by any of the interventions.

Table 3.2 Baseline values [mean \pm SD] for heart rate [HR], energy expenditure [EE], respiratory exchange ratio [RER] and plasma metaholites in the obese low intensity [LI] and high intensity [HI] training group, the obese control [C] group and the lean $\mathrm{LI}$ group hefore [1] and after [2] the intervention.

\begin{tabular}{|c|c|c|c|c|c|c|c|c|}
\hline & obese LI [1] & [2] & HI [1] & [2] & C [1] & [2] & lean LI [1] & [2] \\
\hline HR (bears.min ${ }^{-1}$ ) & $66 \pm 11$ & $63 \pm 7$ & $60 \pm 9$ & $58 \pm 8$ & $68 \pm 12$ & $66 \pm 12$ & $59 \pm 5$ & $59 \pm 8$ \\
\hline $\mathrm{EE}\left(\mathrm{kJ} \cdot \mathrm{min}^{-1}\right)$ & $5.84 \pm 0.94$ & $6.10 \pm 0.91$ & $6.35 \pm 0.67$ & $6.16 \pm 0.61$ & $6.07 \pm 0.73$ & $5.89 \pm 0.58$ & $4.83 \pm 0.41 \#$ & $4.92 \pm 0.57$ \\
\hline $\mathrm{EE} / \mathrm{FFM}\left(\mathrm{J} \cdot \mathrm{min}^{-1} \cdot \mathrm{kg}^{-1}\right)$ & $85 \pm 10$ & $87 \pm 6$ & $87 \pm 9$ & $86 \pm 6$ & $93 \pm 14$ & $91 \pm 14$ & $83 \pm 4$ & $86 \pm 11$ \\
\hline RER & $0.84 \pm 0.02$ & $0.85 \pm 0.03$ & $0.84 \pm 0.04$ & $0.84 \pm 0.02$ & $0.82 \pm 0.04$ & $0.86 \pm 0.04 *$ & $0.82 \pm 0.02$ & $0.83 \pm 0.05$ \\
\hline FFA $\left(\mu \mathrm{mol}^{1-1} \mathrm{I}^{-1}\right)$ & $453 \pm 236$ & $368 \pm 175$ & $361 \pm 139$ & $394 \pm 77$ & $530 \pm 193$ & $383 \pm 126$ & $376 \pm 84$ & $239 \pm 85 *$ \\
\hline glycerol $\left(\mu \mathrm{mol}^{1} \mathrm{I}^{-1}\right)$ & $75.6 \pm 33.3$ & $67.9 \pm 17.8$ & $76.1 \pm 21.1$ & $61.7 \pm 13.5$ & $81.3 \pm 22.6$ & $66.5 \pm 19.5$ & $68.5 \pm 22.0$ & $49.7 \pm 18.0$ \\
\hline glucose $\left(\mathrm{mmol} .1^{-1}\right)$ & $5.23 \pm 0.38$ & $5.32 \pm 0.57$ & $5.47 \pm 0.41$ & $5.51 \pm 0.34$ & $5.55 \pm 0.68$ & $5.64 \pm 0.56$ & $4.85 \pm 0.49 \mathrm{~S}$ & $5.09 \pm 0.55$ \\
\hline insulin $\left(\mu U \mathrm{~m}^{-1} \mathrm{l}^{-1}\right)$ & $12.3 \pm 5.8$ & $12.7 \pm 5.0$ & $12.4 \pm 5.6$ & $11.9 \pm 4.4$ & $9.1 \pm 3.2$ & $12.3 \pm 7.4$ & $4.53 \pm 1.20 \#$ & $4.84 \pm 1.08$ \\
\hline lactate $\left(\mathrm{mmol} . \mathrm{l}^{-1}\right)$ & $1.02 \pm 0.44$ & $1.13 \pm 0.27$ & $0.89 \pm 0.29$ & $0.95 \pm 0.17$ & $0.94 \pm 0.28$ & $0.95 \pm 0.19$ & $0.61 \pm 0.12 \#$ & $0.75 \pm 0.26$ \\
\hline
\end{tabular}

Infusion of ISO significantly increased plasma FFA, insulin, lactate and glycerol concentrations $(\mathrm{P}<0.05-0.001)$ and significantly decreased plasma glucose concentrations $(\mathrm{P}<0.05-0.01)$ (Table 3.3). Basal plasma concentrations before the intervention were not significantly different among groups and did not change due to the intervention (Table 3.2).

Table 3.3 Average ISD-induced change [mean \pm SD] in plasma metabolite concentrations in the obese $\mathrm{LI}, \mathrm{HI}$ and $\mathrm{C}$ group and the lean LI group before [1] and after [2] the intervention.

\footnotetext{
obese LI [1] [2]

HI [1]

[2]

[ [1]

[2]

lean Ll [1] [2]

FFA $\left(\mu\right.$ mol. $\left.1^{-1}\right) \quad 313 \pm 133+\quad 450 \pm 130+368 \pm 171+416 \pm 117+223 \pm 1725$

slycerol ( $\left(\right.$ moll.1-1) $27.7 \pm 12.0 \# 46.6 \pm 30.0+27.9 \pm 28.3+53.6 \pm 18.0^{*}+22.6 \pm 26.3$

$342 \pm 201+384 \pm 179+321 \pm 128+$ glucose (mmol..$\left.^{-1}\right)-0.48 \pm 0.64 \$-0.16 \pm 0.31$

$-0.25 \pm 0.14 \#-0.32 \pm 0.295-0.67 \pm 0.88 \#$

$32.9 \pm 30.8 \# 41.2 \pm 19.6+26.1 \pm 20.5 \$$

insulin $\left(\mu \mathrm{U} . \mathrm{mll}^{-1}\right) \quad 5.0 \pm 3.8 \#$

$7.0 \pm 2.7+$

$4.9 \pm 3.2+\quad 5.1 \pm 2.2 \# \quad 3.4 \pm 2.4 \#$

$-0.27 \pm 0.17 \#$

lacate $\left.\left(m m o l^{-1}\right)^{-1}\right) \quad 0.09 \pm 0.15$

$0.09 \pm 0.15 \$$

$0.10 \pm 0.18 \$$

$0.09 \pm 0.10 \$-0.01 \pm 0.18$

$7.3 \pm 4.2 * \mathrm{~s}$

$2.4 \pm 1.9$ \# $2.3 \pm 0.8 \#$

* significandly different from before $\mathrm{P}<0.05$

$\$$ significant clange versus baseline $P<0.05$

\# significant change versus basseline $\mathrm{P}<0.01$

+ significant change versus baseline $P<(),(0) 1$
} 

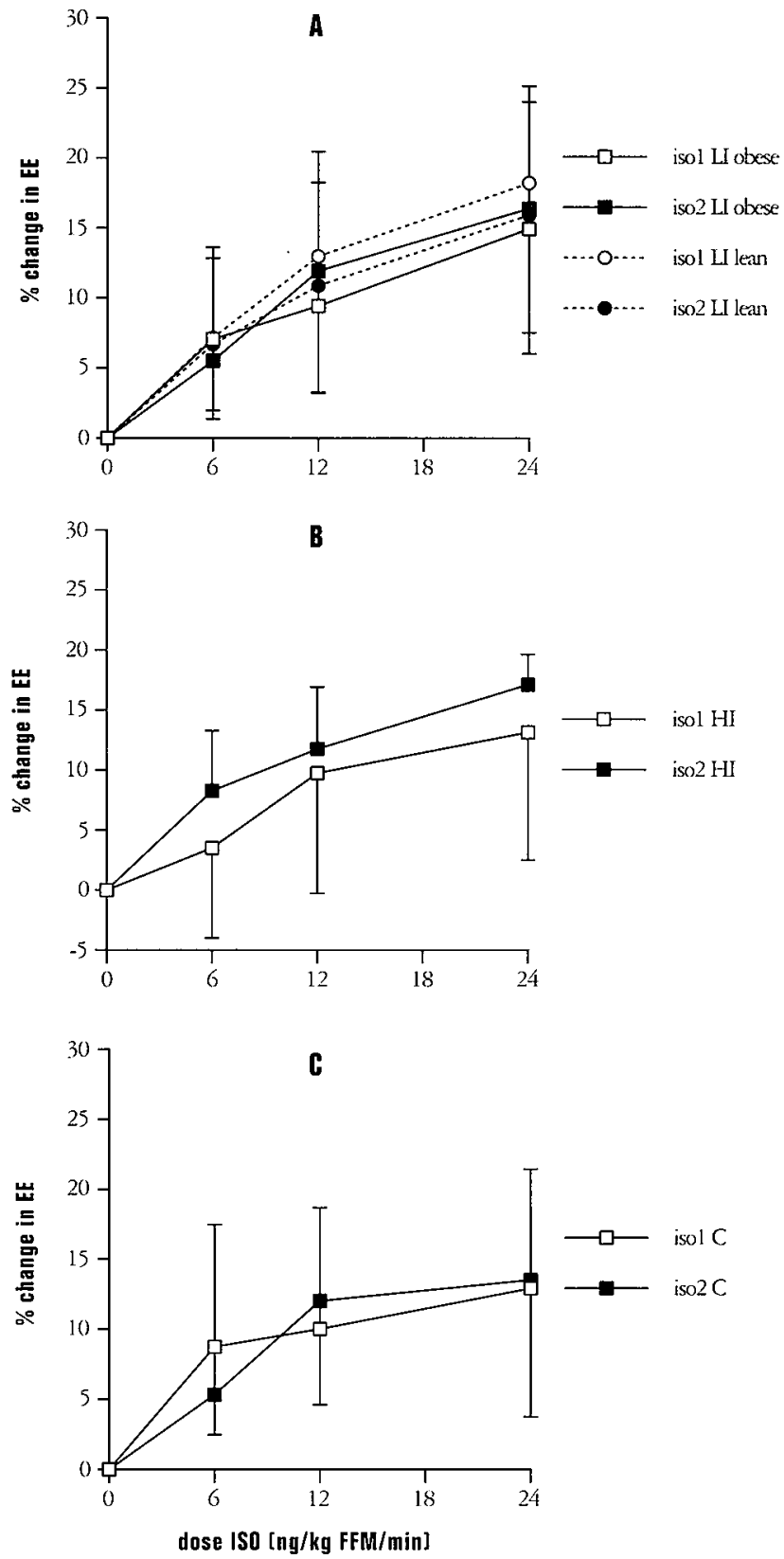

Figure 3.2 Percentage change in energy expenditure [EE] from basal before [1] and after [2] exercise training in the low intensity [LI] lean and obese group [A] and the obese high intensity [HI] [B] and control [C] group [C]. 

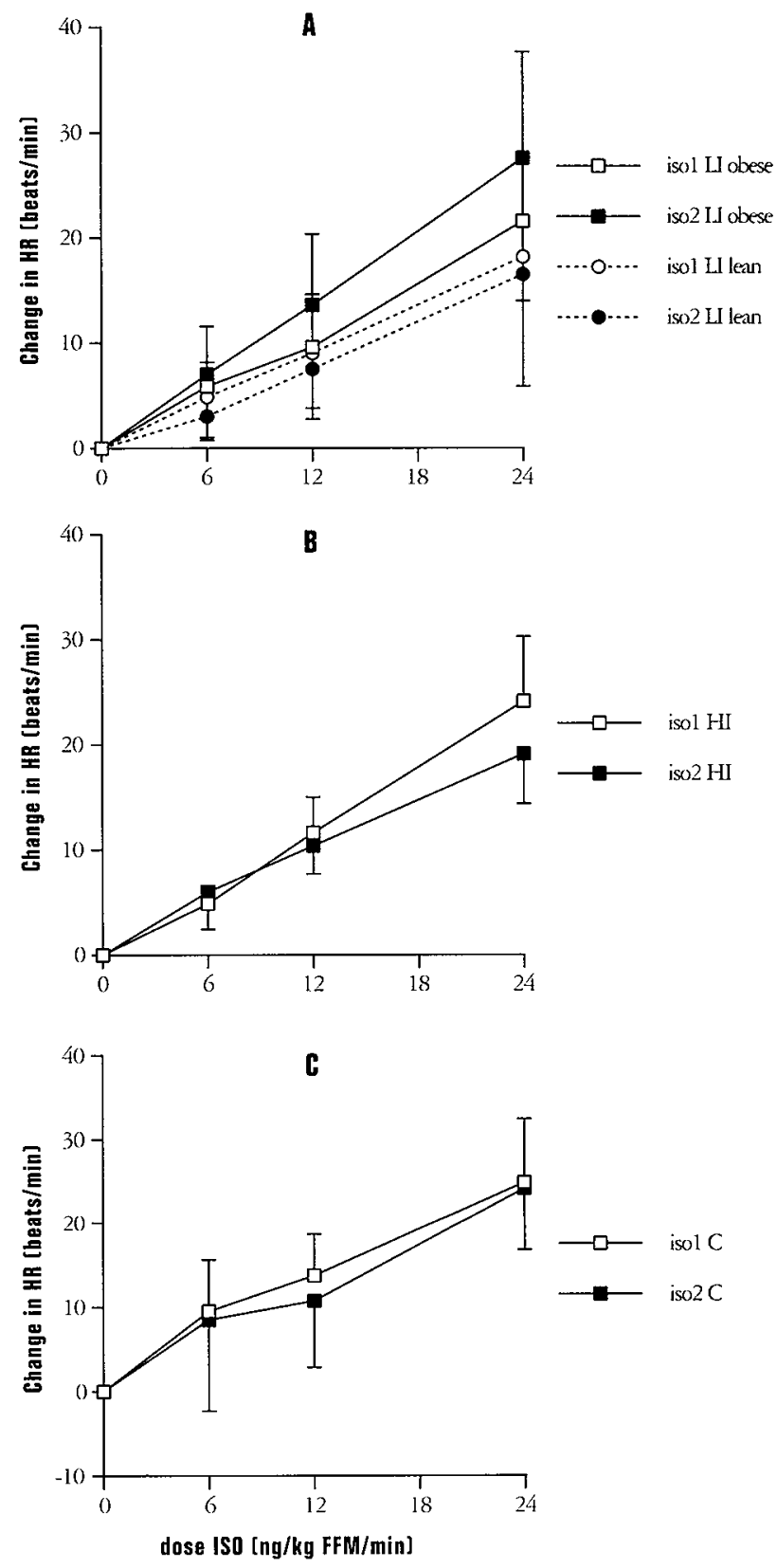

Figure 3.3 Change in heart rate [HR] [beats/min] from basal hefore [1] and after [2] exercise training in the low intensity [LI] lean and obese group [A] and the obese high intensity [HI] [B] and control [C] group [C]. 

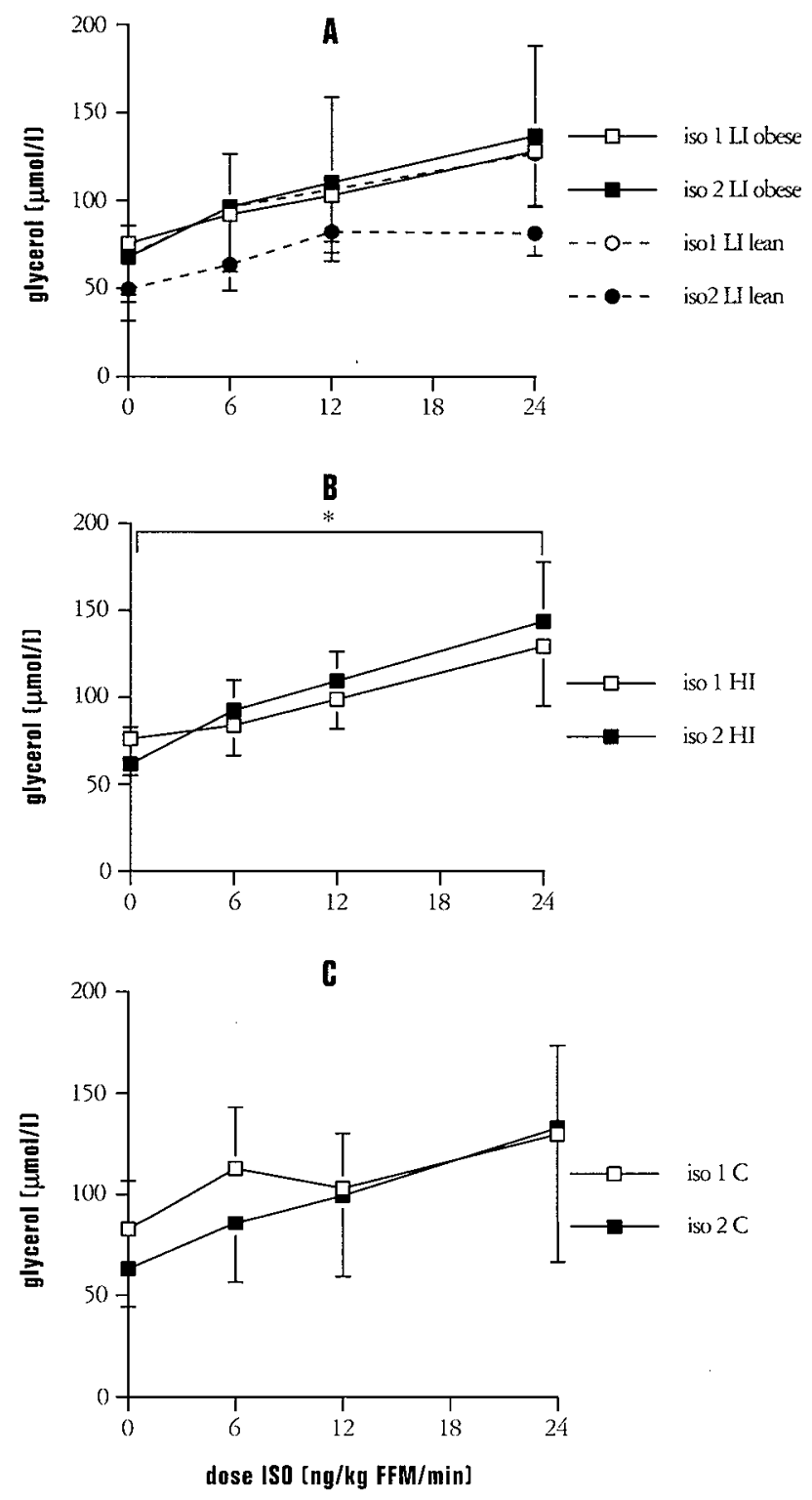

Figure 3.4 Plasma glycero] concentrations [ [ $\mathrm{mmol} / \mathrm{l}$ ] before [1] and after [2] exercise training in the low intensity [LI] lean and obese group [A] and the obese high intensity [HI] [B] and control [C] group [C].

* average increase significantly different from hefore $P<0.05$ 

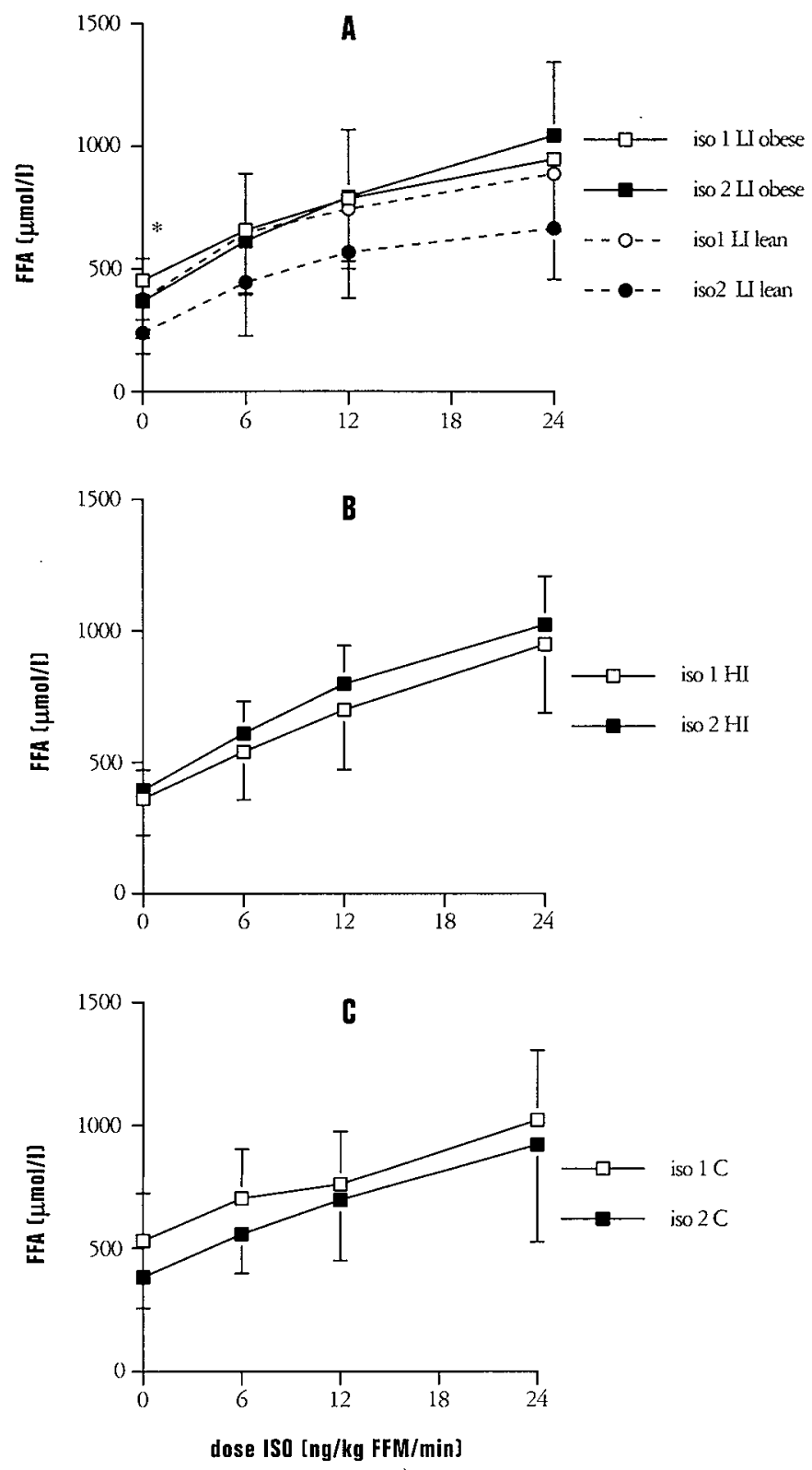

Figure 3.5 Plasma FFA concentrations [ $\mu \mathrm{mol} / / \mathrm{l}$ ] before [1] and after [2] exercise training in the low intensity [L]] lean and obese group [A] and the obese high intensity [HI] [B] and control [C] group [C].

* LI lean significantly different from before $P<0.05$ 
$\mathrm{HI}$ exercise training only increased the effect of ISO on plasma glycerol concentration significantly $(\mathrm{P}<0.05)$ (Figure 3.4), but did not affect plasma FFA concentrations (Figure 3.5 ). In the LI and C group, the ISO induced increase in plasma glycerol and FFA concentrations after the intervention were not different from before. None of the interventions affected the ISO-induced changes in plasma glucose, insulin or lactate concentrations (Table 3.3).

\section{Effect of LI exercise training on B-adrenergic mediated fat metabolism in obese versus lean subjects}

Baseline values for body weight, BMI and fat percentage were significantly lower in the lean group compared to the obese LI group $(\mathrm{P}<0.01)$ (Table 3.1). Baseline $\mathrm{VO}_{2}$ max was not different between the lean and obese group. However, expressed per kg FFM the lean group showed higher values $(\mathrm{P}<0.05)$. The increase in $\mathrm{VO}_{2} \max$, due to exercise training was significantly greater in the obese LI group compared to the lean LI group $(\mathrm{P}<0.05)$ and $\mathrm{VO}_{2} \mathrm{max} / \mathrm{FFM}$ showed a similar tendency $(\mathrm{p}=0.06)$. Attendance at the exercise training sessions by lean subjects was $85.7 \pm 10.4 \%$.

Before the intervention, infusion of ISO did not decrease RER significantly in the lean group (Figure 3.1). However, resting RER (Table 3.2) and the ISO-induced decrease in RER in lean subjects were not significantly different from those in obese subjects. Exercise training had no effect on ISO induced decrease in RER in the lean group as in the obese LI group. Basal energy expenditure in lean subjects was significantly lower than in obese subjects $(\mathrm{p}=0.001)$, but not when adjusted for fat free mass (Table 3.2). Infusion of ISO significantly increased energy expenditure $(\mathrm{P}<0.001)$ (Figure 3.2) and heart rate $(\mathrm{P}<0.001)$ (Figure 3.3). The ISOinduced increase in energy expenditure and heart rate was not different before and after LI exercise training in lean and obese subjects.

Before the intervention basal plasma concentrations of lactate $(\mathrm{P}<0.01)$, glucose $(\mathrm{P}<0.05)$ and insulin $(\mathrm{P}=0.001)$ were significantly lower in the lean group compared to the obese (Table 3.2). The intervention did not affect basal plasma concentrations, except for the basal FFA concentration which decreased due to the intervention ( $\mathrm{P}<0.05$ ). ISO-induced changes in plasma concentrations before the intervention were not significantly different between the lean and obese group (Table 3.3). LI exercise training neither in obese, nor in lean subjects influenced the effect of ISO on plasma concentrations (Table 3.3). 
The main finding of the present study was that neither low nor high intensity exercise training in obese men increased the sensitivity to in vivo $B$-adrenergic stimulation with respect to RER, EE, HR and plasma metabolites. However, also in lean subjects LI exercise training failed to affect B-adrenergic sensitivity in vivo.

The present study was designed to investigate whether the impaired sympathetically mediated fat oxidation, reported in obese subjects in several studies $(1,2,5,31)$, could be improved by exercise training independent from changes in body mass and body composition. However, the obese subjects who participated in the present study did not appear to have a blunted $B$-adrenergically mediated fat oxidation. Infusion of ISO in an incremental dose increased relative fat oxidation in obese subjects $(\mathrm{P}<0.01)$. This effect was in agreement with that previously found in lean $(1,2,5,31)$. Apparently the effect of $B$-adrenergic stimulation on fat oxidation is variable in obese subjects. Unfortunately no data were available to compare the level of physical fitness of the obese subjects in our study with the obese subjects in the studies mentioned above. However, it is possible that the obese subjects in the present study, who volunteered in an exercise training program, were better trained than the average obese subject participating in other non-training studies $(1,2,5,31)$. It is known in lean that exercise trained subjects have an increased $\beta$-adrenergic lipolytic response in vitro compared to sedentary subjects $(6,7,9,10,17,20)$. Moreover, also variations in habitual energy expenditure seem to play a role in the difference between high and low responders of $B$-adrenergic adipocyte lipolysis (9).

In the present study exercise training in obese subjects was not effective in increasing the effect of in vivo $\beta$-adrenergic stimulation on relative fat oxidation. Nevertheless, exercise training sessions were well attended (about 90\%) and physical fitness improved in both the obese LI and the $\mathrm{HI}$ exercise training groups. Moreover, the failure to improve $B$-adrenergic sensitivity did not seem to be biased by concentration differences of ISO in plasma before and after the intervention, which were not significantly different (highest dose $278 \pm 64 \mathrm{ng} / \mathrm{l}$ before and $255 \pm 46 \mathrm{ng} / \mathrm{l}$ after the intervention in the HI group).

Data on plasma metabolites are in agreement with the failure to improve ISO-stimulated relative fat oxidation by exercise training. The effect of ISO 
infusion on plasma metabolites was similar before and after exercise training, except for the concentration glycerol in the HI group which increased more after the intervention $(\mathrm{P}<0.05)$. This might indicate that $\mathrm{HI}$ exercise training slightly increased $B$-adrenergic mediated lipolysis in obese.

Another study in obese subjects reported an increased ISO-stimulated FFA and glycerol response after moderate to high intensity exercise training (27), while fat mass and fat free mass were not changed. They also found an increased $\beta$-adrenergic stimulated lipolytic activity in subcutaneous adipose tissue. In adipocytes, training also has been shown to enhance the $B$-adrenergic lipolytic response and to blunt the antilipolytic effect of insulin and $\alpha 2$-adrenoceptor stimulation (8). However, these experiments were performed in vitro and in situ. In vitro measurement of fat cell lipolysis can not be used to directly predict in vivo FFA metabolism, due to the different environment of metabolites and hormones of the adipose cell in vivo compared to in vitro (15). In the present study $B$-adrenergic stimulation significantly increased heart rate $(\mathrm{P}<0.001)$. Exercise training did not influence this effect, which is in agreement with data on epinephrine infusion in lean trained and untrained subjects (26).

As in the obese subjects, exercise training did not affect in vivo stimulated $\beta$-adrenergic fat metabolism in the lean subjects in the present study either. Another study showed an increased whole body lipid oxidation during epinephrine infusion in trained compared to untrained subjects (26), but the discrepancy in training state between trained and untrained was much higher in that study compared to ours. Another factor confounding the comparison is that in the study of Stallknecht et al (26) the sympathetic nervous system was activated by epinephrine $\alpha$ - and $\beta$-agonist, while in the present study only a $\beta$-agonist was used.

Since the effect of ISO infusion on plasma metabolite concentrations was not changed in lean subjects in the present study, exercise training did not seem to affect $\beta$-adrenergic mediated lipolysis. However, cross-sectional in vitro studies in lean subjects found an increased adipocyte lipolytic response in lean trained subjects compared to untrained, which could be explained by an increased $\beta$-adrenergic sensitivity $(6,17,29)$ and a decreased $\alpha$ adrenoceptor sensitivity (17). On the other hand, another study found no difference in epinephrine stimulated in situ lipolysis in adipose tissue of lean trained and untrained subjects (26).

In the present study indirect methods were used to determine lipolysis (plasma glycerol and FFA) and fat oxidation (RER). Confirmation of the results with more direct techniques (e.g. $\left[\mathrm{U}^{-1} \mathrm{C}\right]$ palmitate infusion and 
microdialysis) is desirable and can be suggested for future research.

In summary, the present study demonstrated that 12 weeks of exercise training in obese subjects at either high or low intensity did not affect in vivo

- B-adrenergic stimulation of relative fat oxidation. Beta-adrenergicmediated lipolysis might be increased after $\mathrm{HI}$ exercise training in obese subjects. The effect of low intensity exercise training on ISO-induced fat metabolism was similar in lean and obese men.

\section{References}

I. Blaak, E. E., W. H. Saris, and B. H. Wolffenbuttel. Substrate utilization and thermogenic responses to beta-adrenergic stimulation in obese subjects with NIDDM. Int J Obes. 23: 4II-8, I999.

2. Blaak, E. E., M. A. Van Baak, G. J. Kemerink, M. T. Pakbiers, G. A. Heidendal, and W. H. Saris. Beta-adrenergic stimulation of energy expenditure and forearm skeletal muscle metabolism in lean and obese men. Am J Physiol. 267: E306-I5, I994.

3. Calles-Escandón, J., M. I. Goran, M. O'Connell, K. S. Nair, and E. Danforth, Jr. Exercise increases fat oxidation at rest unrelated to changes in energy balance or lipolysis. Am J Physiol. 270: EI009-14, 1996.

4. Colberg, S. R., J. A. Simoneau, F. L. Thaete, and D. E. Kelley. Skeletal muscle utilization of free fatty acids in women with visceral obesity. $J$ Clin Invest. 95: $1846-53$, 1995 .

5. Connacher, A. A., W. M. Bennet, R. T. Jung, D. M. Bier, C. C. Smith, C. M. Scrimgeour, and M. J. Rennie. Effect of adrenaline infusion on fatty acid and glucose turnover in lean and obese human subjects in the post-absorptive and fed states. Clin Sci Colch. 8I: 635-44, I9gr.

6. Crampes, F, M. Beauville, D. Rivière, and M. Garrigues. Effect of physical training in humans on the response of isolated fat cells to epinephrine. J Appl Physiol. 6I: 25-9, 1986.

7. Crampes, F, D. Rivière, M. Beauville, M. Marceron, and M. Garrigues. Lipolytic response of adipocytes to epinephrine in sedentary and exercisetrained subjects: sex-related differences. Eur I Appl Physiol. 59: 249-55, Ig89.

8. De Glisezinski, I., F. Crampes, I. Harant, M. Berlan, J. Hejnova, D. Langin, D. Rivière, and $V$. Stich. Endurance training changes in lipolytic responsiveness of obese adipose tissue. Am I Physiol. 275: E95I-6, x998.

9. Després, J. P., C. Bouchard, R. Savard, A. Tremblay, M. Marcotte, and 
$G$. Theriault. Effects of exercise-training and detraining on fat cell lipolysis in men and women. Eur J Appl Physiol. 53: 25-30, 1984.

Io. Després, J. P., C. Bouchard, R. Savard, A. Tremblay, M. Marcotte, and $G$. Theriault. Level of physical fitness and adipocyte lipolysis in humans. J Appl Physiol. 56: II57-6I, I984.

II. Friedlander, A. L., G. A. Casazza, M. A. Horning, T. F. Buddinger, and $G$. A. Brooks. Effects of exercise intensity and training on lipid metabolism in young women. Am J Physiol. 275: E853-63, 1998.

I2. Gutmann, I., and A. W. Wahlefeld. $L-(+)$-Lactate, determination with lactate dehudrogenase and NAD. In: Methods in enzymatic analysis (second ed.). New York: Academic press, 1974, p. 1464-I468.

13. Kiens, B., B. Essen Gustavsson, N. J. Christensen, and B. Saltin. Skeletal muscle substrate utilization during submaximal exercise in man: effect of endurance training. J Physiol Lond. 469: 459-78, 1993.

14. Leijssen, D. P. C., W. H. M. Saris, and M. A. Van Baak. The effect of exercise training at different intensities on repiratory exchange ratio (RER) of obese men [abstract]. Int J Obes. 22: $S_{2} 83,1998$.

I5. Lillioja, S., J. Foley, C. Bogardus, D. Mott, and B. V. Howard. Free fatty acid metabolism and obesity in man: in vivo in vitro comparisons. Metabolism. 35: 505-I4, 1986.

16. Mauriège, P., J. P. Després, D. Prud'homme, M. C. Pouliot, M. Marcotte, A. Tremblay, and C. Bouchard. Regional variation in adipose tissue lipolysis in lean and obese men. J Lipid Res. 32: I625-33, I99I.

17. Mauriège, P., D. Prud'homme, M. Marcotte, M. Yoshioka, A. Tremblay, and J. P. Després. Regional differences in adipose tissue metabolism between sedentary and endurance-trained women. Am J Physiol. 273: E497-506, 1997 .

I8. Poeblman, E. T., A. W. Gardner, P. J. Arciero, M. I. Goran, and J. Calles Escandon. Effects of endurance training on total fat oxidation in elderly persons. J Appl Physiol. 76: 2281-7, I994.

I9. Reynisdottir, S., H. Wahrenberg, K. Carlstrom, S. Rossner, and P. Arner. Catecholamine resistance in fat cells of women with upper-body obesity due to decreased expression of beta 2-adrenoceptors. Diabetologia. 37: 428-35, I994.

20. Rivière, D., F. Crampes, M. Beauville, and M. Garrigues. Lipolytic response of fat cells to catecholamines in sedentary and exercise-trained women. J Appl Physiol. 66: 330-5, xg89.

21. Romijn, J. A., S. Klein, E. F. Coyle, L. S. Sidossis, and R. R. Wolfe. Strenuous endurance training increases lipolysis and triglyceride-fatty acid 
cycling at rest. J Appl Physiol. 75: 108-13, 1993.

22. Schiffelers, S. L. H., W. H. M. Saris, and M. A. Van Baak. $\beta_{2}$-adrenoceptor mediated lipolysis and lipid oxidation are reduced in obese men. Int J Obes. 22: S75, I9g8.

23. Siri, W. E. The gross composition of the body. Adv Biol Med Physiol. 4: $239-280,1956$.

24. Smedes, F, J. C. Kraak, and H. Poppe. Simple and fast solvent extraction system for selective and quantitative isolation of adrenaline, noradrenaline and dopamine from plasma and urine. J Chromatogr. 23I: 25-39, rg82.

25. Snitker, S., J. Hellmér, M. Boschmann, M. B. Monroe, and E. Ravussin. Whole body fat oxidation is related to in situ adipose tissue lipolytic response to isoproterenol in males. Am J Physiol. 275: E400-04, 1998.

26. Stallknecht, B., L. Simonsen, J. Bülow, J. Vinten, and H. Galbo. Effect of training on epinephrine-stimulated lipolysis determined by microdialysis in human adipose tissue. Am J Physiol. 269: EI059-66, 1995.

27. Stich, V., I. de Glisezinski, J. Galitzky, J. Hejnova, F Crampes, D. Rivière, and $M$. Berlan. Endurance training increases the beta-adrenergic lipolytic response in subcutaneous adipose tissue in obese subjects. Int J Obes. 23: 374-8I, 1999.

28. Tataranni, P. A., L. Christin, S. Snitker, G. Paolisso, and E. Ravussin. Pima Indian males have lower beta-adrenergic sensitivity than Caucasian males. J Clin Endocrinol Metab. 83: 1260-3, 1998.

29. Tremblay, A., S. Conveney, J. P. Després, A. Nadeau, and D. Prud'homme. Increased resting metabolic rate and lipid oxidation in exercise-trained individuals: evidence for a role of $\beta$-adrenergic stimulation. Can J Physiol Pharmacol. 70: 1342-1347, 1992.

30. Turcotte, L. P., E. A. Richter, and B. Kiens. Increased plasma FFA uptake and oxidation during prolonged exercise in trained vs. untrained humans. Am J Physiol. 262: E79I-9, I992.

3r. Webber, J., J. Taylor, H. Greathead, J. Dawson, I. J. Buttery, and I. A. Macdonald. A comparison of the thermogenic, metabolic and haemodynamic responses to infused adrenaline in lean and obese subjects. Int J Obes. I8: 717-24, I994.

32. Weir, J. B. New methods for calculating metabolic rate with special reference to protein metabolism. J Physiol. Iog: 1-9, I949. 


\section{|1IIIIIIIIIIIIIIIIIIIIIIII Effects of low intensity exercise training on fat metabolism in obese women}

Dorien P.C. van Aggel-Leijssen, Wim H.M. Saris, Moniek Homan and Marleen A. van Baak

Accepted Obesity Research

\section{Abstract}

Objective: To investigate the effect of low intensity exercise training on fat metabolism $U B$ and $L B$ obese premenopausal women.

Methods: Twenty-one bealtby, premenopausal women with either $L B$ obesity (waist-to-bip ratio (WHR) $\leqslant 0.79 ; n=8$ ) or $U B$ obesity (WHR $\geqslant 0.85 ; n=13$ ) participated in the present study. The $U B$ obese women were matched and randomly divided in an exercise training group (UB) and a nonexercising control group $(U B-C)$. Subjects in the $U B$ and $L B$ group participated in a low intensity exercise training program (40\%VO2max) (3 times per week for I 2 weeks). Before and after the intervention, measurements of fat metabolism at rest and during exercise, body composition and maximal aerobic capacity were performed.

Results: Exercise training did not change respiratory exchange ratio $(R E R)$ at rest in the $U B$ and $L B$ group. During exercise, fat oxidation increased in the $U B$ group by $19 \%(P<0.05)$, while no change in the $L B$ and $U B-C$ group was found. Plasma FFA oxidation did not change by exercise training, but the change in non-plasma fatty acid (FA) oxidation tended to be bigher in the UB group compared to the UB-C group $(P=0.08)$. Conclusion: Low intensity exercise training increased the contribution of fat oxidation to total energy expenditure during exercise, but not at rest, in $U B$ obese women. 


\section{Exercise training had no significant effect on fat metabolism in LB obese women.}

\section{Introduction}

Human obesity has been classified by Vague et al (44) in a typically male or female type of fat distribution, called upper body (UB) or lower body (LB) obesity respectively. However, both types of fat distribution may occur in obese women. UB obese women are known to have an increased risk to develop metabolic disorders like insulin resistance, hypertension and hyperlipidemia compared to LB obese and non-obese women $(18,21,23)$. Body fat from the abdominal region is recognized as being much more lipolytic than adipose tissue from the gluteal-femoral regions $(1,23)$. An in vivo study has shown that $\mathrm{UB}$ obese women, compared to LB obese or non-obese women, have an overall greater resting free fatty acid (FFA) mobilization $(14,15,26)$, but FFA mobilization relative to fat mass was higher in non-obese compared to UB obese women (14). LB obese women seem to have an increased ability to down-regulate resting lipolysis to maintain normal FFA availability (26). However, respiratory exchange ratio (RER) at rest (38) and over $24 \mathrm{~h}$ (3) and resting metabolic rate (RMR) (38) are similar in UB and LB obese women. Epinephrine infusion (15) and an exercise bout (16) showed a reduced lipolytic response in UB obese women compared to LB obese and non-obese women. Therefore, fat oxidation and FFA availability during the total exercise bout seem to be similar in UB and LB obese women $(16,43)$. Furthermore, since UB obese women seem to have an impaired post-absorptive FFA utilization in skeletal muscle (4), while FFA mobilization is elevated, FFA mobilization and oxidation do not seem to be coupled. Therefore, plasma FFA concentrations are elevated in UB obese women which may be responsible for the increased risk to develop metabolic complications (38). A study by Ranneries et al (32) showed that obese subjects have an impaired ability to oxidize fat, even after weight loss has been achieved. A low ability to oxidize fat might predispose for weight gain $(2,33)$. In Pima Indians, a population with a high prevalence of obesity, weight gain is associated with a low 24 h ratio of fat to carbohydrate oxidation (45). Therefore, interventions to increase the capacity to oxidize FFA in obese are important in weight management and in reducing the risk for metabolic complications associated with obesity. Endurance exercise training is known to increase fat oxidation during sub- 
maximal exercise at a fixed work load in lean subjects $(7,9,11,12,31)$. A recent study at our laboratory showed that 12 weeks of low intensity exercise training can induce an increase in fat oxidation during exercise in obese men independent of weight changes (24). Only a few studies have reported effects of exercise training on fat oxidation in lean women $(7,8)$ showing an increased fat oxidation after training. However, to our knowledge, no study on the effect of exercise training on fat oxidation in obese women has been performed so far. Because of the differences in fat metabolism between UB and LB obese women described above, it seems to be important to distinguish the effects of exercise training in UB and LB obese women. The present study was undertaken to investigate the effects of low intensity exercise training on fat metabolism in obese women, and compare the effects in UB and LB obese women. At recruitment for this exercise training study, subjects were told that no voluntary energy restriction was allowed during the study, since changes in body weight affect fat metabolism and therefore interfere with the effect of exercise training on fat metabolism.

\section{Metbods}

\section{Subjects}

Twenty one obese female subjects (BMI $\left.\geqslant 29 \mathrm{~kg} \cdot \mathrm{m}^{-2}\right)$ with either lower body obesity (LB) $(\mathrm{n}=8)$ (waist-to-hip ratio (WHR) $\leqslant 0.79$ ) or upper body obesity (UB) $(n=13)$ (WHR $\geqslant 0.85)$ participated in this study. The subjects were premenopausal and reported to have a normal menstrual cycle. Subjects with upper body obesity were matched in pairs based on age, BMI, and maximal oxygen uptake per $\mathrm{kg}$ fat free mass and randomly divided into an exercise training group (UB) $(n=7)$ or a non-training control group (UB-C) $(n=6)$. Because recruitment of LB women was extremely difficult, the LB group happened to be too small to divide into a training and non-training group. Therefore, all subjects in the LB group participated in the exercise training program $(n=8)$. Physical characteristics are indicated in Table 4.1. All subjects were in good health as assessed by medical history and physical examination and were weight stable for at least the previous 2 months $(<3$ $\mathrm{kg}$ weight change). None of the subjects received medication known to affect the variables measured.. The subjects did not spend more than 2 hours per week in sports activities and did not have a physically demanding job. Subjects were requested to maintain their dietary habits during the study. 
The study protocol was approved by the Ethics Committee of Maastricht University. Written informed consent was obtained from all subjects.

Table 4.1. Subject characteristics hefore and after the intervention period in the lower body obese (LB] [n=8], upper body obese [UB] [ $n=7$ ] and upper body obese control group [UB-C] [ $n=6$ ].

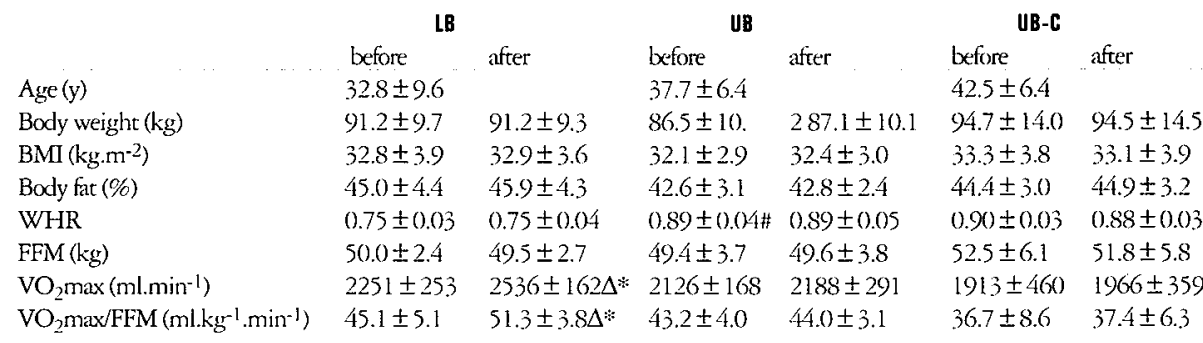

Values are expressed as means $\pm \mathrm{SD}$

* significantly different from before $\mathrm{P}<0.05$

\# significantly different from $\mathrm{LB}$ before $\mathrm{P}<0.01$

$\Delta$ change significantly different from UB $P<0.05$

\section{Experimental design}

Two of the three groups (LB and UB) participated in an exercise training intervention of 12 weeks. The third group served as a non-training control group (UB-C). Measurements of body composition, maximal aerobic capacity and fat metabolism were made before the start of the exercise training program and repeated within two weeks after 12 weeks of exercise training. Measurements of fat metabolism were performed in the mid follicular phase of the menstrual cycle. The exercise training program was continued until all measurements were performed.

\section{Exercise training}

The exercise training program consisted of cycling on an ergometer (Bodyguard Cardiocycle, Sandnes, Norway or Lode, Groningen, The Netherlands) at low intensity ( $\left.40 \% \mathrm{VO}_{2} \max \right)$. Eight lower body obese women and seven upper body obese women participated in the exercise training program. Subjects trained for at least 12 weeks, three times per week. Since measurements of fat metabolism were performed in the mid follicular phase, exact duration of the training program was dependent on 
the length of the menstrual cycle. Energy expenditure of each subject in each training session was set at $5 \mathrm{kcal} . \mathrm{kg}$ fat-free mass $^{-1}(\sim 250 \mathrm{kcal})$. The average training duration was $57 \pm 6 \mathrm{~min}$. Heart rate was monitored continuously during the training sessions (Polar Electro, Oy, Finland). After 4 and 8 weeks of exercise training, training intensity was checked by a maximal aerobic exercise test and adjusted if necessary. All training sessions took place at the university under supervision of a professional instructor.

\section{Measurements}

1. Body composition

Subjects were weighed on a digital balance accurate to $0.1 \mathrm{~kg}$ (Sauter D-7470, Ebingen, Germany). Height was measured to the nearest $0.1 \mathrm{~cm}$ using a wall-mounted stadiometer (Seca, model 220, Hamburg, Germany). Body density was measured by hydrostatic weighing, with a correction for residual lung volume measured by helium dilution with a spirometer (Volugraph 2000, Mijnhardt, The Netherlands) at the moment of under water weighing. Body composition was calculated according to the formula of Siri (41). Fat distribution was estimated by measuring waist-to-hip ratio (WHR) with a flexible, inelastic tape with the subject in standing position. All measurements were recorded within the nearest $0.1 \mathrm{~cm}$ and the mean of two measurements was calculated. Measurements were performed after a normal expiration with the subject in standing position, the abdomen relaxed, the arms at the sides and the feet together. Waist circumference was measured at the smallest circumference between the ribs and iliac crest. Hip circumference was performed at the level of maximal extension of the buttocks (25).

\section{Maximal aerobic capacity}

Maximal $\mathrm{O}_{2}$ uptake $\left(\mathrm{VO}_{2} \max \right)$ for each subject was determined by an incremental exercise test on an electromagnerically braked cycle ergometer (Excalibur Lode, Groningen, The Netherlands). After a warming up period of 4 minutes at $50 \mathrm{~W}$, workload was increased every 3 minutes by $30 \mathrm{~W}$ until exhaustion. During the experiment ventilatory and gas exchange responses were measured continuously, using indirect calorimetry (Oxycon B, Mijnhardt, The Netherlands). Heart rate was recorded continuously by 
an electrocardiogram. The highest oxygen uptake achieved over $30 \mathrm{~s}$ was taken as $\mathrm{VO}_{2} \max$.

\section{Measurements of fat oxidation and Ra FFA during rest and exercise}

Fat metabolism was studied by means of indirect calorimetry and stable isotope tracer methodology. In order to study fat metabolism, all subjects participated in two tracer tests before and after the training intervention, in which palmitate and acetate were infused respectively. The acetate infusion test was performed to obtain a correction factor for the loss of ${ }^{13} \mathrm{C}$ label in the tricarboxylic acid cycle. The tracer tests were separated by a week to prevent carry over of the label. The sequence of the tracer tests was random. Subjects filled in a food and exercise questionnaire 3 days before the first tracer test. They were instructed to adjust to the same food and exercise habits 3 days before the second tracer test and the tracer tests after the training intervention in order to exclude bias by these factors.

\section{3a. $\left[\mathrm{U}_{-13}{ }^{13} \mathrm{C}\right]$-palmitate infusion}

This experiment was performed at least $36 \mathrm{~h}$ and at the most $64 \mathrm{~h}$ after the last exercise bout with subjects in the mid follicular phase of the menstrual cycle. Subjects were asked to refrain from consumption of naturally ${ }^{15} \mathrm{C}$ enriched food products for one week before the experiment. After an overnight fast, subjects came to the laboratory by car or bus. Subjects remained in semi-supine position throughout the first $2.5 \mathrm{~h}$ of the experiment. Catheters were inserted in an arm vein for infusion of the palmitate tracer and retrogradely into a contralateral dorsal hand vein for blood sampling. The cannulated hand was placed in a hot box, in which warm air of $60^{\circ} \mathrm{C}$ circulated, in order to obtain arterialized venous blood. A baseline arterialized blood sample was taken after $30 \mathrm{~min}$. Baseline expired breath was sampled in a $15 \mathrm{ml}$ vacutainer tube (Becton Dickinson, Meyland Cedex, France) in order to determine the background enrichment. Immediately after taking baseline samples, subjects were given an intravenous dose of $1.0 \mu \mathrm{mol} / \mathrm{kg} \mathrm{NaH}^{13} \mathrm{CO}_{3}$ to prime the bicarbonate pool. Then a constant infusion $0.0062 \mu \mathrm{mol} . \mathrm{kg}^{-1} \cdot \mathrm{min}^{-1}\left[\mathrm{U}-{ }^{13} \mathrm{C}\right]$-palmitate was started $(\mathrm{t}=0)$, using an IVAC pump (IVAC Medical, Amersfoort, The Netherlands). This infusion was continued for $120 \mathrm{~min}$, with the subject in semi-supine position. Subsequently, subjects started to exercise in sitting position for $1 \mathrm{~h}$ at $50 \%$ of pretraining $\mathrm{VO}_{2}$ max on a cycle ergometer (Lode, Groningen, The 
Netherlands). The infusion rate during exercise was doubled to minimize changes in isotopic enrichment. At rest $\mathrm{VCO}_{2}$ and $\mathrm{VO}_{2}$ were measured using an open circuit ventilated hood system and a mouthpiece was used during exercise (Oxycon B, Mijnhardt, The Netherlands). At rest and during exercise, $\mathrm{VCO}_{2}$ and $\mathrm{VO}_{2}$ were measured during 5 min immediately before taking a breath sample for measurement of ${ }^{13} \mathrm{CO}_{2}$ enrichment. The accuracy of the system for measuring $\mathrm{VCO}_{2}$ and $\mathrm{VO}_{2}$ was tested regularly to be within $5 \%$. Breath samples were taken at $t=100,110$ and $120 \mathrm{~min}$ at rest and at $\mathrm{t}=40,50$ and $60 \mathrm{~min}$ during exercise. The exact infusion rate of $\left[\mathrm{U}-{ }^{13} \mathrm{C}\right]$-palmitate was determined for each experiment by measuring the concentrations of the infusates (see sample analyses). Blood samples were taken at $t=100,110$ and $120 \mathrm{~min}$ of rest and at $t=40,50$ and $60 \mathrm{~min}$ during exercise. Blood samples were put into EDTA or heparin plus $300 \mu \mathrm{l}$ glutathion ( $45 \mu \mathrm{g} / \mathrm{l}$ saline) containing chilled $10 \mathrm{ml}$ tubes and immediately centrifuged at $800 \mathrm{x}$ g for $10 \mathrm{~min}$ at $4^{\circ} \mathrm{C}$. Plasma was stored at $-80^{\circ} \mathrm{C}$ until analyses. The EDTA containing blood was used for analyses of plasma glucose, FFA, insulin, triglyceride and palmitate concentrations as well as the plasma enrichment of palmitate. The heparin and glutathion containing blood was used for analysis of plasma catecholamines. During rest $(t=0,90$ and 120) and exercise ( $t=30$ and 60) blood was sampled for the measurement of oxygen saturation (Hemoxymeter OSM2, Copenhagen, Denmark) in order to check the arterialization. Before infusion, the palmitate tracer (60 mg of potassium salt of $\left\{\mathrm{U}-{ }^{15} \mathrm{C}\right\}$-palmitate, enrichment $98.9 \%$, Cambridge Isotope Laboratories, Andover, $\mathrm{MA}$ ) was bound to albumin by dissolving it in heated $\left(60^{\circ} \mathrm{C}\right)$ sterile water and passing it through a $0.2 \mu \mathrm{m}$ filter into a $5 \%$ warm $\left(60^{\circ} \mathrm{C}\right)$ human serum albumin solution to make a $0.670 \mathrm{mM}$ solution.

\section{3b. $\left[1,2-{ }^{13} \mathrm{C}\right]$-acetate infusion}

Palmitate oxidation rates were corrected for loss of tracer in products of the tricarboxylic acid cycle using the acetate correction factor previously described by Sidossis et al. (40) and Schrauwen et al. (37). The protocol for the acetate infusion experiment was the same as for the palmitate infusion experiment, except that no blood was sampled. The acetate tracer (sodium salt of [1,2${ }^{13} \mathrm{C}$-acetate, enrichment 99\%, Cambridge Isotope Laboratories) was dissolved in $0.9 \%$ saline. The acetate infusion rate was $0.0496 \mu \mathrm{mol} . \mathrm{kg}^{-1} \cdot \mathrm{min}^{-1}$ at rest and was doubled during exercise. Before starting the acetate infusion, an intravenous dose of $1.0 \mu \mathrm{mol} / \mathrm{kg} \mathrm{NaH}{ }^{13} \mathrm{CO}_{3}$ was given to prime the bicarbonate pool. 


\section{Sample analysis}

Plasma total FFA, glucose, glycerol and triglyceride concentrations were measured on a COBAS FARA centrifugal spectrophotometer. For analysis of plasma total FFA concentrations a NEFA C kit (Wako Chemicals, Neuss, Germany) was used. Plasma glucose concentrations were measured with a GLUC HK kit (Hoffman-La Roche, Basel, Switzerland). Plasma glycerol and triglyceride concentrations were analysed using a Glycerol kit (Boehringer, Mannheim, Germany). Plasmas with known concentrations were included in each run for quality control. Plasma insulin concentrations were measured with a double-antibody radio-immunoassay (Insulin RIA 100; Pharmacia, Uppsala, Sweden). Plasma catecholamine concentrations were analyzed by HPLC with electrochemical detection (42). The chemical and isotopic purity (99\%) of the palmitate and acetate tracers were checked by ' $\mathrm{H}$ and ' $\mathrm{C}$ NMR and GC/MS. Breath samples were analyzed for ${ }^{13} \mathrm{C} /{ }^{12} \mathrm{C}$ ratio using a gas chromatography-isotope ratio mass spectrometer (GC-IRMS, Finnigan MAT 252, Bremen, Germany). For determination of the plasma palmitate concentration, FFA were extracted from plasma, isolated by thin-layer chromatography and derivatized to methyl esters. Palmitate concentration was determined on an analytical GC with flame ionization detection using heptadecanoic acid as internal standard. The isotope tracer/tracee ratio of palmitate was determined using GC combustion IRMS, with correction for the extra methyl group in the derivative. The concentration of the acetate infusate was determined on a COBAS FARA with an enzymatic method kit no 148261 (Boehringer, Mannheim, Germany). The concentration of the palmitate infusate was determined as described above for plasma samples.

\section{Calculations}

Total fat oxidation was calculated by the following equation (6): total fat oxidation $(\mathrm{g} / \mathrm{min})=1.67 * \mathrm{VO}_{2}-1.67 * \mathrm{VCO}_{2}$ with $\mathrm{VCO}_{2}$ and $\mathrm{VO}_{2}$ in liters per minute. Total fatty acid (FA) oxidation was determined by converting the rate of total fat oxidation to its molar equivalent, with the assumption that the average molecular weight of triglyceride is $860 \mathrm{~g} / \mathrm{mol}$, and multiplying the molar rate of triglyceride oxidation by three, because each molecule contains three moles of fatty acids. 
${ }^{13} \mathrm{C}$ enrichment of breath $\mathrm{CO}_{2}$ and plasma palmitate is expressed as tracer/tracee ratio (TTR). TTR was defined as: $\left({ }^{13} \mathrm{C} /{ }^{12} \mathrm{C}\right)$ sa $-\left({ }^{13} \mathrm{C} /{ }^{12} \mathrm{C}\right)$ bk in which $s \hat{a}=$ sample and $b k=$ background

Fractional recovery of infused acetate ${ }^{13} \mathrm{C}$ label in breath $\mathrm{CO}_{2}$ was calculated as: Acetate recovery $(\mathrm{ar})=\left(\mathrm{TTR} \mathrm{CO}_{2} * \mathrm{VCO}_{2}\right) / \mathrm{F}$ where $\mathrm{F}$ is infusion rate $(\mathrm{mmol} / \mathrm{min})$

The rate of $\left[\mathrm{U}^{-13} \mathrm{C}\right]$-palmitate oxidation was calculated as:

Plasma palmitate oxidation $(\mu \mathrm{mol} / \mathrm{min})=\left(\mathrm{TTR} \mathrm{CO}_{2} * \mathrm{VCO}_{2}\right) /(\mathrm{TTR}$ plasma $*$ ar) $* 1000$

The average $\mathrm{VCO}_{2}$ over the last three time points at rest and during exercise was used.

The total plasma FA oxidation was then calculated by dividing palmitate oxidation by the fractional contribution of palmitate to the total FFA concentration. The average fraction palmitate/FFA was used in this equation and total plasma FA oxidation per time point was calculated over the rest and exercise period.

Non-plasma derived FA oxidation ( $\mu \mathrm{mol} / \mathrm{min}$ ) which refers to intramuscular triglycerides and plasma triacylglycerol, was calculated at rest and during exercise as the average total FA oxidation minus the average plasma FFA oxidation.

Rate of appearance ( $\mathrm{Ra}$ ) of palmitate in plasma, which under steady state conditions is equal to the rate of disappearance $(\mathrm{Rd})$ minus tracer infusion rate, was calculated as:

$\mathrm{Ra}(\mu \mathrm{mol} / \mathrm{min})=(($ TTRinfusate $/$ TTRplasma $)-1) * \mathrm{~F}$

Percentage of plasma FFA cleared from the circulation that was oxidized was calculated as: \% Ra oxidized = plasma FFA oxidation/ Ra FFA

\section{Statistics}

Data are expressed as means $\pm \mathrm{SD}$. Differences between the $\mathrm{LB}$ and UB group and between the UB and UB-C group were tested by the MannWhitney test. Changes within groups were analyzed by the Wilcoxon signed rank test. A P value $<0.05$ was regarded as statistically significant. 


\section{Results}

\section{Subject characteristics}

Before the intervention, subject characteristics were not significantly different between groups, except for the WHR which was, as intended, significantly higher in the UB group compared to the LB group $(\mathrm{P}<0.01)$ (Table 4.1). Exercise training did not significantly affect body weight or body composition in any group. In the LB group exercise training induced a significant increase in $\mathrm{VO}_{2} \max$ and $\mathrm{VO}_{2} \max / \mathrm{kgFFM}(\mathrm{P}<0.05)$ and the effect in the LB group was significantly different from that in the UB group $(\mathrm{P}<0.05)$. The absolute work loads during the exercise test $(50 \%$ of pretraining $\mathrm{VO}_{2}$ max) in the $\mathrm{LB}, \mathrm{UB}$ and UB-C group were respectively 65 $\pm 18,55 \pm 11$ and $45 \pm 30 \mathrm{~W}$. Work loads were not significantly different between $\mathrm{LB}$ versus UB and UB versus UB-C group. Attendance at the exercise training sessions was $81 \pm 19 \%$ for the $\mathrm{LB}$ and $88 \pm 17 \%$ for the UB group.

Rest

Data from indirect calorimetry showed that relative fat oxidation during the last $20 \mathrm{~min}$ of the resting period, expressed as respiratory exchange ratio (RER), did not change due to the intervention in any group (Table 4.2). Total FA oxidation, energy expenditure (Table 4.2) and percentage fat oxidation of total energy expenditure (Figure 4.1A) did not change in any of the groups either.

Plasma palmitate enrichment was at plateau (change 1.6\%) during the last 20 minutes of the resting period. Therefore, tracer calculations of plasma palmitate oxidation were made using the values of plasma palmitate enrichment measured over the $100-120$ min period. These tracer calculations were corrected by acetate recovery factors which were measured over the same time points. 

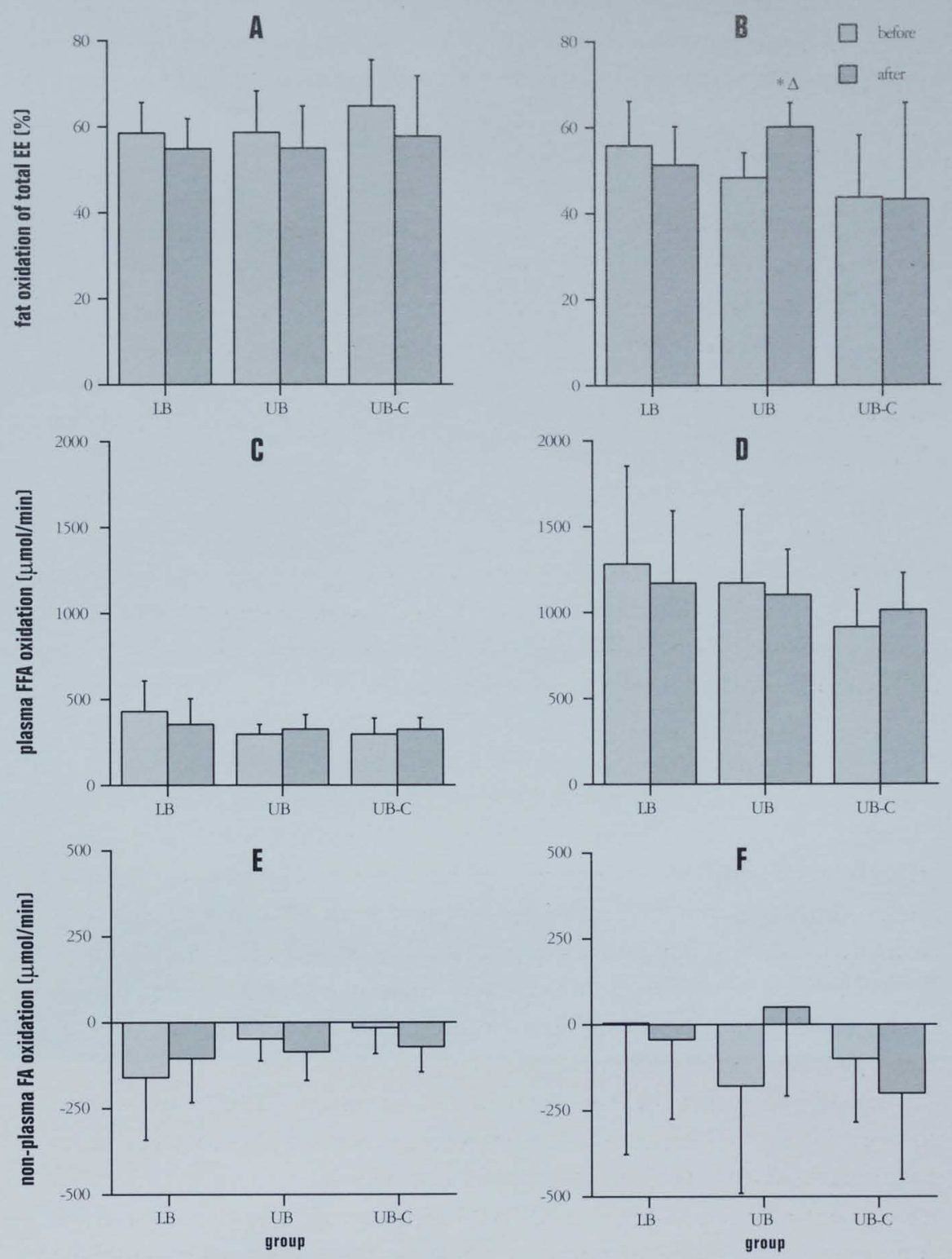

Figure 4.1 Fat oxidation as a percentage of total energy expenditure [\%], plasma FFA oxidation [ $\mu \mathrm{mol} / \mathrm{min}]$ and non-plasma FA oxidation [intramuscular and VLDL-TG] [ $\mu \mathrm{mol} / \mathrm{min}$ ] over the last 20 min during rest [A, C, and $\mathbf{E}$ respectively] and exercise [B, D and F respectively] in the lower body ohese [LB], upper body obese [UB] and upper body obese control group [UB-C] before and after the intervention.

* significantly different from before $\mathrm{P}<0.05$

$\Delta$ change significantly different from LB and UB-C group. 
Table 4.2 Energy expenditure and substrate oxidation results from indirect calorimetry at rest and during exercise before and after the intervention period in the lower obese [LB], upper obese [UB] and upper obese control [UB-E] group.

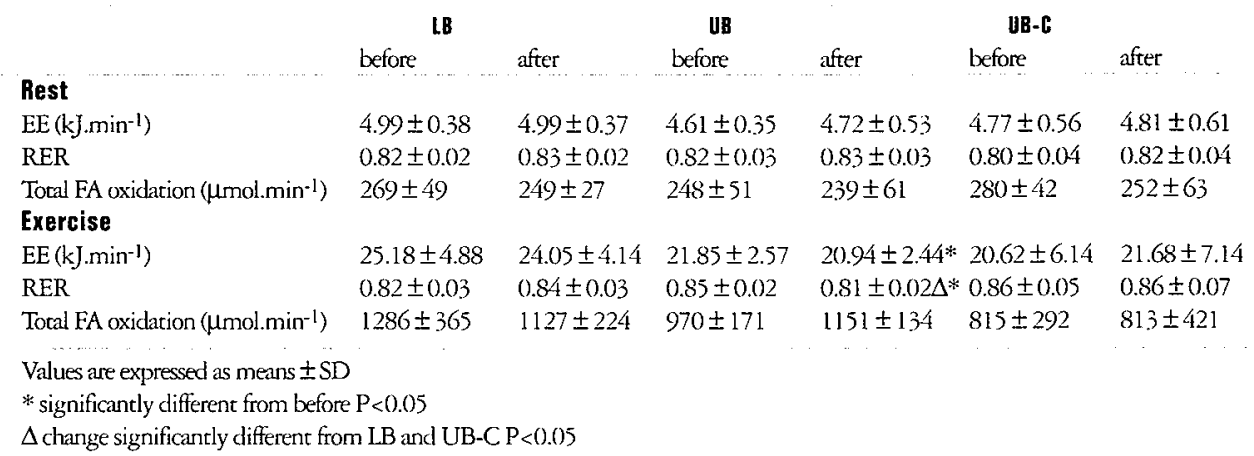

The fractional recovery of acetate before the intervention increased gradually at rest from $22.2 \pm 1.9 \%$ at $100 \mathrm{~min}$ to $25.4 \pm 2.2 \%$ at $120 \mathrm{~min}$ after the start of the tracer infusion. Exercise training did not significantly influence the acetate recovery factor. Exercise training did not affect resting plasma FFA oxidation (Figure 4.1C), non-plasma FA oxidation (plasma triacylglycerol and intramuscular triglycerides; calculated as total FA oxidation minus plasma FFA oxidation) (Figure 4.1E), Ra FFA (Figure 4.2A) and FFA oxidation as a percentage of Ra FFA (Figure 4.2A; numbers between brackets). Non-plasma FA oxidation at rest was significantly lower than zero before and after exercise training $(\mathrm{P}<0.05)$.

Average plasma concentrations (mean of last $20 \mathrm{~min}$ at rest) of FFA (Figure 4.3A) and glycerol (Figure 4.3C) were not significantly different after the intervention from before. Plasma triglyceride (TG) concentrations before the intervention were significantly lower in the LB compared to the UB group $(\mathrm{P}<0.05$ ) (Figure 4.3E). Exercise training did not affect plasma $\mathrm{TG}$ concentrations. Plasma insulin concentration was significantly increased in the $\mathrm{LB}$ group after the intervention $(\mathrm{P}<0.05)$, but did not change in the UB and UB-C group. However, the change in the LB group was not significantly different from the UB group. Plasma glucose concentrations did not change over the intervention period (data not shown). Plasma epinephrine and norepinephrine concentrations were unchanged after the intervention (Table 4.3). 

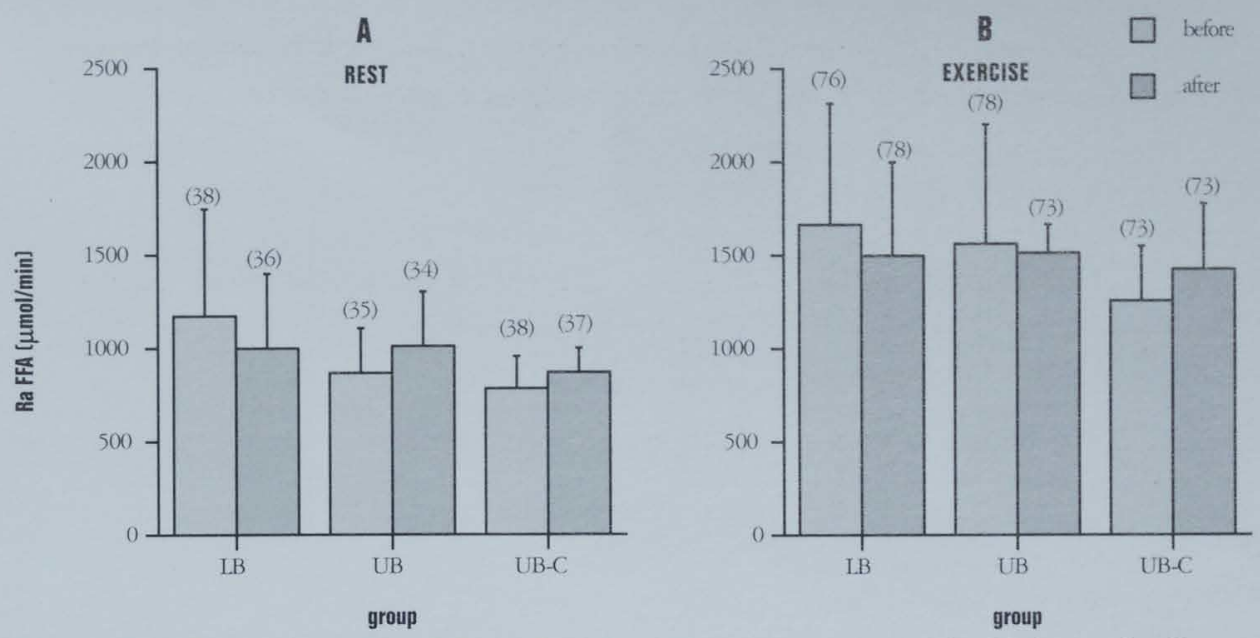

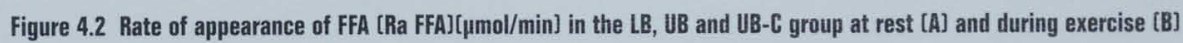
before and after the intervention. Numbers between brackets: \% Ra FFA oxidized.

Table 4.3 Average plasma concentrations of epinephrine [ng/l], norepinephrine $[\mathrm{ng} / \mathrm{l}]$ and insulin $[\mathrm{pU} / \mathrm{ml}]$ in the $\mathrm{LB}$, UB and UB-C group before and after the intervention.

\begin{tabular}{|lllllll}
\hline & \multicolumn{2}{c}{ epinephrine } & \multicolumn{2}{c}{ norepinephrine } & \multicolumn{2}{c}{ insulin } \\
\hline Group & rest & exercise & rest & exercise & rest & exercise \\
\hline LB before & $33 \pm 9$ & $70 \pm 11$ & $271 \pm 91$ & $1008 \pm 318$ & $8.1 \pm 1.8$ & $7.1 \pm 1.4$ \\
LB after & $32 \pm 9$ & $71 \pm 34$ & $299 \pm 85$ & $910 \pm 300$ & $9.6 \pm 2.0 *$ & $8.3 \pm 2.6$ \\
UB before & $36 \pm 10$ & $100 \pm 81$ & $339 \pm 119$ & $919 \pm 293$ & $10.2 \pm 3.2$ & $8.0 \pm 2.5$ \\
UB after & $41 \pm 18$ & $74 \pm 41$ & $330 \pm 87$ & $874 \pm 243$ & $9.5 \pm 3.1$ & $7.5 \pm 1.8$ \\
UB-C before & $34 \pm 14$ & $60 \pm 37$ & $335 \pm 69$ & $950 \pm 542$ & $12.2 \pm 6.8$ & $9.9 \pm 3.7$ \\
UB-C after & $34 \pm 18$ & $73 \pm 49$ & $324 \pm 80$ & $999 \pm 547$ & $14.2 \pm 10.5$ & $9.9 \pm 2.5$ \\
\\
Values are expressed as means \pm SD \\
* significantly increase compared to before the intervention $(\mathrm{P}<0.05)$. & & & & \\
\hline
\end{tabular}

\section{Exercise}

During the last $20 \mathrm{~min}$ of exercise RER was significantly decreased in the UB group after exercise training $(\mathrm{P}<0.05)$, whereas in the LB and UB-C group RER did not change. The change in RER in the UB group was significantly different from the change in the LB and UB-C group $(P<0.05)$ (Table 4.2 and expressed as percentage fat oxidation of total energy expenditure in Figure 4.1B). Since energy expenditure significantly decreased in the UB group $(\mathrm{P}<0.05)$, total FA oxidation did not change significantly in the UB group (Table 4.2). 

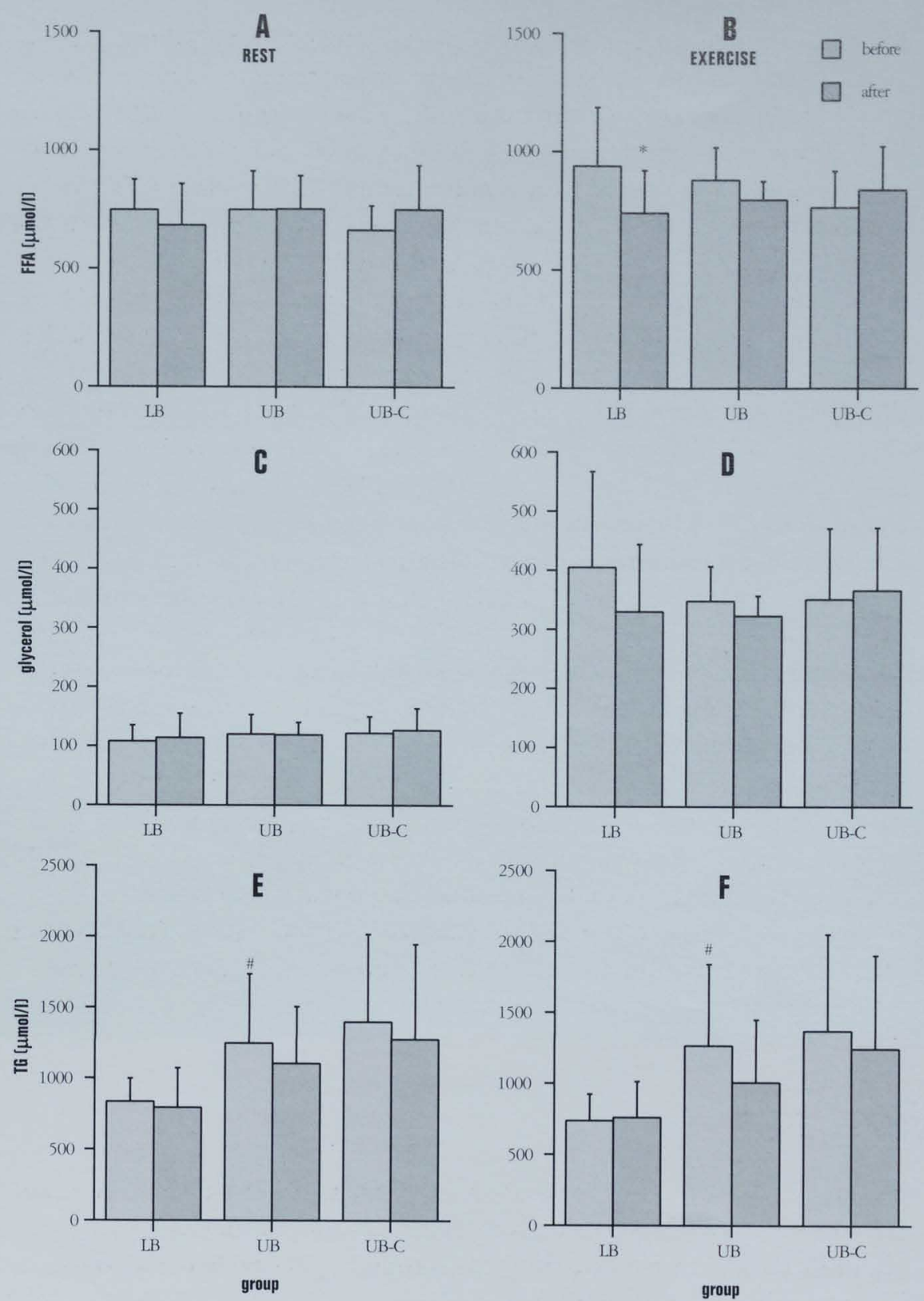

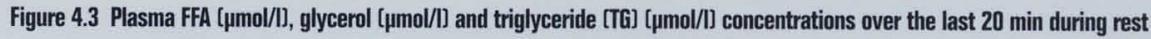
$[A, C$, and $E$ respectively] and exercise $[B, D$ and $F$ respectively] in the $L B$, UB and UB- $C$ group hefore and after the intervention.

* significantly different from before $\mathrm{P}<0.05$

\# significantly different from LB before $\mathrm{P}<0.05$ 
Plasma palmitate enrichment was at plateau (change 1.1\%) during the last 20 minutes of the exercise period. The acetate correction factor increased gradually during exercise from $60.0 \pm 7.5 \%$ after $40 \mathrm{~min}$ to $63.5 \pm 8.0 \%$ after 60 minutes of exercise at $50 \% \mathrm{VO}_{2} \max$ before the intervention. The intervention did not change the acetate recovery factor. Plasma FFA oxidation before the intervention was not different between groups and was not affected by exercise training (Figure 4.1D). Non plasma FA oxidation during exercise was not significantly different from zero (Figure 4.1F). Exercise training did not significantly influence non-plasma FA oxidation, although the change in non plasma $\mathrm{FA}$ oxidation tended to be different in the UB group compared to the UB-C group $(P=0.08)$. Neither the rate of appearance of FFA (Figure 4.2B) nor the percentage FFA oxidized from the rate of appearance of FFA (Figure 4.2B; numbers between brackets) changed due to the intervention.

Plasma FFA concentrations after exercise training were significantly lower than before in the LB group $(\mathrm{P}<0.05)$ (Figure 4.3B). However, concentrations before the intervention and the changes due to the intervention were not significantly different between groups. Plasma glycerol concentrations were not significantly different between groups before the intervention (Figure 3D). Plasma glycerol concentrations tended to decrease after the intervention in the LB group $(P=0.07)$. Changes were not different between groups. Plasma triglyceride concentrations were significantly higher in the UB group compared to the LB group $(\mathrm{P}<0.05)$ (Figure 4.3F). Exercise training did not affect plasma triglyceride concentrations significantly. Plasma glucose concentrations did not change. After exercise training plasma insulin, epinephrine and norepinephrine concentrations were not different from before (Table 4.3).

\section{Discussion}

The major new finding of the present study is that low intensity exercise training increases the contribution of fat oxidation to total energy expenditure during exercise in premenopausal upper body obese women, but not in lower body obese women.

Low intensity exercise training increased the relative fat oxidation during exercise in the UB group by $19 \%(\mathrm{P}<0.05)$ whereas it remained unchanged in the LB and UB-C group. In a previous study, in which obese men executed the same protocol as the women in the present study, we found an 
increased fat oxidation during exercise of $40 \%$ (24). Since fat distribution in obese men was comparable to UB women, this suggests that fat distribution, and associated metabolic features, plays an important role in the effect of low intensity exercise training on fat oxidation, which is also suggested by Krotkiewski et al. (20).

The increase in relative fat oxidation in the UB group after training could be explained by an increased non-plasma FA oxidation rather than by changes in plasma FFA oxidation. Lipolysis from adipose tissue did not seem to change with exercise training since Ra FFA, plasma FFA and glycerol concentrations did not differ from before the intervention. Although non-plasma FA oxidation did not change significantly in the UB group $(\mathrm{P}=0.25)$, the change tended to be significant from the change in the UB-C group ( $\mathrm{P}=0.08)$. An increase in non-plasma FA oxidation in the UB group was in line with results found in obese men after the same exercise training protocol (unpublished results from our laboratory). An increase in non-plasma FA oxidation after exercise training could either implicate an increased intramuscular triglyceride (IMTG) oxidation or an increased very low density lipoprotein triglyceride (VLDL-TG) oxidation or both. Data in the present study can not distinguish between the two. No consistent data on training effects on VLDL-TG or IMTG oxidation are available in the literature. Some studies reported an increased IMTG oxidation by exercise training $(13,30)$, while others showed no change $(17,29)$. Data on the contribution of VLDL-TG to fat oxidation during exercise are also inconsistent $(10,17,27)$. However, since plasma TG concentrations in the UB obese group tended to be lowered after exercise training $(P=0.09)$, this might indicate that TG clearance was increased with exercise training in UB obesity. An increased clearance of TG from the circulation might be due to an increased skeletal muscle LPL activity $(28,39)$. Adipose tissue LPL activity seems to be reduced after exercise training in both gluteal and abdominal fat depots (22). The cleared TG from plasma may be used as fuel in the muscle. However, since the increased fat oxidation in UB obese women seems to be coming from non-plasma FA pools (IMTG and VLDL-TG), rather than from plasma FFA (lipolysis from adipose tissue), the question can be raised whether training will help to reduce adipose mass in the UB obese women. However, the depleted non-plasma FA pools after exercise could be restored by FFA from adipose tissue which could implicate the importance of trafficking of substrates between tissues. Whether this increase in fat utilization during exercise in the UB group contributes to positive/ favorable effects of exercise training on body mass remains to be studied. 
Exercise training in obese women has been reported to result in a comparatively greater loss of fat from the abdominal region compared to the gluteal region as measured by computed tomography (5).

Similarly, there was a significant decrease in WHR after 6 months of exercise training in obese, young women who lost weight, as well as in those who did not lose weight as a result of exercise training (19). This suggests a greater fat loss from abdominal fat depots compared to glureal fat due to exercise training. Although subjects in the present study did not lose weight or fat mass and WHR did not change due to exercise training, the increase in fat oxidation in the UB group might suggest that more fat was mobilized from the abdominal fat depot compared to the gluteal fat depot due to exercise training. The different effect of exercise training in UB compared to LB obese women could probably not be explained by a different effect of exercise training on muscle morphology since no changes in muscle morphology were reported after exercise training in UB and LB obese women (20).

Pre-intervention data from our study show no difference in fat metabolism between UB and LB obese women at rest and during exercise. In agreement with our data, others also showed no difference in total fat oxidation between UB and LB obese women at rest (38), over $24 \mathrm{~h}$ (3) and over a total exercise bout $(16,43)$. However, the increase in FFA availability during exercise was reported to be higher in LB obese (16). Furthermore, we found Ra of FFA and plasma concentrations of FFA and glycerol to be similar in UB and LB obese women. This is not according to others, reporting an increased basal lipolysis in UB compared to LB obese women (15, 26). However, the significantly higher level of circulating TG in UB compared to LB obese women, also reported by Jensen et al (14), might indicate a low adipose tissue LPL activity in UB obese, which is in agreement with data reported by others $(34,35)$. The effects of exercise training on fat metabolism found in the present study seem to be independent from changes in $\mathrm{VO}_{2} \max$, since $\mathrm{VO}_{2}$ max increased significantly in the $\mathrm{LB}$ obese women but not, despite a similar exercise training program, performance at maximal aerobic capacity test and attendance, in the UB group.

\section{Methodological considerations}

In the present study only a UB obese control group participated and, due to lack of LB participants, no LB control group. In the present study 
exercise training did not affect fat metabolism in the LB obese women. However, it is not very likely that lipolysis and/or fat oxidation would decrease when no exercise training was executed, since fat mass did not change and the time span of the study was relatively short. Therefore, lack of a LB obese control group was not expected to affect the interpretation of the outcome of the study.

In the present study the acetate recovery factor was used to correct for label loss in the tricarboxylic acid cycle (TCA) during the palmitate infusion test (40). The acetate correction is dependent on basal metabolic rate, percentage body fat and RER and needs to be determined in each subject (36).

Therefore, measurements of acetate recovery were performed individually both before and after exercise training. At rest the acetate recovery factor has a large impact on plasma FFA oxidation rates since only about $24 \%$ of ${ }^{13} \mathrm{C}$ label was recovered in expired breath. During exercise label recovery was about $62 \%$. When the acetate recovery factor would have been ignored, plasma palmitate oxidation would have been underestimated by about $76 \%$ at rest and about $38 \%$ during exercise. Calculated non-plasma FA oxidation rates at rest before and after the intervention were significantly. lower than zero $(P<0.05)$. These negative values suggest that values for plasma palmitate oxidation rates were probably overcorrected by using the acetate correction factor. This may indicate that more ${ }^{13} \mathrm{C}$ acetate is trapped in the TCA cycle than $\mathrm{C}$ palmitate. However, it can be assumed that this over correction is similar before and after the intervention and does not influence the comparisons.

In conclusion, in UB obese women low intensity exercise training increases relative fat oxidation during exercise, but not at rest. In LB obese women, however, low intensity exercise training does not affect fat metabolism. Nevertheless, low intensity exercise training should not necessarily be discouraged in LB obese women, since exercise training increases physical fitness and might have positive effects on other health aspects like blood lipid levels and blood pressure.

\section{Referevces}

I. Arner, P., E. Kriegholm, P. Engfeldt, and J. Bolinder. Adrenergic regulation of lipolysis in situ at rest and during exercise. $J$ Clin Invest. 85: 893-8, x990. 
2. Astrup, A., B. Buemann, C. Gluud, P. Bennett, T. Tjur, and N. Christensen. Prognostic markers for diet-induced weight loss in obese women. Int J Obes Relat Metab Disord. 19: 275-8, I995.

3. Buemann, B., A. Astrup, F. Quaade, and J. Madsen. 24-Hour energy expenditure and substrate oxidation rates are unaffected by body fat distribution in obese women. Metabolism. 43: 109-II3, I994.

4. Colberg, S. R., J. A. Simoneau, F. L. Thaete, and D. E. Kelley. Skeletal muscle utilization of free fatty acids in women with visceral obesity. $J$ Clin Invest. 95: 1846-53, I995.

5. Després, J. P., M. C. Pouliot, S. Moorjani, A. Nadeau, A. Tremblay, P. J. Lupien, G. Theriault, and C. Bouchard. Loss of abdominal fat and metabolic response to exercise training in obese women. Am J Physiol. 26r: EI59-Ex67, I99I.

6. Frayn, $K . N$. Calculation of substrate oxidation rates in vivo from gaseous exchange. J Appl Physiol. 55: 628-34, I983.

7. Friedlander, A. L., G. A. Casazza, M. A. Horning, T. F. Buddinger, and $G$. A. Brooks. Effects of exercise intensity and training on lipid metabolism in young women. Am J Physiol. 275: E853-63, 1998.

8. Friedlander, A. L., G. A. Casazza, M. A. Horning, M. J. Huie, M. F. Piacentini, J. K. Trimmer, and G. A. Brooks. Training-induced alterations of carbohydrate metabolism in women: women respond differently from men. J Appl Physiol. 85: II75-II86, r998.

9. Friedlander, A. L., G. A. Casazza, M. A. Horning, A. Usaj, and G. A. Brooks. Endurance training increases fatty acis turnover, but not fat oxidation, in young men. J Appl Physiol. 86: 2097-2105, 1999.

Io. Havel, R. J., B. Pernow, and N. L. Jones. Uptake and release of free fatty acids and other metabolites in the legs of exercising men. J Appl Physiol. 23: 90-9, 1967 .

II. Henriksson, J. Training induced adaptation of skeletal muscle and metabolism during submaximal exercise. J Physiol Lond. 270: 66I-75, I977.

I2. Hurley, B. F, P. M. Nemeth, W. H. d. Martin, J. M. Hagberg, G. P. Dalsky, and J. O. Holloszy. Muscle triglyceride utilization during exercise: effect of training. J Appl Physiol. 60: 562-7, 1986.

13. Jansson, E., and L. Kaijser. Substrate utilization and enzymes in skeletal muscle of extremely endurance-trained men. I Appl Physiol. 62: 999-roos, I987.

I4. Jensen, M. D. Regulation of forearm lipolysis in different types of obesity. J Clin Invest. 87: 187-193, I99x. 
15. Jensen, M. D., M. W. Haymond, R. A. Rizza, P. E. Cryer, and J. $M$. Miles. Influence of body fat distribution on free fatty acid metabolism in obesity. J Clin Invest. 83: II68-73, rg89.

I6. Kanaley, J. A., P. E. Cryer, and M. D. Jensen. Fatty acid kinetic responses to exercise. Effects of obesity, body fat distribution, and energy-restricted diet. J Clin Invest. 92: 255-61, 1993.

17. Kiens, B., B. Essen Gustavsson, N. J. Christensen, and B. Saltin. Skeletal muscle substrate utilization during submaximal exercise in man: effect of endurance training. J Physiol Lond. 469: 459-78, 1993.

I8. Kissebah, A. H., N. Vydelingum, R. Murray, D. J. Evans, A. J. Hartz, R. $K$. Kalkhoff, and P. W. Adams. Relation of body fat distribution to metabolic complications of obesity. J Clin Endocrinol Metab. 54: 254-60, Ig82.

I9. Krotkiewski, M. Can body fat patterning be changed? Acta Med Scand. 723 Suppl: 213-223, I988.

20. Krotkiewski, M., and P. Björntorp. Muscle tissue in obesity with different distribution of adipose tissue. Int J Obes. 10: 33I-34I, 1986.

2I. Krotkiewski, M., K. Mandroukas, L. Morgan, T. William Olsson, G. E. Feurle, H. von Schenck, P. Bjorntorp, L. Sjostrom, and U. Smith. Effects of physical training on adrenergic sensitivity in obesity. $J$ Appl Physiol. 55: $1811-7,1983$.

22. Lamarche, B., J. P. Despres, S. Moorjani, A. Nadeau, P. J. Lupien, A. Tremblay, $G$. Theriault, and $C$. Bouchard. Evidence for a role of insulin in the regulation of abdominal adipose tissue lipoprotein lipase response to exercise training in obese women., 1993.

23. Landin, K., P. Lonnroth, M. Krotkiewski, G. Holm, and U. Smith. Increased insulin resistance and fat cell lipolysis in obese but not lean women with a high waist/hip ratio. Eur J Clin Invest. 20: 530-5, I9go.

24. Leijssen, D. P. C., W. H. M. Saris, and M. A. Van Baak. The effect of exercise training at different intensities on repiratory exchange ratio (RER)

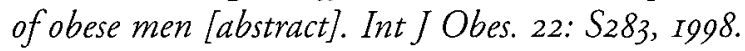

25. Lobman, T. G., A. F. Roche, and R. Martorell. Anthropometric Standardization Reference Manual. Illinois: Campaign, I 988.

26. Martin, M. L., and M. D. Jensen. Effects of body fat distribution on regional lipolysis in obesity. J Clin Invest. 88: 609-613, I99I.

27. Nikkilä, E. A., and A. Konttinen. Effect of physical activity on postprandial levels of fats in serum. Lancet. I: IISI-IIS4, I962.

28. Oscai, L. B., J. A. Patterson, D. L. Bogard, R. J. Beck, and B. L. Rothermel. Normalization of serum triglycerides and lipoprotein 
electrophoretic patterns by exercise. Am J Cardiol. 30: 775-80, 1972.

29. Phillips, D. I., S. Caddy, V. Ilic, B. A. Fielding, K. N. Frayn, A. C. Borthwick, and $R$. Taylor. Intramuscular triglyceride and muscle insulin sensitivity: evidence for a relationship in nondiabetic subjects. Metabolism. 45: 947-50, 1996.

30. Phillips, S. M., H. J. Green, M. A. Tarnopolsky, G. F. Heigenhauser, R. E. Hill, and S. M. Grant. Effects of training duration on substrate turn over and oxidation during exercise. J Appl Physiol. 8I: 2I82-9I, 1996.

3I. Poeblman, E. T., A. W. Gardner, P. J. Arciero, M. I. Goran, and J. Calles Escandon. Effects of endurance training on total fat oxidation in elderly persons. J Appl Physiol. 76: 2281-7, 1994.

32. Ranneries, C., J. Bulow, B. Buemann, N. J. Christensen, J. Madsen, and A. Astrup. Fat metabolism in formerly obese women. Am J Physiol. 274: EI55-6I, 1998.

33. Ravussin, E., and B. A. Swinburn. Metabolic predictors of obesity: cross-

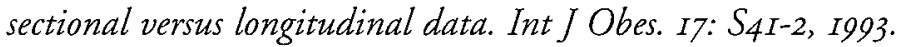

34. Rebuffé-Scrive, M., L. Enk, N. Crona, P. Lonnroth, L. Abrahamsson, $U$. Smith, and P. Bjorntorp. Fat cell metabolism in different regions in women: effect of menstrual cycle, pregnancy, and lactation. J Clin Invest. 75: $1973-1976,1985$.

35. Richelsen, B., S. B. Pedersen, T. Moller-Pedersen, O. Schmitz, N. Moller, and J. D. Børglum. Lipoprotein lipase activity in muscle tissue influenced by fatness, fat distribution and insulin in obese females. Eur J Clin Invest. 23: 226-233, 1993 .

36. Schrauwen, P., E. E. Blaak, D. P. C. Van Aggel-Leijssen, L. B. Borghouts, and $A$. J. M. Wagenmakers. Determinants of the acetate recovery factor: implications for estimation of ${ }_{13} C$ substrate oxidation. Clin Sci. 98:587-592, 2000.

37. Schrauwen, P., D. P. Van Aggel-Leijssen, W. D. Van Marken Lichtenbelt, M. A. Van Baak, A. P. Gijsen, and A. J. Wagenmakers. Validation of the $\left[I, 2{ }^{13} \mathrm{C}\right]$ acetate recovery factor for correction of $\left[U_{-}{ }^{13} \mathrm{C}\right]$ palmitate oxidation rates in humans. J Physiol Lond. 513: 2I5-23, 1998.

38. Schutz, Y., and A. Tremblay. Does lipid oxidation differ in gynoid and android obese women? Int J Obes. 16: 67-69, 1992.

39. Seip, R. L., T. J. Angelopoulos, and C. F. Semenkovich. Exercise induces human lipoprotein lipase gene expression in skeletal muscle but not adipose tissue. Am J Physiol. 268: E229-36, 1995.

40. Sidossis, L. S., A. R. Coggan, A. Gastaldelli, and R. R. Wolfe. A new correction factor for use in tracer estimations of plasma fatty acid 
oxidation. Am J Physiol. 269: E649-56, x995.

4I. Siri, W. E. The gross composition of the body. Adv Biol Med Physiol. 4: 239-280, 1956 .

42. Smedes, F, J. C. Kraak, and H. Poppe. Simple and fast solvent extraction system for selective and quantitative isolation of adrenaline, noradrenaline and dopamine from plasma and urine. J Chromatogr. 23I: 25-39, 1982.

43. Swan, P. D., and E. T. Howley. Substrate utilization during prolonged exercise in obese women differing in body fat distribution. Int $J$ Obes. 18: 263-8, 1994 .

44. Vague, J. La differenciation sexuelle, facteur determinant des formes de l'obesité. La Presse Medical. 53: 339, I947.

45. Zurlo, F, S. Lillioja, A. Esposito Del Puente, B. L. Nyomba, I. Raz, M. F. Saad, B. A. Swinburn, W. C. Knowler, C. Bogardus, and E. Ravussin. Low ratio of fat to carbohydrate oxidation as predictor of weight gain: study of 24-h RQ. Am J Physiol. 259: E650-7, 19go. 
Dorien P.C. van Aggel-Leijssen, Wim H.M. Saris, Gabby B. Hul, and Marleen A. van Baak

Accepted American Journal of Clinical Nutrition

\section{Abstract}

Objective: To investigate the effect of addition of low intensity exercise training to energy restriction on post-diet fat oxidation and on the contribution of the sympatbetic nervous system to fat oxidation.

Metbods: Forty obese males were at random divided in a diet $(D)$ or a diet plus exercise group (DE). Both groups received an energy restriction program for $I 0$ weeks.

Subjects in the DE group also participated in a low intensity exercise training program (40\% VO2max) during $I_{2}$ weeks, 3 times per week. Before the intervention and after I 2 weeks, at stable body weight, measurements of body composition, maximal oxygen uptake and substrate oxidation at rest, during exercise at $50 \%$ VO 2 max and recovery were performed with and without administration of the $\beta$-adrenergic antagonist propranolol (PRP).

Results: Body weight, fat mass and fat free mass ( $P \leqslant 0.0 o I)$ decreased similarly in both groups. Both interventions failed to affect maximal oxygen uptake.

The effect of the intervention on Respiratory Exchange Ratio ( $R E R$ ) was significant different in the $D$ group compared to the DE group (2-way ANOVA; $P<0.05)$. The effect on $\beta$-adrenergic mediated RER tended to be different between the $D$ and $D E$ group (2-way $A N O V A ; p=0.09$ ) 
Conclusion: These results indicate that addition of low intensity exercise training to energy restriction counteracts the decline in fat oxidation in the post-diet period, possibly by maintaining sympathetic nervous system activity.

\section{Introduction}

Obesity is a risk factor for the development of cardiovascular diseases (18) and type 2 diabetes mellitus (4). The prevalence of obesity is increasing in the United States (14) and in Europe (29) and is identified nowadays as a serious health problem. A common treatment for obesity is energy restriction. Although this is usually successful for short term weight loss, on long-term there is a high rate of recidivism $(10,12,30,37)$.

The poor long-term outcome of energy restriction may be due to metabolic adaptations to weight loss in the obese. Body weight reduction has been shown to decrease fat oxidation (20) and resting metabolic rate $(8,16,22$, 28 ) after body weight has stabilized. This may predispose to weight regain $(1,25)$.

We previously found that low intensity exercise training in obese men increased fat oxidation (17). Therefore, low intensity exercise training might be able to prevent the post-weight loss decline in fat oxidation. Previous studies have reported that addition of exercise training to energy restriction could prevent the post-weight loss-induced decline in fat oxidation in obese women at rest (20), but not during exercise at a workload of 30 Watt (35). Although Nicklas et al. (20) used low intensity exercise training, they did not report on fat oxidation during exercise. A low intensity exercise training program, could improve adherence and reduce risk for musculo-skeletal injuries in obese subjects. Therefore, the first aim of the present study was to investigate whether low intensity exercise training is able to prevent the decline in fat metabolism during rest and exercise associated with body weight loss in obese subjects after stabilization of body weight.

Our second aim was to study the effect of weight loss and exercise training on the role of the sympathetic nervous system in the regulation of fat oxidation. To our knowledge, no data are available on the effect of exercise training in combination with diet-induced body weight loss on $\beta$-adrenergic mediated fat metabolism. Studies on the effect of $\beta$-adrenergic stimulation on relative fat oxidation after body weight loss are not consistent $(3,15)$. 
Exercise training is found to increase $B$-adrenergic mediated fat metabolism in obese subjects in vitro (6) and in situ (34), but no in vivo data are available. The present study therefore also investigated the effect of weight loss with or without exercise training on the contribution of the $\beta$-adrenergic nervous system to fat oxidation.

\section{Methods}

\section{Subjects}

Forty obese male subjects, recruited by an advertisement in a local newspaper, participated in this study. All subjects were in good health as assessed by medical history and physical examination. The subjects did not spend more than 2 hours a week in sports activities and had no physically demanding job. Subjects had a stable body weight $(<3 \mathrm{~kg}$ change) over the last 3 months and did not receive medication known to influence the variables measured. Subjects were matched with respect to age, body mass index (BMI), fat percentage, weight and maximal oxygen uptake and randomly divided in two groups, the diet (D) or diet + exercise group (DE). The study protocol was approved by the Ethics Committee of Maastricht University. Written informed consent was obtained from all subjects. Three subjects in the D group did not complete the weight loss intervention ( 1 due to illness (enteritis) and 2 due to lack of motivation). Subject characteristics of the remaining study population are indicated in Table 5.1.

Table 5.1 Subject characteristics before and after the intervention in the diet [D] $[n=17]$ and diet plus exercise [DE] $[n=20]$ group.

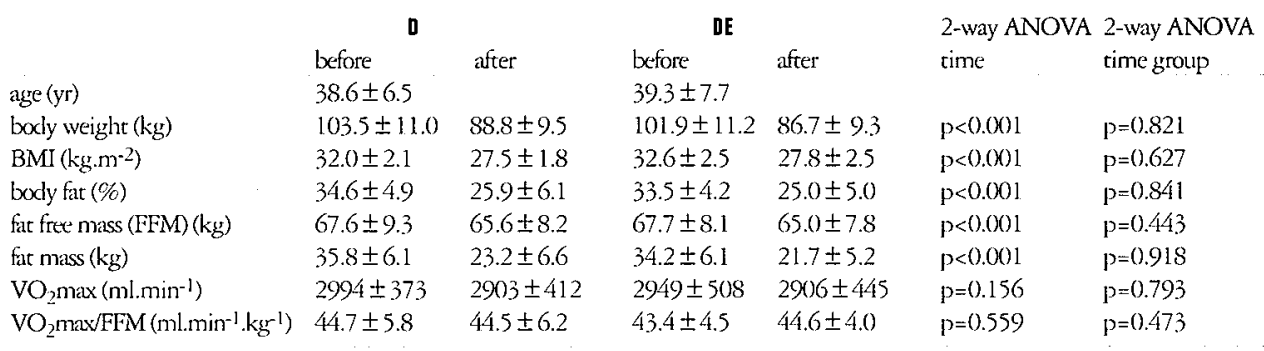

Data are expressed as means $\pm S D$ 


\section{Experimental design}

All subjects in the $\mathrm{D}$ and $\mathrm{DE}$ group participated in an energy restriction program for 10 weeks. Twenty subjects took also part in a low intensity exercise training program during 12 weeks (DE group). Before the start of the intervention program and after 12 weeks, body composition, maximal aerobic capacity, basal metabolic rate, energy and substrate metabolism at rest and during exercise with and without administration of a non-selective B-adrenergic antagonist were determined.

$\underline{\text { Diet }}$

All subjects participated in the energy restriction program. The first six weeks subjects received a very low energy diet (VLCD) (Modifast, Novartis Nutrition, Breda, The Netherlands). This diet provided 2.1 MJ/day and was a protein enriched formula diet, containing $50 \mathrm{~g}$ carbohydrates, $52 \mathrm{~g}$ protein, $7 \mathrm{~g}$ fat and a micronutrient content which meets the Dutch recommended daily allowance. From week 7 until week 10, subjects increased their energy intake gradually. They received less formula diet and were instructed to supplement this with a free choice of foodstuffs. In week 7 and 8 subjects received $1.4 \mathrm{MJ} /$ day of the formula diet and supplemented this up to about $3.5 \mathrm{MJ}$ by a free choice of foodstuffs. In week 9 and 10 they received 0.7 $\mathrm{MJ}$ /day of the formula diet and they supplemented this up to about $4.9 \mathrm{MJ}$ by other foodstuffs. From week 7 until week 10 subjects were asked to keep a food diary. In week 11 and 12 subjects were instructed to return to energy balance in order to stabilize body weight. They filled in a 3-day food diary during 2 week days and 1 weekend day at the end of week 11 . This diary was discussed with the subject and dietary advice was given in order to change food habits if necessary. During the twelve weeks subjects came to the laboratory once a week for body weight measurement and dietary advice.

\section{$\underline{\text { Exercise training }}$}

The subjects in the $\mathrm{D}$ group were instructed not to change their habitual activity pattern during the study period. The subjects in the DE group participated, besides the energy restriction program, in an exercise training program during the 12 week period. They trained 4 rimes one hour per 
week, 3 times at the laboratory under supervision of a professional trainer and once at home. The exercise training program consisted of cycling on an ergometer (Bodyguard Cardiocycle, Sandnes, Norway or Excalibur Lode, Groningen, The Netherlands), walking and aqua-jogging. All exercises were executed at a low intensity $\left(40 \% \mathrm{VO}_{2} \max \right)$. The heart rate corresponding with $40 \% \mathrm{VO}_{2}$ max was determined in an incremental cycle ergometer test (see Maximal aerobic capacity). Training intensity was checked by monitoring heart rate during the laboratory training sessions (Polar Electro, Oy, Finland). Every three months a maximal aerobic capacity test was performed and exercise intensity was corrected if necessary. Subjects were instructed to execute low intensity endurance exercise once a week at home. Subjects attendance at the training sessions was recorded and the trainer inquired for the extra exercise at home regularly.

\section{Measurements}

1. Body composition

Body weight was measured on a digital balance accurate to $0.1 \mathrm{~kg}$ (Sauter D-7470, Ebingen, Germany). Height was measured to the nearest $0.1 \mathrm{~cm}$ using a wall-mounted stadiometer (Seca, model 220, Hamburg, Germany). BMI was calculated from weight and height $\left(\mathrm{kg} / \mathrm{m}^{2}\right)$. Body density was measured by hydrostatic weighing, with a correction for residual lung volume estimated by helium dilution with a spirometer (Volugraph 2000, Mijnhardt, The Netherlands) at the moment of under water weighing. Body composition was calculated according to the formula of Siri (31).

2. Maximal aerobic capacity

Maximal oxygen uptake ( $\left.\mathrm{VO}_{2} \max \right)$ for each subject was determined by an incremental exercise test on an electromagnetically braked cycle ergometer (Excalibur, Lode, Groningen, The Netherlands). After a warming up period of 5 minutes at 80 Watt, workload was increased every 4 minutes by 40 Watt until exhaustion. During the experiment ventilatory and gas exchange responses were measured continuously, using indirect calorimetry (Oxycon B, Mijnhardt, Bunnik, The Netherlands). Heart rate was recorded continuously by electrocardiography. The highest oxygen uptake over $30 \mathrm{sec}$ achieved was taken as $\mathrm{VO}_{2} \max$. 
3. Physical activity

Habitual physical activity was estimated before the intervention and after 12 weeks by the Baecke questionnaire (2) which is subdivided into physical activity at work, sport during leisure time and physical activity during leisure time excluding sport.

\section{Energy and substrate metabolism}

The effect of weight loss with or without exercise training on energy and substrate metabolism at rest and during exercise was determined with subjects in a weight stable situation after the 12 weeks intervention.

Experiments were performed $36-65 \mathrm{~h}$ after the last exercise bout in a room with a temperature between 23 and $25^{\circ} \mathrm{C}$. After an overnight fast, subjects came to the laboratory by car or public transport to minimize physical activity. A catheter was inserted in an arm vein for blood sampling. Subjects remained in semi-supine position for 30 minutes and subsequently cycled on an ergometer (Excalibur, Lode, Groningen, The Netherlands) for 45 minutes at $50 \%$ of pre-intervention $\mathrm{VO}_{2} \max$. After cycling they recovered in semi-supine position for 15 minutes. During the experiment $\mathrm{CO}_{2}$ production, $\mathrm{O}_{2}$ consumption and respiratory exchange ratio (RER) were determined by an open circuit ventilated hood system (Oxycon B, Mijnhardt, Bunnik, The Netherlands). Energy expenditure was calculated according to the formula of Weir (38). During exercise a mouthpiece was used and for subjects' convenience measurements were only conducted from $t=10-15,25-30$ and $40-45 \mathrm{~min}$. The accuracy of the system for measurements of $\mathrm{CO}_{2}$ production and $\mathrm{O}_{2}$ consumption was tested regularly to be within $5 \%$ by combustion of a known amount of ethanol. During the experiment heart rate was recorded continuously by electrocardiography. Blood was sampled after 30 minutes of rest $(t=0)$, after 5,15 , 30 and 45 minutes cycling and after 15 minutes recovery. The sample was divided into EDTA or $300 \mu \mathrm{l}$ glutathion ( $45 \mu \mathrm{g} / \mathrm{l}$ saline) plus heparin containing chilled $10 \mathrm{ml}$ rubes and immediately centrifuged for $10 \mathrm{~min}$ at $800 \mathrm{~g}$ at $4{ }^{\circ} \mathrm{C}$. Plasma was stored at $-80^{\circ} \mathrm{C}$ until analyses. The EDTA containing blood was used for analyses of plasma glucose, FFA, insulin, glycerol and lactate concentrations. The heparin and glutathion containing blood was used for analyses of plasma epinephrine and norepinephrine concentrations. 
5. B-Adrenoceptor-mediated energy and substrate metabolism

The same experiment as described above was conducted in at random order on another day with infusion of the non-selective $\beta$-antagonist propranolol (PRP) (Zeneca B.V., Ridderkerk, The Netherlands). An extra catheter was inserted in a vein of the contralateral arm for propranolol infusion. Propranolol was infused by a Harvard syringe pump in a dose of $0.71 \mu \mathrm{g} . \mathrm{kg}$ fat free mass ${ }^{-1} \cdot \mathrm{min}^{-1}$ with a prime of $229.4 \mu \mathrm{g}$.kg fat free mass ${ }^{-1}$ which was administered in at least $10 \mathrm{~min}$. During the experiment blood pressure was measured every 10 minutes and heart rate continuously by electrocardiography. Infusion was stopped when heart rate had reached 45 beats/min.

\section{Biochemical analysis}

Plasma concentrations of FFA (NEFA C kit; Wako Chemicals, Neuss, Germany), glucose (GLUC HK kit; Hoffmann-La Roche, Basel, Switzerland), glycerol (Glycerol kit; Boehringer, Mannheim, Germany) and lactate (11) were measured on a COBAS FARA centrifugal spectrophotometer (Roche Diagnostica, Basel, Switzerland). Standard samples with known concentrations were included in each run for quality control. Plasma insulin concentrations were measured with a double-antibody radio-immunoassay (Insulin RIA 100; Pharmacia, Uppsala, Sweden).

Plasma epinephrine and norepinephrine concentrations for the test without PRP infusion were analyzed by HPLC with electrochemical detection (32).

\section{Statistics}

Data are expressed as means \pm SD. Since fat free mass decreased significantly due to the intervention in both groups, data on energy expenditure were corrected for individual changes in fat free mass according to the method described by Ravussin et al. (23). Differences in baseline subject characteristics between groups were tested with an unpaired t-test. Subject characteristics and substrate oxidation, energy expenditure and plasma variables measured before and after the intervention in the rest, exercise and recovery period within the $\mathrm{D}$ and $\mathrm{DE}$ group the were compared by a two-way repeated-measurement ANOVA (time $\mathrm{x}$ condition). Post-hoc testing was done by a paired-ttest over the rest, exercise (mean $t=15,30$ and 45 ) and recovery period. P-values of the post-hoc comparisons were corrected according to Bonferroni inequalities. Differences in baseline measurements of substrate oxidation, 
energy expenditure and plasma variables (rest, exercise, recovery) between groups were tested with a two-way repeated-measurement ANOVA (group $\mathrm{x}$ condition). In order to compare the effects of D and DE on the measured parameters, differences between results before and after the interventions were calculated for the rest, exercise (average $t=15,30$ and 45) and recovery period. A two-way repeated-measurement ANOVA (group x condition) was used to test differences between the $\mathrm{D}$ and $\mathrm{DE}$ group. Post-hoc testing was done by an unpaired-t-test over the rest, exercise (mean $t=15,30$ and 45) and recovery period. P-values of the post-hoc comparisons were corrected according to Bonferroni inequalities. Areas under the curve (AUC) of the RER versus time graph were calculated and differences between groups were tested by a 2-way ANOVA (time $x$ group). A paired t-test was used to test differences within groups. A P value $<0.05$ was regarded as statistically significant.

\section{Results}

\section{Subject characteristics}

Subject characteristics were not significantly different between the two groups before the intervention (Table 5.1). The intervention induced a decrease in body weight $(14.8 \pm 5.3$ and $15.2 \pm 6.3$ in the D and DE group respectively), $\mathrm{BMI}$, body fat percentage, fat mass and fat free mass (2-way ANOVA; time $\mathrm{P}<0.001$ ) in both groups, but the effect was not different between the $\mathrm{D}$ and $\mathrm{DE}$ group (2-way ANOVA; group NS, time $\mathrm{x}$ group NS). Heart rate and RER at maximal workload before and after the intervention were not significantly different within the two groups. The intervention did not affect $\mathrm{VO}_{2} \max$ or $\mathrm{VO}_{2} \mathrm{max} / \mathrm{FFM}$ in any group. In the DE group the score for sport activity during leisure time, including participation in the exercise training program of the present study, increased significantly after the intervention (from $2.3 \pm 0.7$ to $2.9 \pm 0.7 ; \mathrm{P}<0.05$ ). In the $\mathrm{D}$ group sport activity during leisure time did not change but physical activity during leisure time excluding sport increased significantly (from $2.4 \pm 0.5$ to $2.6 \pm 0.4 ; \mathrm{P}=0.05$ ). The $\mathrm{DE}$ group increased their sport activity during leisure time significantly more than the $\mathrm{D}$ group $(\mathrm{P}<0.05)$, while changes in physical activities during work and leisure time excluding sport were not significantly different between the groups. As an indication for weight balance, subjects body weight changed on average $+0.17 \pm$ $0.96 \%(+0.14 \pm 0.89 \mathrm{~kg})$ during the last week of the study (NS), without differences between groups. Subjects in the DE group attended $75 \pm 20 \%$ of 
the training sessions at the laboratory between the last pre-intervention test and the first post-intervention test. Subjects who could not attend a training session at the laboratory due to work responsibilities were required to exercise (walking or cycling) at home during one hour. They received a heart rate monitor in order to check training intensity at home by themselves. Causes of absence at training sessions were illness, holidays and work responsibilities. The lower adherence leads to an underestimation of the effect of exercise training. If subjects performed the same percentage of the required exercise sessions at home ( $75 \%$ of once a week) as they did in the laboratory ( $75 \%$ of three times a week), this would implicate that they exercised on average 3 times instead of 4 times a week. The calculated energy expenditure per training session was on average $1.4 \pm 0.2 \mathrm{MJ}$.

Effects of weight loss with or without low intensity exercise training on substrate metabolism

Before the intervention energy expenditure during rest and exercise was not significantly different between the groups. Energy expenditure adjusted for changes in fat free mass (EE adj FFM) was significantly lower after the intervention in both the $\mathrm{D}$ and DE group (2-way ANOVA; time $\mathrm{P}<0.05$, time $\mathrm{x}$ condition $\mathrm{P}<0.01$ ) (Figure 5.1).
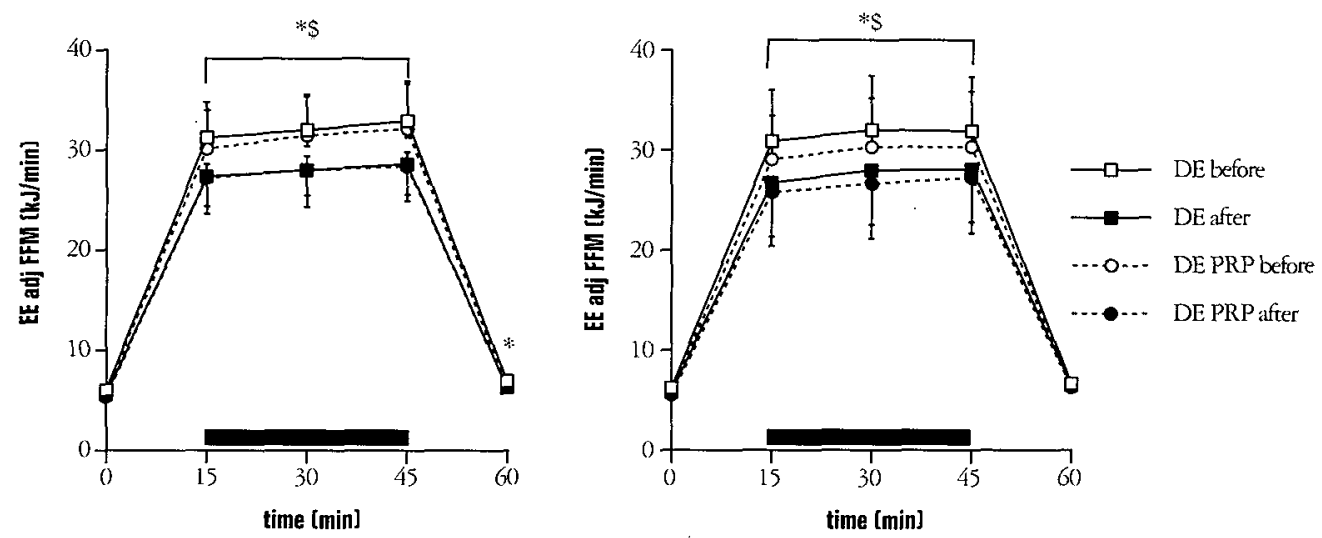

Figure 5.1 Energy expenditure [EE] [kJ/min] adjusted for changes in FFM in the diet $[D]$ and diet-exercise [DE] group before and after the intervention, at rest $[t=0]$ during exercise [mean $t=15-45$; black bar] and recovery $[t=60]$ with propranolol [PRP] and without PRP administration. 2-way ANOVA test without PRP: $D$ : time $P<0.001$, time $x$ condition $P<0.001$; DE: time $P<0.05$, time $x$ condition $P<0.01$. 2-way ANOVA test with PBP: $D$ : time $P<0.01$, time $x$ condition $P<0.01$; DE: time $P<0.05$, time $x$ condition $P<0.05$.

* test without PRP significantly different from before $\{P<0.05] ; \$ P R P$ test significantly different from hefore $[P<0.05]$ 
Changes in adjusted energy expenditure were not different between the groups. RER before the intervention was not significantly different between the groups. RER increased significantly due to the intervention in the D group (2-way ANOVA; time $\mathrm{P}<0.05$ ), but not in the DE group (Figure 5.2). The effect of the intervention on RER was significantly different in the D compared to the $\mathrm{DE}$ group (2-way ANOVA; $\mathrm{P}<0.05$ ). AUC of $\mathrm{RER}$ versus time was significantly higher after the intervention from before (2-way ANOVA; $\mathrm{P}<0.05)$ and the interaction effect time $\mathrm{x}$ group tended to be significant $(\mathrm{P}=0.07)$ (Figure 5.3). The AUC for RER in the D group increased significantly after the intervention $(P<0.05)$, but remained similar in the DE group.
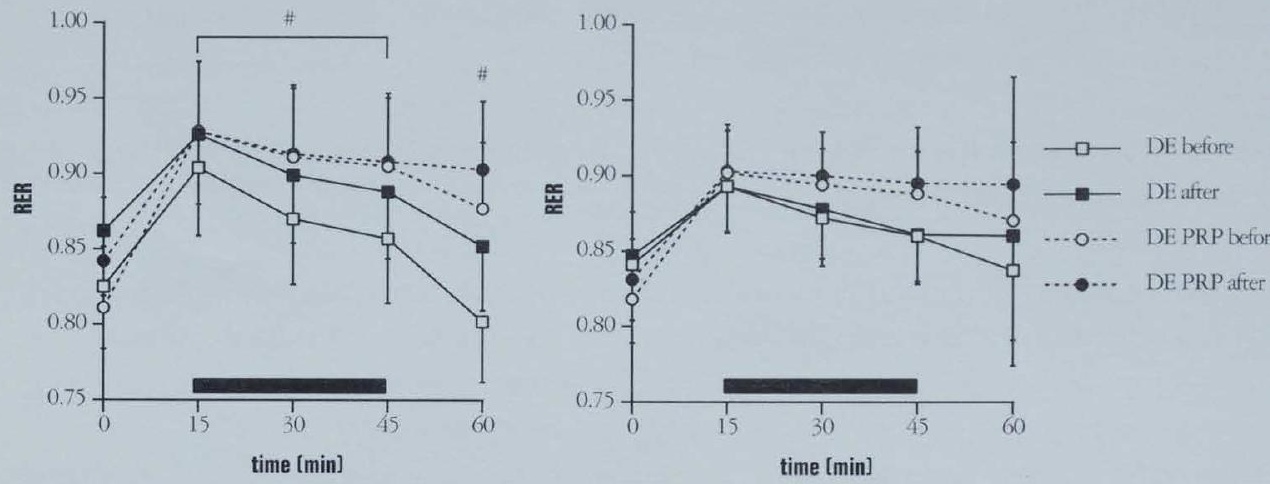

Figure 5.2 Respiratory Exchange Ratio [RER] in the diet [D] and diet-exercise [DE] group before and after the intervention, at rest $[t=0]$ during exercise $[t=15-45$; black bar] and recovery $[t=60]$ with propranolol [PRP] and without PRP administration.

\# test PRP hefore significantly different from test without PRP before $[P<0.05]$

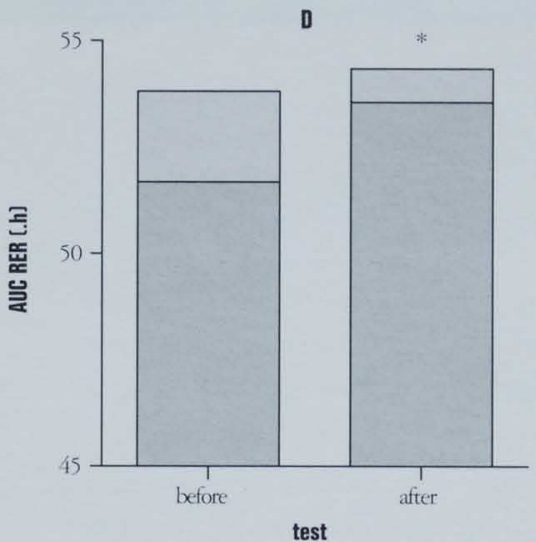

test

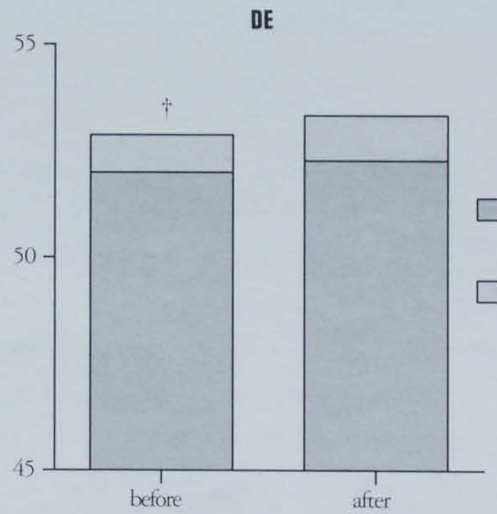

test
RER without PRP infusion

PRP-mediated change in RER 
Figure 5.3 Area under the curve [AUC] for RER [.h] in the diet [D] and diet-exercise [DE] group hefore and after the intervention without propranolol [PRP] administration and the PRP-mediated change in RER.

2-way ANOVA test without PRP. time $p<0.05$, time $x$ group $p=0.07 ; 2$-way ANOVA test with PRP. time NS, time $x$ group $p=0.09$ † PRP-mediated change in RER significantly different from $D[p<0.05]$; * test without PRP significantly dffferent from before [p<0.05]

Heart rates at rest, exercise and recovery were $69 \pm 9,129 \pm 18$ and $85 \pm$ 12 beats/min in the $\mathrm{D}$ group and $72 \pm 10,117 \pm 17$ and $81 \pm 10$ beats/min in the DE group before the intervention (NS between groups). Heart rates did not change in the $\mathrm{D}$ group due to the intervention, but were significantly lower after the intervention in the DE group at rest $(-10$ \pm 8 beats/min; $\mathrm{P}<0.001)$ and recovery $(-11 \pm 11$ beats/min; $\mathrm{P}<0.01)$, but not during exercise $(-8 \pm 16$ beats/min; NS) None of the changes in plasma metabolites due to the intervention were different between the groups, but there were some changes in metabolites within the groups (Figure $4 \mathrm{~A}$ and B). Plasma FFA and glycerol concentrations decreased significantly due to the intervention in both groups. Plasma lactate concentrations tended to be lower after the intervention, but only decreased statistically significantly in the $\mathrm{DE}$ group during exercise $(\mathrm{P}<0.01)$ and in the $\mathrm{D}$ group during recovery $(\mathrm{P}<0.05)$. Plasma glucose concentrations did not change in any group (data not shown). Plasma insulin concentrations declined significantly in both groups at rest and recovery $(\mathrm{P} \leqslant 0.01)$ (Table 5.2). Plasma epinephrine and norepinephrine concentrations decreased significantly in both groups (2-way ANOVA; time $\mathrm{P}<0.05$ and $\mathrm{P}<0.0001$ respectively) (Table 5.2). Changes were not different between the $\mathrm{D}$ and $\mathrm{DE}$ group.

Table 5.2 Plasma insulin [pU/ml], epinephrine [ng/l] [Epi], norepinephrine [ng/l] [Norepi] before and after the intervention in the diet [D] and diet-exercise [DE] group at rest, after $\mathbf{4 5} \mathrm{min}$ exercise and after $15 \mathrm{~min}$ recovery.

\begin{tabular}{|c|c|c|c|c|c|c|c|}
\hline & & & rest & exercise & recovery & $\begin{array}{l}\text { 2-way ANOVA } \\
\text { time }\end{array}$ & $\begin{array}{l}\text { 2-way ANOVA } \\
\text { rime } x \text { conclition }\end{array}$ \\
\hline \multirow[t]{4}{*}{ insulin } & D & before & $13.3 \pm 4.3$ & $9.4 \pm 2.4$ & $19.3 \pm 9.9$ & $P=0.018$ & $\mathrm{P}=0.0005$ \\
\hline & & after & $10.1 \pm 5.3^{*}$ & $8.1 \pm 3.8$ & $10.9 \pm 6.2 *$ & & \\
\hline & $\mathbf{D E}$ & before & $14.3 \pm 6.5$ & $9.7 \pm 4.5$ & $15.6 \pm 6.3$ & $\mathrm{P}=0.001$ & $P=0.039$ \\
\hline & & after & $8.8 \pm 3.9^{*}$ & $7.0 \pm 2.9$ & $10.3 \pm 4.6^{*}$ & & \\
\hline \multirow[t]{4}{*}{ Epi } & D & before & $43 \pm 30$ & $123 \pm 63$ & $49 \pm 27$ & $P=0.042$ & $P=0.252$ \\
\hline & & after & $29 \pm 21$ & $89 \pm 42$ & $35 \pm 17$ & & \\
\hline & DE & before & $41 \pm 19$ & $142 \pm 114$ & $54 \pm 31$ & $\mathrm{P}=0.024$ & $P=0,043$ \\
\hline & & after & $29 \pm 16 \%$ & $88 \pm 40$ & $37 \pm 17^{*}$ & & \\
\hline \multirow[t]{4}{*}{ Norepi } & D & $b x$ fore & $511 \pm 117$ & $1500 \pm 450$ & $683 \pm 188$ & $\mathrm{P}<0.0001$ & $P=0.0002$ \\
\hline & & after & $344 \pm 122 * *$ & $940 \pm 3176 \%$ & $416 \pm 159 \% *$ & & \\
\hline & DE & before & $589 \pm 164$ & $1316 \pm 311$ & $684 \pm 212$ & $P<0.0001$ & $\mathrm{P}=0.000 \mathrm{l}$ \\
\hline & & after & $384 \pm 186$ & $779 \pm 270 \%$ & $425 \pm 169 \%$ & & \\
\hline
\end{tabular}

Data are expressed as means $\pm \mathrm{SD}$

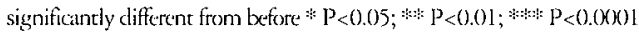


chapter 5
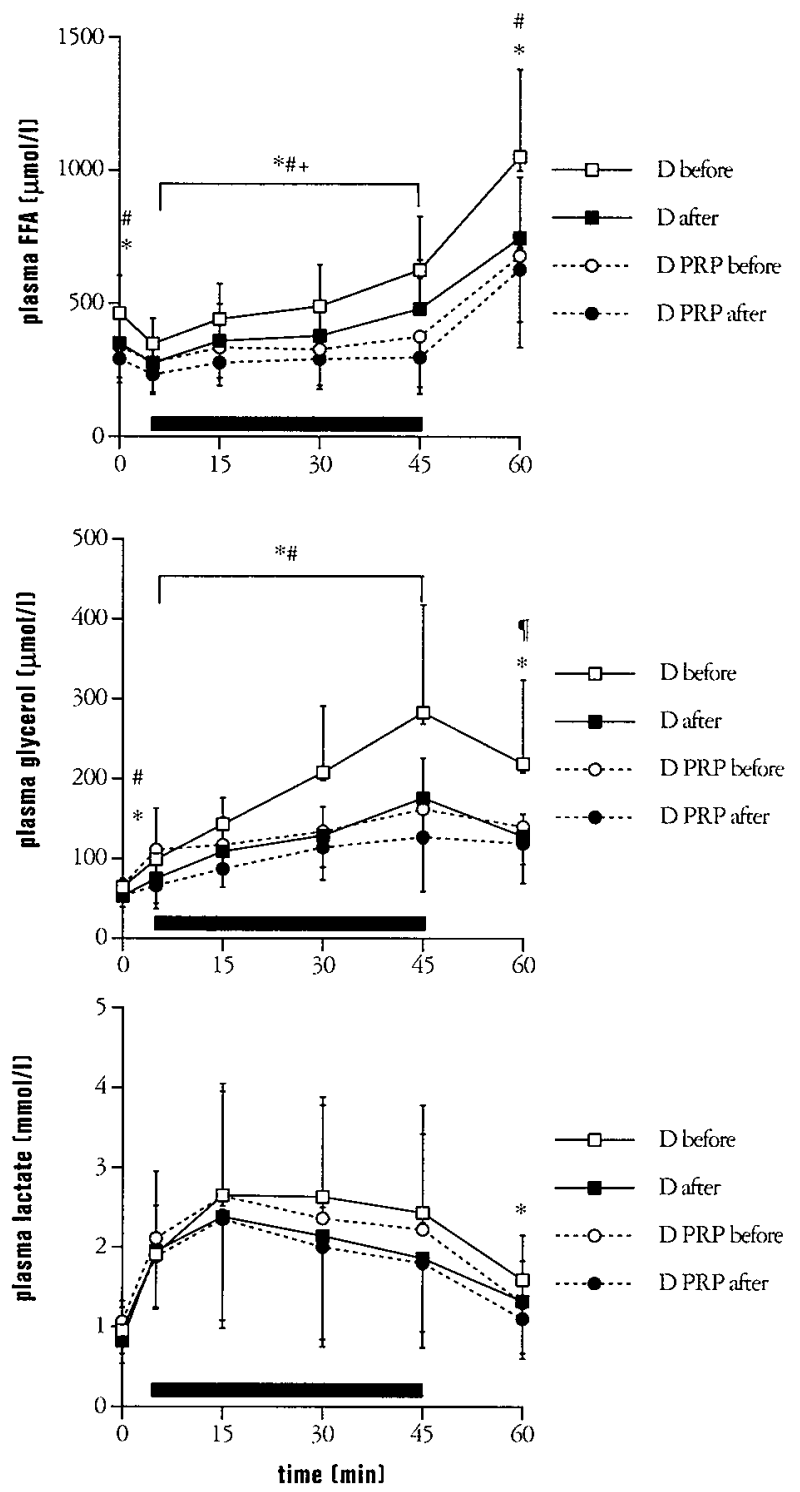

Figure 5.4 A + B Plasma concentrations of FFA [pmol/I], glycerol [pmol/l] and lactate [mmol/l] the diet $(D]$ [A] and diet-exercise [DE] [B] group before and after the intervention, at rest $[t=0$ ] during exercise [mean $t=5$-45; black har] and recovery $[t=60]$ with propranolol $[P R P]$ and without PRP administration. Plasma FFA: 2-way ANOVA test without $P R P$ : D: time $P<0.01$, time $x$ condition $P<0.01$; DE: time $P<0.01$, time $x$ condition $P<0.0001$. Plasma glycerol: 2-way ANDVA test without PAP: D: time $\mathrm{P}<0.01$, time $x$ condition $\mathrm{P}<0.001$; $\mathrm{DE}$ : time $\mathrm{P}<0.01$, time $x$ condition $\mathrm{P}<0.05$. 2-way ANOVA test with PRP: D: time $P<0.01$, time $x$ condition NS; $D E$ : time $P=0.001$, time $x$ condition $P=0.07$. Plasma lactate: 2-way ANOVA test without PRP: D: time $P=0.09$, time $x$ condition $P=0.01$; $D E$ : time $P<0.01$, time $x$ condition 

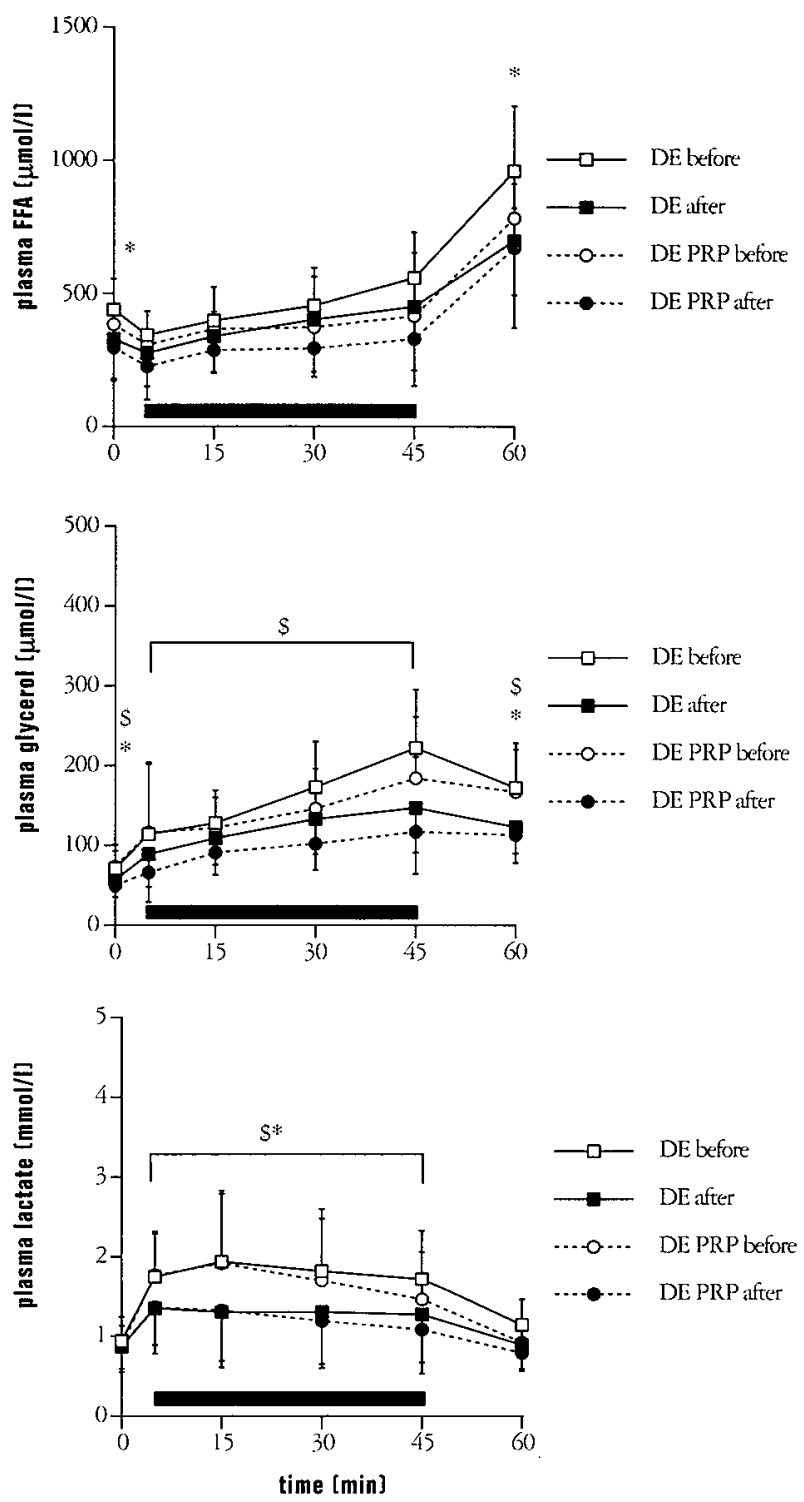

$P<0.001$. 2-way ANOVA test with PRP: DE: time $P<0.05$, time $x$ condition $P<0.01$.

* test without PRP significantly different from before $[P<0.05]$

$S$ PRP test significantly different from before $[P<0.05]$

\# test PRP hefore significantly different from test without PRP hefore $[P<0.05]$

+ test PRP after significantly different from test without PRP after $[P<0.05]$

I) PRP-induced change [PRP-without PRP] significantly different from before $[P<0.05]$ 
Effects of weight loss with or without low intensity exercise training on $\boldsymbol{B}$-adrenoceptor-mediated substrate metabolism

Energy expenditure in the PRP test was not different from the test without infusion in both groups before and after the intervention (Figure 5.1). RER at baseline, during exercise and recovery, increased with PRP infusion in the $\mathrm{D}$ group $(\mathrm{P}<0.01)$ (Figure 5.2). The PRP mediated change in RER (expressed as AUC of RER) before the intervention was significantly higher in the $D$ group compared to the $D E$ group $(P<0.05)$. The PRP mediated change in RER tended to be different between the $D$ and $D E$ group (2way ANOVA; time $x$ group $P=0.09$ ) (Figure 5.3). PRP infusion decreased the heart rate $(\mathrm{HR})$ significantly (2-way ANOVA; $\mathrm{P}<0.05)$ during rest, exercise and recovery in both groups (D group: $-10 \pm 5,-26 \pm 12$ and -15 \pm 11 beats/min; DE group: $-10 \pm 7,-18 \pm 16$ and $-17 \pm 19$ beats $/ \mathrm{min}$ ). PRP induced changes in HR were similar before and after the intervention. $\mathrm{PRP}$ infusion lowered plasma FFA concentrations in the $\mathrm{D}$ group before and after the intervention (2-way ANOVA; time $\mathrm{P}<0.05$, time $\mathrm{x}$ condition $\mathrm{P}<0.0001$ (before) and $\mathrm{P}=0.09$ (after)). PRP infusion lowered glycerol concentrations in the $\mathrm{D}$ group before the intervention (2-way ANOVA; time $\mathrm{P}<0.05$ and time $\mathrm{x}$ condition $\mathrm{P}<0.0001)$ and in the $\mathrm{DE}$ group after the intervention (2-way ANOVA; time $\mathrm{P}<0.05$, time $\mathrm{x}$ condition NS) (Figure $5.4 \mathrm{~A}$ and $\mathrm{B}$ ). No significant difference in PRP-induced changes in FFA concentration were found, neither before nor after the intervention. Plasma glycerol concentrations were significantly lower during PRP infusion after the intervention in both groups (2-way ANOVA; time $\mathrm{P}<0.01$ ). The PRP induced change in plasma glycerol was significantly reduced after the intervention compared to before in the D group (2-way ANOVA; test $\mathrm{P}<0.05$ ). PRP infusion did not affect plasma glucose concentrations (data not shown). Plasma lactate concentrations did not change by PRP infusion.

\section{Discression.}

The most important finding of the present study is that low intensity exercise training is able to prevent the weight loss-induced decline in fat oxidation in the post-diet period in obese men. The sympathetic nervous system is probably involved in these metabolic changes, since the responsiveness to sympathetic stimulation of lipolysis and fat oxidation tended to be reduced by weight loss and these changes could be prevented by low inten- 
sity exercise training.

The present study showed that a decrease in fat oxidation in the post-diet period $(\mathrm{P}<0.05)$ is a metabolic adaptation to loss of body fat mass. Others already reported an association of a reduced fat mass with a reduced fat oxidation $(8,28)$. Furthermore, the significantly reduced plasma FFA and glycerol concentrations $(\mathrm{P}<0.05)$ in the present study suggest that adipose tissue lipolysis may have been reduced. A decreased lipolysis after body weight loss is in agreement with data from previous studies $(13,20,26$, 33 ) and is reported to be caused by a reduction of the hormone sensitive lipase activity after weight loss (26).

Addition of exercise training to a weight loss period caused no short term additional effects on changes in body mass and composition, in agreement with the outcome of a meta-analysis of weight loss studies over the past 25 years (19). Nevertheless, addition of exercise training to the weight loss program was successful in preventing the undesirable decline in fat oxidation in the post-diet period. Weight loss resulted in a decline of fat oxidation at rest, during exercise and recovery in a weight stable situation (2-way ANOVA; test $\mathrm{p}<0.05$ ), which was counteracted when weight loss was combined with low intensity exercise training. This is in line with a previous study, showing that low intensity exercise training, without body weight loss, improved fat oxidation in obese subjects (17). A prevention of a decrease in resting fat oxidation due to weight loss by exercise training was also found in obese women in a weight stable situation (20). These women used a walking program, which is probably of comparable intensity as the training program used in our study, no data on fat oxidation were available during exercise and recovery from exercise.

The present study produced data on the involvement of the sympathetic nervous system in metabolic adaptations to weight loss. However, the PRP-mediated increase in RER before the intervention was significantly higher in the $\mathrm{D}$ group, compared to the $\mathrm{DE}$ group $(\mathrm{P}<0.05)$. Since the subjects were randomly divided over the two groups, we can not explain this accidental difference. Nevertheless, although interpretation needs some caution, changes due to the interventions could still be relevant. The PRPmediated change in RER tended to be different between the D and DE group (2-way ANOVA; time $\mathrm{x}$ group $\mathrm{P}=0.09$ ). In the $\mathrm{D}$ group blockade of $\beta$-receptors tended to increase RER less after than before weight loss (2way ANOVA; test $\mathrm{P}=0.09$ ). In addition, $\beta$-adrenergic blockade induced a smaller decline in plasma glycerol concentration in the diet group after the intervention than before $(\mathrm{P}<0.05)$. In contrast, in the DE group, the chan- 
ge in RER and glycerol during $\beta$-adrenergic blockade was not different before and after the intervention. Furthermore, plasma catecholamine concentrations before the intervention and changes due to the intervention were not different in the $\mathrm{D}$ and $\mathrm{DE}$ group. These results might indicate that exercise training during weight loss maintains fat oxidation by maintaining the sensitivity of the $B$-adrenergic nervous system.

This is in agreement with in vitro data from Nicklas et al. (20) showing a decreased cAMP- and epinephrine-stimulated lipolysis in the weight loss group but not in the weight loss plus exercise group. Moteover, a decreased cAMP-stimulated lipolysis suggested a defect at the post-receptor mechanism. Tremblay et al. reported that $B$-adrenergic blockade decreased resting fat oxidation and metabolic rate in exercise-trained, but not in untrained subjects (36), suggesting an increased $\beta$-adrenergic sensitivity in trained subjects. Moreover, several in vitro studies have found an increased $B$-adrenergic mediated lipolysis in the trained compared to the untrained state ( 5 , $6,27,34)$. The results of studies investigating the effects of weight reduction in obese subjects on $\beta$-adrenergic sensitivity are not consistent. Although a study of Blaak et al. (3) reported no significant effect of weight loss on $B$-adrenergic sensitivity of whole body and skeletal muscle in obese subjects, the data showed a trend toward a worsening of $\beta$-adrenergic mediated lipolytic activity in weight reduced subjects. In contrast, Leibel et al. showed an increased lipolytic response to epinephrine infusion in weight-reduced obese subjects at a stable body weight (15). The present study showed that weight loss, whether or not combined with exercise training, did not induce significant changes in resting energy expenditure when energy expenditure was adjusted for changes in FFM. This is in agreement with data from Ravussin et al. (24), indicating that a decreased resting energy expenditure after weight loss can be explained by a decreased FFM. On the other hand, other studies showed a decreased resting energy expenditure adjusted for FFM after body weight loss when body weight had stabilized (20) or probably stabilized $(8,9)$, but no significant decrease in resting energy expenditure when exercise training was added to the weight loss period $(20,21)$. However, as in our study, the change in RMR was not different between the D and DE group (20). The decreased energy expenditure adjusted for FFM during exercise seems to result from an increased mechanical efficiency since the workload before and after the intervention was similar.

Despite the difference in fat oxidation, there was no difference in weight change over short term between the $\mathrm{D}$ and $\mathrm{DE}$ group. The decreased fat 
oxidation after a weight loss program increases the risk of a positive fat balance when returning to the regular diet (7). A new fat balance will be achieved by increasing fat mass (28). Since addition of a low intensity exercise training program to a weight loss period maintains fat oxidation at a lower fat mass, fat balance can be achieved without increasing fat mass. However, the effects of continuation of exercise training on long term need further research.

In conclusion, addition of low intensity exercise training to a weight loss program counteracts the decline in fat oxidation induced by body weight loss in the post-diet period. This effect is mediated by maintenance of sympathetic nervous system sensitivity, which tends to be reduced after weight loss alone.

\section{References}

I. Astrup, A., B. Buemann, C. Gluud, P. Bennett, T. Tjur, and N. Christensen. Prognostic markers for diet-induced weight loss in obese women. Int J Obes. x9: 275-8, rg95.

2. Baecke, J. A., J. Burema, and J. E. Frijters. A short questionnaire for the measurement of habitual physical activity in epidemiological studies. Am J Clin Nutr. 36: 936-42, 1982.

3. Blaak, E. E., M. A. Van Baak, G.J. Kemerink, M. T. Pakbiers, $G$. A. Heidendal, and W. H. Saris. Beta-Adrenergic stimulation of skeletal muscle metabolism in relation to weight reduction in obese men. Am J Physiol. 267: E316-22, I994.

4. Bray, G. A. Obesity and surgery for a chronic disease. Obes Res. 4:30I-3, I996.

5. Crampes, F, D. Rivière, M. Beauville, M. Marceron, and M. Garrigues. Lipolytic response of adipocytes to epinephrine in sedentary and exercisetrained subjects: sex-related differences. Eur I Appl Physiol. 59: 249-55, I989.

6. De Glisezinski, I., F. Crampes, I. Harant, M. Berlan, J. Hejnova, $D$. Langin, D. Rivière, and V. Stich. Endurance training changes in lipolytic responsiveness of obese adipose tissue. Am J Physiol. 275: EgsI-6, I998.

7. Flatt, J. P. Importance of nutrient balance in body weight regulation. Diabetes Metab Rev. 4: 57I-8I, I988.

8. Franssila Kallunki, A., A. Rissanen, A. Ekstrand, A. Ollus, and L. Groop. Weight loss by very-low-calorie diets: effects on substrate oxidation, energy 
expenditure, and insulin sensitivity in obese subjects. Am J Clin Nutr. 56 : $247 S-248 S$, 1992.

9. Frey-Hewitt, B., K. M. Vranizan, D. M. Dreon, and P. D. Wood. The effect of weight loss by dieting or exercise on resting metabolic rate in overweight men. Int J Obes. I4: 327-34, 1990.

1o. Froidevaux, F., Y. Schutz, L. Christin, and E. Jéquier. Energy expenditure in obese women before and during weight loss, after refeeding, and in the weight-relapse period. Am J Clin Nutr. 57: 35-42, 1993.

II. Gutmann, I., and A. W. Wablefeld. L-(+)-Lactate, determination with lactate dehudrogenase and NAD. In: Methods in enzymatic analysis (second ed.). New York: Academic press, 1974, p. I464-I468.

12. Hensrud, D. D., R. L. Weinsier, B. E. Darnell, and G. R. Hunter. A prospective study of weight maintenance in obese subjects reduced to normal body weight without weight-loss training. Am J Clin Nutr. 60: 688-94, I994.

13. Klein, S., K. Luu, S. Gasic, and A. Green. Effect of weight loss on whole body and cellular lipid metabolism in severely obese humans.

Am I Physiol. 270: E739-45, 1996.

14. Kuczmarski, R. J., K. M. Flegal, S. M. Campbell, and C. L. Johnson. Increasing prevalence of overweight among US adults. The National Health and Nutrition Examination Surveys, I960 to I9gI. JAMA. 272: 205-II, I994.

15. Leibel, R. L., E. M. Berry, and J. Hirsch. Metabolic and hemodynamic responses to endogenous and exogenous catecholamines in formerly obese subjects. Am J Physiol. 260: R785-9I, I99I.

I6. Leibel, R. L., M. Rosenbaum, and J. Hirsch. Changes in energy expenditure resulting from altered body weight. $N$ Engl J Med. 332: 621-8, 1995.

17. Leijssen, D. P. C., W. H. M. Saris, and M. A. Van Baak. The effect of exercise training at different intensities on respiratory exchange ratio (RER) of obese men [abstract]. Int J Obes. 22: S283, 1998 .

18. Manson, J. E., W. C. Willett, M. J. Stampfer, G. A. Colditz, D. J. Hunter, S. E. Hankinson, C. H. Hennekens, and F. E. Speizer. Body weight and mortality among women. $N$ Engl J Med. 333: 677-85, 1995.

I9. Miller, W. C., D. M. Koceja, and E. J. Hamilton. A meta-analysis of the past 25 years of weight loss research using diet, exercise or diet plus exercise intervention. Int J Obes. 2I: $941-7$, 1997.

20. Nicklas, B. J., E. M. Rogus, and A. P. Goldberg. Exercise blunts declines in lipolysis and fat oxidation after dietary-induced weight loss in obese older women. Am J Physiol. 273: EI49-55, 1997. 
21. Pasman, W. J., W. H. Saris, E. Muls, G. Vansant, and M. S. Westerterp Plantenga. Effect of exercise training on long-term weight maintenance in weight-reduced men. Metabolism 48: 15-2I, I999.

22. Racette, S. B., D. A. Schoeller, R. F. Kushner, K. M. Neil, and K. Herling Iaffaldano. Effects of aerobic exercise and dietary carbohydrate on energy expenditure and body composition during weight reduction in obese women. Am J Clin Nutr. 6r: 486-94, 1995.

23. Ravussin, E., and C. Bogardus. Relationship of genetics, age, and physical fitness to daily energy expenditure and fuel utilization. Am J Clin Nutr. 49: 968-75, 2989 .

24. Ravussin, E., B. Burnand, Y. Schutz, and E. Jéquier. Energy expenditure before and during energy restriction in obese patients. Am J Clin Nutr. 4I: 753-9, 1985 .

25. Ravussin, E., and B. A. Swinburn. Metabolic predictors of obesity:

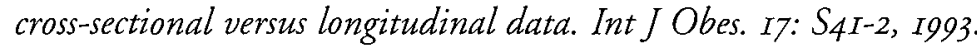

26. Reynisdottir, S., D. Langin, K. Carlstrom, C. Holm, S. Rossner, and P. Arner. Effects of weight reduction on the regulation of lipolysis in adipocytes of women with upper-body obesity. Clin Sci Colch. 89: 42I-9, xo95.

27. Rivière, D., F. Crampes, M. Beauville, and M. Garrigues. Lipolytic response of fat cells to catecholamines in sedentary and exercise-trained women. J Appl Physiol. 66: 330-5, 1989.

28. Schutz, Y., A. Tremblay, R. L. Weinsier, and K. M. Nelson. Role of fat oxidation in the long-term stabilization of body weight in obese women. Am J Clin Nutr. 55: 670-4, 1992.

29. Seidell, J. C. Obesity in Europe. Obes Res. 3: 89s-935, 1995.

30. Sikand, G., A. Kondo, J. P. Foreyt, P. H. Jones, and A. M. Gotto, Jr. Two-year follow-up of patients treated with a very-low-calorie diet and exercise training. J Am Diet Assoc. 88: 487-8, 1988.

31. Siri, W. E. The gross composition of the body. Adv Biol Med Physiol. 4: 239-280, 1956 .

32. Smedes, F., J. C. Kraak, and H. Poppe. Simple and fast solvent extraction system for selective and quantitative isolation of adrenaline, noradrenaline and dopamine from plasma and urine. J Chromatogr. 23I: 25-39, 1982.

33. Smith, U., J. Hammersten, P. Bjorntorp, and J. G. Kral. Regional differences and effect of weight reduction on human fat cell metabolism. Eur J Clin Invest. 9: 327-32, 1979.

34. Stich, V., I. de Glisezinski, J. Galitzky, J. Hejnova, F. Crampes, $D$. Rivière, and M. Berlan. Endurance training increases the beta- 
adrenergic lipolytic response in subcutaneous adipose tissue in abese subjects. Int J Obes. 23: 374-81, 1999.

35. Svendsen, O. L., M. Krotkiewski, C. Hassager, and C. Christiansen. Effects on muscle of dieting with or without exercise in overweight postmenopausal women. I Appl Physiol. 80: 1365-70, 1996.

36. Tremblay, A., S. Conveney, J. P. Després, A. Nadeau, and $D$. Prud'homme. Increased resting metabolic rate and lipid oxidation in exercise-trained individuals: evidence for a role of $\beta$-adrenergic stimulation. Can J Physiol Pharmacol. 70: 1342-1347, 1992.

37. Van Dale, D., W. H. Saris, and F ten Hoor. Weight maintenance and resting metabolic rate $18-40$ months after a dietlexercise treatment. Int J Obes. I4: 347-59, 1990.

38. Weir, J. B. New methods for calculating metabolic rate with special reference to protein metabolism. J Physiol. 109: I-9, 1949. 


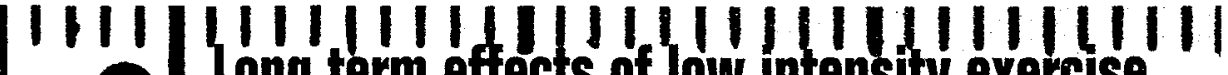 Long term effects of low intensity exercise training on fat metaholism in weight-reduced obese men}

Dorien P.C. van Aggel-Leijssen, Wim H.M. Saris, Gabby B. Hul, and Marleen A. van Baak

Submitted Obesity Research

\section{Abstract}

Objective: To investigate the effect of long term continuation of low intensity exercise training on weight maintenance, substrate metabolism and $\beta$-adrenergic mediated fat oxidation in weight-reduced obese men.

Methods: Preceding this part of the study subjects lost IS \pm $6 \mathrm{~kg}$ of body weight by energy restriction with or without low intensity exercise training. Twenty nine subjects (diet group $n=15$; diet + exercise group $n=14$ ) participated in the follow-up study of 40 weeks in which the former diet + exercise group continued their exercise training program. Pre-and post follow-up, measurements of body weight, body composition, maximal aerobic capacity and substrate oxidation during rest, exercise and recovery with or without infusion of the $\beta$-adrenergic antagonist propranolol (PRP) were performed.

Results: Over the follow-up period, body weight, fat mass and fat free mass increased in both groups $(P<0.00 o I)$, witbout differences between groups.

Attendance at exercise training sessions was negatively correlated with regain of body weight $(r=0.6, P<0.05)$.

Relative fat oxidation and energy expenditure and $\beta$-adrenergic mediated fat oxidation during rest, exercise and recovery were maintained over the follow-up period in botb groups. 
Conclusions: Continuation of low intensity exercise training after weight reduction did not limit regain of body weight, unless exercise training was frequently performed. Relative ( $\beta$-adrenergic mediated) fat oxidation and energy expenditure were maintained at post-diet level in both groups.

\section{Introduction}

The prevalence of obesity is increasing in the United States (8) and Europe (18). Obesity is identified nowadays as a serious health problem which can be treated by energy restriction. Although energy restriction programs are successful on short term, on long term there is a great risk for body weight regain $(5,7,19,24)$. Addition of exercise training is suggested to be the cornerstone for long term weight maintenance $(9,13)$. Although several studies have shown that addition of exercise training during and after energy restriction limits the regain of body weight on long term compared to energy restriction only $(3,24)$, others found no difference in body weight regain between the diet only and diet plus exercise group $(4,7,10,11$, 26). The decreased fat oxidation accompanying a decrease in fat mass due to weight loss $(10,17)$ is suggested to be involved in the regain of body weight after weight loss $(1,15)$. In a first report on the present study we have shown that low intensity exercise training (exercise intensity $40 \% \mathrm{VO}_{2} \max , 3-4$ times per week for 12 weeks) in combination with a VLCD (Very Low Calorie Dier; $2 \mathrm{MJ} /$ day) (DE group) resulted in a weight loss of $15 \pm 6 \mathrm{~kg}$ after 12 weeks, which did not differ from the weight loss in the group only receiving VLCD (D group) (23). After body weight had stabilized, respiratory exchange ratio (RER) was higher in the $\mathrm{D}$ group than in the DE group in fasting conditions $(\Delta 0.04 \pm 0.05 ; \mathrm{P}<0.05)$, after $45 \mathrm{~min}$ exercise at $50 \% \mathrm{VO}_{2} \max (\Delta 0.03 \pm 0.07 ; \mathrm{NS})$ and after $15 \mathrm{~min}$ recovery $(\Delta 0.05 \pm 0.04 ; \mathrm{P}<0.001)$. Another study reported similar results for RER at rest after 6 months of low intensity exercise training and energy restriction (10). In addition, in our study some evidence was found for a role of the sympathetic nervous system in preventing the decline in fat oxidation by low intensity exercise training (unpublished data). Although low intensity exercise training added to a VLCD period did not result in increased weight loss within 12 weeks, maintenance of a lower RER can be hypothesized to prevent or limit long term weight regain. Therefore, this part of the study investigated the effect of continuation of the low intensity 
exercise training program for 40 weeks after weight loss on RER, sympatheric nervous system activity and regain of body weight or fat mass in the exercise group (former DE group) and compared it with changes in the control group (former $\mathrm{D}$ group) who did not follow this training program.

\section{Metbods}

\section{Subjects}

Thirty seven obese male subjects (BMI $>27 \mathrm{~kg} \cdot \mathrm{m}^{-2}$ ) participated in the present study. Baseline body weight was $103 \pm 11 \mathrm{~kg}$. All subjects participated the 12 weeks preceding this part of the study in an energy restriction program (VLCD; $2 \mathrm{MJ} /$ day) (diet period). Twenty subjects also participated in an exercise training program as described below. Results of the diet period have been reported previously. After these initial 12 weeks, subjects were followed during a period of 40 weeks (follow-up period). They were instructed to maintain body weight at the post-VLCD level. The exercise training group continued the same exercise training program.

All subjects were in good health as assessed by medical history and physical examination. At baseline none of the subjects spend more than 2 hours a week in sports activities or had a physically demanding job. They did not take medication known to influence the variables measured. Before the energy restriction program started, subjects were matched with respect to age, body mass index (BMI), fat percentage, weight and maximal oxygen uptake and randomly divided in two groups, the diet $(D)$ or diet plus exercise group (DE). The last two weeks of the diet period, subjects stabilized body weight (change during the last week $+0.17 \pm 0.96 \%(0.14 \pm 0.89$ $\mathrm{kg})$ ). On average weight loss was $15.0 \pm 5.8 \mathrm{~kg}$. The study protocol was approved by the Ethics Committee of Maastricht University. Written informed consent was obtained from all subjects.

In this part of the study, subjects in the former $\mathrm{D}$ group form the control group $(C)$ and subjects in the former $\mathrm{DE}$ group form the exercise group (E). Two subjects from the control group did not participate in the measurements after the follow-up period (due to lack of motivation). In the exercise group 6 subjects did not participate in the final measurements ( 3 due to illness ( 2 knee injuries not related to the training program; 1 nephritis) and 3 due to lack of motivation). Subject characteristics of the remaining study population are shown in Table 6.1. 
Table 6.1 Subject characteristics at baseline, post-diet and the change during the follow-up period of $\mathbf{4 0}$ weeks in the control and exercise group.

\begin{tabular}{|c|c|c|c|c|c|c|}
\hline & \multicolumn{3}{|l|}{ Control group } & \multicolumn{3}{|l|}{ Exercise group } \\
\hline & baseline & $\begin{array}{l}\text { post-dier } \\
(\mathrm{n}=15)\end{array}$ & $\begin{array}{l}\Delta \text { follow-up } \\
(n=15)\end{array}$ & baseline & $\begin{array}{l}\text { post-diet } \\
(n=14)\end{array}$ & $\begin{array}{l}\Delta \text { follow-up } \\
(n=14)\end{array}$ \\
\hline Age $(y r)$ & & $38.6 \pm 6.5$ & & & $39.3 \pm 7.7$ & \\
\hline Body weight $(\mathrm{kg})$ & $103.6 \pm 11.7$ & $88.2 \pm 9.6$ & $7.1 \pm 4.6$ & $102.6 \pm 9.8$ & $87.8 \pm 7.1$ & $8.9 \pm 4.3$ \\
\hline BMI $\left(\mathrm{kg}_{\mathrm{g}} \cdot \mathrm{m}^{-2}\right)$ & $32.0 \pm 2.2$ & $27.3 \pm 1.8$ & $2.3 \pm 1.5$ & $32.1 \pm 2.6$ & $27.5 \pm 2.2$ & $2.8 \pm 1.4$ \\
\hline Body fat (\%) & $34.1 \pm 4.4$ & $24.9 \pm 5.1$ & $3.5 \pm 2.6$ & $32.7 \pm 3.8$ & $23.8 \pm 4.1$ & $3.9 \pm 4.2$ \\
\hline Fat free mass (FFM) $(\mathrm{kg}$ ) & $68.3 \pm 9.6$ & $66.2 \pm 8.5$ & $1.8 \pm 2.1$ & $68.9 \pm 5.8$ & $66.8 \pm 5.1$ & $2.8 \pm 1.4$ \\
\hline Far mass $(\mathrm{kg})$ & $35.2 \pm 5.6$ & $22.0 \pm 5.1$ & $5.3 \pm 3.5$ & $33.7 \pm 6.2$ & $21.0 \pm 4.5$ & $6.0 \pm 5.0$ \\
\hline $\mathrm{VO}_{2} \max \left(\mathrm{ml} \cdot \mathrm{min}^{-1}\right)$ & $3025 \pm 370$ & $2962 \pm 398$ & $109 \pm 305$ & $3011 \pm 441$ & $2950 \pm 367$ & $246 \pm 233$ \\
\hline $\mathrm{VO}_{2} \max / \mathrm{FFM}$ & $44.7 \pm 5.5$ & $45.1 \pm 6.3$ & $0.1 \pm 5.1$ & $43.7 \pm 5.1$ & $44.2 \pm 3.9$ & $1.8 \pm 3.4$ \\
\hline
\end{tabular}

Data are expressed as means $\pm \mathrm{SD}$

\section{$\underline{\text { Experimental design }}$}

In the follow-up period subjects in the exercise group continued their low intensity exercise training program. Body weight was measured in both groups every two weeks. Before and after the follow-up period, measurements of body composition, maximal aerobic capacity, energy and substrate metabolism at rest and during exercise with and without administration of a non-selective $B$-adrenergic antagonist were performed in both groups.

\section{$\underline{\text { Exercise training }}$}

Twenty subjects participated in an exercise training program during the follow-up period of 40 weeks (exercise group (E)). The subjects in the control group $(\mathrm{C})$ were instructed not to change their habitual activity pattern over this period. The subjects in the exercise group trained 4 times one hour per week, 3 times at the laboratory under supervision of a professional trainer and once at home. The exercise training program consisted of cycling on an ergometer (Bodyguard Cardiocycle, Sandnes, Norway or Excalibur, Lode, Groningen, The Netherlands), walking and aqua jogging. All exercises were executed at a low intensity ( $\left.40 \% \mathrm{VO}_{2} \mathrm{max}\right)$.

Every three months a maximal aerobic capacity test was performed and 
exercise intensity was corrected if necessary. Heart rate corresponding to $40 \% \mathrm{VO}_{2} \max$ was determined from these tests and was used as the training heart rate. Heart rate was monitored continuously during the training sessions (Polar Electro, Oy, Finland). Subjects attendance at the training sessions was recorded and the trainer inquired for the extra exercise at home regularly.

\section{Measurements}

1. Body composition

Body weight was measured on a digital balance accurate to $0.1 \mathrm{~kg}$ (Sauter D-7470, Ebingen, Germany). Height was measured to the nearest $0.1 \mathrm{~cm}$ using a wall-mounted stadiometer (Seca, model 220, Hamburg, Germany). BMI was calculated from weight and height $\left(\mathrm{kg} / \mathrm{m}^{2}\right)$. Body density was measured by hydrostatic weighing, with a correction for residual lung volume estimated by helium dilution with a spirometer (Volugraph 2000, Mijnhardt, The Netherlands) at the moment of under water weighing. Body composition was calculated according to the formula of Siri (20).

2. Maximal aerobic capacity

Maximal oxygen uptake ( $\left.\mathrm{VO}_{2} \mathrm{max}\right)$ for each subject was determined by an incremental cycling exercise test on an electromagnetically braked cycle ergometer (Excalibur, Lode, Groningen, The Netherlands). After a warming up period of 5 minutes at 80 Watt, workload was increased every 4 minutes by 40 Watt until exhaustion. During the experiment ventilatory and gas exchange responses were measured continuously, using indirect calorimetry (Oxycon B, Mijnhardt, Bunnik, The Netherlands). Heart rate was recorded continuously by electrocardiography. The highest oxygen uptakeover $30 \mathrm{sec}$ achieved was taken as $\mathrm{VO}_{2} \max$.

3. Physical activity

Habitual physical activity was estimated by the Baecke questionnaire (2) which is subdivided into physical activity at work, sport during leisure time and physical activity during leisure time excluding sport. 


\section{Energy and substrate metabolism}

Energy and substrate metabolism at rest and during exercise was determined at the beginning and the end of the 40 week follow-up period.

Experiments were performed $36-65 \mathrm{~h}$ after the last exercise bout in a room with a temperature between 23 and $25^{\circ} \mathrm{C}$. After an overnight fast, subjects came to the laboratory by car or public transport to minimize physical activity. A catheter was inserted in an arm vein for blood sampling. Subjects remained in semi-supine position on a bed for 30 minutes and subsequently cycled on an ergometer (Excalibur, Lode, Groningen, The Netherlands) for 45 minutes at $50 \%$ of $\mathrm{VO}_{2} \max$, determined by a maximal aerobic capacity test before the weight reduction period. Absolute workload were kept the same in the pre- and post-follow-up test and was $89 \pm 11 \mathrm{~W}$ in the $\mathrm{C}$ group and $92 \pm 17 \mathrm{~W}$ in the $\mathrm{E}$ group. After cycling subjects recovered in semi-supine position on a bed for 15 minutes. During the experiment $\mathrm{CO}_{2}$ production, $\mathrm{O}_{2}$ consumption, respiratory exchange ratio (RER) were determined by an open circuit ventilated hood system at rest and recovery (Oxycon $B$, Mijnhardt, Bunnik, The Netherlands). During exercise a mouthpiece was used and for subjects' convenience measurements were only conducted from $t=10-15,25-30$ and 40-45 min. Energy expenditure was calculated according to the formula of Weir (25). The accuracy of the system for measurements of $\mathrm{CO}_{2}$ production and $\mathrm{O}_{2}$ consumption was tested regularly to be within $5 \%$. During the experiment heart rate was recorded continuously by electrocardiography. Blood was sampled after 30 minutes of rest $(t=0)$, after $5,15,30$ and 45 minutes cycling and after 15 minutes recovery. The sample was divided into EDTA or $300 \mu$ glutathion $(45 \mu \mathrm{g} / \mathrm{l}$ saline) plus heparin containing chilled $10 \mathrm{ml}$ tubes and immediately centrifuged at $800 \mathrm{x} \mathrm{g}$ for $10 \mathrm{~min}$ at $4{ }^{\circ} \mathrm{C}$. Plasma was stored at $-80^{\circ} \mathrm{C}$ until analyses. The EDTA containing blood was used for analyses of plasma glucose, FFA, insulin, glycerol and lactate concentrations. The heparin and glutathion containing blood was used for analyses of plasma epinephrine and norepinephrine concentrations.

\section{$\underline{\beta \text {-adrenoceptor-mediated energy and substrate metabolism }}$}

The same experiment as described above was conducted on another day with infusion of the non-selective $B$-antagonist propranolol (PRP) (Zeneca B.V., Ridderkerk, The Netherlands). An extra catheter was inserted in a 
vein of the contralateral arm for propranolol infusion. Propranolol was infused by a Harvard syringe pump in a dose of $0.71 \mu \mathrm{g} . \mathrm{kg}$ fat free mass ${ }^{-1}$. $\mathrm{min}^{-1}$ with a prime of $229.4 \mathrm{\mu g} / \mathrm{kg}$ fat free mass which was administered in at least $10 \mathrm{~min}$. During the experiment blood pressure was measured every 10 minutes and heart rate continuously by electrocardiography. Infusion was stopped when heart rate had reached 45 beats $/ \mathrm{min}$. The test with and without PRP infusion were performed in random order.

\section{Biochemical analysis}

Plasma concentrations of FFA (NEFA C kit; Wako Chemicals, Neuss, Germany), glucose (GLUC HK kit; Hoffmann-La Roche, Basel, Switzerland), glycerol (Glycerol kit; Boehringer, Mannheim, Germany) and lactate (6) were measured on a COBAS FARA centrifugal spectrophotometer (Roche Diagnostica, Basel, Switzerland). Plasma insulin concentrations were measured with a double-antibody radio-immunoassay (Insulin RIA 100; Pharmacia, Uppsala, Sweden). Plasma epinephrine and norepinephrine concentrations for the test without PRP infusion were analyzed by HPLC with electrochemical detection (21).

\section{Statistics}

Data are expressed as means \pm SD. Since fat free mass increased significantly over the follow-up period in both groups, data on energy expenditure were corrected for individual changes in fat free mass according to the method described by Ravussin et al. (14). Subject characteristics at the beginning of the follow-up period were tested for differences between groups with an unpaired t-test. Changes in subject characteristics over the follow-up period were tested with a two-way repeated-measurement ANOVA (time $\mathrm{x}$ group). Pearson correlations were calculated in the exercise group between training hours and regain of body weight. Values measured before and after followup of the rest, exercise and recovery period within the control and exercise group were compared by a two-way repeated-measurement ANOVA (time and time $\mathrm{x}$ condition). Post-hoc testing was done by a paired-t-test over the rest, exercise (mean $t=15,30$ and 45 ) and recovery period. P-values of the post-hoc comparisons were corrected according to Bonferroni inequalities. Measurements of RER, energy expenditure and plasma variables before the 
follow-up period between groups were tested by a two-way repeatedmeasurement ANOVA (group and group x condition). In order to compare the effects of exercise training on the measured parameters, changes over the follow-up period were calculated for the rest, exercise (average $t=15,30$ and 45) and recovery period. A two-way repeated-measurement ANOVA was used to test differences between the control and exercise group (group and group $\mathrm{x}$ condition). Areas under the curve (AUC) of the RER versus time graph were calculated and differences between groups were tested by a two-way repeated-measurement ANOVA (time and time $\mathrm{x}$ group). A P value $<0.05$ was regarded as statistically significant.

\section{Results}

\section{$\underline{\text { Subject characteristics }}$}

At the end of the diet period, subject characteristics were not significantly different between groups. Over the follow-up period, body weight, BMI, fat percentage, fat mass and fat free mass increased significantly in both groups without differences between groups (2-way ANOVA; group NS, time $\mathrm{P}<0.0001$, time $\mathrm{x}$ group $\mathrm{NS}$ ). $\mathrm{VO}_{2} \max$ increased significantly over the follow-up period without differences between groups (2-way ANOVA; group NS, time $\mathrm{P}<0.01$, time $\mathrm{x}$ group $\mathrm{NS}$ ). $\mathrm{VO}_{2} \mathrm{max} / \mathrm{FFM}$ did not change over the follow-up period (Table 6.1).

Subjects in the exercise group attended $57 \pm 20 \%$ of the exercise sessions at the laboratory during the follow-up period ( 4 subjects attended $>75 \%$ and 1 subject attended $<25 \%$ of the training sessions). Causes for absence at exercise training sessions were illness, holidays and work responsibilities. Subjects who could not attend a training session at the laboratory due to work responsibilities reported to exercise at home during one hour. They received a heart rate monitor in order to check training intensity by themselves. Since we could not check whether subjects trained at home or not, training sessions at home were not registered. Energy expenditure per training session was estimated to be $1.5 \pm 0.2 \mathrm{MJ}$. Attendance at exercise training sessions was negatively correlated with regain of body weight $(\mathrm{r}=0.6 ; \mathrm{P}<0.05$; regain $(\mathrm{kg})=-0.1 *$ exercise training during follow-up $(h)+15.8)$. The score for sport activity during leisure time (including exercise training at laboratory in the E group) derived from the Baecke Questionnaire was significantly higher in the E group compared to the 
C group and did not change over the follow-up period (2-way ANOVA; group $\mathrm{P}<0.01$, time NS, group $\mathrm{x}$ time NS) (changed from $2.29 \pm 0.55$ to $2.25 \pm 0.59$ in the $C$ group and from $2.98 \pm 0.68$ to $3.09 \pm 0.80$ in the $E$ group). Physical activity during leisure time excluding sport was not different between groups and did not change over the follow-up period in both groups (changed from $2.59 \pm 0.46$ to $2.64 \pm 0.53$ in the $C$ group and from $2.95 \pm 0.75$ to $3.16 \pm 0.67$ in the $\mathrm{E}$ group).

Effects of exercise training during follow-up on energy and substrate metabolism

At the beginning of the follow-up period, energy expenditure adjusted for differences in fat free mass (EE adj FFM) and respiratory exchange ratio (RER) were not significantly different between the control and exercise group. EE adj FFM and RER did not change over the follow-up period in the $\mathrm{C}$ and $\mathrm{E}$ group and changes were not significantly different between the groups (Figure 6.1 and 6.2 respectively).
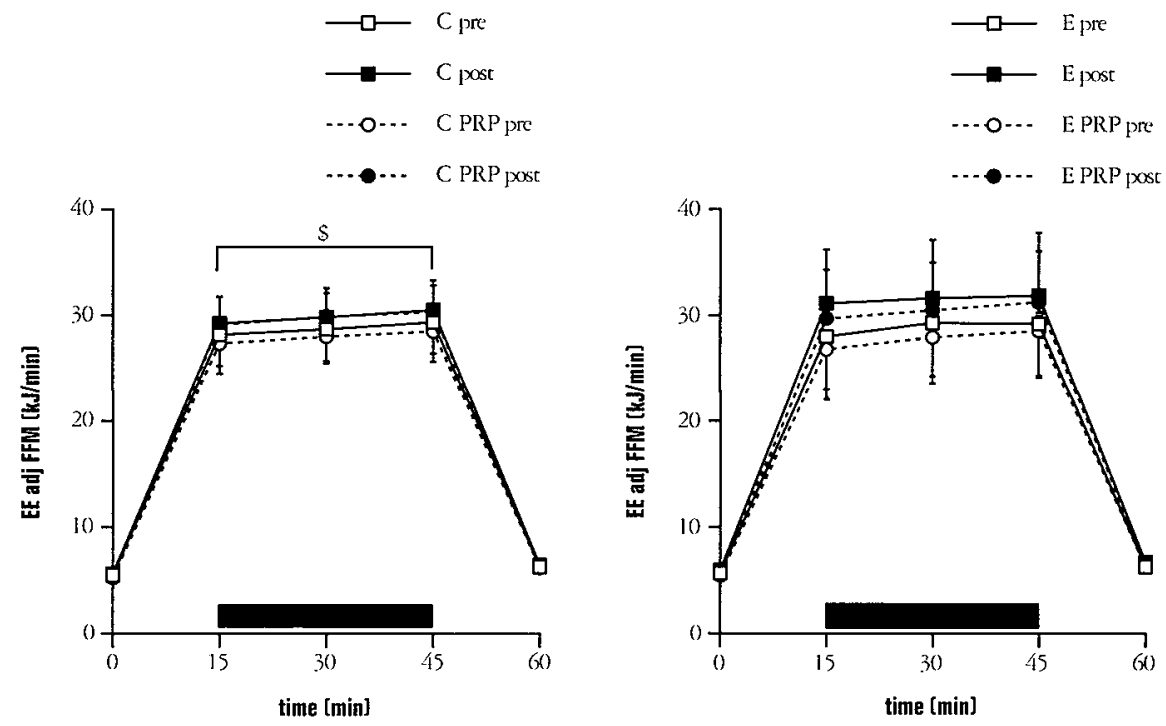

Figure 6.1 Energy expenditure [EE] [kJ/min] adjusted for changes in FFM in the control [C] and exercise [E] group pre and post follow-up, at rest $[t=0]$, during exercise $[t=15-45$; black bar] and recovery [t=60] with propranolol [PRP] and without PRP administration. Test with PRP: $C$ group: 2-way ANOVA; time $P<0.05$, time $x$ condition $P<0.05$ $\$$ intervention effect: post-PRP test significantly different from pre-PRP test $P<0.05$ [average $t=15,30$ and 45 ] 


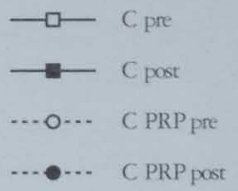

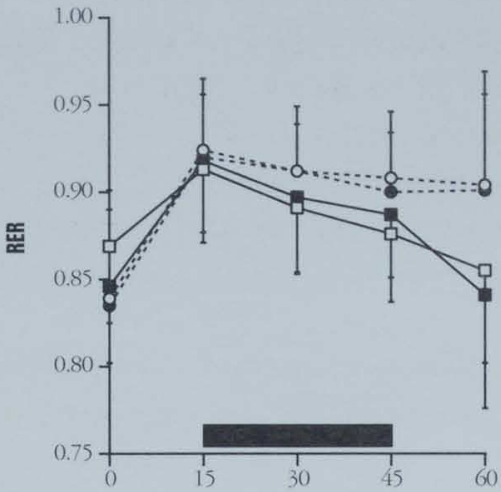

time [min]

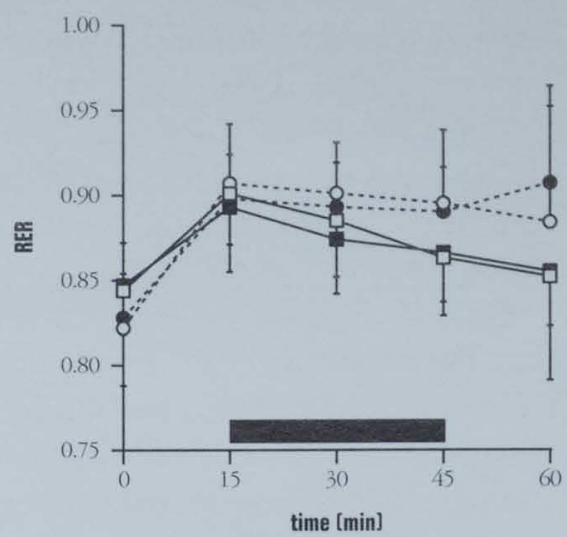

Figure 6.2 Respiratory exchange ratio [RER] in the control [C] and exercise [E] group pre and post follow-up, at rest $[\mathrm{t}=0]$, during exercise $[\mathrm{t}=15-45$; black bar] and recovery $[\mathrm{t}=60]$ with propranolol $[\mathrm{PRP}]$ and without PRP administration. Post follow-up test with PRP different from test without PRP: E group: 2-way ANOVA; time P<0.05, time $x$ condition $\mathrm{P}<0.0001$.

RER without PRP infusion

C

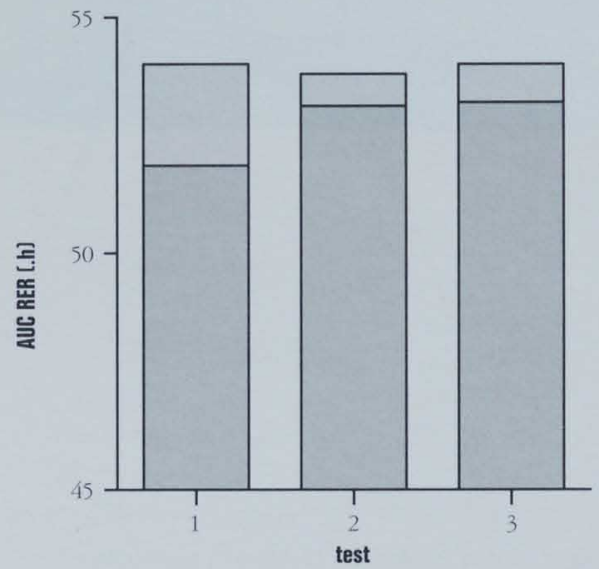

E

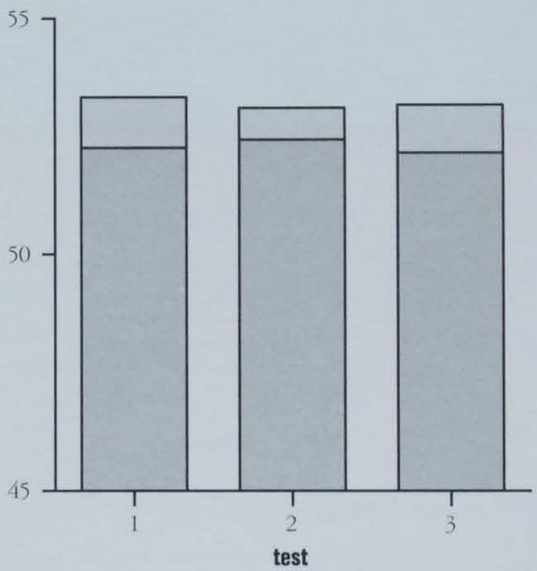

Figure 6.3 Area under the curve [AUC] for RER [.h] in the control [C] and exercise [E] group at baseline [1], pre follow-up [post-diet] [2] and post follow-up [3] with and without propranolol [PRP] administration. 
AUC of RER was not different after the follow-up period from before in both groups (Figure 6.3). However, RER after follow-up in the $\mathrm{C}$ group tended to be higher than baseline (2-way ANOVA; time $\mathrm{P}=0.09$, time $\mathrm{x}$ condition NS). Heart rates at rest, exercise and recovery were $62 \pm 7,120 \pm 16$ and $75 \pm 10$ beats/min in the $C$ group and $60 \pm 7,111 \pm 9$ and $68 \pm 10$ beats/min in the E group pre-follow-up (NS between groups). During the follow-up period, heart rates did not change in both groups. Pre-follow-up, plasma concentrations of FFA, glucose, glycerol, insulin, epinephrine and norepinephrine were not significantly different between the control and exercise group, but the lactate concentration was significantly lower in the exercise group compared to the control group (2-way ANOVA; group $\mathrm{P}=0.05$, group $\mathrm{x}$ condition $\mathrm{P}<0.05)$. Plasma concentrations of FFA, glycerol and lactate in the control (Figure 6.4A) and exercise group (Figure 6.4B) and insulin and epinephrine (Table 6.2) did not change significantly over the follow-up period.

Table 6.2 Plasma insulin [pU/ml], glucose [mmol/l], epinephrine [ng/l] [Epi], norepinephrine [ng/l] [Norepi] pre and post follow-up of 40 weeks after weight reduction in the control [C] and exercise [E] group at rest, after $\mathbf{4 5}$ min exercise and 15 min recovery.

\begin{tabular}{|c|c|c|c|c|c|c|c|}
\hline & & & rest & exercise & recovery & $\begin{array}{l}\text { 2-way ANOVA } \\
\text { time }\end{array}$ & $\begin{array}{l}\text { 2-way ANOVA } \\
\text { time } x \text { condition }\end{array}$ \\
\hline \multirow[t]{2}{*}{ insulin } & $\varepsilon$ & $\begin{array}{l}\text { pre } \\
\text { post }\end{array}$ & $\begin{array}{l}8.9 \pm 2.5 \\
9.6 \pm 4.5\end{array}$ & $\begin{array}{l}7.5 \pm 2.5 \\
6.6 \pm 2.0\end{array}$ & $\begin{array}{l}9.7 \pm 2.8 \\
11.0 \pm 4.9\end{array}$ & NS & NS \\
\hline & $\mathbf{E}$ & $\begin{array}{l}\text { pre } \\
\text { post }\end{array}$ & $\begin{array}{l}9.0 \pm 4.2 \\
10.8 \pm 4.6\end{array}$ & $\begin{array}{l}6.9 \pm 3.2 \\
8.0 \pm 2.7\end{array}$ & $\begin{array}{l}10.3 \pm 4.7 \\
12.5 \pm 5.3\end{array}$ & NS & NS \\
\hline \multirow[t]{2}{*}{ glucose } & C & $\begin{array}{l}\text { pre } \\
\text { post }\end{array}$ & $\begin{array}{l}5.11 \pm 0.42 \\
5.27 \pm 0.43\end{array}$ & $\begin{array}{l}4.78 \pm 0.38 \\
4.91 \pm 0.42\end{array}$ & $\begin{array}{l}4.80 \pm 0.65 \\
5.09 \pm 0.44\end{array}$ & NS & NS \\
\hline & $\mathbf{E}$ & $\begin{array}{l}\text { pre } \\
\text { pose }\end{array}$ & $\begin{array}{l}5.05 \pm 0.34 \\
5.17 \pm 0.39\end{array}$ & $\begin{array}{l}4.75 \pm 0.34 \\
4.99 \pm 0.32\end{array}$ & $\begin{array}{l}4.91 \pm 0.39 \\
5.15 \pm 0.40\end{array}$ & $P<0.05$ & NS \\
\hline Epi & C & $\begin{array}{l}\text { pre } \\
\text { post } \\
\text { pre } \\
\text { post }\end{array}$ & $\begin{array}{l}31 \pm 21 \\
34 \pm 25 \\
29 \pm 16 \\
30 \pm 13\end{array}$ & $\begin{array}{l}93 \pm 43 \\
102 \pm 40 \\
98 \pm 42 \\
92 \pm 37\end{array}$ & $\begin{array}{l}36 \pm 17 \\
45 \pm 24 \\
36 \pm 15 \\
46 \pm 20\end{array}$ & $\begin{array}{l}\text { NS } \\
\text { NS }\end{array}$ & $\begin{array}{l}\text { NS } \\
\text { NS }\end{array}$ \\
\hline \multirow[t]{2}{*}{ Norepi } & C & $\begin{array}{l}\text { pre } \\
\text { post }\end{array}$ & $\begin{array}{l}340 \pm 126 \\
479 \pm 145 *\end{array}$ & $\begin{array}{l}901 \pm 212 \\
1254 \pm 168 *\end{array}$ & $\begin{array}{l}404 \pm 153 \\
618 \pm 1.47 \%\end{array}$ & $P<0.0(X) 1$ & $\mathrm{P}<0.01$ \\
\hline & $\mathbf{E}$ & $\begin{array}{l}\text { pre } \\
\text { post }\end{array}$ & $\begin{array}{l}356 \pm 130 \\
553 \pm 158^{*}\end{array}$ & $\begin{array}{l}746 \pm 269 \\
1183 \pm 367 *\end{array}$ & $\begin{array}{l}385 \pm 134 \\
628 \pm 268^{*}\end{array}$ & $P<0.01$ & $P<0.01$ \\
\hline
\end{tabular}

Data are expressed as means $\pm S D$

Significantly different from pre follow-up * $P \leqslant 0.001$ 
chapter 6
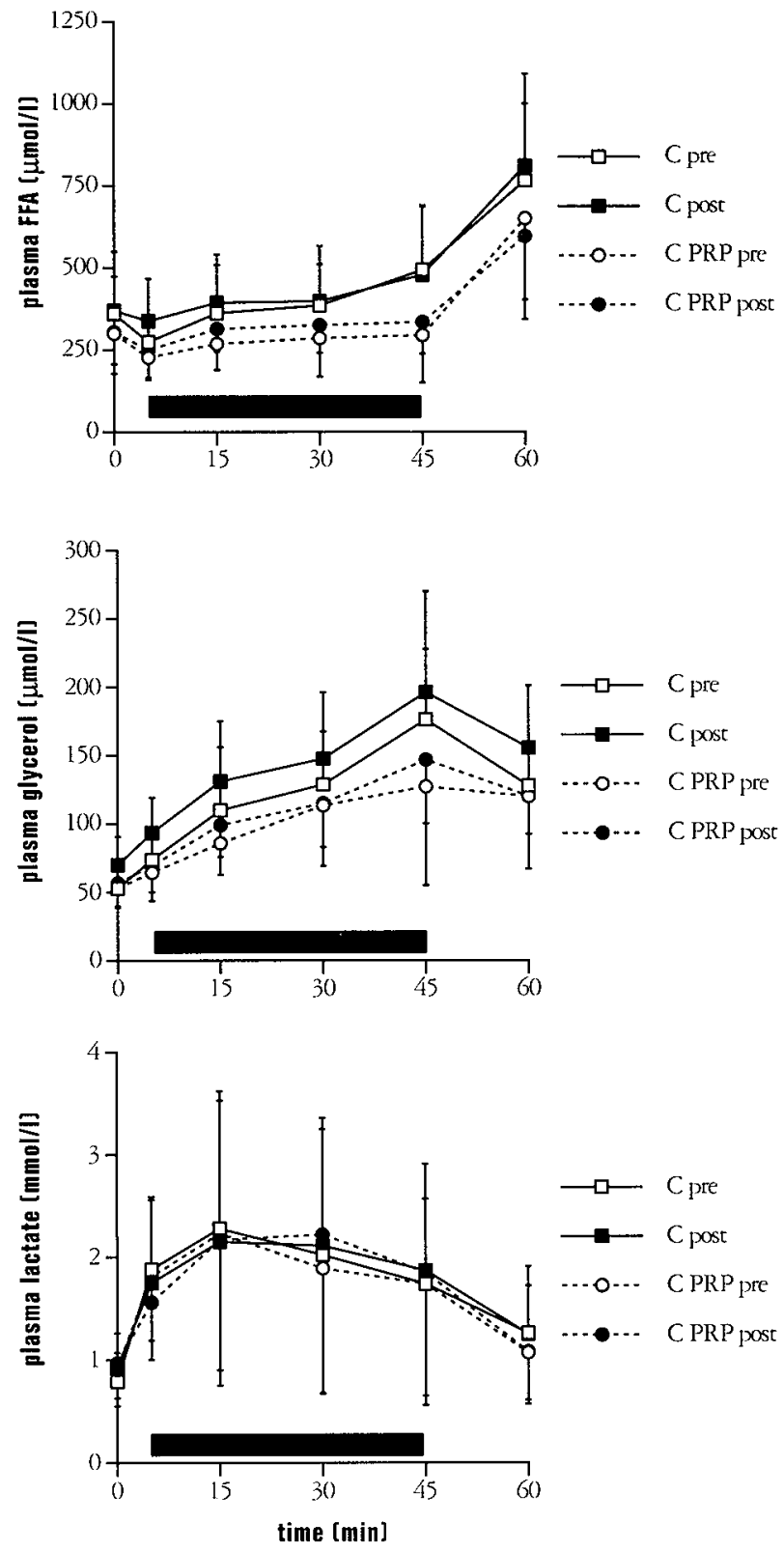

Figure 6.4 Plasma concentrations of FFA [umol/]), glycerol [umol/l] and lactate [mmol/l] in the control [C] group [A] and exercise [E] group [B] pre and post follow-up, at rest $[t=0]$, during exercise $[t=5-45$; black bar] and recovery $[t=60]$ with propranolol $[P R P]$ and without PAP administration. 

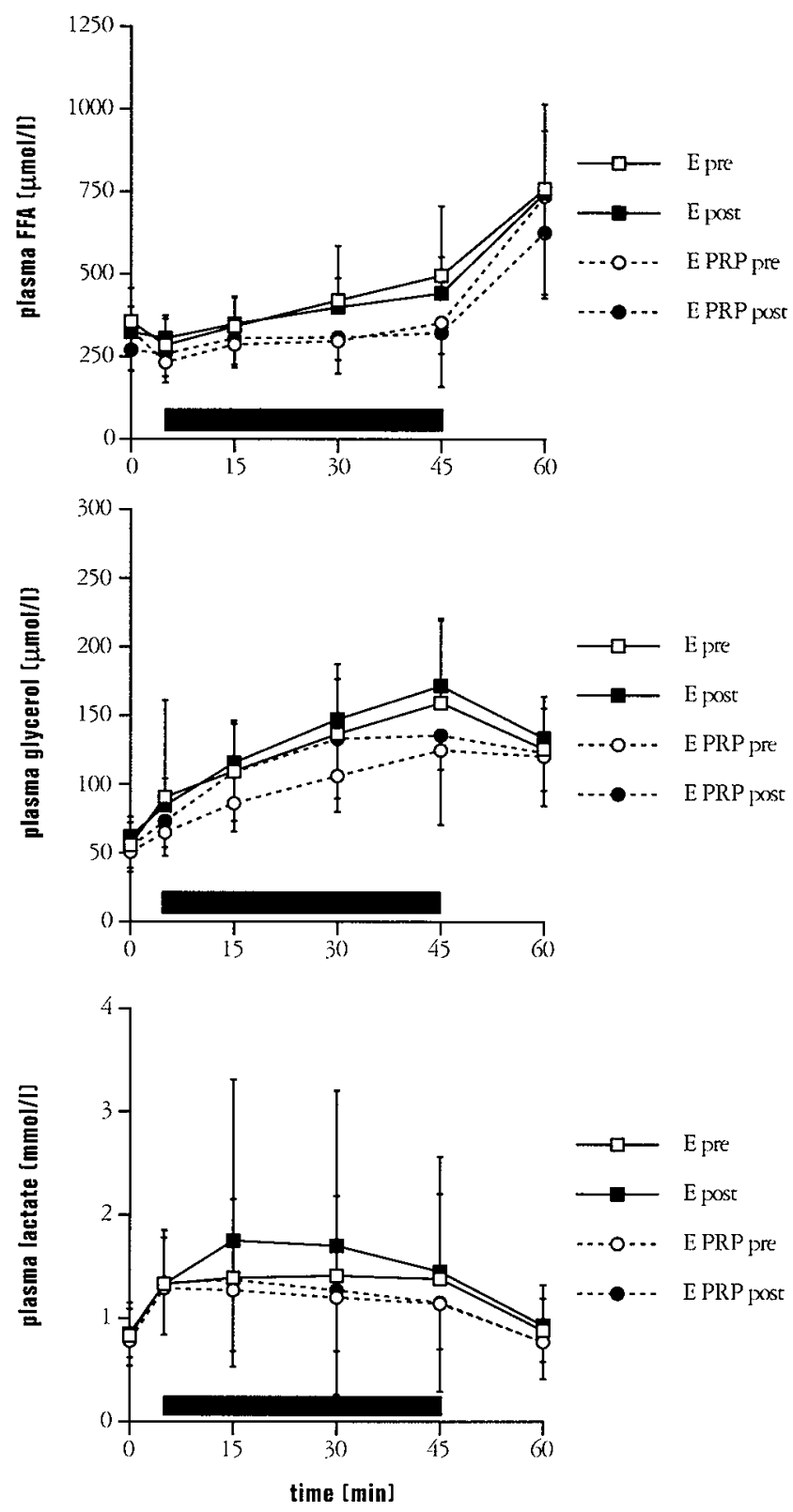

FFA: Pre follow-up test with PRP different from test without PRP: 2-way ANOVA; 6 group: time $P<0.05$, time $x$ condition NS. Post follow-up test with PRP significantly different from test without PRP: 2-way ANOVA; $\square$ group: time $P<0.05$, time $x$ condition $P<0.01 ; E$ group: time $P<0.05$, time $x$ condition NS. Glycerol: Post follow-up test with PRP significantly different from test without PRP: 2-way ANOVA; $C$ group: time $P<0.01$, time $x$ condition NS. 
Plasma glucose concentration at rest, exercise and recovery was significantly increased after the follow-up period in the exercise group (2-way ANOVA; time $\mathrm{P}<0.05$, time $\mathrm{x}$ condition NS) while the change was not statistically significant in the $\mathrm{C}$ group (Table 6.2). Plasma norepinephrine concentration increased significantly in both groups over the follow-up period during rest, exercise and recovery (2-way ANOVA; time $\mathrm{P}<0.01$, time $\mathrm{x}$ condition $\mathrm{P}<0.01$ ) (Table 6.2). None of the changes were significantly different between groups.

\section{Effects of exercise training during follow-up on $\beta$-adrenoceptor- mediated substrate metabolism}

Pre-follow-up, energy expenditure, RER, HR and measured plasma variables during PRP infusion did not differ significantly between groups. PRP infusion did not affect energy expenditure. Energy expenditure with PRP infusion was significantly higher after the follow-up period compared to before in the $\mathrm{C}$ group (2-way ANOVA; time $\mathrm{P}<0.05$, time $\mathrm{x}$ condition $\mathrm{P}<0.05$ ), but not in the $\mathrm{E}$ group (Figure 6.1). PRP infusion increased RER significantly in the $\mathrm{E}$ group after the follow-up period (2-way ANOVA; time $\mathrm{P}<0.05$, time $\mathrm{x}$ condition $\mathrm{P}<0.0001$ ) (Figure 6.2). The PRP mediated change in RER (expressed as AUC of RER) was not significantly different before and after the follow-up period in both groups (Figure 6.3). PRP infusion significantly decreased heart rate (2-way ANOVA; time $\mathrm{P}<0.001$, time $\mathrm{x}$ condition $\mathrm{P}<0.001)$ during rest, exercise and recovery in both groups $(C:-9 \pm 5,-24 \pm 11$ and $-15 \pm 7$ beats/min; E group: $-5 \pm 5,-20 \pm$ 12 and $-9 \pm 5$ beats $/ \mathrm{min}$ ) and the effect was not different after follow-up. The effect of PRP infusion on plasma FFA, glucose (data not shown), glycerol and lactate was not significantly different after compared to before follow-up (Figure 6.4A and B). PRP infusion decreased plasma FFA concentration in the $\mathrm{C}$ group before and after follow-up (2-way ANOVA; time $\mathrm{P}<0.05$ ) and in the $\mathrm{E}$ group after follow-up (2-way ANOVA; time $\mathrm{P}<0.05$ ). Plasma glycerol concentration decreased significantly in the $\mathrm{C}$ group due to PRP infusion after follow-up (2-way ANOVA; time $\mathrm{P}<0.01$ ). $\mathrm{PRP}$ infusion did not affect plasma lactate and glucose concentration. 


\section{Discussion}

The present study demonstrated that continuation of a low intensity exercise training program $\left(40 \% \mathrm{VO}_{2} \mathrm{max}\right)$ over a follow-up period of 40 weeks after weight reduction, with an average adherence rate of $57 \pm 20 \%$, did not limit body weight regain. Relative fat oxidation and energy expenditure as well as the contribution of the sympathetic nervous system to relative fat oxidation were maintained at post-diet level over the follow-up period. The present study showed that training attendance was negatively correlated with body weight regain $(r=0.6 ; \mathrm{P}<0.05)$. From the regression equation it can be predicted that if exercise training is performed three times a week as compared to once a week during the follow-up period, average body weight regain would be $4 \mathrm{~kg}$ instead of $12 \mathrm{~kg}$. This suggests that attendance at exercise training sessions is a very important factor in a better weight maintenance success. However, regain of body weight in the control group, without exercise training, was on average $7.1 \pm 4.6 \mathrm{~kg}$ over the follow-up period. This indicates that frequency of low intensity exercise training should be at least 3 times a week in order to attain meaningful differences in weight regain with non-exercising individuals.

During the follow-up period, relative fat oxidation did not change, neither in the control nor in the exercise group. Comparison of the present study with baseline (before the diet period) revealed that in the exercise group, RER at the end of the follow-up period was not different from baseline. On the contrary, in the $C$ group RER after follow-up tended to be increased compared to baseline (2-way ANOVA; time $\mathrm{P}=0.09$ ). Changes in fat mass have been shown to correlate positively with changes in fat oxidation (17). Therefore, the increase in fat mass in the control and exercise group during the follow-up period would have been expected to induce an increased fat oxidation. However, we failed to detect an increase in fat oxidation during follow-up and changes in fat oxidation did not correlate with changes in fat mass, but changes may have been too small to detect with the methods used. Continuation of exercise training during weight maintenance did not affect fat oxidation, which was also reported by Pasman et al. (12) for fasting RER. It might be suggested that the effect of exercise training on fat oxidation was already complete in the weight loss phase of the study and prevented the weight-loss-induced decrease in fat oxidation. Therefore, the most important effect of continuation of exercise training during the followup period in trained subjects might be maintenance of fat oxidation at the relatively higher pre-follow-up level compared to the control group, rather 
than a further increase in fat oxidation.

The present study also showed that the contribution of $B$-adrenergic nervous system activity to substrate oxidation was not changed over the follow-up period in both the control and exercise group. Results of the preceding diet period showed that weight reduction tended to reduce the contribution of $B$-adrenergic activity to fat oxidation but not when exercise training was added to the diet period (22). In agreement to the results on fat oxidation, the results of the present study also suggest that the effect of exercise training on $B$-adrenergic nervous system activity was completed in the weight loss phase of the study and continuation of exercise training during the follow-up period only maintained the reached effect. Data of the present study of the total group did nor indicate a role for low intensity exercise training as a cornerstone for weight maintenance on long term. This is in agreement with a study of Fogelholm et al. (4) who investigated effects of walking on weight maintenance in obese women. Even in the group who exercised 4-6 h a week (weekly energy expenditure during physical activity $7.7 \mathrm{MJ}$ ) weight maintenance was not improved compared to the non-exercising group (4). This was in contrast to a study of Ewbank et al. (3) showing that the total energy expenditure used for physical activity estimated from the Harvard Alumni Physical Activity Survey Questionnaire predicted weight loss and percentage regain. Schoeller et al. (16) also showed that the Physical Activity Index is a predictor of weight and fat gain. They showed that there is a threshold of physical activity for minimizing weight gain of $47 \mathrm{~kJ}$ per $\mathrm{kg}$ body weight per day. This threshold corresponded to $80 \mathrm{~min}$ per day of moderate-intensity physical activity or $35 \mathrm{~min}$ per day of vigorous physical activity. In the present study energy expenditure for exercise training during the follow-up period at the laboratory was $4.1 \pm$ $1.7 \mathrm{~kJ}$ per $\mathrm{kg}$ body weight per day (range $0.9-6.2 \mathrm{~kJ}$ ). This would implicate that in order to increase energy expenditure by low intensity exercise training ( $40 \% \mathrm{VO}_{2} \mathrm{max}$ ) to $47 \mathrm{~kJ}$ per $\mathrm{kg}$ body weight per day, the subjects should exercise or be physically active approximately $3 \mathrm{~h}$ per day. In conclusion the present study showed that continuation of low intensity exercise training for 40 weeks after weight reduction did not limit regain of body weight in obese men, unless exercise training was frequently performed ( $\geqslant 3$ times a week). Relative fat oxidation and energy expenditure and $B$-adrenergic mediated fat oxidation were maintained at post-diet levels whether or not low intensity exercise training was performed during followup. This might indicate that performance of low intensity exercise training after weight loss can reduce the risk to develop a positive fat balance. 


\section{References}

1. Astrup, A., B. Buemann, C. Gluud, P. Bennett, T. Tjur, and $N$. Christensen. Prognostic markers for diet-induced weight loss in obese women. Int J Obes. 19: 275-8, 1995.

2. Baecke, J. A., J. Burema, and J. E. Frijters. A short questionnaire for the measurement of habitual physical activity in epidemiological studies. Am J Clin Nutr. 36: 936-42, I982.

3. Ewbank, P. P., L. L. Darga, and C. P. Lucas. Physical activity as a predictor of weight maintenance in previously obese subjects. Obes Res. 3: 257-263, I995.

4. Fogelholm, M., K. Kukkonen-Harjula, and P. Oja. Eating control and physical activity as determinants of short-term weight maintenance after a very-low-calorie diet among obese women. Int J Obes. 23: 203-210, I999.

5. Froidevaux, F, Y. Schutz, L. Christin, and E. Jéquier. Energy expenditure in obese women before and during weight loss, after refeeding; and in the weight-relapse period. Am J Clin Nutr. 57: 35-42, 1993.

6. Gutmann, I., and $A$. W. Wablefeld. L-(+)-Lactate, determination with lactate dehudrogenase and NAD. In: Methods in enzymatic analysis (second ed.). New York: Academic press, 1974, p. 1464-1468.

7. Hensrud, D. D., R. L. Weinsier, B. E. Darnell, and G. R. Hunter. A prospective study of weight maintenance in obese subjects reduced to normal body weight without weight-loss training. Am J Clin Nutr. 60: 688-94, x994.

8. Kuczmarski, R. J., K. M. Flegal, S. M. Campbell, and C. L. Jobnson. Increasing prevalence of overweight among US adults. The National Health and Nutrition Examination Surveys, xg6o to I9gr. JAMA. 272: 205-II, 1994.

9. Miller, W. C., D. M. Koceja, and E. J. Hamilton. A meta-analysis of the past 25 years of weight loss research using diet, exercise or diet plus exercise intervention. Int J Obes. 21: 941-7, 1997.

Io. Nicklas, B. J., E. M. Rogus, and A. P. Goldberg. Exercise blunts declines in lipolysis and fat oxidation after dietary-induced weight loss in obese older women. Am J Physiol. 273: EI49-55, 1997.

II. Pasman, W. J., W. H. Saris, E. Muls, G. Vansant, and M. S. Westerterp Plantenga. Effect of exercise training on long-term weight maintenance in weight-reduced men. Metabolism 48: 15-21, 1999.

12. Pasman, W. J., M. S. Westerterp-Plantenga, and W. H. M. Saris. The effect of body weight changes and endurance training on $24 \mathrm{~h}$ substrate 
oxidation. Int J Obes. 23: 1223-I232, 1999.

13. Pronk, N. P., and R. R. Wing. Physical activity and long-term maintenance of weight loss. Obes Res. 2: 587-599, 1994.

14. Ravussin, E., and C. Bogardus. Relationship of genetics, age, and physical fitness to daily energy expenditure and fuel utilization. Am J Clin Nutr. 49: $968-75,1989$.

15. Ravussin, E., and B. A. Swinburn. Metabolic predictors of obesity: cross-

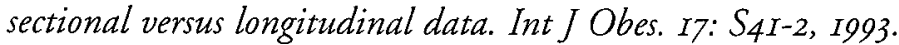

16. Schoeller, D. A., K. Shay, and R. F. Fushner. How much physical activity is needed to minimize weight gain in previously obese women? Am J Clin Nutr. 66: 551-556, I997.

17. Schutz, Y., A. Tremblay, R. L. Weinsier, and K. M. Nelson. Role of fat oxidation in the long-term stabilization of body weight in obese women. Am J Clin Nutr. 55: 670-4, 1992.

18. Seidell, J. C. Obesity in Europe. Obes Res. 3: 89s-93s, I995.

19. Sikand, G., A. Kondo, J. P. Foreyt, P. H. Jones, and A. M. Gotto, Jr. Two-year follow-up of patients treated with a very-low-calorie diet and exercise training. I Am Diet Assoc. 88: 487-8, 1988 .

20. Siri, W. E. The gross composition of the body. Adv Biol Med Physiol. 4: 239-280, 2956 .

2I. Smedes, F, J. C. Kraak, and H. Poppe. Simple and fast solvent extraction system for selective and quantitative isolation of adrenaline, noradrenaline and dopamine from plasma and urine. J Chromatogr. 23I: 25-39, 1982.

22. Van Aggel-Leijssen, D. P., W. M. Saris, G. B. Hul, and M. A. Van Baak. Short term effects of weight loss with or without low intensity exercise training on fat metabolism in obese men. Am J Clin Nutr. [submitted].

23. Van Aggel-Leijssen, D. P. C., W. H. W. Saris, and M. A. Van Baak. Effects of VLCD and low intensity exercise training on fat oxidation in obese men [abstract]. Med Sci Sports Exerc. 3I: S340, I9g9.

24. Van Dale, D., W. H. Saris, and F. ten Hoor. Weight maintenance and resting metabolic rate $18-40$ months after a dietlexercise treatment. Int J Obes. 14: 347-59, 1990.

25. Weir, J. B. New methods for calculating metabolic rate with special reference to protein metabolism. J Physiol. I09: I-9, x949.

26. Wood, P. D., M. L. Stefanick, P. D. Williams, and W. L. Haskell. The effects on plasma lipoproteins of a prudent weight-reducing diet with or without exercise, in overweight men and women. $N$ Engl J Med. 325: $46 x-466$, I99I. 


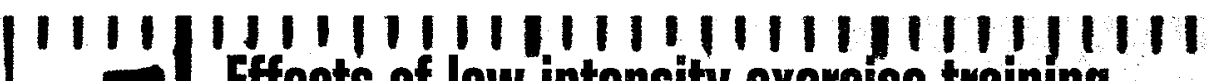 Effects of low intensity exercise training on weight maintenance and cardiovascular risk factors in obese men}

Dorien P.C. van Aggel-Leijssen, ElisabethJ. Balkestein,

Wim H.M. Saris, Luc M. van Bortel and Marleen A. van Baak

Submitted Medicine and Science in Sports and Exercise

\section{Abstract}

Objective: To investigate the effect of low intensity exercise training during weight reduction and follow-up on body weight and cardiovascular risk profile in obese men. Metbods: Twenty-nine obese men participated in this pairmatched randomized intervention study. An energy restriction period of 12 weeks was followed by a weight maintenance period of 40 weeks. Over the total period, fourteen subjects participated in a low intensity exercise training program. Measurements of body composition, body weight, waist-to-bip ratio (WHR) blood pressure and maximal aerobic capacity were performed before the intervention, after weight loss and follow-up. Fasting serum total, LDL and HDL cholesterol, triglycerides and plasma insulin and glucose concentrations were determined. Vessel wall properties of the brachial (BA) and carotid artery (CCA) were assessed using a vessel wall movement detector system combined with applanation tonometry.

Results: Body weight, body composition, systolic blood pressure, WHR, insulin/glucose ratio and serum lipid concentrations improved with weight reduction $(P<0.05)$ and were still improved at the end of the follow-up $(P<0.05)$, except for serum lipids. Weight loss did not affect vessel wall properties, but during follow-up, isobaric crosssectional compliance (isoCC), CC and distensibility 
coefficient (DC) of the BA increased. After one year, vessel wall properties of the $B A$ and $C C A$ were not different from before. Exercise training during and after weight loss did not positively affect any of these changes. Conchusions: Long-term weight loss improved fat distribution, SBP and insulin/glucose ratio, but did not affect vessel wall properties and serum lipids. Low intensity exercise training bad no additional effect on these parameters.

\section{Introduction}

The prevalence of obesity has increased in the United States (1) as well as in Europe (45) over the last decades. An increase in body weight is directly associated with an increase in mortality from all causes (36). The risk for cardiovascular disease is 3.3 fold increased in subjects with a body mass index (BMI) above $29 \mathrm{~kg} / \mathrm{m}^{2}$ compared to those with a BMI of less than $21 \mathrm{~kg} / \mathrm{m}^{2}(35)$. Besides total body fat mass, abdominal fat is positively associated with risk for cardiovascular diseases (9). Hyperlipidemia and hypertension are important components in this increased risk (5). In addition, large artery compliance may play a role (16). In normotensive obese subjects a similarly reduced compliance is found as in lean subjects with mild essential hypertension (34). Furthermore, obese subjects are reported to have a decreased distensibility of muscular, but not elastic, large arteries compared to lean subjects (47). Obesity is associated with a diminished insulin sensitivity in peripheral tissues (4), which is also a risk factor for cardiovascular disease.

In order to diminish the risk for cardiovascular disease, it is important to accomplish long-term body weight loss in the obese. Exercise training during and after energy restriction is one of the best predictors of longterm success of weight loss $(37,43,55)$. Several studies showed that weight loss combined with exercise training limited long-term body weight regain $(11,24,51)$. However, other studies failed to show an effect of additional exercise training on body weight changes (14, 52).

Long term weight loss combined with moderate or high inrensity exercise training is known to decrease serum total cholesterol and LDL concentration $(24,27)$ and increase serum HDL concentrations $(27,56)$. Furthermore, weight loss combined with exercise training has been reported to induce a decrease in blood pressure $(24,38)$. Weight loss increases vascular compliance 
of large vessels $(48,57)$, but a decrease in blood pressure rather than structural changes in the vessels might explain this effect. On short term, high intensity exercise training may have a positive effect on vascular compliance in lean subjects (6), but effects in obese subjects have not been reported so far. Long-term weight loss with exercise training has been shown to improve insulin sensitivity in an oral glucose tolerance test $(27,52)$. All above mentioned studies on the effect of weight loss combined with exercise training on cardiovascular risk factors used moderate to high intensity exercise training. However, in obese subjects low intensity exercise training may be preferable to high intensity exercise training, because of a lower risk of musculoskeletal injuries and better adherence (42). The present study aimed to investigate whether low intensity exercise training during and after energy restriction limits regain of body weight and affects cardiovascular risk factors, such as large artery compliance, blood pressure, serum cholesterol concentrations and plasma insulin and glucose concentrations.

\section{Methods}

\section{Subjects}

Forty obese male subjects $\left(\mathrm{BMI}>27 \mathrm{~kg} \cdot \mathrm{m}^{-2}\right)$, recruited by an advertisement in a local newspaper, participated in the present study. All subjects were in good health as assessed by medical history and physical examination and had no cardiovascular disorders (diastolic blood pressure $(D B P) \leqslant 95 \mathrm{~mm}$ $\mathrm{Hg}$ and systolic blood pressure (SBP) $\leqslant 145 \mathrm{mmHg}$ ). The subjects did not spend more than 2 hours a week in sports activities and had no physically demanding job. Subjects had a stable body weight over the last 3 months $(<3 \mathrm{~kg}$ change) and did not receive medication known to influence the variables measured. Subjects were matched with respect to age, BMI, fat percentage, weight and maximal oxygen uptake and randomly divided in two groups, the diet (D) or diet+exercise group (DE).

The study protocol was approved by the Ethics Committee of Maastricht University. Written informed consent was obtained from all subjects. Three subjects in the $\mathrm{D}$ group did not complete the weight loss intervention of 12 weeks ( 1 due to illness (enteritis) and 2 due to lack of motivation). Another 2 subjects in the $\mathrm{D}$ group did not participate in the final measurements after one year (due to lack of motivation). In the DE 
group 6 subjects did not participate in the final measurements $(3$ due to lack of motivation and 3 due to illness; 2 had knee injuries not related to the intervention and 1 had nephritis). Subject characteristics of the remaining study population are shown in Table 7.1.

Table 7.1 Subject characteristics before (week 0 ] and 12 weeks after the start of the diet [D] or diet plus exercise [DE] intervention [week 13] and 52 weeks after the start of the intervention [week 53 ].

\begin{tabular}{|c|c|c|c|c|c|c|c|}
\hline \multirow{2}{*}{ week } & \multicolumn{3}{|l|}{ 0 } & \multicolumn{3}{|l|}{ DE } & \multirow{2}{*}{$\begin{array}{l}\text { ANOVA } \\
\text { Time effect }\end{array}$} \\
\hline & $O(n=15)$ & $13(n=15)$ & $53(\mathrm{n}=15)$ & $0(n=14)$ & $13(n=14)$ & $53(n=1.4)$ & \\
\hline Age (yг) & $38.6 \pm 6.5$ & & $39.3 \pm 7.7$ & & & & \\
\hline Body weight $(\mathrm{kg})$ & $103.6 \pm 11.7$ & $88.2 \pm 9.6$ & $95.3 \pm 10.5$ & $102.6 \pm 9.8$ & $87.8 \pm 7.1$ & $96.7 \pm 9.6$ & $P<0.0001 \mathrm{abc}$ \\
\hline $\mathrm{BMI}\left(\mathrm{kg} \cdot \mathrm{m}^{-2}\right)$ & $32.0 \pm 2.2$ & $27.3 \pm 1.8$ & $29.6 \pm 2.7$ & $32.1 \pm 2.6$ & $27.5 \pm 2.2$ & $30.3 \pm 3.1$ & $\mathrm{P}<0.0001 \mathrm{abc}$ \\
\hline Body fat $(\%)$ & $34.1 \pm 4.4$ & $24.9 \pm 5.1$ & $28.4 \pm 6.3$ & $32.7 \pm 3.8$ & $23.8 \pm 4.1$ & $27.7 \pm 4.4$ & $\mathrm{P}<0.0001 \mathrm{abc}$ \\
\hline $\mathrm{FFM}(\mathrm{kg})$ & $68.3 \pm 9.6$ & $66.2 \pm 8.5$ & $68.0 \pm 7.7$ & $68.9 \pm 5.8$ & $66.8 \pm 5.1$ & $69.6 \pm 4.8$ & $\mathrm{P}<0.0001 \mathrm{ab}$ \\
\hline Fat mass $(\mathrm{kg})$ & $35.2 \pm 5.6$ & $22.0 \pm 5.1$ & $27.3 \pm 7.3$ & $33.7 \pm 6.2$ & $21.0 \pm 4.5$ & $27.0 \pm 6.4$ & $\mathrm{P}<0.0001 \mathrm{abc}$ \\
\hline WHR & $0.99 \pm 0.04$ & $0.90 \pm 0.044$ & $0.93 \pm 0.05$ & $0.98 \pm 0.05$ & $0.91 \pm 0.04$ & $0.94 \pm 0.04$ & $\mathrm{P}<0.0001 \mathrm{abc}$ \\
\hline $\mathrm{VO}_{2} \max \left(\mathrm{ml} \mathrm{min}^{-1}\right)$ & $3025 \pm 370$ & $2962 \pm 398$ & $3027 \pm 424$ & $3011 \pm 441$ & $2950 \pm 367$ & $3197 \pm 317$ & $P=0.0059 b$ \\
\hline $\mathrm{VO}_{2} \max / \mathrm{FFM}\left(\mathrm{ml}^{2} \cdot \mathrm{min}^{-1} \cdot \mathrm{kgr}^{-1}\right)$ & $44.7 \pm 5.5$ & $45.1 \pm 6.3$ & $45.2 \pm 5.4$ & $43.7 \pm 5.1$ & $44.2 \pm 3.9$ & $46.0 \pm 3.8$ & NS \\
\hline Resting HR (beats.min ${ }^{-1}$ ) & $66 \pm 8$ & $57 \pm 7$ & $61 \pm 8$ & $66 \pm 10$ & $60 \pm 6$ & $66 \pm 9$ & $\mathrm{P}<0.0007 \mathrm{ab}$ \\
\hline $\mathrm{DBP}(\mathrm{mmHg})$ & $81 \pm 7$ & $72 \pm 7$ & $75 \pm 8$ & $81 \pm 8$ & $76 \pm 5$ & $75 \pm 6$ & $P=0.0034 \mathrm{a}$ \\
\hline $\mathrm{SBP}(\mathrm{mmHg})$ & $129 \pm 10$ & $117 \pm 6$ & $123 \pm 9$ & $130 \pm 11$ & $122 \pm 6$ & $124 \pm 6$ & $\mathrm{P}<0.0001 \mathrm{abc}$ \\
\hline
\end{tabular}

No differences exist berween groups. Data are means $\pm S D$. Significant differences for all subjects $(D+D E)$ between measurements $(\mathrm{P}<0.05)$ are indicated with initials: a: week 0 versus week 13 ; b: week 13 versus week 53 ; : week 0 versus week 53 . NS, not significant; BMI, body mass index; FFM, far free mass; WHR, waist-to-hip ratio; DBP, diastolic blood pressure; SBP, systolic blood pressure

\section{$\underline{\text { Experimental design }}$}

All subjects in D and DE group participated in an energy restriction program for 12 weeks. Fourteen subjects also participated in a low intensity exercise training program during 52 weeks (DE group), starting at the beginning of the diet period. Before the start of the energy restriction program, after 12 weeks (week 13) (weight reduction period) and 52 weeks (week 53) (40 week follow-up period), measurements of body composition, body fat distribution, maximal aerobic capacity, blood pressure, resting heart rate, brachial and common carotid artery wall properties, plasma lipid profile and glucose and insulin concentrations were performed in all subjects.

\section{Diet}

All subjects participated in the energy restriction program for ten weeks. The first six weeks subjects received a very low energy diet (VLCD) 
(Modifast, Novartis Nutrition, Breda, The Netherlands). This diet provided $2.1 \mathrm{MJ} /$ day and was a protein enriched formula diet, containing $50 \mathrm{~g}$ carbohydrates, $52 \mathrm{~g}$ protein, $7 \mathrm{~g}$ fat and a micro nutrient content which meets the Dutch recommended daily allowance. From week 7 until week 10 subjects increased their energy intake gradually. Subjects received less formula diet and were instructed to supplement this with a free choice of foodstuffs. In week 7 and 8 subjects received $1.4 \mathrm{MJ} /$ day of the formula diet and supplemented this up to about $3.5 \mathrm{MJ}$ by a free choice of foodstuffs. In week 9 and 10 they received $0.7 \mathrm{MJ}$ /day of the formula diet and they supplemented this up to about $4.9 \mathrm{MJ}$ by other foodstuffs. From week 7 until week 10 subjects were asked to keep a food diary. In week 11 and 12 subjects were instructed to stabilize body weight. They filled in a 3-day food diary during 2 week days and 1 weekend day at the end of week 11 . This diary was discussed with the subject and dietary advice was given in order to change food habits when necessary. During the twelve weeks subjects came to the laboratory once a week for body weight measurements and dietary advice. From week 13 until week 52 subjects came once every two weeks to the laboratory for body weight measurements. No further dietary advice or other instructions related to weight maintenance was given.

\section{$\underline{\text { Exercise training }}$}

The subjects in the $\mathrm{D}$ group were instructed not to change their habitual activity pattern over the 52 week study period. The subjects (DE group) participated in an exercise training program during 52 weeks, beginning at the start of the energy restriction period. The subjects in the DE group trained 4 times one hour per week, 3 times at the laboratory under supervision of a professional trainer and once at home. The exercise training program consisted of cycling on an ergometer (Bodyguard Cardiocycle, Sandnes, Norway or Excalibur, Lode, Groningen, The Netherlands), walking and aquajogging. All exercises were executed at a low intensity ( $40 \% \mathrm{VO}_{2} \max$ ). Training intensity was checked by monitoring heart rate (Polar Electro, Oy, Finland). Heart rate corresponding with the training intensity of $40 \% \mathrm{VO}_{2}$ max was determined in the maximal aerobic capacity test. Every three months a maximal aerobic capacity test was performed and exercise intensity was corrected if necessary. Subjects were instructed to execute low intensity endurance exercise once a week at home. Subjects 
attendance at the training sessions was recorded and the trainer inquired for the extra exercise at home regularly.

\section{Measurements}

1. Body weight, body composition and body fat distribution

Body weight was measured on a digital balance accurate to $0.1 \mathrm{~kg}$ (Sauter D-7470, Ebingen, Germany). Height was measured to the nearest $0.1 \mathrm{~cm}$ using a wall-mounted stadiometer (Seca, model 220, Hamburg, Germany). BMI was calculated from weight and height $\left(\mathrm{kg} \cdot \mathrm{m}^{-2}\right)$. Fat distribution was determined by measuring waist-hip ratio (WHR) with a flexible, inelastic tape. Measurements were performed after a normal expiration with the subject in standing position, the abdomen relaxed, the arms at the sides and the feet together. Waist circumference was measured at the smallest circumference between the ribs and iliac. Hip circumference was performed at the level of maximal extension of the buttocks (33). All measurements were recorded within the nearest $0.1 \mathrm{~cm}$ and the mean of two measurements was calculated. The WHR was calculated by dividing waist circumference by hip circumference.

Body density was measured by hydrostatic weighing, with a correction for residual lung volume estimated by helium dilution with a spirometer (Volugraph 2000, Mijnhardt, The Netherlands) at the moment of under water weighing. Body composition was calculated according to the formula of Siri (46).

\section{Maximal aerobic capacity}

Maximal oxygen uptake ( $\left.\mathrm{VO}_{2} \max \right)$ for each subject was determined by an incremental exercise test on an electromagnetically braked cycle ergometer (Excalibur, Lode, Groningen, The Netherlands). After a warming up period of 5 minutes at 80 Watt, workload was increased every 4 minutes by 40 Watt until exhaustion.

During the experiment ventilatory and gas exchange responses were measured continuously, using indirect calorimetry (Oxycon B, Mijnhardt, Bunnik, The Netherlands). Heart rate (HR) was recorded continuously by electrocardiography. The highest oxygen uptake over $30 \mathrm{sec}$ achieved was taken as $\mathrm{VO}_{2} \max$. 
3. Plasma lipid profile

After a $10 \mathrm{~h}$ overnight fast, two blood samples of $10 \mathrm{ml}$ were taken. One was put into a $10 \mathrm{ml}$ clotting tube for serum lipid and lipoprotein measurements. Serum was obtained by centrifugation of blood after one hour at room temperature. Serum was stored at $-20{ }^{\circ} \mathrm{C}$ until analysis. Total cholesterol (CHOD-PAP method; Monotest cholesterol, Boehringer Mannheim, Mannheim, Germany), HDL cholesterol (precipitation method; Monotest cholesterol, Boehringer Mannheim, Mannheim, Germany) and triacylglycerol (GPO-Trinder; Sigma Diagnostics, St. Louis, MO) were determined enzymatically. LDL cholesterol was calculated by the Friedewald equation (15).

The other $10 \mathrm{ml}$ blood sample was put into an EDTA containing chilled tube and immediately centrifuged at $800 \mathrm{~g}$ for $10 \mathrm{~min}$ at $4^{\circ} \mathrm{C}$. Plasma was stored at $-80^{\circ} \mathrm{C}$ until analyses of insulin and glucose. Plasma glucose was analyzed on a COBAS FARA centrifugal spectrophotometer (Roche Diagnostica, Basel, Switzerland) (GLUC HK kit; Hoffmann-La Roche, Basel, Switzerland) and plasma insulin concentrations were measured with a double-antibody radio-immunoassay (Insulin RIA 100; Pharmacia, Uppsala, Sweden).

4. Blood pressure and vessel wall properties of the brachial and common carotid artery

For hemodynamic measurements subjects were fasting for four hours and refrained from smoking two hours prior to examination. On the measurement day, prior to examination, subjects also refrained from physical exercise. Follow-up measurements were performed at the same time of day for each subject. To limit the influence of habituation of subjects to the test procedure, hemodynamic measurements were performed for the first time at selection and these data were kept out of the analysis.

Measurements started after $15 \mathrm{~min}$ of supine rest. Artery wall properties of the muscular brachial (BA) and elastic common carotid artery (CCA) were measured. Blood pressure and heart rate were recorded simultaneously. Systolic blood pressure (SBP), diastolic blood pressure (DBP), mean arterial pressure (MAP) and HR were recorded every $3 \mathrm{~min}$ at the left arm using a semi-automated device (Dinamap, Critikon, Tampa, Florida, USA), with exception of the period of measurement of brachial artery wall properties. Cuff size was adapted to arm circumference $(40,44)$. The mean of all 
recordings was calculated. Pulse pressure at the brachial artery was defined as SBP minus DBP. Pulse pressure at the common carotid artery was assessed by calibration of applanation tonometer waveforms at the brachial and common carotid artery (Millar, Houston, Texas, USA). Calibration assumed that MAP and DBP are not different between large arteries $(16,32)$. Arterial wall properties were assessed by a vessel wall movement detector system (Wall Track System, Pie Medical, Maastricht, The Netherlands) and applanation tonometry. Arterial diameter $(D)$, change in diameter $(\Delta D)$ during the heart cycle and changes in arterial pressure $(\Delta \mathrm{P})$ were measured and used to calculate cross sectional compliance (CC) and distensibility coefficient (DC) as described previously (1).

$\mathrm{CC}$ and DC at operating pressures were calculated using pulse pressure at the artery of interest as $\Delta \mathrm{P}$. Isobaric distensibility (isoDC) and compliance (isoCC) were determined from the ascending limbs of the distension and pressure waves obtained from the vessel wall movement detector system and applanation tonometer, respectively. They were calculated at 98 $\mathrm{mmHg}$, by taking a pressure window of $10 \mathrm{mmHg}$.

\section{$\underline{\text { Statistics }}$}

Data are expressed as means $\pm \mathrm{SD}$. A 2-way repeated measurement ANOVA (group $x$ time) was used to test differences between groups and between time points. A paired student t-test was used to test differences within groups and between time points for the total $(\mathrm{D}+\mathrm{DE})$ group. Spearman correlation coefficients $(r)$ were calculated between training attendance and changes in body weight and $\mathrm{VO}_{2} \max$. Furthermore, correlation coefficients were calculated between changes in isoDC and isoCC of the $\mathrm{BA}$ and $\mathrm{CCA}$ and changes in body weight, $\mathrm{VO}_{2} \mathrm{max} /$ per $\mathrm{kg}$ fat free mass (FFM) and serum cholesterol levels. Stepwise regression analysis was used to explain the variation in serum cholesterol and plasma insulin/glucose ratio by changes in body weight and $\mathrm{VO}_{2} \max / F F M$. A $\mathrm{P}$ value $<0.05$ was regarded as statistically significant. 


\section{Results}

\section{Subject characteristics and exercise training program}

Subjects in the DE group attended $75 \pm 20 \%$ (range 36-100\%) and $57 \pm$ $20 \%$ (range 15-80\%) of the supervized training sessions at the laboratory during the weight loss period and the follow-up period, respectively. Energy expenditure per training session was on average $1.4 \pm 0.2 \mathrm{MJ}$. Attendance at supervised training sessions in the follow-up period (week 13-52) was negatively correlated with regain of body weight $(r=-0.6$; $\mathrm{P}<0.05$ ), while attendance during the weight loss period (week 0-12) was not significantly correlated with changes in body weight. The level of performance during the maximal aerobic exercise tests was comparable before and after the intervention, since maximal Respiratory Exchange Ratio (RER) and maximal attained heart rate were not significantly different (data not shown). $\mathrm{VO}_{2}$ max increased significantly in the follow-up period only $(\mathrm{P}<0.01)$, but changes were not significantly different between groups (Table 7.1). $\mathrm{VO}_{2} \mathrm{max} / \mathrm{FFM}$ did not change significantly over the intervention periods. Changes in $\mathrm{VO}_{2}$ max were not correlated with training attendance.Body weight, body composition and fat distribution were not significantly different between the two groups before the intervention (Table 7.1). The intervention induced a significant change in these characteristics (2-way ANOVA; time $\mathrm{P}<0.0001$ ) without differences between groups (2-way ANOVA; time $\mathrm{x}$ group NS). In the weight reduction period, body weight, BMI, body fat percentage, fat mass, FFM and WHR were significantly decreased $(\mathrm{P}<0.0001)$ in both groups, whereas these parameters increased again in the follow-up period $(\mathrm{P}<0.0001)$. However, values after the follow-up period were still significantly lower than baseline values $(\mathrm{P}<0.0001)$, except for FFM.

$\mathrm{HR}$ at rest was not significantly different between groups before the intervention and changes due to the intervention were not significantly different between groups. Weight reduction was associated with a decrease in $\mathrm{HR}(\mathrm{P}<0.001)$, but HR increased again during the follow-up period $(\mathrm{P}<0.01)$ in both groups. At the end of the study HR had reached baseline values again. Blood pressure was not significantly different between groups before the intervention. The change in blood pressure (DBP and SBP) during the intervention (2-way ANOVA; time $\mathrm{P}<0.01$ ) was not significantly different between the groups. Blood pressures (DBP and SBP) decreased during the weight reduction period in both groups $(P<0.01)$. SBP increased 
again in the follow-up period $(\mathrm{P}<0.05)$, while $\mathrm{DBP}$ did not change statistically significantly. After the intervention SBP was still lower than before $(P<0.05)$ and DBP tended to be lower than before $(P=0.07)$.

\section{$\underline{\text { Blood lipids }}$}

The intervention induced a significant change in fasting concentrations of total cholesterol, HDL, LDL, HDL to LDL ratio and TG (2-way ANOVA; $\mathrm{P}<0.05)$. Addition of exercise training did not affect the results (2-way ANOVA; group $x$ time NS) (Table 7.2). With weight reduction, concentrations of total cholesterol, LDL and TG decreased and HDL concentration and $\mathrm{HDL} / \mathrm{LDL}$ ratio increased $(\mathrm{P}<0.05)$. In the follow-up period, concentrations of total cholesterol and LDL increased again $(\mathrm{P}<0.0001)$, while there was no significant change in TG and HDL concentrations. Thus, the ratio of HDL to LDL decreased in the follow-up period $(\mathrm{P}<0.0001)$. At the end of the intervention, concentrations of total cholesterol, HDL, LDL, $\mathrm{HDL} / \mathrm{LDL}$ ratio and TG were no longer significantly different from before the intervention. Stepwise regression analysis revealed that changes in serum total cholesterol concentrations over the weight reduction period were best predicted by body weight changes (explaining $18 \%$ of variance; $\mathrm{P}<0.05$ ), but this was not found over the follow-up period.

Table 7.2 Fasting concentrations of total serum cholesterol, high density lipoprotein [HDL], low density lipoprotein [LDL], HOL/LDL ratio and triglycerides [TG] and fasting concentrations of plasma glucose, insulin and insulin/glucose ratio hefore [week 0 ] and 12 weeks after the start of the diet [D] or diet plus exercise [DE] intervention [week 13] and 52 weeks after the start of the intervention [week 53].

\begin{tabular}{|c|c|c|c|c|c|c|c|}
\hline & 0 & & & OE & & & ANOVA \\
\hline week & $O(n=15)$ & $1.3(n=15)$ & $53(\mathrm{n}=15)$ & $0(n=14)$ & $13(n=14)$ & $53(n=14)$ & Time effect \\
\hline [total cholesterol] $\left(\mathrm{mmol}^{\left.1 \mathrm{I}^{-1}\right)}\right.$ & $4.9 \pm 1.2$ & $4.6 \pm 1.0$ & $4.8 \pm 1.0$ & $5.4 \pm 1.2$ & $4.5 \pm 0.97$ & $5.3 \pm 0.95$ & $\mathrm{P}<0.0001 \mathrm{ab}$ \\
\hline$[\mathrm{HDL}]\left(\mathrm{mmol} . .^{-1}\right)$ & $0.87 \pm 0.26$ & $1.02 \pm 0.32$ & $1.00 \pm 0.33$ & $0.98 \pm 0.22$ & $1.07 \pm 0.20$ & $1.01 \pm 0.20$ & $P=0.0043 a$ \\
\hline [LDL](mmol..$\left.^{-1}\right)$ & $3.33 \pm 1.01$ & $2.84 \pm 0.72$ & $3.3 \pm 0.84$ & $3.7 \pm 1.1$ & $3.0 \pm 0.8$ & $3.8 \pm 0.8$ & $P<0.0001 \mathrm{ab}$ \\
\hline [HDU/LDL] & $0.27 \pm 0.09$ & $0.37 \pm 0.12$ & $0.32 \pm 0.12$ & $0.28 \pm 0.08$ & $0.38 \pm 0.12$ & $0.28 \pm 0.08$ & $\mathrm{P}<0.0001 \mathrm{ab}$ \\
\hline$\left[\right.$ TG] $\left(\right.$ mmol. $\left.^{-1}\right)$ & $1.6 \pm 0.7$ & $1.4 \pm 0.9$ & $1.3 \pm 0.5$ & $1.4 \pm 0.5$ & $1.1 \pm 0.4$ & $1.2 \pm 0.5$ & $\mathrm{P}=0.027 \mathrm{a}$ \\
\hline [glucose $]\left(\mathrm{mmol}^{\left.1 . l^{-1}\right)}\right.$ & $5.37 \pm 0.48$ & $5.11 \pm 0.42$ & $5.27 \pm 0.43$ & $5.28 \pm 0.42$ & $5.05 \pm 0.34$ & $5.17 \pm 0.39$ & $\mathrm{P}<0.0032 \mathrm{a}$ \\
\hline [insulin\} $\left(\mu U \mathrm{ml}^{-1}\right)$ & $12.7 \pm 4.1$ & $8.9 \pm 2.5$ & $9.6 \pm 4.5$ & $15.2 \pm 6.8$ & $9.0 \pm 4.2$ & $10.8 \pm 4.6$ & $\mathrm{P}<0.0001$ ac \\
\hline [insulin/glucose] & $2.35 \pm 0.71$ & $1.74 \pm 0.45$ & $1.81 \pm 0.75$ & $2.87 \pm 1.18$ & $1.76 \pm 0.72$ & $2.10 \pm 0.91$ & $\mathrm{P}=0.0059 \mathrm{ac}$ \\
\hline
\end{tabular}

No differences exist between groups. Data are means $\pm S D$. Significant differences for all subjects $(D+D E)$ between measurements $(P<0.05)$ are indicarted with inirials: a: week 0 versus week 13 ; b: week 13 versus week 53 ; c: week 0 versus week 53 


\section{$\underline{\text { Plasma glucose and insulin }}$}

Plasma glucose and insulin concentrations and insulin/glucose ratio changed significantly during the intervention period (2-way ANOVA; time $\mathrm{P}<0.01$ ). Addition of exercise training did not affect the outcome (2-way ANOVA; group $\mathrm{x}$ time NS). Plasma glucose and insulin concentrations and insulin/glucose ratio decreased with weight loss $(\mathrm{P}<0.05)$; concentrations did not change significantly during the follow-up period. Therefore, plasma insulin and glucose concentrations and insulin/glucose ratio were still lower at the end of the study compared to the beginning $(\mathrm{P}<0.01)$, although the difference failed to reach statistical significance for glucose concentration. Stepwise regression analysis revealed that changes in plasma insulin/glucose in the total group during the weight loss period are for $27 \%$ explained by changes in body weight and for an additional $15 \%$ by changes in $\mathrm{VO}_{2} \mathrm{max} / \mathrm{FFM}(\mathrm{P}<0.001)$. During the follow-up period changes in body weight explained $17 \%$ and changes in $\mathrm{VO}_{2}$ max/FFM explained an additional $4 \%(\mathrm{P}=0.01)$ of the change in insulin/glucose ratio.

\section{$\underline{\text { Vessel wall properties }}$}

Vessel wall properties of the brachial artery (BA) were not significantly different between groups before the start of the intervention. The effect of the intervention on the BA properties $\mathrm{DC}, \mathrm{CC}$, isoDC and isoCC was significantly different between groups (2-way ANOVA; time NS, time $\mathrm{x}$ group $\mathrm{P} \leqslant 0.001$, group NS) (Figure 7.1). Weight loss, whether or not combined with exercise training, did not induce changes in DC, CC, isoDC and isoCC. During the follow-up period, however, the $\mathrm{D}$ group showed a significant increase in $\mathrm{DC}, \mathrm{CC}$ and isoCC $(\mathrm{P}<0.05)$. IsoDC showed a tendency to increase $(\mathrm{P}=0.08)$. The $\mathrm{DE}$ group, on the contrary, showed no changes in vessel wall properties of the BA during the followup period. After one year, vessel wall properties of the BA were not different from before weight loss, neither in the $\mathrm{D}$, nor in the $\mathrm{DE}$ group. The interventions did not significantly affect the diameter of the BA.

Diameters before the intervention, after weight loss and after the follow-up period were $5.3 \pm 0.5,5.6 \pm 0.7$ and $5.4 \pm 0.5 \mathrm{~mm}$, respectively in the $\mathrm{D}$ group and $5.5 \pm 0.5,5.5 \pm 0.5$ and $5.3 \pm 0.3 \mathrm{~mm}$, respectively in the DE group. 

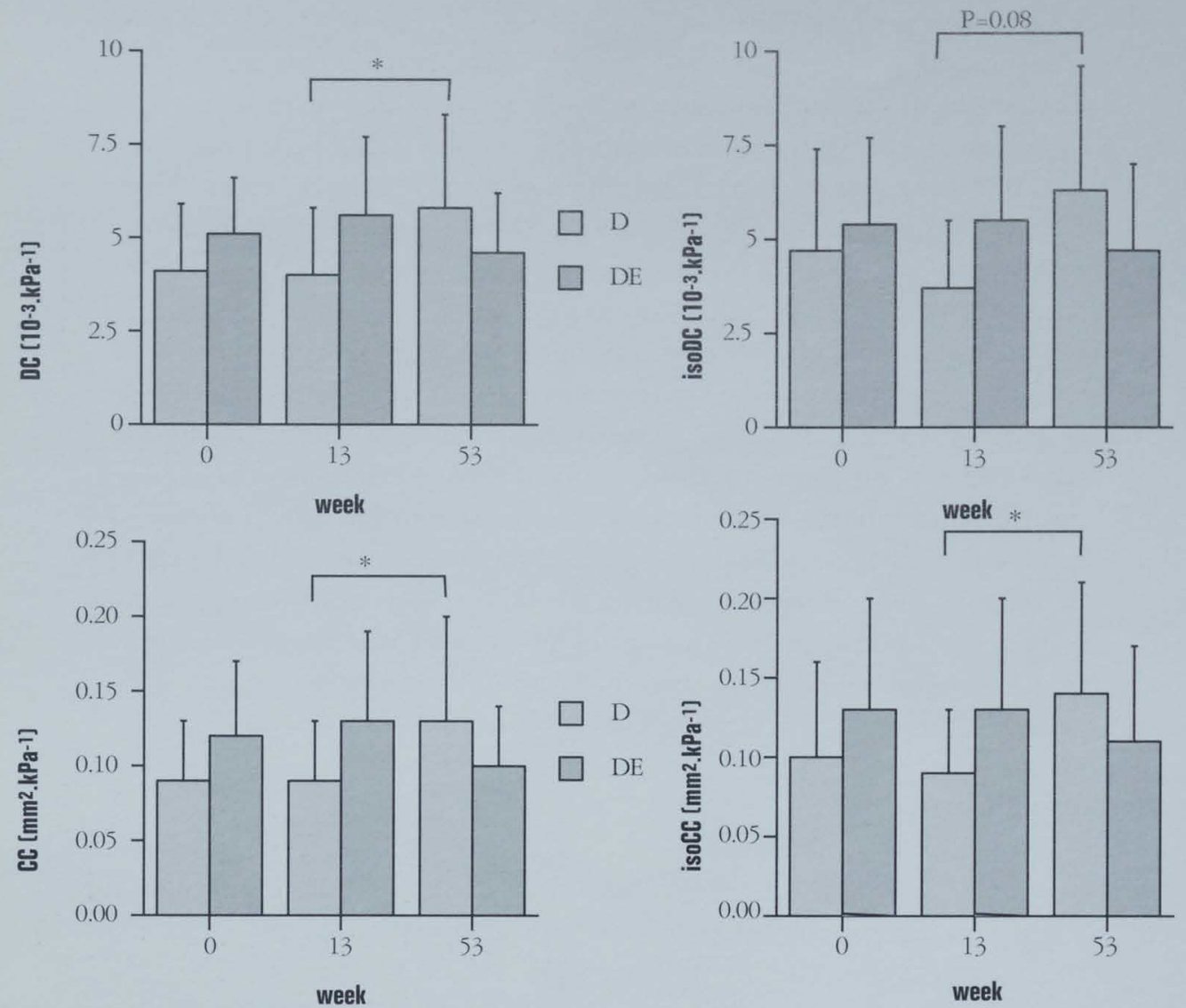

Figure 7.1 Distensibility [DC] $\left[10^{-3} . \mathrm{kPa}^{-1}\right][\mathrm{A}]$, isobaric $\mathrm{DC}$ [isoDC] $\left[10^{-3} \cdot \mathrm{kPa}^{-1}\right]$ [B],cross sectional compliance [CC] $\left[\mathrm{mm}^{2} . \mathrm{kPa}^{-1}\right]$ [C] and isoCC $\left[\mathrm{mm}^{2} . \mathrm{kPa}^{-1}\right]$ [D] of the brachial artery hefore [week 0 ], 12 weeks after the start of the diet [D] or diet plus exercise [DE] intervention [week 13] and 52 weeks after the start of the intervention [week 53].

* significantly different $\mathrm{P}<0.05$

Vessel wall properties of the CCA were not significantly different between the D and DE group. The weight loss intervention and the follow-up period, whether or not combined with exercise training, had no effect on $\mathrm{DC}, \mathrm{CC}$, isoDC and isoCC of the CCA (Figure 7.2). The diameter of the CCA before the intervention, after weight loss and after the follow-up period was $7.9 \pm 0.6,7.8 \pm 0.5$ and $7.9 \pm 0.5 \mathrm{~mm}$ respectively in the $\mathrm{D}$ group and $7.8 \pm 0.5,7.7 \pm 0.5$ and $7.7 \pm 0.7 \mathrm{~mm}$ respectively in the DE group. 
Changes in isoDC and isoCC of the $\mathrm{BA}$ and $\mathrm{CCA}$ during the weight loss and follow-up period did not significantly correlate with changes in body mass, cholesterol or physical fitness.
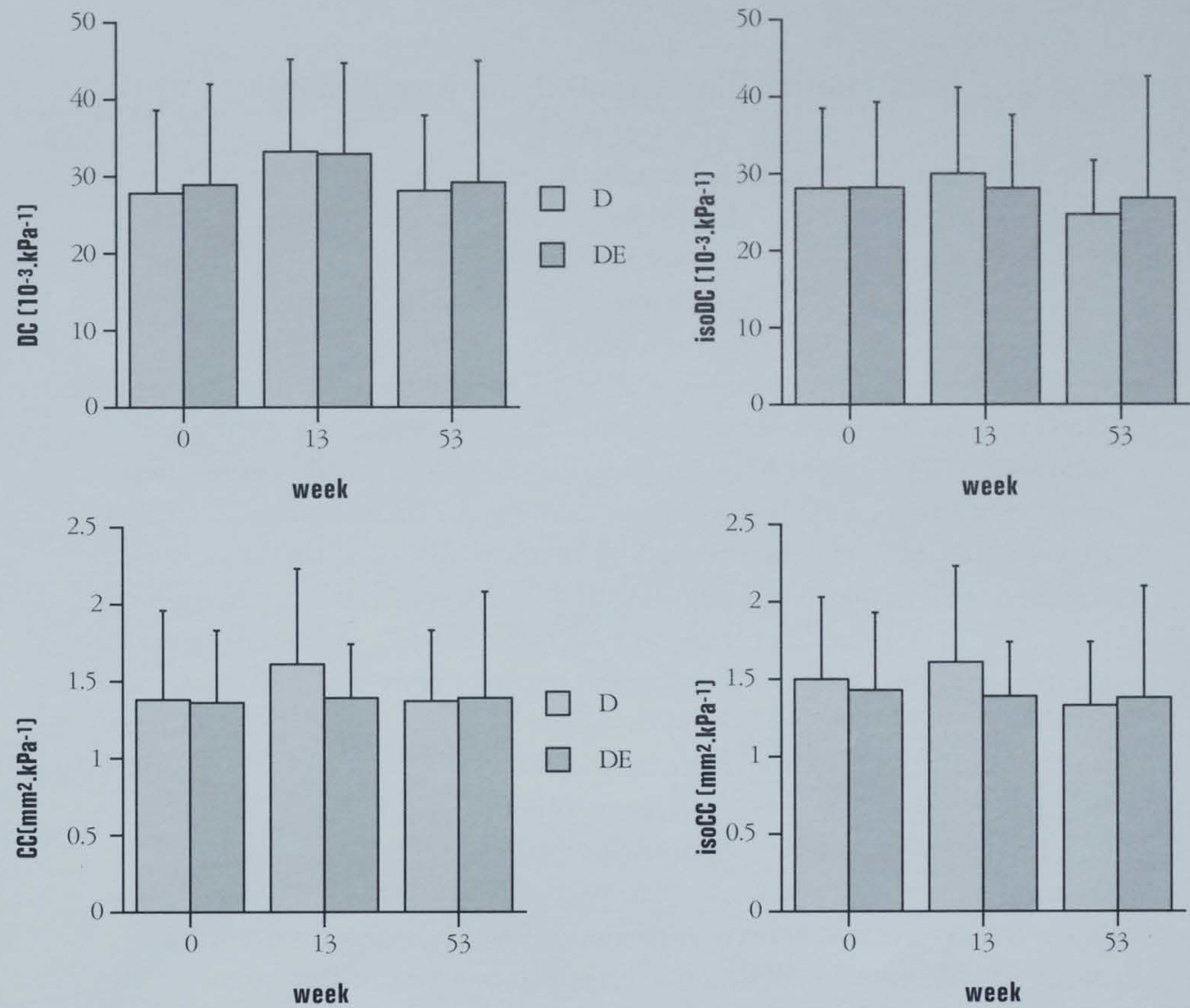

Figure 7.2 Distensibility [DC] $\left[10^{-3} . \mathrm{kPa}^{-1}\right][\mathrm{A}]$, isobaric $\mathrm{DC}$ [isoDC] $\left[10^{-3} . \mathrm{kPa} \mathrm{A}^{-1}\right]$ [B], cross sectional compliance [CC] $\left[\mathrm{mm}^{2} . \mathrm{kPa}^{-1}\right][\mathrm{C}]$ and isoCC $\left[\mathrm{mm}^{2} . \mathrm{KPa}{ }^{-1}\right][\mathrm{D}]$ of the carotid artery hefore [week 0 ], 12 weeks after the start of the diet $[\mathrm{D}]$ or diet plus exercise [DE] intervention [week 13] and 52 weeks after the start of the intervention [week 53].

\section{Discrussion}

The present study showed that long-term maintenance of diet-induced body weight loss induced improvements in a number of cardiovascular risk factors i.e. fat distribution, systolic blood pressure and insulin/glucose ratio. No effect of addition of low intensity exercise training to the weight 
loss period and continuation of exercise training during the follow-up period on changes in body weight and improvements of cardiovascular risk factors could be shown.

\section{$\underline{\text { Body weight, body composition and body fat distribution }}$}

The present study showed that energy restriction reduced body weight $(14.7 \pm 4.1 \%)$, fat mass $(37.7 \pm 11.0 \%)$, FFM $(2.8 \pm 2.9 \%)$ and WHR $(9.2 \pm 3.1 \%)$ in the D group over a 12 week period. Low intensity exercise training had no significant additional effect on these changes. Continuation of low intensity exercise training in the DE group did not diminish the regain of body weight or fat mass after the diet-induced weight loss period. However, the intensity or the frequency of exercise training during the follow-up period might have been too low to induce an additional effect of exercise training on body weight loss and weight maintenance. A too low frequency is supported by the finding that attendance of the DE group at training sessions was negatively correlated with regain of body weight $(r=0.6)$. This suggests that frequent ( $\geqslant 3$ times a week) low intensity exercise training may play a role in limiting the regain of body weight on long term. Other studies $(11,22-24,38,51)$ suggested a role for moderate to high intensity exercise training in the maintenance of a reduced body weight or fat mass on long term. However, some other studies failed to show an effect of additional exercise training on body weight changes $(14,52)$. As far as we know, only one long term intervention study used a comparable low intensity exercise training program during and after a weight loss program (14). In agreement with our study, one year of low intensity exercise training (by walking) had no additional effect on changes in body weight, body composition and fat distribution.

\section{$\underline{\text { Blood pressure }}$}

Blood pressure decreased in conjunction with diet-induced weight loss and remained lower during weight maintenance in the present study. Addition of exercise training at low intensity did not seem to affect these changes. Pasman et al. (38) showed that high intensity exercise training did not affect diet-induced changes in blood pressure either. Long term exercise training has been shown to decrease blood pressure in normotensive and 
hypertensive subjects $(26,50)$. The role of exercise training intensity is not fully clear. Two meta-analytic studies on the effects of exercise training on blood pressure reported that the blood pressure lowering effect of exercise training was independent of the intensity or frequency of exercise training $(12,19)$. However, another study reported a more pronounced blood pressure lowering effect when low to moderate intensity compared with high intensity exercise training was executed (18). Katzel et al. (26) compared the effect of 9 months weight loss or moderate intensity exercise training on blood pressure of obese men. They showed a $8 \%$ decrease in both systolic and diastolic blood pressure after weight loss and a $3 \%$ and $2 \%$ decrease in systolic and diastolic blood pressure respectively after exercise training. Apparently exercise training and weight loss both induce changes in blood pressure, but our study as well as the study of Katzel et al. (26) suggest that the effect of body weight loss may overrule the effect of exercise training on blood pressure.

\section{$\underline{\text { Blood lipids }}$}

The present study indicated that a decrease in body weight had a positive effect on lipid profile while low intensity exercise training had no additional effect on plasma lipids during the weight reduction and follow-up period. With body weight regain during the follow-up period, lipid levels reached baseline values again. Other studies also showed a decrease in serum toral cholesterol, LDL cholesterol and TG concentrations and an increase of serum HDL cholesterol after weight loss $(26,27,38)$. In agreement with the present study, with regain of body weight, serum lipid concentrations returned to baseline within 16 months (38). We found the change in body weight during weight reduction to be a predictor of changes in total cholesterol concentration. This association was not found over the followup period, probably since changes in body weight were smaller. Reported effects of exercise training alone are not consistent. When body weight was kept stable, some studies reported an increase in HDL concentrations $(3,17,21,27)$, while others reported no change $(26,49)$. Effects on total cholesterol and LDL were also not fully clear. Some investigators reported no change $(3,17,26,27)$, while a meta-analysis reported a decrease (49). Differences might be due to differences in training duration, intensity or frequency, but there are also indications that an improvement of serum lipid profile could be explained by a decreased fat mass rather 
than by an increased physical firness $(10,41)$. Long term exercise training of $>8.5 \mathrm{MJ}$ per week, independent of exercise intensity, has been reported to improve the blood lipid profile. This is suggested to be caused by an increase in micro-circulation in the muscle which increases the lipolytic action of lipoprotein lipase and therefore facilitates triglyceride degradation (20). In the present study, energy expenditure related to exercise training was at most 5.6 MJ per week and may therefore not have been enough to induce an increase in lipoprotein lipase activity.

\section{$\underline{\text { Plasma insulin and glucose }}$}

The present study showed that plasma glucose and insulin concentrations decreased by weight reduction and addition of exercise training did not further decrease these concentrations. However, results of the stepwise analysis showed that both weight loss and changes in physical fitness explained the change in plasma insulin/glucose ratio, but the effect of weight loss was stronger. A study comparing exercise training directly with weight loss found only an effect of weight loss, but not of exercise training on fasting insulin and glucose (26). In addition, others also reported that body weight was correlated with plasma insulin and glucose concentrations $(7,10,13,39)$. Several studies have shown that exercise training also decreases fasting plasma insulin concentrations $(8,17,31)$ and increases insulin sensitivity $(25,30)$, while body weight did not change. It can be suggested that both weight loss and exercise training improve plasma insulin and glucose concentrations, but the effect of weight loss might be stronger.

\section{$\underline{\text { Large artery compliance }}$}

One year after the start of the weight loss intervention, the present study showed that isobaric vessel wall properties of the BA and CCA were not different from before. Low intensity exercise training during and after weight loss did not influence these results. Nevertheless, maintenance of body weight improved isoCC, $\mathrm{CC}$ and $\mathrm{DC}(\mathrm{P}<0.05)$ and tended to improve isoDC of the $\mathrm{BA}(\mathrm{P}=0.08)$, but not of the $C C A$, in the non-exercising group. This might indicate that long term weight loss may induce favorable functional changes in muscular arteries. However, we are not able to 
explain why the exercise training group, showing a similarly reduced body weight as in the non-exercising group, did not improve vessel wall properties of the BA during the follow-up period.

Only a few studies on the effect of weight reduction on vessel wall properties have been published so far. They showed that a $10 \%$ weight reduction within one month increased arterial distensibility and compliance in the brachial artery (48) and 10\% weight reduction within 16 weeks increased cross-sectional compliance of the aorta (57). However, both studies could not exclude that the effect was caused by a decrease in blood pressure. To our knowledge, no study has been performed on the effects of long-term relative maintenance of body weight loss on vessel wall properties. The mechanism behind these changes in muscular vessel wall properties due to long term weight reduction needs further research.

Low intensity exercise training did not affect vessel wall properties on short as well as on long term, and there was no correlation with training attendance. On short term, others also reported no effect of exercise training on vessel wall properties (53), but one study suggested an improved systemic arterial compliance with training (6). However, the effect might be due to changes in blood pressure rather than changes in the vessel walls. As far as we know, no long-term exercise intervention study on the effects of vessel wall properties has been published. Only some data are available on differences in vessel wall properties of trained and untrained subjects, showing a decreased whole body arterial compliance in weight-trained athletes compared to sedentary controls (2). Others showed an increased compliance in trained compared to untrained subjects in the femoral and brachial artery $(29,54)$ and systemic aorta respectively $(28)$, while blood pressures were not different between groups.

In conclusion, one year after the start of the intervention, the cardiovascular risk factors body weight, body composition, fat distribution, systolic blood pressure, insulin/glucose ratio and fasting insulin concentrations were still improved in both groups. Improvements of vessel wall properties of the brachial artery were found during the follow-up period in the non-exercising group only. Addition of exercise training to and after a VLCD treatment did not contribute to these effects. 


\section{References}

I. Balkestein, E. J., D. P. van Aggel-Leijssen, M. A. van Baak, H. A. Struijker-Boudier, and L. $M$. van Bortel. The effect of weight loss with or without exercise training on large artery compliance in healthy obese men. I Hypertens. I7: 1831-1835, I999.

2. Bertovic, D. A., T. K. Waddell, C. D. Gatzka, J. D. Cameron, A. M. Dart, and B. A. Kingwell. Muscular strength training is associated with low arterial compliance and high pulse pressure. Hypertens. 33: 1385-I39I, I999.

3. Blumenthal, J.A., C. F. Emery, D.J. Madden, R. E. Coleman, M. W. Riddle, S. Schniebolk, F. R. Cobb, M. J. Sullivan, and M. B. Higginbotham. Effects of exercise training on cardiorespiratory function in men and women older than 60 years of age. Am J Cardiol. 67: 633-639, I99I.

4. Bonadonna, R. C., and E. Bonora. Glucose and free fatty acid metabolism in buman obesity. Diabetes Rev. S: 2I-SI, I997.

5. Bray, G. A. Obesity and surgery for a chronic disease. Obes Res. 4: 30I-3, I996.

6. Cameron, J. D., and A. M. Dart. Exercise training increases total systemic arterial compliance in bumans. Am. J. Physiol. 266: H693-H70I, I994.

7. Dagnone, D., I. Janssen, A. Paddags, R. H. Hudson, P. Jones, and $R$. Ross. Exercise without weigth loss improves insulin sensitivity in obese men. Int J Obes. 23: D84, I998.

8. DeFronzo, R. A., R. S. Sherwin, and N. Kraemer. Effect of physical training on insulin action in obesity. Diabetes. 36: 1379-1385, 1987.

9. Després, J. P., S. Moorjani, P. J. Lupien, A. Tremblay, A. Nadeau, and C. Bouchard. Regional distribution of body fat, plasma lipoproteins, and cardiovascular disease. Arteriosclerosis. I0: 497-5II, xggo.

ro. Després, J. P., M. C. Pouliot, S. Moorjani, A. Nadeau, A. Tremblay, P. J. Lupien, G. Theriault, and C. Bouchard. Loss of abdominal fat and metabolic response to exercise training in obese women. Am J Physiol. 26I: EIS9-EI67, I99I.

II. Ewbank, P. P, L. L. Darga, and C. P. Lucas. Physical activity as a predictor of weight maintenance in previously obese subjects. Obes Res. 3: 257-263, rg95.

I2. Fagard, R. H. The role of exercise in blood pressure control: supportive evidence. I Hypertens. 13: 1223-1227, I995.

13. Fagerberg, B., A. Berglund, O. K. Andersson, and G. Berglund. Weight reduction versus antihypertensive drug therapy in obese men with high 
blood pressure: effects upon plasma insulin levels and association with changes in blood pressure and serum lipids. J Hypertens. 10: 1053-106r, 1992.

I4. Fogelholm, M., K. Kukkonen-Harjula, and P. Oja. Eating control and physical activity as determinants of short-term weight maintenance after a very-low-calorie diet among obese women. Int J Obes. 23: 203-210, 1999.

I5. Friedewald, W. T., R. I. Levy, and D. S. Frederickson. Estimation of the concentration of low-density lipoprotein cholesterol in plasma, without use of preparative ultracentrifuge. Clin Chem. 18: 499-502, 1972.

I6. Giannattasio, C., M. Failla, A. A. Mangoni, L. Scandola, N. Fraschini, and $G$. Mancia. Evaluation of arterial compliance in humans.. Clin Exp Hypertens. 18: 347-362, 1996.

17. Hagberg, J. M. Physiologic adaptations to prolonged high-intensity exercise training in patients with coronary artery disease. Med Sci Sports Exerc. 23: 66I-667, x99I.

18. Hagberg, J. M., and M. D. Brown. Does exercise training play a role in the treatment of essential hypertension? J Cardiovasc Risk. 2: 296-302, 1995.

19. Halbert, J. A., C. A. Silagy, P. Finucane, R. T. Withers, P. A. Hamdorf, and $G$. R. Andrews. The effectiveness of exercise training in lowering blood pressure: a meta-analysis of randomised controlled trials of 4 weeks or longer. J Human Hypertens. II: 641-649, rg97.

20. Hardman, A. E. Physical activity, obesity and blood lipids. Int J Obes. 23: $S_{64}-S_{71}$, rg9g.

2I. Hardman, A. E., A. Hudson, P. R. Jones, and N. G. Norgan. Brisk walking and plasma high density lipoprotein cholesterol concentration in previously sedentary women. Br J Sports Med. 28: 26I-266, I989.

22. Harris, J. K., S. A. French, R. W. Jeffery, P. G. McGovern, and R. R. Wing. Dietary and physical activity correlates of long-term weight loss. Obes Res. 2: 307-313, 1994.

23. Hartman, W. M., M. Stroud, D. M. Sweet, and J. Saxton. Long-term maintenance of weight loss following supplemented fasting. Int $J$ Eat Disord. I4: 87-93, I993.

24. Hensrud, D. D., R. L. Weinsier, B. E. Darnell, and G. R. Hunter. Relationship of co-morbidities of obesity to weight loss and four-year weight maintenancelrebound. Obes Res. 3: 217S-222S, 1995.

25. Hickey, M. S., J. A. Houmard, R. V. Considine, G. L. Tyndall, J. B. Midgette, K. E. Gavigan, M. L. Weidner, M. R. McCammon, R. G. Israel, and J. F. Caro. Gender-dependent effects of exercise training on serum leptin levels in humans. Am J Physiol. 272: E562-E566, I997. 
26. Katzel, L. I., E. R. Bleecker, E. G. Colman, E. M. Rogus, J. D. Sorkin, and $A$. $P$. Goldberg. Effects of weight loss vs aerobic exercise training on risk factors for coronary disease in healthy, obese, middle-aged and older men. JAMA 274: 1915-1921, I995.

27. Katzel, L. I., R. Bleecker, E. M. Rogus, and A. P. Goldberg. Sequential effects of aerobic exercise training and weight loss on risk factors for coronary disease in healthy, obese middle-aged and older men. Metabolism 46: I44I-I447, 1997.

28. Kingwell, B. A., J. D. Cameron, K. J. Gillies, G. L. Jennings, and A. M. Dart. Arterial compliance may influence baroreflex function in athletes and hypertensives. Am J Physiol. 268: $\mathrm{H}_{4 I I}-\mathrm{H}_{41}$ 8, I995.

29. Kool, M. J., H. A. Struijker Boudier, J. A. Wijnen, A. P. Hoeks, and L. M. van Bortel. Effects of diurnal variability and exercise training on properties of large arteries. J Hypertens. 10: $S_{49} 9-S_{52}, 1992$.

30. Lamarche, B., J. P. Despres, S. Moorjani, A. Nadeau, P. J. Lupien, A. Tremblay, G. Theriault, and C. Bouchard. Evidence for a role of insulin in the regulation of abdominal adipose tissue lipoprotein lipase response to exercise training in obese women. Int J Obes. 17: 255-26I, 1993.

31. Lamarche, B., J. P. Despres, M. C. Pouliot, S. Moorjani, P. J. Lupien, G. Theriault, A. Tremblay, A. Nadeau, and C. Bouchard. Is body fat loss a determinant factor in the improvement of carbohydrate and lipid metabolism following aerobic exercise training in obese women? Metabolism 4I: $1249-1256,1992$.

32. Lévy, B. I., and M. Safar. Ventricular afterload and aortic impedance. In: Cardiac hypertrophy and failure, edited by B. Swyngedauw. London: J. Libbey INSERM, x990, p. 521-530.

33. Lohman, T. G., A. F. Roche, and R. Martorell. Anthropometric Standardization Reference Manual. Illinois: Campaign, 1988.

34. Mangoni, A. A., C. Giannattasio, A. Brunani, M. Failla, M. Colombo, G. Bolla, F. Cavagnini, G. Grassi, and G. Mancia. Radial artery compliance in young, obese, normotensive subjects. Hypertens. 26: 984-988, 1995.

35. Manson, J. E., G. A. Colditz, M. J. Stampfer, W. C. Willett, B. Rosner, R. R. Monson, F. E. Speizer, and C. H. Hennekens. A prospective study of obesity and risk of coronary heart disease in women. $N$ Engl J Med. 322: 882-889, 1990 .

36. Manson, J. E., W. C. Willett, M. J. Stampfer, G. A. Colditz, D. J. Hunter, S. E. Hankinson, C. H. Hennekens, and F. E. Speizer. Body weight and mortality among women. $N$ Engl J Med. 333: 677-85, 1995. 
37. Miller, W. C., D. M. Koceja, and E. J. Hamilton. A meta-analysis of the past 25 years of weight loss research using diet, exercise or diet plus exercise intervention. Int J Obes. 2I: 94I-7, 1997.

38. Pasman, W. J., W. H. Saris, E. Muls, G. Vansant, and M. S. Westerterp Plantenga. Effect of exercise training on long-term weight maintenance in weight-reduced men. Metabolism. 48: 15-21, Ig9g.

39. Pekkarinen, T., I. Takala, and P. Mustajoki. Weight loss with very-lowcalorie diet and cardiovascular risk factors in moderately obese women: one-year follow-up study including ambulatory blood pressure monitoring. Int J Obes. 22: 66I-666, 1998.

40. Petrie, J. C., E. T. O'Brien, W. A. Litter, and M. Swiet de. Recommendations on blood pressure measurement. Brit Med J. 293: 6rt-6rs, I986.

41. Poirier, P., C. Catellier, A. Tremblay, and A. Nadeau. Role of body fat loss in the exercise-induced improvement of the plasma lipid profile in noninsulin-dependent diabetes mellitus. Metabolism. 45: 1383-1387, 1996.

42. Pollock, M. L., H. Miller, R. Janeway, A. C. Linnerud, Robertson, B., and $R$. Valentino. Effects of walking on body composition and cardiovas cular function of middle-aged men. J Appl Physiol. 30: 126-I30, 1971.

43. Pronk, N. P., and R. R. Wing. Physical activity and long-term maintenance of weight loss. Obes Res. 2: 587-599, 1994.

44. Russell, A. E., L. M. H. Wing, S. A. Smith, P. E. Aylward, R. J. McRitchie, R. M. Hassam, M. J. West, and J. P. Chalmers. Optimal size of cuff bladder for indirect measurement of arterial pressure in adults. J Hypertens. 7: 607-613, 1989 .

45. Seidell, J. C. Obesity in Europe. Obes Res. 3: 89s-93s, I995.

46. Siri, W. E. The gross composition of the body. Adv Biol Med Physiol. 4: 239-280, 1956 .

47. Spek, J. J., A. P. G. Hoeks, H. A. J. Struijker Boudier, and L. M. A. B. Van Bortel. Differences in vessel wall properties of large arteries between obese and lean subjects. Nier und Hochdruckkrankheiten. 24: 43I-432, 1995.

48. Toto-Moukouo, J. J., A. Achimastos, R. G. Asmar, C. J. Hugues, and M. E. Safar. Pulse wave velocity in patients with obesity and hypertension. Am Heart J. II2: 136-140, 1986.

49. Tran, Z. V., A. Weltman, G. V. Glass, and D. P. Mood. The effect of exercise on blood lipids and lipoproteins: a meta-analysis of studies. Med Sci Sports and Exerc. 15: 393-402, 1983.

5o. Van Baak, M. A. Exercise and hypertension: facts and uncertainties. Br J Sports Med. 32: 6-10, Igg8. 
5x. Van Dale, D., W. H. Saris, and F. ten Hoor: Weight maintenance and resting metabolic rate $18-40$ months after a dietlexercise treatment. Int J Obes. I4: 347-59, I990.

52. Weinstock, R. S., H. Dai, and T. A. Wadden. Diet and exercise in the treatment of obesity. Arch Intern Med. 158: 2477-2483, I998.

53. Wijnen, J. A., M. J. Kool, J. P. Kooman, M. A. van Baak, A. P. Hoeks, H. A. Struijker Boudier, and L. M. Van Bortel. Vessel wall properties of large arteries and endurance training. J Hypertens. II: S88-S89, 1993.

54. Wijnen, J. A., H. Kuipers, M. J. Kool, A. P. Hoeks, M. A. van Baak, H. A. Struyker Boudier, F. T. Verstappen, and L. M. Van Bortel. Vessel wall properties of large arteries in trained and sedentary subjects. Basic Res Cardiol. 86: S25-S29, I99I.

55. Wing, R. R. Behavioral treatment of severe obesity. Am J Clin Nutr. 55: 545S-5I5S, 1992.

56. Wood, P. D., M. L. Stefanick, P. D. Williams, and W. L. Haskell. The effects on plasma lipoproteins of a prudent weight-reducing diet with or without exercise, in overweight men and women. $N$ EnglJ Med. 325: 46I-466, I99I.

57. Yamashita, T., T. Sasahara, S. E. Pomeroy, G. Collier, and P. J.. Nestel. Arterial compliance, blood pressure, plasma leptin, and plasma lipids in women are improved with weight reduction equally with a meat-based diet and a plant-based diet. Metabolism. 47: 1308-1314, I998. 


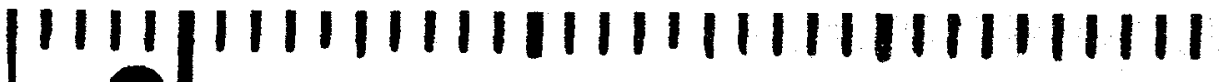 General discussion}

The leading thread running through the research in the present thesis is the effect of regular exercise on metabolism of fat as an energy substrate in obese subjects and its effects on body weight control. Obesity is associated with an impaired ability to use fat as a fuel (45) and an impaired catecholamine-induced lipolysis and fat oxidation $(4,41)$. A low ability to oxidize fat implicates that the fuel mix oxidized is relatively high in carbohydrate and low in fat, which may lead to a faster depletion of glycogen stores. According to Flatts model of nutrient balance this leads to greater food (and therefore fat) intake and to a positive energy balance (15). When the diet is high in fat, the increased food intake needed to maintain stable glycogen stores results in a larger fat intake and storage. The resulting increase in fat mass raises fat oxidation until it matches fat intake. Thus energy and fat balances are reestablished (46). Therefore, an impaired ability to oxidize fat may lead to gain of fat mass, as is also suggested by others $(2,34)$.

We firstly evaluated if exercise training is a valuable tool to improve ( $\beta$-adrenergic mediated) fat oxidation in obese subjects and what intensity of exercise training is most recommendable. Secondly, it was questioned whether an exercise-induced increase in fat oxidation could prevent a dietinduced decrease in fat oxidation when body weight was stabilized. In a follow-up study, the effect of continuation of exercise training on longterm ( $B$-adrenergic mediated) fat oxidation was studied. Subsequently, it is evaluated whether an improvement fat oxidation will be of benefit for short and long term weight control. Finally, the question is posed whether a better weight management and/or physical fitness will lead to an improved cardiovascular risk profile. 


\section{Fat metabalism}

In the studies described in chapter 2 and 4 , the effect of exercise training on total fat metabolism was studied in a randomly controlled trial. The training program lasted 12 weeks, since previous studies have shown that 8-12 weeks of exercise training caused significant increases in fat oxidation at rest and during exercise in lean men $(21,25,33)$. In men as well as in women, fat oxidation during sub-maximal exercise is 3-5 times higher than at rest. Therefore, if exercise training affects fat oxidation, the effect is most likely to become apparent during exercise. Low intensity exercise training did increase fat oxidation in men and upper body obese women during exercise. However, the effect was just significant, since the variability in the change in fat oxidation between subjects was higher as the mean increase in fat oxidation in the group. Since the increase in fat oxidation during exercise was not very impressive, an effect of exercise training at rest was not likely to be demonstrated.

High intensity exercise training clearly increases fat oxidation in lean subjects $(20,21,25,32,47)$. Our study in obese men did not show an increased fat oxidation after high intensity exercise training, since the increased non-plasma FA oxidation was accompanied by a decrease in plasma FFA oxidation. Nevertheless, the results of the HI group need to be interpreted with some caution, since the HI group already tended to oxidize more fat (NS) during exercise before the intervention compared to the LI and $\mathrm{C}$ group, despite subjects were matched and randomly divided over the groups. The upper body obese men and women, despite their impaired ability to mobilize and oxidize fat $(4,6,41)$, increased fat oxidation during exercise after exercise training at $40 \% \mathrm{VO}_{2} \max$ (chapter 2 and 4 ). The lower body obese women failed to increase their fat oxidation by low intensity exercise training (chapter 4). This indicates that in lower body obese women low intensity exercise training of this extent is not a suitable tool to increase fat mobilization and oxidation. In lean subjects, to our knowledge, the effect of exercise training at $40 \% \mathrm{VO}_{2} \max$ on fat oxidation has not been studied yet. For comparison, we performed a study in which lean men participated in the same low intensity exercise training program $\left(40 \% \mathrm{VO}_{2} \max \right)$ as the obese men and the same measurements were performed before and after the exercise training program. In the lean men $(n=6)$, low intensity exercise training also increased total fat oxidation during exercise $(P=0.06)$, but not at rest (43). The increased fat oxidation was also most likely to result from an increased non-plasma $F A$ oxidation $(P=0.09)$. 
From these results we concluded that low intensity exercise training in upper body obese subjects improves fat oxidation during moderate intensity exercise as in lean subjects. Comparing the effect of high intensity exercise training on fat oxidation in obese subjects (chapter 2) with the effect in lean subjects described in the literature $(20,21,25,32,47)$, it seems that high intensity exercise training is not as effective to stimulate fat oxidation in obese compared to lean subjects. Overall, from the studies described in chapter 2 and 4 the conclusion can be drawn that low intensity exercise training can be recommended to increase far oxidarion in upper body obese men and women, but not in lower body obese women.

In chapter 2 and 4 studies are described in which the effect of exercise training on fat metabolism was demonstrated by measuring fat metabolism after an overnight fast at rest and during an exercise bout of 60 minutes at moderate intensity. Fasting rest and exercise normally occur during a day, but are absolutely not representative for fat metabolism over $24 \mathrm{~h}$. An increase in $24 \mathrm{~h}$ fat metabolism is in fact the primary endpoint in the concept of a beneficial effect of exercise training on weight maintenance. Other moderate to high intensity exercise training studies have shown a decrease in $24 \mathrm{~h}$ fat oxidation (31) or a decreased relative fat oxidation during the night (55). Westerterp et al. (55) suggests that the decreased relative fat oxidation levels after exercise training could be the result of an increased insulin sensitivity. A better insulin action results in higher glycogen stores and carbohydrate oxidation. Saris et al. (40) suggested that increased levels of exercise training could also lead to a shift in dietary intake from fat to carbohydrate to meet the higher requirements for glycogen. This change in dietary intake could cause a change in substrate utilization postexercise. Since we did not control for food intake in the studies described in chapter 2 and 4, we can not exclude this possibility.

The studies in the present thesis measured fat oxidation at least $36 \mathrm{~h}$ after the last exercise bout. This implicates that the acute and semi-acute effects of an exercise bout are not included in the effects of the interventions. Therefore is should be stressed that the effects measured are only due to the exercise training intervention. Correct comparison of the pre- and postexercise training effects would be more difficult when the acute effects of exercise training would be included.

In addition to the positive effect of low intensity exercise training on fat metabolism at a stable body weight, exercise training also appeared to be successful in combination with weight loss (chapter 5). Fat metabolism was measured at stabilized body weight after an overnight fast at rest, 
during exercise and for 15 min during recovery from exercise. It was demonstrated that a decrease in fat oxidation due to weight loss could be prevented by low intensity exercise training. This indicates that the increase in fat oxidation due to exercise training compensates the decrease in fat oxidation due to weight loss at stabilized body weight. This was also reported by Nicklas et al. (29) for the resting period only. Continuation of low intensity exercise training after the weight reduction period maintained the level of fat oxidation at pre-diet levels (chapter 6). This suggests that the effect of low intensity exercise training on fat oxidation in obese untrained subjects becomes manifest within the first 12 weeks of exercise training and continues for a long period afrer weight reduction.

\section{Role of sympotbetic nervous system in the regulation of fat metabolism}

One of the principal metabolic functions of adipose tissue is hydrolysis of stored triglycerides (TG) into FFA and glycerol (11). The sympathetic nervous system plays an important role in this hydrolysis process. The steps leading to hydrolysis in adipocytes are well known (Figure 8.1). Lipolysis is regulated through a chain of events that involve hormone binding and the coupling of the hormone-receptor complex to the membranebound enzyme adenylate cyclase. Lipolytic hormones bind to their receptors and activate the stimulatory guanine nucleotide protein (Gs). Antilipolytic hormones bind to their receptors and activate the inhibitory guanine nucleotide protein ( $\mathrm{Gi}$ ). The balance between these opposing pathways determines the magnitude of cyclic adenosine monophospate (cAMP) production by adenylate cyclase.

The concentration of cAMP controls the activity of cAMP-dependent protein kinase, which ultimately controls the phosphorylation and activation state of the hormone-sensitive lipase (HSL). HSL is the rate limiting enzyme that catalyzes the hydrolysis of TG into FFA and glycerol (13). The FFA hydrolyzed from TG are either reesterified by the adipocyte or released to the plasma, where they bind to albumin and are transported to other tissues for oxidation and/or TG synthesis. In humans, catecholamines and insulin are the most important hormones regulating adipocyte lipolysis. Norepinephrine and epinephrine stimulate lipolysis by binding to one of the three different $B$-adrenoceptor subtypes $\left(\beta_{1}, \beta_{2}\right.$ or $\left.\beta_{;}\right)(1)$. Insulin inhibits lipolysis through receptor and post-receptor mechanisms (24). 


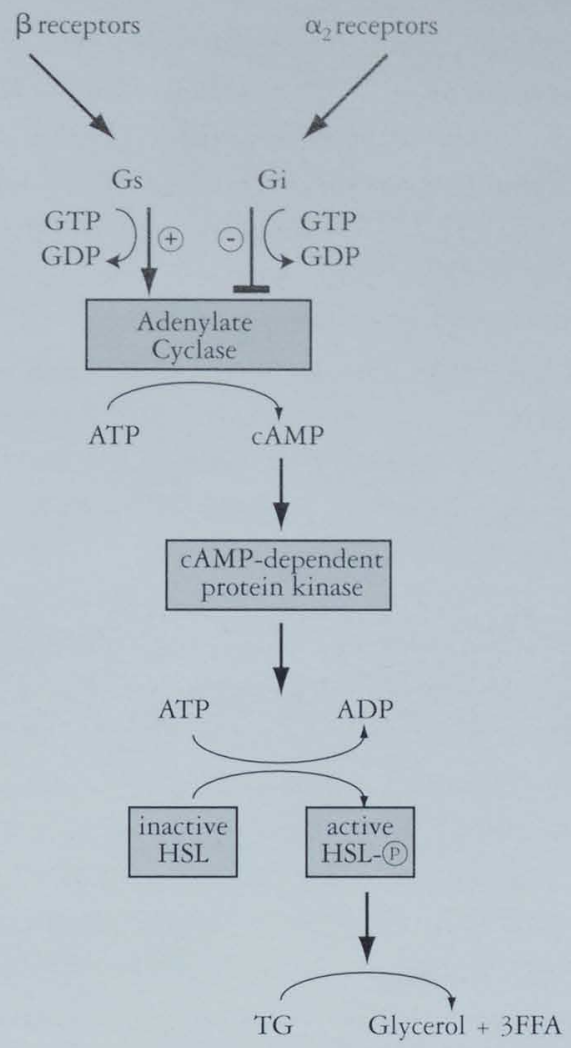

Figure 8.1 Adrenergic regulation of the lipolytic cascade in adipocytes [GTP, guanine triphosphate; GDP, guanosine diphosphate; ATP, adenosine triphosphate; ADP, adinosine diphosphate; TAG, triacylglycerol] [28].

In vitro studies in subcutaneous fat cells have shown that obese subjects have a decreased expression and function of $\beta_{2}$-adrenoceptors (36) and an increased antilipolytic action of $\alpha_{2}$-adrenoceptors (26). An in vivo study from our laboratory showed also that the $\beta_{2}$-adrenoceptor-mediated rises in thermogenesis, fat oxidation and lipolysis are blunted in the obese. This suggests that obese subjects may have a defect in the $B_{2}$-adrenoceptor itself, its density or the pathway it mediates (41). However, in the study described in chapter 3 we found no difference between lean and obese subjects in the $B$-adrenergic-mediated rise in fat oxidation. Furthermore, exercise training did not affect the in vivo $\beta$-adrenergic mediated rise in fat oxidation in obese and lean men. This was in contrast to the results from the only other exercise training intervention study in obese $(8,48)$. That study 
showed an increased $B$-adrenergic stimulated lipolytic activity after moderate to high intensity exercise training ( 4 days per week; $30-45$ min per session; 3 months; $60-65 \%$ heart rate reserve) in obese $(8,48)$, through an enhancement of $B$-adrenergic response and a concomitant blunting of adipocyte antilipolytic activity (48). However, these experiments were performed in vitro and in situ. In vitro measurement of fat cell lipolysis can not be used to directly predict in vivo FFA metabolism, due to the different environment of metabolites and hormones of the adipose cell in vivo compared to in vitro (23).

Although exercise training alone did not affect $\beta$-adrenergic mediated fat oxidation, in combination with energy restriction it maintained $B$-adrenergic mediated fat oxidation, while $\beta$-adrenergic mediated fat oxidation tended to decrease by energy restriction (chapter 5 ). The decrease in B-adrenergic mediated fat metabolism by weight loss might be caused by a deceased cAMP-stimulated lipolysis (29). This suggests that weight loss caused cellular adaptations at the HSL step of the lipolytic cascade. In vitro studies have also shown a decreased response of adipocytes to cAMP and a reduction in HSL expression and activity after weight loss $(22,35)$. Exercise training seems to prevent a decreased HSL expression. In vitro studies comparing trained and untrained subjects reported that exercise training affects the lipolytic cascade beyond the receptor-adenylate cyclase system $(7,37)$. During the follow-up period after weight loss, $\beta$-adrenergic mediated fat oxidation was maintained at the post-diet level, whether or not low intensity exercise training was performed (chapter 7).

\section{Body weight control}

In the exercise training studies described in chapter 2 and 4, subjects were requested to maintain their usual eating pattern. Although fat oxidation increased due to the low intensity exercise training program in the upper body obese men and women, body weight did not change over the intervention period. In addition, body weight in the high intensity exercise training group and the non-exercising control group did not change either over the same time period. This indicates that although low intensity exercise training caused an increase in fat oxidation, it did not affect body weight control over these 12 week time period. These results do not show an association between an improvement of fat oxidation and a better body weight control. However, it is possible that energy intake has been increased 
in the exercise training group to compensate for the extra energy expended during exercise training ( $\sim 1.5 \mathrm{MJ}$ per session), although a study of Woo et al. (57) did not confirm this. In addition to our results, other exercise training studies did not report an effect of exercise training on body weight either $(5,18,19,33,47)$. A meta-analysis of 10 studies showed that exercise training of 4-12 months alone produced only a modest weight loss of $1-2 \mathrm{~kg}$ on average (56).

Chapter 5 describes a randomly controlled short term weight loss study combined with low intensity exercise training. Low intensity exercise training prevented a weight loss induced decrease in fat oxidation, but exercise training had no additional effect on diet-induced body weight loss. Previous studies as reviewed by Saris (38) and as shown in a meta-analysis (56) also reported no additional effect of exercise training on diet-induced body weight loss. In the post-weight loss period maintenance of body weight is difficult to achieve. Total dietary fat intake is higher in the postdiet period compared to during the energy restriction period. This affects body weight control according to Flatts hypothesis (15). The increased dietary fat must be oxidized or stored. Therefore, due to the lower fat oxidation rate after weight reduction without exercise training, fat storage is likely to increase (15). However, maintenance of body weight did not appear to be different between the exercise and non-exercising group during follow-up after the weight loss period (chapter 6). Nevertheless, fat metabolism was maintained at the higher post-diet level in the exercise group compared to the non-exercising group. This does not support the concept that an improved fat oxidation does lead to better weight control. Nevertheless, since attendance at exercise training sessions was moderate during the follow-up period, the amount of exercise training should be taken into account. Attendance was on average $57 \%$ during the follow-up period. Using the regression equation from attendance at the exercise training sessions and body weight regain, it appeared that when exercise training was performed 3 times a week compared to none in the non-exercise group, calculated body weight regain would be $4 \mathrm{~kg}$ instead of $7 \mathrm{~kg}$ in the nonexercising control group. Therefore, maintenance of the higher post-diet fat oxidation could be related to a lower regain of body weight if exercise training was performed at a frequent basis.

Whether the effect of exercise training on body weight control can be explained by the fuel mix oxidized or the amount of energy outpur needs further discussion. Tremblay et al. (50) showed that body weight did not change during an intermittent and uninterrupted exercise training program. 
However, an intermittent training program produced a greater reduction in fat mass than an uninterrupted exercise training program at a similar exercise intensity but of a greater total energy cost. Schoeller et al. (42) showed that energy expenditure for physical exercise is important for minimizing weight gain. According to their results, energy expenditure for physical exercise should be at least $47 \mathrm{~kJ}$ per $\mathrm{kg}$ of body weight per day to minimize weight gain. This would implicate that exercise training at low intensity would not be suitable for weight management, since it would cost $3 \mathrm{~h}$ a day to reach the prescribed energy expenditure. Saris (39) calculated that an active obese woman has to exercise 105 minutes a day at moderate intensity to meet the criteria for maintenance of body weight. Fogelholm et al. (16) used two walking programs of 2-3 h and 4-6 h per week during and after weight reduction to study the effect on weight loss in combination with energy restriction and regain during follow-up. They showed no difference in loss and regain of body weight and fat mass between the group only receiving energy restriction and the two exercise training groups. This suggests that the time spend on low intensity exercise per week is does not affect the regulation of body weight. In summary the above mentioned studies show no consistency on whether fat oxidation or energy output is the most important factor in body weight regulation. Further research is needed to compare the role of energy output and substrate oxidation in body weight regulation.

In the studies described in the present thesis, exercise training and the addition of exercise training to a weight loss program did not affect total body weight as well as body composition. This was in agreement with most other exercise training studies with $(12,29,51)$ and without energy restriction $(5,10,17,33,51)$. On the contrary, some studies reported a decrease in fat mass and an increase in fat free mass due to exercise training with (49) and without energy restriction (55). During weight maintenance, the study described in chapter 6 showed no difference in regain of fat mass between the exercise and non-exercise group, but others $(30,52)$ showed less regain of fat mass when exercise training was continued. Ballor et al. (3) showed that exercise intensity did not affect changes in body composition in combination with energy restriction. However, the combination of the exercise-induced increase in energy expenditure and the severity of energy restriction are probably of influence on the non-consistency of changes in body composition. 


\section{Cardiovascular risk fototos}

Weight management, as ascribed above, points directly towards body weight loss and maintenance of a long-term healthy body weight. Indirect results of weight management may involve important health aspects. One of the factors influenced by weight loss is the risk for cardiovascular disease. Short-term weight reduction improved waist-to-hip ratio, systolic blood pressure, insulin/glucose ratio and serum lipid concentrations. When the lower body weight was partly maintained during 12 months after the start of the weight loss period, waist-to-hip ratio, systolic blood pressure, plasma insulin concentrations and insulin/glucose ratio were still significantly lower from before. Blood lipid profile returned to baseline again and vessel wall properties of the brachial artery, but not the carotid artery, improved (chapter 7). Addition of low intensity exercise training did not influence these results, neither during weight loss, nor during follow-up. Therefore, it seems that maintenance of a significant body weight loss is the key factor involved in improvement of cardiovascular risk factors.

A review study of Després and Lamarche (9) reported on the effect of exercise intensity on cardiovascular risk factors. They proposed that prolonged endurance exercise of moderate intensity $\left(-50 \% \mathrm{VO}_{2} \mathrm{max}\right)$ performed on a daily basis seems to slightly decrease body weight and to improve metabolic cardiovascular risk factors like insulin sensitivity, plasma insulin and glucose and blood lipids. These improvements might be independent from the training-related changes in cardio-respiratory fitness $\left(\mathrm{VO}_{2} \max \right)$.

Therefore they introduced the term 'metabolic fitness' to indicate that it is more important to affect metabolic variables relevant to cardiovascular risk by physical activity than to increase $\mathrm{VO}_{2}$ max by high intensity exercise. In this regard it is important to increase daily energy expenditure, which can be done by low intensity exercise during a subsequent part of the day.

Overall, this study suggests that low intensity exercise training can be a suitable tool in weight management and improvement of the cardiovascular risk factors in obese, provided that the frequency of exercise training is at least three times one hour per week.

Low intensity exercise training during and after energy restriction had no additional effect on cardiovascular risk factors. 


\section{Recommendations for future research}

The present study investigated the effect of exercise training on fat metabolism after an overnight fast at rest and during moderate intensity exercise training. Fat oxidation was increased during exercise, but not at rest. Results from other studies suggest that $24 \mathrm{~h}$ fat oxidation is decreased by exercise training possibly due to compensatory mechanisms $(5,31,55)$. Since our measurements did not continue for the rest of the day and night, the effect of low and high intensity exercise training on $24 \mathrm{~h}$ fat oxidation is unknown. Furthermore, in the studies described in the present thesis, fat and energy intake were not estimated although measurements of fat oxidation can be influenced. by subjects fat and energy intake during the days previous to the measurements $(14,44)$. Therefore, in a future study the effect of low and high intensity exercise training on 24 h substrate oxidation should be measured in order to complete the picture on the best exercise intensity to increase fat oxidation. In addition, subjects should be fed in fat and energy balance 3 days before the measurements in order to avoid interference of energy intake with fat oxidation.

To further complete the picture on the effect of intensity of exercise training on metabolism of obese subjects, effects of the exercise training program on non-exercise energy expenditure need to be measured. A review article of Westerterp (54) showed that exercise training does not influence spontaneous activities during the day, except in the elderly. Van Dale et al. (53) reported an increase in physical activity on a non-exercising day after exercise training and also after weight loss. Meijer et al. (27) showed an increase in nonexercising energy expenditure after 20 weeks of exercise training measured by doubly labeled water technique, but not by accelerometer measurements. Exercise training programs in these studies were at moderate to high intensity. Effects of low intensity exercise training on non-exercising energy expenditure needs further research.

Although the study described in chapter 7 showed no effect of low intensity exercise training during and after a weight reduction program on large artery compliance, further research on the frequency or intensity of exercise training for improvement of vessel wall properties could be of interest. 


\section{References}

1. Arner, P. Control of lipolysis and its relevance to development of obesity in man. Diabetes Metab Rev. 4: 507-515, 1988.

2. Astrup, A., B. Buemann, C. Gluud, P. Bennett, T. Tjur, and $N$. Christensen. Prognostic markers for diet-induced weight loss in obese women. Int J Obes. 19: 275-8, 1995.

3. Ballor, D. L., J. P. McCarthy, and E. J. Wilterdink. Exercise intensity does not affect the composition of diet-an exercise-induced body mass loss. Am J Clin Nutr. 51: 142-146, 1990.

4. Blaak, E. E., M. A. Van Baak, G. J. Kemerink, M. T. Pakbiers, G. A. Heidendal, and W. H. Saris. Beta-adrenergic stimulation of energy expenditure and forearm skeletal muscle metabolism in lean and obese men. Am J Physiol. 267: E306-15, 1994.

5. Buemann, B., A. Astrup, and N. J. Christensen. Three months aerobic training fails to affect 24-hour energy expenditure in weight-stable, postobese women. Int J Obes. 16: 809-816, 1992.

6. Colberg, S. R., J. A. Simoneau, F. L. Thaete, and D. E. Kelley. Skeletal muscle utilization of free fatty acids in women with visceral obesity. J Clin Invest. 95: 1846-53, 1995.

7. Crampes, F, D. Rivière, M. Beauville, M. Marceron, and M. Garrigues. Lipolytic response of adipocytes to epinephrine in sedentary and exercisetrained subjects: sex-related differences. Eur J Appl Physiol. 59: 249-55, 1989.

8. De Glisezinski, I., F. Crampes, I. Harant, M. Berlan, J. Hejnova, $D$. Langin, D. Rivière, and V. Stich. Endurance training changes in lipolytic responsiveness of obese adipose tissue. Am J Physiol. 275: E951-6, 1998.

9. Després, J.-P., and B. Lamarche. Low-intensity endurance exercise training, plasma lipoproteins and the risk of coronary heart disease. J Int Med. 236: 7-22, 1994.

10. Després, J. P., C. Bouchard, R. Savard, A. Tremblay, M. Marcotte, and $G$. Theriault. The effect of a 20 -week endurance training program on adipose-tissue morphology and lipolysis in men and women. Metabolism 33: 235-9, 1984.

11. Dole, V. P. A relation between non-esterified fatty acids in plasma and the metabolism of glucose. J Clin Invest. 35: 150-154, 1956.

12. Donnelly, J. E., N. P. Pronk, D. J. Jacobsen, S. J. Pronk, and J. M. Jakicic. Effects of a very-low-calorie diet and physical-training regimens on body composition and resting metabolic rate in obese females. 
Am J Clin Nutr. 54: 56-61, 1991.

13. Fain, J. N., and J. A. Garcia-Sainz. Adrenergic regulation of adipocyte metabolism. J Lipid Res. 24: 945-966, 1983.

14. Flatt, J.P. Dietary fat, carbohydrate balance, and weight maintenance: effects of exercise. Am J Clin Nutr. 45: 296-306, 1987.

15. Flatt, J. P. Importance of nutrient balance in body weight regulation. Diabetes Metab Rev. 4: 571-81, 1988.

16. Fogelholm, M., K. Kukkonen-Harjula, and P. Oja. Eating control and physical activity as determinants of short-term weight maintenance after a very-low-calorie diet among obese women. Int J Obes. 23: 203-210, 1999.

17. Friedlander, A. L., G. A. Casazza, M. A. Horning, T. F. Buddinger, and G. A. Brooks. Effects of exercise intensity and training on lipid metabolism in young women. Am J Physiol. 275: E853-63, 1998.

18. Friedlander, A. L., G. A. Casazza, M. A. Horning, M. J. Huie, M. F. Piacentini, J. K. Trimmer, and G. A. Brooks. Training-induced alterations of carbohydrate metabolism in women: women respond differently from men. J Appl Physiol. 85: 1175-1186, 1998.

19. Friedlander, A. L., G. A. Casazza, M. A. Horning, A. Usaj, and $G$. A. Brooks. Endurance training increases fatty acis turnover, but not fat oxidation, in young men. J Appl Physiol. 86: 2097-2105, 1999.

20. Henriksson, J. Training induced adaptation of skeletal muscle and metabolism during submaximal exercise. J Physiol Lond. 270: 661-75, 1977.

21. Hurley, B. F., P. M. Nemeth, W. H. d. Martin, J. M. Hagberg, G. P. Dalsky, and J. O. Holloszy. Muscle triglyceride utilization during exercise: effect of training. J Appl Physiol. 60: 562-7, 1986.

22. Klein, S., K. Luu, S. Gasic, and A. Green. Effect of weight loss on whole body and cellular lipid metabolism in severely obese humans. Am J Physiol. 270: E739-45, 1996.

23. Lillioja, S., J. Foley, C. Bogardus, D. Mott, and B. V. Howard. Free fatty acid metabolism and obesity in man: in vivo in vitro comparisons. Metabolism 35: 505-14, 1986.

24. Lonnroth, P., and U. Smith. The antilipolytic effect of insulin in human adipocytes requires activation of the phoshodiesterase. Biochem Biophys Res Commun. 141: 1157-1161, 1986.

25. Martin III, W. H., G. P. Dalsky, B. F. Hurley, D. E. Matthews, D. M. Bier, J. M. Hagberg, M. A. Rogers, D. S. King, and J. O. Holloszy. Effect of endurance training on plasma free fatty acid turnover and oxidation during exercise. Am J Physiol. 265: E708-14, 1993. 26. Mauriège, P., D. Prud'homme, S. Lemieux, A. Tremblay, and J. P. 
Després. Regional differences in adipose tissue lipolysis from lean and obese women: exixtence of postreceptor alterations. Am J Physiol. 269: E341E350, 1995.

27. Meijer, G. A. L. Physical activity: implications for human energy metabolism. In: Human Biology. Maastricht, The Netherlands: University of Limburg, 1990.

28. Nicklas, B. J. Effects of endurance exercise on adipose tissue metabolism. Exerc and Sport Sc. 25: 77-103, 1997.

29. Nicklas, B. J., E. M. Rogus, and A. P. Goldberg. Exercise blunts declines in lipolysis and fat oxidation after dietary-induced weight loss in obese older women. Am J Physiol. 273: E149-55, 1997.

30. Pasman, W. J., W. H. Saris, E. Muls, G. Vansant, and M. S. Westerterp Plantenga. Effect of exercise training on long-term weight maintenance in weight-reduced men. Metabolism 48: 15-21, 1999.

31. Pasman, W. J., M. S. Westerterp-Plantenga, and W. H. M. Saris. The effect of body weight changes and endurance training on $24 \mathrm{~h}$ substrate oxidation. Int J Obes. 23: 1223-1232, 1999.

32. Phillips, S. M., H. J. Green, M. A. Tarnopolsky, G. F. Heigenhauser, R. E. Hill, and S. M. Grant. Effects of training duration on substrate turnover and oxidation during exercise. J Appl Physiol. 81: 2182-91, 1996.

33. Poeblman, E. T., A. W. Gardner, P. J. Arciero, M. I. Goran, and J. Calles Escandon. Effects of endurance training on total fat oxidation in elderly persons. J Appl Physiol. 76: 2281-7, 1994.

34. Ravussin, E., and B. A. Swinburn. Metabolic predictors of obesity: crosssectional versus longitudinal data. Int J Obes. 17: S41-2, 1993.

35. Reynisdottir, S., D. Langin, K. Carlstrom, C. Holm, S. Rossner, and P. Arner. Effects of weight reduction on the regulation of lipolysis in adipocytes of women with upper-body obesity. Clin Sci Colch. 89: 421-9, 1995.

36. Reynisdottir, S., H. Wahrenberg, K. Carlstrom, S. Rossner, and P. Arner. Catecholamine resistance in fat cells of women with upper-body obesity due to decreased expression of beta ${ }_{2}$-adrenoceptors. Diabetologia 37: 428-35, 1994.

37. Rivière, D., F. Crampes, M. Beauville, and M. Garrigues. Lipolytic response of fat cells to catecholamines in sedentary and exercise-trained women. J Appl Physiol. 66: 330-5, 1989.

38. Saris, W. H. M. Exercise with or without dietary restriction and obesity treatment. Int J Obes. 19: S113-S116, 1995.

39. Saris, W. H. M. Fit, fat and fat free: The metabolic aspects of weight 
control. Int J Obes. 22: S15-S21, 1998.

40. Saris, W. H. M. Physiological aspects of exercise in weight cycling. Am J Clin Nutr. 49: 1099-1104, 1989.

41. Schiffelers, S. L. H., W. H. M. Saris, and M. A. Van Baak. $\beta_{2}$-adrenoceptor mediated lipolysis and lipid oxidation are reduced in obese men. Int J Obes. 22: S75, 1998.

42. Schoeller, D. A., K. Shay, and R. F. Fushner. How much physical activity is needed to minimize weight gain in previously obese women? Am J Clin Nutr. 66: 551-556, 1997.

43. Schrauwen, P., D. P. C. van Aggel-Leijssen, A. J. M. Wagenmakers, M. A. van Baak, and W. H. M. Saris. Low-intensity exercise training increases non-plasma derived triglyceride oxidation. Int $J$ Obes. 24 (suppl 1): S181, 2000.

44. Schrauwen, P., W. D. Van Marken Lichtenbelt, W. H. M. Saris, and $K . R$. Westerterp. Fat balance in obese subjects: role of glycogen stores. Am J Physiol. 274: E1027-E1033, 1998.

45. Schutz, Y., J. P. Flatt, and E. Jéquier. Failure of dietary fat intake to promote fat oxidation: a factor favoring the development of obesity. Am J Clin Nutr. 50: 307-314, 1989.

46. Schutz, Y., A. Tremblay, R. L. Weinsier, and K. M. Nelson. Role of fat oxidation in the long-term stabilization of body weight in obese women. Am J Clin Nutr. 55: 670-4, 1992.

47. Sial, S., A. R. Coggan, R. C. Hickner, and S. Klein. Training-induced alterations in fat and carbohydrate metabolism during exercise in elderly subjects. Am J Physiol. 274: E785-90, 1998.

48. Stich, V., I. de Glisezinski, J. Galitzky, J. Hejnova, F. Crampes, $D$. Rivière, and $M$. Berlan. Endurance training increases the beta-adrenergic lipolytic response in subcutaneous adipose tissue in obese subjects. Int $J$ Obes. 23: 374-81, 1999.

49. Svendsen, O. L., M. Krotkiewski, C. Hassager, and C. Christiansen. Effects on muscle of dieting with or without exercise in overweight post menopausal women. J Appl Physiol. 80: 1365-70, 1996.

50. Tremblay, A., J. A. Simoneau, and C. Bouchard. Impact of exercise intensity on body fatness and skeletal muscle metabolism. Metabolism 43: 814-818, 1994.

51. Utter, A. C., D. C. Niemann, E. M. Shannonhouse, D. E. Butterworth, and $C$. N. Nieman. Influence of diet andlor exercise on body composition and cardiorespiratory fitness in obese women. Int J Sports Nutr. 8: 213-222, 1998. 
52. Van Dale, D., W. H. Saris, and F. ten Hoor. Weight maintenance and resting metabolic rate $18-40$ months after a diet/exercise treatment. Int J Obes. 14: 347-59, 1990.

53. Van Dale, D., P. F. M. Schoffelen, F. Ten Hoor, and W. H. M. Saris. Effects of addition of exercise to energy restriction on 24-hour energy expenditure, sleeping metabolic rate adn daily physical activity. Eur J Clin Nutr. 43: 441-451, 1989.

54. Westerterp, K. R. Alterations in energy balance with exercise. Am J Clin Nutr. 68 (suppl): 970S-974S, 1998.

55. Westerterp, K. R., G. A. L. Meier, P. F. M. Schoffelen, and E. M. E. Jansen. Body mass, body composition and sleeping metabolic rate before, during and after endurance training. Eur J Appl Phys. 69: 203-208, 1994.

56. Wing, $R$. R. Physical activity in the treatment of the adulthood over weight and obesity: current evidence and research issues. Med Sci Sports Exerc. 31: S547-S552, 1999.

57. Woo, R., and J. S. Garrow. Voluntary food intake during prolonged exercise in obese women. Am J Clin Nutr. 36: 478-484, 1982. 


\section{Acknowledgements}

The author thanks Novartis Benelux for providing the VLCD diet, Lode B.V. for providing the electromagnetically braked cycles and the department of physiotherapy from the Academic Hospital Maastricht for the availability of the aqua-jogging facilities. 
Obese subjects are known to have a reduced ability to mobilize and oxidize fatty acids. Furthermore, the stimulatory effect of the sympathetic nervous system on fat metabolism is blunted in obese subjects. This reduced mobilization and oxidation of fat in obese may contribute to the development and maintenance of large fat stores. The studies described in this thesis investigated the role of exercise training in weight management and the effect on cardiovascular risk factors in obese.

Fat oxidation in lean subjects is known to be improved by endurance exercise rraining. The effect of high $\left(70 \% \mathrm{VO}_{2} \max \right)$ and low $\left(40 \% \mathrm{VO}_{2} \max \right)$ intensity exercise training on fat metabolism in obese men was described in chapter 2.

The results of this randomized control trial showed that 12 weeks of low intensity exercise training increased total fat oxidation during moderate intensity exercise by $40 \%(\mathrm{P}<0.05)$. The high intensity exercise training group and the non-exercising control group showed no significant increase in fat oxidation. Exercise training did not affect fat oxidation under resting conditions. The exercise-induced change in fat oxidation could not be explained by a change of the influence of the sympathetic nervous system on fat metabolism, as described in chapter 3 . Low intensity exercise training in lean subjects showed similar results.

The effect of low intensity exercise training on fat metabolism was also studied in premenopausal obese women (chapter 4). Since upper body obese women seem to have an overall greater resting free fatty acid mobilization compared to lower body obese and non-obese women, obese women with either upper body or lower body obesity were studied. After 12 weeks of exercise training, relative fat oxidation during exercise, but not at rest, increased by $19 \%(\mathrm{P}<0.05)$ in the upper body obese women. However, no significant change in fat oxidation was found in lower body obese women. Based on the positive effect of low intensity exercise training on fat oxidation in the upper body obese, a randomly controlled trial was executed in which exercise training was combined with energy restriction. Weight loss without exercise training is known to be accompanied by a decrease in fasting far oxidation after body weight has been stabilized. A decrease in fat oxidation is suggested to predispose to weight regain and should therefore be prevented. The study described in chapter 5 and 6 (short and long term respectively) investigated the effect of addition of exercise training during and after energy restriction on ( $\beta$-adrenergic mediated) fat oxidation. 
In a weight stable situation after an energy restriction period of 12 weeks, fat oxidation was decreased in the group only participating in the energy restriction program $(\mathrm{P}<0.05)$. A decrease in fat oxidation was prevented when low intensity exercise training was added to the energy restriction program. The sympathetic nervous system might be involved in the changes in fat oxidation between the exercise and non-exercise group. During energy restriction addition of exercise training to weight loss did not affect changes in body weight and fat mass. Subsequently, subjects were followed during 40 weeks after energy restriction, while the exercise group continued exercise training. Subjects attended during this 40 weeks on average $57 \pm 21 \%$ of the three exercise training sessions per week. The continuation of exercise training after weight reduction did not limit the regain of body weight. However, if exercise training during follow-up would have been performed three times per week compared to ones a week, average body weight regain would be $4 \mathrm{~kg}$ in stead of $12 \mathrm{~kg}$. Fat oxidation as well as the contribution of the sympathetic nervous system to fat oxidation were maintained at post-diet levels, whether or not exercise training was executed.

Although the effect of low intensity exercise training on body weight management was poor, exercise training and weight loss could have positive effects on cardiovascular risks factors. This was studied in chapter 7 . Body weight, body composition, systolic blood pressure, WHR, insulin/glucose ratio and serum lipid concentrations improved with weight reduction $(\mathrm{P}<0.05)$ and were still improved at the end of the follow-up $(\mathrm{P}<0.05)$, except for serum lipids. Weight loss did not affect the vessel wall properties large artery compliance and distensibility of the brachial and carotid artery. The exercise training program studied (intensity at $40 \% \mathrm{VO}_{2} \max$; frequency of 3 times per week; attendance $75 \pm 20 \%$ during weight loss and $57 \pm 21 \%$ during follow-up) failed to demonstrate a positive effect on the measured cardiovascular risk factors. Whether exercise training at a higher intensity or frequency can improve the cardiovascular risk factors needs further research.

In conclusion, the above findings demonstrate that low intensity exercise training is effective in increasing fat metabolism in upper body obese subjects. Regarding this, low intensity exercise training is a suitable tool to prevent a diet-induced decrease in fat oxidation. On long term, (ß-adrenergic mediated) fat oxidation was maintained when low intensity exercise training was continued after energy restriction. No additional effects of this low intensity exercise training program during and after energy 
restriction could be demonstrated on cardiovascular risk factors.

Continuation of low intensity exercise training after energy restriction, if performed at least three times per week, has shown to be a successful tool in the limitation of body weight regain on long term. 
Mensen met overgewicht hebben een verminderd vermogen om vetten te mobilizeren en te oxideren. Tevens is de invloed van het sympatisch zenuwstelsel op het vetmetabolisme verstoord bij mensen met overgewicht. Deze verminderde mobilizatie en oxidatie van vetten bij mensen met overgewicht kan bijdragen tot het ontwikkelen en handhaven van grote vetvoorraden. De onderzoeken beschreven in dit proefschrift bestuderen de rol van training in de regulatie van het lichaamsgewicht en het effect op risicofactoren voor hart- en vaatziekten bij mensen met overgewicht. Vetverbranding bij mensen zonder overgewicht kan worden verbeterd door duurtraining. Het effect van hoge $\left(70 \% \mathrm{VO}_{2} \max \right)$ en lage $\left(40 \% \mathrm{VO}_{2} \max \right)$ intensiteit training op de vetverbranding van mannen met overgewicht wordt beschreven in hoofdstuk 2. Deze gerandomiseerde controle interventie toonde aan dat lage intensiteit training gedurende 12 weken de vetverbranding tijdens middelmatige intensiteit inspanning verhoogde $(\mathrm{P}<0.05)$. De mannen die op een hoge intensiteit trainden en degene die niet trainden (controle-groep) hadden geen verbeterde vetverbranding na 12 weken. Training verbeterde de vetverbranding tijdens rust niet. Het onderzoek, beschreven in hoofdstuk 3, toonde aan dat de verandering in vetverbranding niet kon worden verklaard door een toename van de invloed van het sympatisch zenuwstelsel op het vetmetabolisme. Hetzelfde resultaat werd echter gevonden na lage intensiteit training bij mannen zonder overgewicht.

Het effect van lage intensiteit training op de vetverbranding werd ook bestudeerd bij vrouwen met overgewicht die nog niet in de menopauze zijn (hoofdstuk 4). Vrouwen met overgewicht op de buik blijken meer vet te mobiliseren dan vrouwen zonder overgewicht en vrouwen met overgewicht op de heupen. Het effect van lage intensiteit training op de vetverbranding bij vrouwen met overgewicht werd gemeten bij vrouwen met òf voornamelijk vetopslag op de heupen òf voornamelijk op de buik. Na 12 weken training was de vetverbranding tijdens inspanning toegenomen met $19 \%$ bij vrouwen met overgewicht op de buik $(\mathrm{P}<0.05)$, maar niet toegenomen bij vrouwen met overgewicht op de heupen.

Gezien de positieve effecten van lage intensiteit inspanning op de vetverbranding bij mensen met overgewicht op de buik, werd een gerandomiseerde controle-interventie uitgevoerd waarbij training werd gecombineerd met een verminderde inname van energie. Het is bekend dat gewichtsverlies zonder training gepaard gaat met een daling van de 
vetverbranding wanneer het lichaamsgewicht stabiel is. Een daling in de vetverbranding kan leiden tot een toename van het lichaamsgewicht en dient daarom te worden voorkomen. Het onderzoek, beschreven in hoofdstuk 5 en 6 (korte respectievelijk lange termijn), bestudeert het effect van training tijdens en na een laag calorisch dieet op de ververbranding en de invloed van het sympatisch zenuwstelsel op de vetverbranding. $\mathrm{Na}$ het bereiken van een stabiel lichaamsgewicht was de vetverbranding gedaald in de groep die alleen een laag calorisch dieet volgde gedurende 10 weken $(\mathrm{P}<0.05)$. Een daling van de vetverbranding werd voorkomen door een lage intensiteit trainingsprogramma te volgen tijdens het dieetprogramma. Het sympatisch zenuwstelsel zou een rol gespeeld kunnen hebben bij de handhaving van de vetverbranding in de trainingsgroep. Trainen tijdens het dieetprogramma had geen invloed op het gewichts- en vetverlies.

$\mathrm{Na}$ de dieetperiode werden de proefpersonen nog gevolgd gedurende 40 weken, waarbij de trainingsgroep doorging met het trainen. De proefpersonen woonden $57 \pm 21 \%$ van de drie trainingen per week bij. Dit leidde niet tot een verminderde toename van het lichaamsgewicht. Als de anwezigheid bij de trainingssessies drie in plaats van één keer per week zou zijn geweest, zou het gewicht met 4 in plaats van 12 kilogram zijn toegenomen. De vetverbranding en de invloed van het sympatisch zenuwstelsel op de vetverbranding bleven op het niveau van na de dieetperiode, zowel met als zonder training. Hoewel her handhaven van het lichaamsgewicht met het trainingsprogramma teleurstellend was, zou het trainingsprogramma wel een positief effect kunnen hebben gehad op het risico op hart- en vaatziekten. Onderzoek hiernaar staat beschreven in hoofdstuk 7.

Lichaamsgewicht, lichaamssamenstelling, systolische bloeddruk, buik-heup omtrek, de insuline/glucose verhouding en serum lipoproteïne concentratie verbeterde door gewichtsverlies $(\mathrm{P}<0.05)$ en was nog steeds verbeterd aan het eind van de 40 weken $(P<0.05)$, behalve voor de serum lipoproteïnen. Gewichtsverlies leidde niet tot een verandering van de vaatwandeigenschappen compliantie en distensibiliteit van de slagaders carotis en de brachialis. Het trainingsprogramma (intensiteit $40 \% \mathrm{VO}_{2} \max$; frequentie 3 keer per week; aanwezigheid $75 \pm 20 \%$ tijdens gewichtsverlies en $57 \pm 21 \%$ gedurende de vervolgperiode) leidde niet tot een verbetering van risicofactoren voor hart- en vaatziekten. Of dit wel het geval is met een trainingsprogramma van een hogere intensiteit of frequentie vereist nader onderzoek.

Uit het onderzoek beschreven in dit proefschrift kan worden geconcludeerd dat lage intensiteit training de vetverbranding van mensen met overgewicht 
op de buik kan verbeteren. Lage intensiteic training is daarom geschikt gebleken om een daling van de vetverbranding na een laag calorisch dieet te voorkomen. Op lange termijn wordt de vetverbranding en de invloed van het sympatisch zenuwstelsel op de vetverbranding gehandhaafd wanneer het trainingsprogramma wordt vervolgd. Er kon geen toegevoegd effect van lage intensiteit training tijdens en na gewichtsreductie worden aangetoond op het risico voor hart- en vaatziekten. Wel is aangetoond dat een toename van het lichaamsgewicht op lange termijn, na een dieetperiode, kan worden verminderd door tenminste 3 keer per week aan lage intensiteit inspanning te doen. 


\section{Abbreviations}

ANOVA analysis of variance

AUC area under the curve

BA brachial artery

BMI body mass index

BMR basal metabolic rate

BP blood pressure

C control

CC cross sectional compliance

CCA carotid artery

$\mathrm{CHO}$ carbohydrate

$\mathrm{CO}_{2} \quad$ carbon dioxide

$\mathrm{D}$ diet group

DC distensibility coefficient

DE diet plus exercise group

EE energy expenditure

FA fatty acid

FFA free fatty acid

FFM fat free mass

FM fat mass

h hour

HDL high density lipoprotein

HI high intensity

HR heart rate

IMTG intramuscular triglyceride

ISO isoprenaline

iso isobaric

$\mathrm{J} \quad$ Joule

kcal kilo calorie

kg kilogram

kJ kilojoule

$1 \quad$ liter

LDL low density lipoprotein

LI low intensity

m meter

$\min$ minute

MJ megajoule

n number 


\begin{tabular}{|c|c|}
\hline NS & not significant \\
\hline $\mathrm{O}_{2}$ & oxygen \\
\hline $\mathbf{P}$ & probability \\
\hline PRP & propranolol \\
\hline $\mathbf{r}$ & correlation \\
\hline RER & respiratory exchange ratio \\
\hline RMR & resting metabolic rate \\
\hline$s$ & second \\
\hline $\mathrm{SD}$ & standard deviation \\
\hline TG & triglyceride \\
\hline VLCD & very low calorie diet \\
\hline VLDL & very low density lipoprotein \\
\hline $\mathrm{VO}_{2}$ & oxygen consumption \\
\hline $\mathrm{VCO}_{2}$ & carbon dioxide production \\
\hline $\begin{array}{l}\mathrm{VO}_{2} \max \\
\text { vs }\end{array}$ & $\begin{array}{l}\text { maximal oxygen uptake } \\
\text { versus }\end{array}$ \\
\hline W & watt \\
\hline$W_{\max }$ & maximal power output \\
\hline WHR & waist-hip ratio \\
\hline$y$ & years \\
\hline
\end{tabular}


Het schrijven van een proefschrift kan worden vergeleken met het bouwen van een huis. Beiden kunnen niet door één persoon alleen worden gemaakt, maar vereisen een goede samenwerking tussen vele mensen met verschillende disciplines. Zo hebben ook aan het tot stand komen van dit proefschrift vele mensen hun steentje bijgedragen. Een aantal mensen wil ik met name noemen.

Allereerst was er Marleen, die als de architect van het project een gedegen basis heeft gelegd voor de onderzoeken beschreven in dit proefschrift. Met haar heldere en kritische visie op onderzoek heeft ze als co-promotor het onderzoek begeleid en bijgestuurd waar nodig. Wim, als promotor, kan meer worden vergeleken met een projectontwikkelaar. Hij zorgde ervoor dat alle middelen aanwezig waren, maar was minder betrokken bij de dagelijkse uitvoering. Met zijn kritische opmerkingen en inhoudelijke suggesties, met name met betrekking tot de manuscripten, bewaakte hij de grote lijnen van het project.

Bij de uitvoering van het eerste onderzoek hielp Moniek. Als mede-uitvoerder coachte zij de proefpersonen zodanig, dat er niet één afhaakte. $\mathrm{Bij}$ de uitvoering van de andere onderzoeken was er Gabby. Met haar onuitputtelijke energie heeft ze heel wat steentjes bijgedragen aan het tot stand komen van dit proefschrift. Allereerst wist ze als trainer de meeste proefpersonen te motiveren om te blijven trainen, ook als het lang ging duren. Verder was ze als duizendpoot overal inzetbaar en zorgde ze altijd voor een leuke werksfeer.

$B$ ij de uitvoering van grote projecten maken vele handen licht werk. Dit heeft betrekking op de vele stagiaires (Judith, Vanessa, Miku, Janneke, Nicole, Juul, Salmara, Milja, Katja, Carlien en Heidi) die bij de testen meehielpen om de ontelbare bloed- en ademgasmonsters te verzamelen en te verwerken. Ook de handen van Jos, Joan, Wendy, Adje, Frank en Annemie zijn onmisbaar geweest om uit al het verzamelde materiaal nauwkeurig de benodigde concentraties en verrijkingen te bepalen. De vele ECG's werden, ondanks zijn eigen drukke project, altijd snel nagekeken door Edgar. Liesje zorgde voor het uitvoeren van vaatwandmetingen. Ton was betrokken bij de projecten waarbij stabiele isotopen gebruikt werden en gaf verhelderende kritiek op de manuscripten.

$\mathrm{Bij}$ een project zijn ook technici nodig, zeker wanneer er gewerkt wordt mer gevoelige apparatuur die je wel eens in de steek laat. Dan waren er gelukkig Paul en Loek waar altijd een beroep op gedaan kon worden. 
Er zou geen project zijn geweest zonder de bereidwilligheid van de bijna honderd proefpersonen. Het doorzettingsvermogen van deze enthousiaste groep mensen is bewonderingswaardig. Zij hebben zich mogelijk nog het meest in het zweet gewerkt voor het uitfietsen van al de onderzoeken. Voor de finishing touch heeft mijn zus Karin gezorgd. Door haar professionele bewerking zijn de onderzoeken verpakt in een boek dat uitnodigt om gelezen te worden.

Veel werk kan alleen worden verzet wanneer er een leuke werksfeer is. Hiervoor hebben de collega's van de capaciteitsgroep Humane Biologie gezorgd, in het bijzonder mijn kamergenote Wilhelmine.

Naast de mensen die op de werkvloer hun steentje hebben bijgedragen, zou dit proefschrift er niet zijn geweest zonder mijn ouders. Zij gaven mij de kansen en het vertrouwen die nodig waren om zover te komen.

Lieve Dick, jij was er altijd voor mij. Van de eerste tot de laatste pagina van dit proefschrift heb jij mij terzijde gestaan met een luisterend oor, bemoedigende woorden en een helpende hand.

BEDANKT ALLEMAAL!

Het proefschrift is nu klaar, ons huis nog niet...... 


\section{About the autbor}

Dorien Petra Catharina van Aggel-Leijssen was born in Weert, The Netherlands on November 30, 1971. She completed secondary school (VWO) at the Philips van Horne School in Weert in June 1990.

In September 1990 she started to study Health Sciences, with as study discipline Biological Health Sciences, at the Maastricht University. During this study she did two placements; from January to July 1994 at the department of Human Biology, Maastricht University (Prof. Dr. W.H.M. Saris) and from February to August 1995 at the Dunn Clinical Nutrition Centre, Cambridge, UK (Dr. M. Elia). After her graduation in January 1996 she worked until June 2000 as a $\mathrm{PhD}$-student at the Department of Human Biology, Maastricht University (Prof. Dr. W.H.M. Saris and Dr. M.A. van Baak). The research performed during this period is described in this thesis. From June 2000 at she is working as a Clinical Study Manager at Medtronic, Bakken Research Center, in Maastricht. She is involved in research in the field of cardiac arrhythmia. 


\section{Publications}

\section{Articles}

- Leijssen, D.P.C., W.H.M. Saris, A.E. Jeukendrup, and A.J.M.

Wagenmakers. Oxidation of exogenous $\left[{ }^{15} \mathrm{C}\right]$ galactose and

$\left[{ }^{13} \mathrm{C}\right.$ ]glucose during exercise. J Appl Phys. 79: 720-725, 1995.

- Leijssen D.P.C., and M. Elia. Recovery of ${ }^{1:} \mathrm{CO}_{2}$ and ${ }^{15} \mathrm{CO}_{2}$ in human bicarbonate studies: a critical review with original data. Clin Sci. 91: 665-677, 1996.

- Schrauwen, P., D.P.C. van Aggel-Leijssen, W.D. van Marken Lichtenbelt, M.A. van Baak, A.P.G. Gijsen, and A.J.M. Wagenmakers.

Validation of the $\left[1,2-^{13} \mathrm{C}\right]$ acetate recovery factor for correction of $\left\{U^{13} \mathrm{C}\right\}$ palmitate oxidation rates in humans. J Phys. 513: 215-223, 1998.

- van Aggel-Leijssen, D.P.C., M.A. van Baak, R. Tenenbaum, L.A. Campfield, and W.H.M. Saris. Regulation of $24 \mathrm{~h}$ human plasma leptin level; the influence of exercise and physiological changes in energy balance. Int J Obes. 23: 151-158, 1999.

- Balkestein, E.J., D.P.C. van Aggel-Leijssen, M.A. van Baak, H.A. Struijker-Boudier, and L.M. van Bortel. Effects of weight loss with or without exercise training on large artery compliance in healthy obese men. J Hypertens. 17: 1831-1835, 1999.

- Schrauwen, P., E.E. Blaak, D.P.C. van Aggel-Leijssen, L.B. Borghouts, and A.J.M. Wagenmakers. Determinants of the acetate recovery factor: implications for estimation of $\left[{ }^{13} \mathrm{C}\right]$ substrate oxidation. Clin Sci. 98: 587-592, 2000.

- van Aggel-Leijssen, D.P.C., W.H.M. Saris, M. Homan, and M.A. van Baak. Effects of exercise training on B-adrenergic stimulation of fat metabolism in obese men. Int $J$ Obes. (in press).

- van Aggel-Leijssen, D.P.C., W.H.M. Saris, A.J.M. Wagenmakers, J.M.Senden, and M.A. van Baak. The effect of exercise training at different intensities on fat metabolism of obese men. Int $\mathrm{J}$ Obes. (submitted).

- van Aggel-Leijssen, D.P.C., W.H.M. Saris, A.J.M. Wagenmakers, G.B. Hul, and M.A. van Baak. The effect of low intensity exercise training on fat metabolism of obese women. Obes Res. (in press).

- van Aggel-Leijssen, D.P.C., W.H.M. Saris, G.B. Hul, and M.A. van Baak. Short term effects of weight loss with or without low intensity exercise training on fat metabolism in obese men. Am J Clin Nutr. 
(in press).

- van Aggel-Leijssen, D.P.C., W.H.M. Saris, G.B. Hul, and M.A. van Baak. Long term effects of low intensity exercise training on fat metabolism in weight-reduced obese men. Obes Res. (submitted).

- van Aggel-Leijssen, D.P.C., E.J. Balkestein, W.H.M. Saris, L.M. van Bortel, and M.A. van Baak. Effects of low intensity exercise training on weight maintenance and cardiovascular risk factors in obese men. Med Sci Sports Exerc. (submitted).

\section{Abstracts}

- Saris, W.H.M., A.E. Jeukendrup, D. Leijssen, and A.J.M.Wagenmakers. Oxidation of orally ingested galactose and glucose during prolonged exercise. Med Sci Sports Exerc. 27:S206, 1995.

- Leijssen, D.P.C., M.A. van Baak, L.A. Campfield and W.H.M. Saris. The influence of energy balance and exercise on 24 hour plasma leptin profile. Int J Obes. 21 (suppl 2): S102, 1997.

- Leijssen, D.P.C., W.H.M. Saris, and M.A. van Baak. The effect of exercise training at different intensities on respiratory exchange ratio (RER) of obese men. Int J Obes 22 (suppl 3): S283, 1998.

- van Aggel-Leijssen, D.P.C., W.H.M. Saris, and M.A. van Baak. The influence of exercise training on the acetate recovery factor of obese men. Int J Obes. 23 (suppl 3): S74, 1999.

- van Aggel-Leijssen, D.P.C., W.H.M. Saris, and M.A. van Baak. Effects of VLCD and low intensity exercise training on fat oxidation in obese men. Med Sci Sports Exerc. 31 (suppl 5): S340, 1999.

- Blak, E.E., D.P.C. van Aggel-Leijssen, E. de Swart, M.A. van Baak, and W.H.M. Saris. Impaired exercise-induced fat oxidation in obse and obese type 2 diabetic subjects. Int J Obes. 23 (suppl 5): S48, 1999.

- van Baak, M.A., D.P.C. van Aggel-Leijssen, and W.H.M. Saris. The effect of exercise training at different intensities on VO2max, blood pressure (BP), fasting insulin and glucose of obese men. Int J Obes. 23 (suppl 5): S61, 1999.

- Balkestein, E.J., D.P.C. van Aggel-Leijssen, M.A. van Baak, W.H.M. Saris, H.A. Struijker-Boudier, and L.M. van Bortel. The effect of weight loss on large artery compliance in healthy obese men. Int $\mathrm{J}$ Obes.

23 (suppl 5): S136, 1999.

- van Aggel-Leijssen, D.P.C., W.H.M. Saris, and M.A. van Baak. Effects 
of VLCD and low intensity exercise training on fat oxidation in obese men. Int J Obes. 23 (suppl 5): S169, 1999.

- van Bortel, L.M., E.J. Balkestein, D.P.C. van Aggel-Leijssen, M.A. van Baak, and H.A. Struijker-Boudier. The effect of weight loss with or without exercise training on large artery compliance in healthy obese men. Eur Heart J. 20: 664, 1999.

- Balkestein, E.J., D.P.C. van Aggel-Leijssen, M.A. van Baak, W.H.M. Saris, H.A. Struijker-Boudier, and L.M. van Bortel. The effect of weight loss with or without exercise training on large artery compliance in healthy obese men. J Hypertens. 17 (suppl 3): S4, 1999.

- van Aggel-Leijssen, D.P.C., E.J. Balkestein, L.M. van Bortel, H.A. Struijker-Boudier, W.H.M Saris, and M.A. van Baak. Effect of weight loss and low intensity exercise training on arterial compliance in obese men. FASEB 14 (suppl 4): A482, 2000.

- van Aggel-Leijssen, D.P.C., W.H.M. Saris, and M.A. van Baak. Long term effects of low intensity exercise training on fat oxidation. Int $\mathrm{J}$ Obes. 24 (suppl 1): S32, 2000.

- Schrauwen, P., D.P.C. van Aggel-Leijssen, A.J.M. Wagenmakers, M.A. van Baak, and W.H.M. Saris. Low intensity exercise training increases non-plasma derived triglyceride oxidation. Int J Obes. 24 (suppl 1): S181, 2000.

- Blaak, E.E., D.P.C. van Aggel-Leijssen, A.J.M. Wagenmakers, W.H.M. Saris, and M.A. van Baak. Impaired oxidation of plasma-derived FFA in type 2 diabetic subjects during exercise. Int J Obes. 24 (suppl 1): S180, 2000. 